English Applied Linguistics PhD Programme

Graduate School in Linguistics

University of Szeged

\title{
EFL classroom interaction from a multilingual perspective within the Transylvanian school context
}

\author{
PhD Dissertation
}

Zsuzsanna Dégi

Supervisor:

Anna Fenyvesi, PhD, dr. habil. 


\section{Acknowledgements}

I would like to express my sincere gratitude to my supervisor, Dr. Anna Fenyvesi for her guidance and support throughout writing my dissertation. I am also thankful to my supervisor for inviting me to participate in the LINEE (Language in a Network of European Excellence) research project which inspired me to investigate this topic. I would also like to thank Professor Rosamond Mitchell at the University of Southampton for her valuable comments and guidance in the very early stages of my research.

My grateful thanks are also extended to Dr. Lugossy Réka and Donald W. Peckham for their useful comments and valuable insights after reviewing my manuscript before the pre-defense. Their advice and suggestions have been a great help in finalizing the present paper.

I am also greatly indebted to the English teachers who agreed to take part in the study for their cooperation, without their help this work could not have been completed.

Finally, I am extremely thankful to my friends and family for their love, support and constant encouragement during the long years of my research and entire thesis work. 


\section{Contents}

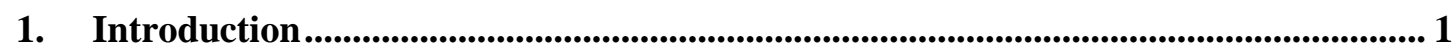

2. Theoretical framework - The multilingual perspective .................................................... 6

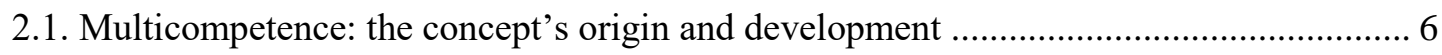

2.2. Multicompetence and the Dynamic Model of Multilingualism (DMM) ........................ 13

2.3. Educational goals of the multicompetence and DMM frameworks............................... 19

2.4. The acquisition of a third language - an educational perspective.................................. 24

2.4.1. Factors that influence the acquisition of a third language............................................ 26

2.4.2. Cross-linguistic influence in third language acquisition ............................................. 33

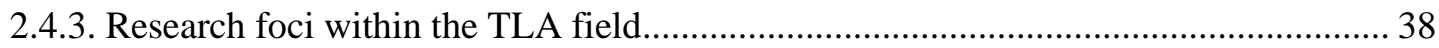

2.5. The most obvious sign of multilingual language use: Codeswitching ........................... 41

2.5.1. Use of non-target languages during foreign language instruction: empirical research on

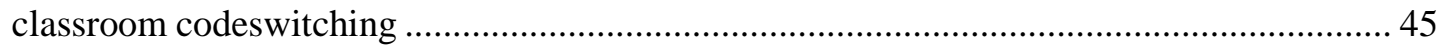

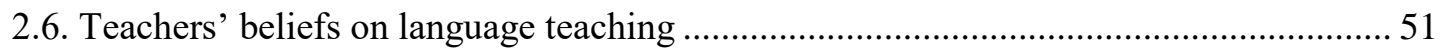

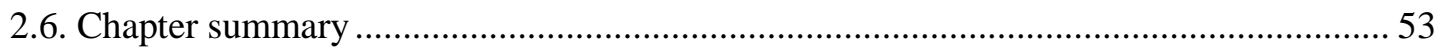

3. Background: Multilingualism within the Hungarian community in Transylvania .... 55

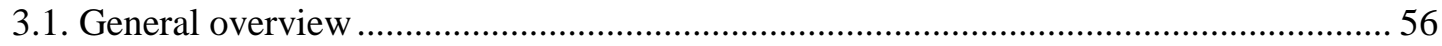

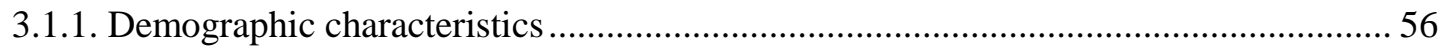

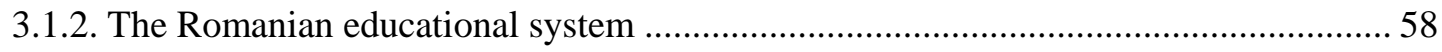

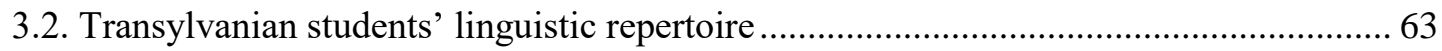

3.3. Types of multilingualism promoted and language attitudes ........................................... 69

3.3.1. Multilingualism perceived by foreign language learners ........................................... 70

3.3.2. The educational stakeholders' views on multilingualism ........................................... 72

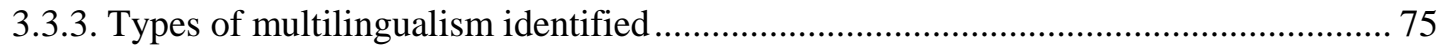

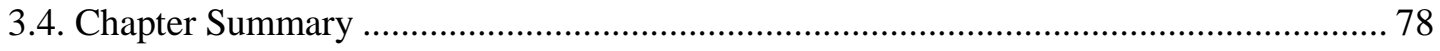

4. Methodology: An empirical study of EFL classroom interaction from a multilingual perspective ............................................................................................................................................. 80

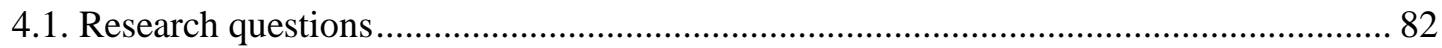

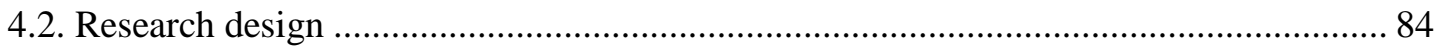

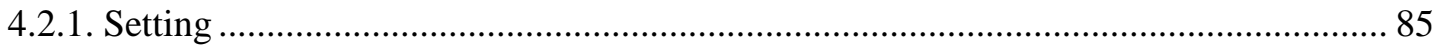

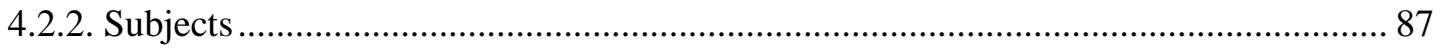

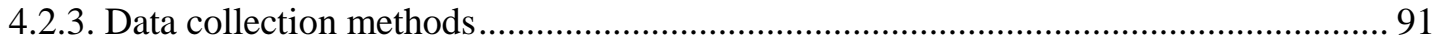

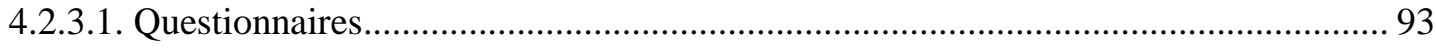




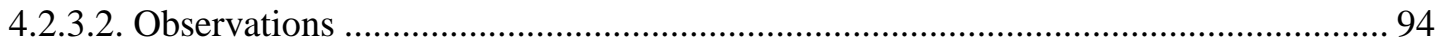

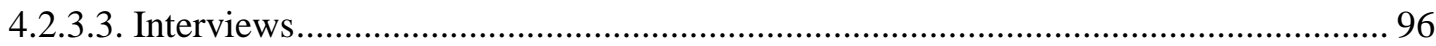

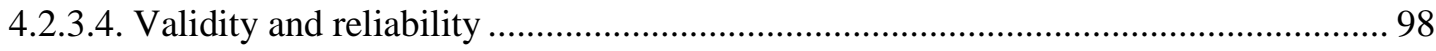

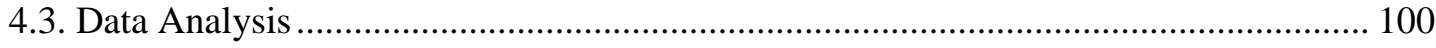

5. EFL classroom language use ................................................................................................. 104

5.1. EFL classroom language use according to the teacher questionnaire ........................... 106

5.2. EFL classroom language use according to classroom observation recordings .............. 112

5.2.1. Classroom observation data from Mureș/Maros county ............................................ 114

5.2.2. Classroom observation data from Harghita/Hargita county ..................................... 128

5.3. EFL classroom language use according to student interviews..................................... 137

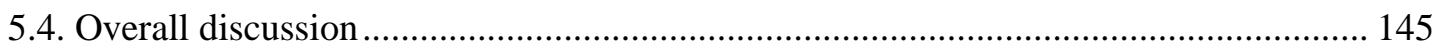

6. Teachers' beliefs regarding EFL classroom language use ................................................ 151

7. Learners' beliefs regarding the role of previously acquired languages in the foreign language learning process ........................................................................................................... 163

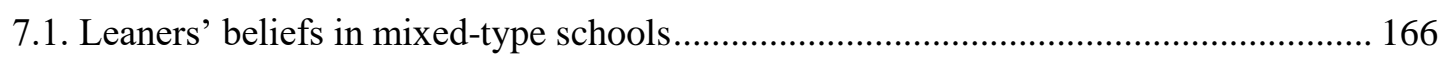

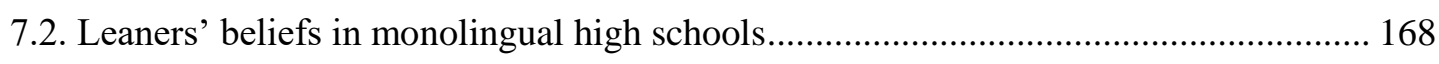

8. Conclusion......................................................................................................................................... 171

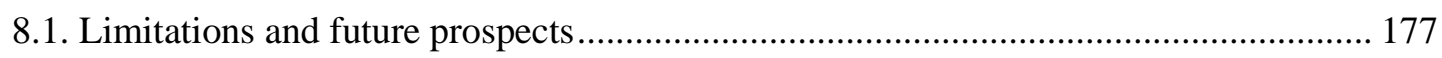

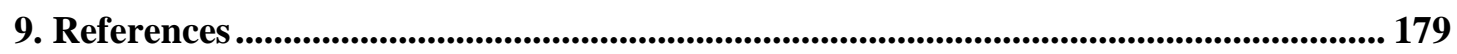

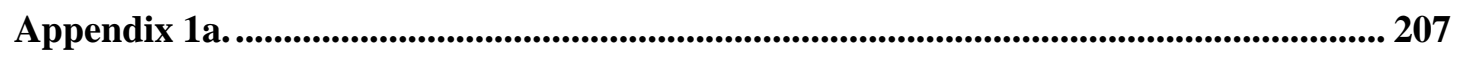

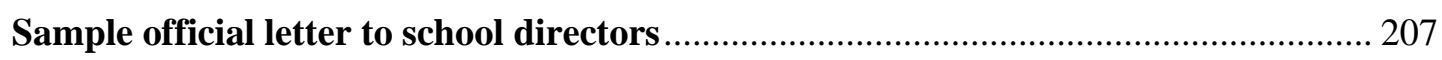

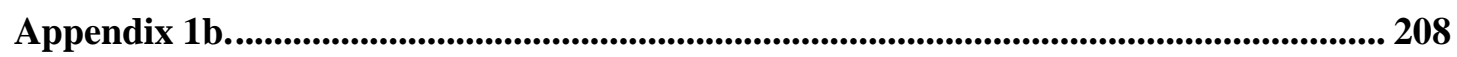

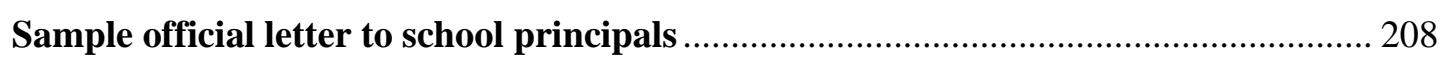

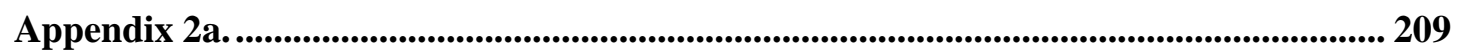

Convenţie civilă bilaterală ............................................................................................. 209

Appendix 2b................................................................................................................................. 210

Bilateral Confidentiality Agreement ...................................................................... 210

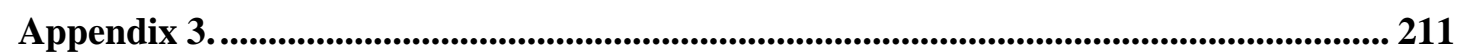

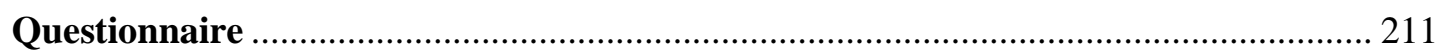

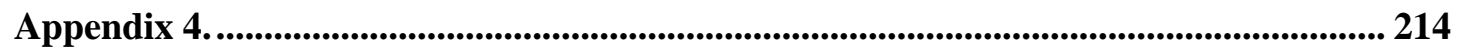

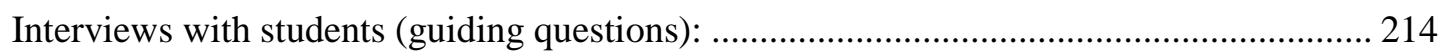

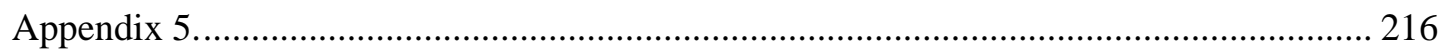

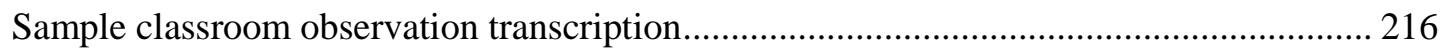




\section{Introduction}

Interest in multilingualism has been gradually increasing in the past two decades, gaining the attention of both researchers and policy makers. Europe has always been multilingual, however, due to the idea of nation states emerging in the $19^{\text {th }}$ century, multilingualism became regarded as the exception from the rule and, on the individual level, was considered to damage the cognitive abilities of speakers. Today the European Union's initiatives to promote multilingualism and encourage its citizens to learn and speak foreign languages (see White Paper on education and training in 1995, which set as an objective that EU citizens should be proficient in three European languages) certainly play an important role in accepting multilingualism as the norm and also in the development of research in multilingualism. In addition, recent changes in the field of linguistics - a shift from a focus on the monolingual ideal speaker's language use and his/her internal language system to research on discourse and textual representation have also had beneficial effects on the multilingualism paradigm, resulting in studies about the relationship of two or more language systems, multilingual language use and language development (Kecskés, 2009: 2). Learning a third language is a common occurrence around the world. Among the five types of trilinguals that have been identified by Hoffman (2001), the most common in Europe is a bilingual who acquires a third language.

Despite the fact that, on a socio-political level, learning a second or third language beside one's mother tongue is considered to be important, multilingualism is still considered as a drawback because it is misunderstood in certain respects. Multilinguals are still expected to be multiple monolinguals in one person, which usually highlights speakers' incompetency in either of their languages (Jessner, 2008).

The benefits of multilingualism and multilingual education have been advocated by a number of scholars (Cook, 2002; Laufer, 2003; Pavlenko, 2003; Jessner, 2008; Cenoz and Gorter, 2013; Cenoz and Gorter, 2015) in recent years. In particular, findings that emerged from new research fields like Third Language Acquisition (TLA) and inquiries that have been made around the notion of multicompetence have contributed to a better understanding of multilingual processes and language use. Although research methods and understanding of terms in the TLA field of study and the notion of multicompetence are sometimes inconsistent and/or blurred, multiple language 
acquisition is common in many countries whose linguistic environment requires or encourages the knowledge and use of more languages.

Trilingual educational programs have been implemented in several tri- or multilingual regions of Europe (e.g. Finland, Friesland, the Basque Country, the Ladin valleys, Catalonia, Luxembourg etc.), and several researchers (Björklund, 2000; Cenoz, 2000, 2008; Ytsma, 2000; Muñoz, 2000, Cenoz and Gorter, 2015; Portolés and Martí, 2017) have proposed methods to create the appropriate school setting for these communities. Although Romania does not fall into this category, it is important to examine how L3 instruction may be conducted for those students who already speak two languages - their mother tongue, Hungarian, and the state language, Romanian.

Researchers have found that being multilingual has many benefits. These are related to the global economy, including job opportunities as well as educational and sociocultural benefits. Although research in the field of multilingualism and third language acquisition is growing, there are no studies on individuals who represent an Eastern European bilingual minority population learning English as a third language.

As in all other domains of language acquisition, the study of L3 or additional language acquisition requires an in-depth analysis and evidence emerging from a wide range of theoretical frameworks. The present paper relies on two theoretical approaches - multicompetence (Cook, 1991b) and the Dynamic Model of Multilingualism (Herdina and Jessner, 2002) - as a lens through which we can discuss foreign language teachers' beliefs towards language teaching, their current teaching practices and provide valuable insights into English foreign language (EFL) classroom interactions.

Historically, most research in L3 acquisition has focused on the structure of the mental lexicon, education and sociolinguistics. More recently, the field has witnessed a sharp increase in the domain of L3 acquisition of morphosyntax and L3 phonology. The foundation of the International Association of Multilingualism and its journal, the International Journal of Multilingualism, as well as many books and research papers that have been published, all allow us to easily understand the significance of L3/Ln acquisition as an important and distinct field of study, not as a simple additive extension of bilingualism.

The notion of multicompetence, first used by Vivian Cook in his 1991 paper (Cook, 1991a), is the term that best describes the linguistic competence of multilinguals and a term often referred to in L3 research papers. Cook bases his concept on 
Grosjean's $(1985,2001)$ qualitatively new view of bilingualism, portraying the bilingual as a competent but specific speaker-hearer. In accordance with Grosjean $(1985,2001)$, Cook $(2003,2006)$ argues that the L2 user (a term which he favours in contrast to "bilingual") develops multicompetence - which considerably differs from monolingual competence - as the multilingual learner cannot simply be described as a monolingual with some extra knowledge. Multilinguals, thus, cannot be understood as double monolingual native speakers - the difference is not just quantitative, but qualitative as well. Multilingual speakers develop a different kind of knowledge of their L1, L2 or Ln associated with a complex language processing system (Jessner, 2008) which allows for the activation of several language elements in a flexible and creative manner (Cenoz and Gorter, 2015). From a multicompetence perspective, multilingual language users are not considered as incompetent speakers but as language users who have at their disposal an "extended and integrated linguistic repertoire" (Edwards and Dewaele, 2007: 35) that is grounded in the actual linguistic practices they engage in.

As these ideas and research fields have emerged relatively recently, a great deal of work in the field is still needed. Both multicompetence and the Dynamic Model of Multilingualism (DMM) adopt a holistic approach when looking at language learning and the linguistic repertoire of multilingual students. These two theoretical proposals are considered to be the forerunners of a new trend in the field of language education that focuses on multilingualism and language integration. The aim of this investigation is on the one hand, to show and describe, through classroom-based empirical research, to what extent are multilingual students' and teachers' linguistic resources activated during foreign language (FL) classroom interaction, thus reflecting upon how multilingualism is incorporated in the educational context under investigation and, on the other hand, to interpret and evaluate classroom language use based the theories outlined in the literature review. Until very recently (and this is still true for some of the schools and teachers), the only guarantee for successful instructed language learning seemed to be a strict separation of the languages in the multilingual learner and in the classroom (Creese and Blackledge, 2010; Dégi, 2010; Crump, 2013; García, 2013, Gorter and Cenoz, 2017). As has been just mentioned, in the 20th century English language teaching theories promoted a monolingual approach (Hall and Cook, 2013) and, thus, the languages of the subjects are often kept totally apart, and contact between them in the curriculum is rejected (sometimes even forbidden) since it is considered a 
hindrance to successful language learning. In order to avoid interference from other languages, teachers keep knowledge about other languages, including the L1, out of the classroom (Dégi, 2010).

Yet, the traditional way of separating languages has been contested on several occasions and new proposals to soften hard boundaries between languages have emerged (Li Wei and Wu, 2009; Makoni and Pennycook, 2007; Garcia, 2009; Canagarajah, 2013, Gorter and Cenoz, 2017). Studies show that languages are not kept in separate containers so during multilingual interaction languages in the mind interplay and speakers rely on their full linguistic repertoire (Dégi, 2010; Tullock and FernándezVillanueva, 2013). Additionally, metalinguistic awareness and metacognitive skills are developed as part of multilingual development and should also be fostered in an instructed context (Jessner, 2006, 2008; Boócz-Barna, 2010; Sindik, 2013).

The present dissertation aims at providing insight into a specific multilingual context, the Transylvanian Hungarian minority situation. I define as the main aim of the present study to reflect upon how students' and teachers' multilingualism is incorporated in the educational context under investigation. In other words, I aim to explore and interpret EFL classroom language use and the current tendencies towards multilingual language teaching (i.e. using and relying on non-target languages) bearing in mind the theoretical concepts and practical suggestions articulated by the concept of multicompetence and the Dynamic Model of Multilingualism. Furthermore, the paper will also consider teachers' and students' beliefs regarding multilingualism and multiple language use during English foreign language instruction. Adopting a multilingual perspective and applying several methods of data collection, such as classroom audio and video recordings, teacher questionnaires, and interviews with both teachers and students, and a comparative content analysis of the data, the present paper intends to examine current foreign language teaching practices and attitudes attached to them, thus contributing to the continuously growing amount of research done in the field of TLA and raising the awareness of other TLA researchers about the valuable data present in the Eastern European minority (Jordan, 1998; Benő and Szilágyi, 2005) context. Results obtained from different schools, teachers and students are compared and contrasted, identifying some good practices and tendencies within current EFL teaching in the Transylvanian educational system. Data provides information not only about language use in EFL classes but also regarding the effects of teachers' beliefs on their educational 
practices, students' attitudes towards multilingualism and multiple language use, and the roles that school types and second language exposure play in shaping language use within the EFL classroom.

In light of what has been said, a wider purpose of this work is to contribute to the development of teacher training, language learning and teaching in general by raising the linguistic and metalinguistic awareness of teachers and learners. As teachers become aware of the use of previous language knowledge that second language students bring to classrooms, and the teaching and learning opportunities they can create by relying on learners' existing language knowledge and language learning experiences, they may be better able to monitor and adjust the patterns of communication so as to maximize students' competencies within the second language classrooms and contribute to the development of students' multicompetence.

To conclude this introductory chapter, I shall briefly review the content and structure of this dissertation, which can be divided into five main chapters. Chapter 2 examines and discusses the notions that constitute the framework for the present study. It presents issues related to multicompetence and the DMM. After outlining the concepts' development and their interrelationship, the focus will be on relevant TLA literature and the most important factors influencing TLA. A separate subsection is devoted to codeswitching and related empirical research studies that focus on the role of non-target languages during foreign language instruction. Chapter 3 provides background information on the Hungarian community in Transylvania, including historical information, information on the educational system, linguistic repertoire and the types of multilingualism present in this community. Chapter 4 reports on the empirical investigation of EFL classroom interaction which constitutes the basis of this dissertation. This chapter includes several subsections: section 4.1, where I formulate the research questions, section 4.2, where I present the design of the study, the data collection methods and a detailed description of the research process. The findings and the discussion of the results are presented and discussed in the next three chapters $(5,6$ and 7) following the order and logic of the research questions. Thus, chapter 5 addresses Research Question 1 regarding EFL classroom language use, followed by chapter 6 on teachers' beliefs, while the next chapter (7) discusses the investigated learners' beliefs and language awareness. Chapter 8 presents a review of the issues discussed, the results, and a concluding summary. 


\section{Theoretical framework - The multilingual perspective}

The present chapter provides an overview on the theoretical issues and concepts related to the learning of a third language. The paper is based on two key concepts: the concept of multicompetence (Cook, 1991b) and the Dynamic Model of Multilingualism, or DMM (Herdina and Jessner, 2002), the latter being a construct developed within the field of TLA. These concepts, usually treated separately, form a similar framework - a holistic perspective in the study of multilingual education and bring about a social turn in the study of multilingualism by challenging previous ideas about the ideal native speaker as the norm and the separation of languages in the school context. These theoretical proposals adopt a holistic approach when looking at the languages of a multilingual speaker and describe the linguistic repertoire of multilingual speakers as complex and dynamic. While DMM was conceived within the emerging TLA research field, multicompetence was developed within the research field of Second Language Acquisition (SLA); however, the concept of multicompetence still provides a useful perspective for additional language acquisition research.

As previously noted, the present dissertation aims at exploring EFL classroom interaction, reflecting on the languages used (target and non-target) within this context and on the factors (teachers' and students' beliefs and attitudes) that might influence such language choice. Therefore, the present chapter focuses not only on the main working concepts, but also on codeswitching phenomena, on cross-linguistic influence within third language acquisition, and the role of non-target languages within the EFL classroom. The chapter ends with a brief summary concerning the issues discussed.

\subsection{Multicompetence: the concept's origin and development}

The concept of multicompetence has contributed to frame recent research on multilingualism. It has attracted significant research attention in the field of applied linguistics and, in particular, in the study of multiple language use and language acquisition. The idea of linguistic multicompetence was first proposed in the early 1990s as "the compound state of mind with two grammars" (Cook, 1991b: 103). The concept of multicompetence originates from Cook's response to Chomsky's Universal Grammar (UG) theory and of his rejection of the Chomskyan ideal monolingual native 
speaker competence. The multicompetence approach basically derived from Cook's reinterpretation and correction of the classical perception of second language acquisition and Selinker's (1972) interlanguage. Figure 1 below represents Cook's understanding of Selinker's (1972) notion of interlanguage as a transitional but independent language of the language learners:

first
language
(L1) $\leftrightarrow \quad \begin{aligned} & \text { L2 } \\ & \text { interlanguage }\end{aligned} \quad \begin{gathered}\text { second } \\ \text { language } \\ \text { (L2) }\end{gathered}$

Figure 1. The learner's independent language (interlanguage). (Cook, 2005)

According to Figure 1 above, second language acquisition includes the stages of arriving from an L1 to an L2 (at the same level) via a transitional phase called interlanguage. Cook (2005), argues that the first language, the interlanguage and other cognitive processes are indeed internal to the speaker, however, the second language itself (at the same native level) does not belong to the second language speaker since native-like level in a second or further language is hardly ever achieved. If the goal of SLA remains to achieve native-like competence in another language, then bilinguals would stay incompetent language users. Thus, Cook (2005) proposes the exclusion of the L2 from the conceptualization in Figure 1 in order for second language speakers to gain a separate identity and not to depend on a goal they would never or hardly ever achieve. Hence, a name was needed for this complex mental state, which included the L1 and the L2 interlanguage but excluded the L2. The term multicompetence, first coined to reflect the sum of these in one mind, was originally expressed as "the compound state of a mind with two grammars" (Cook, 1991b: 103). This original definition was later changed to "the knowledge of two languages in the same mind" (Cook 2005: 2) in order to avoid an exclusive association with generative syntax. This had the consequence of separating someone who knows two languages from the native speaker as a person in their own right. Hence the term "L2 user" became preferred over "L2 learner" as it expressed an independent status rather than a person who constantly strives for an unattainable goal (Cook 2005, 2006). The research that has come out of this conceptualization of multicompetence dealt with the relationships between the existent language systems in the speakers' mind, in particular transfer phenomena from 
subsequently learned languages to the L1 (Cook 2003) and with the relationships between the linguistic systems and L2 users cognitive processes (Cook et al., 2006).

Excluding the native-like L2 from the SLA learning process and considering L2 users as independent speakers in their own right clearly shows the influence of Grosjean's holistic bilingualism concept, according to which bilinguals are "specific and fully competent speaker-hearers who have developed a communicative competence that is equal to, but different in nature from monolinguals" (Grosjean, 1996:22). Cook views multicompetence as a specific cognitive state and, similarly to Grosjean, believes that the interaction of two or more language systems in one's mind results in differences in language use (multilinguals' use of translation and codeswitching) and language performance (both productive and receptive skills, on lexical, phonological etc. levels). Moreover, Cook claims that, apart from quantitative differences, there are also qualitative differences between monolingual and multilingual speakers (see also Herdina and Jessner, 2002; Cenoz, 2005; Kecskés, 2009) regarding their cognitive processing and highlights the additive effects of using a second or an additional language. Among the beneficial consequences of multilingualism he mentions "increased metalinguistic awareness of phonology, syntax, the arbitrary nature of meaning, and gains in cognitive flexibility" (Cook, 1997: 296).

Cook's (1991a, 1991b) definition of the term multicompetence was further developed first by Dewaele and Pavlenko (2003), then by Edwards and Dewaele (2007), who argued that multicompetence should not be perceived as a fixed, ideal end-state but rather as a dynamic, ever-evolving system. To explain the dynamic nature of the languages in contact in one mind, Dewaele and Pavlenko use the metaphor of liquid colours:

"[they] blend unevenly, that is, some areas will take on the new colour resulting from the mixing, but other areas will retain the original colour, while yet others may look like the new colour, but a closer look may reveal a slightly different hue depending on the viewer's angle" (Dewaele and Pavlenko, 2003: 137).

According to Dewaele and Pavlenko's interpretation (2003:137), multicompetence is a "never-ending, complex, nonlinear dynamic process in the 
speaker's mind". However, this does not necessarily entail that some parts of the language systems cannot remain stable for a period of time, but changes in the linguistic environment - for example changes in the linguistic input - can result in the overall restructuring of the language systems "with some islands remaining in their original state" (Edwards and Dewaele 2007:225). Trying to answer the question if there is a unique bilingual or trilingual competence, Edwards and Dewaele (2007) conclude the following:

"[i]f we posit a trilingual competence; the next question could be whether quadrilinguals or pentalinguals have their own unique competence. It probably does not matter. The concept of multicompetence (Cook 1991b, 1992, 2002; Dewaele and Pavlenko, 2003) is probably most useful in describing the knowledge underlying the linguistic processes and the behaviour of individuals who possess two or more languages. We all agree that someone who throws one single ball in the air and catches it could barely qualify as a juggler. From two balls on, that person may catch our attention and deserves to be called a juggler. Our admiration will increase when that person manages to keep three or four or even five balls in the air, but he or she will still be a juggler. Similarly, bilingual code switching is an impressive feat of human cognition, and we may feel even more amazed listening to a trilingual or a quadrilingual switching back and forth, creating new forms along the way, but it is basically the same technique, linked to that individual's unique multicompetence." (Edwards and Dewaele 2007:235)

The above quote suggests that the term multicompetence has been introduced, on the one hand, to eliminate the infinite list of bilingual, trilingual, $n$-lingual competencies and, on the other hand, to highlight the similarity of the techniques and strategies underlying multilingual language behaviour.

The next step in the evolution of the term multicompetence is taken by Hall et al. (2006: 225) by introducing a "usage-based view of multicompetence". The authors first criticize the previous works done in the field of multicompetence: although these works 
succeeded in freeing the multilingual from traditional, idealized monolingual models, they have neglected the notion of language as a discrete system, where the monolingual is defined as stable and the multilingual is dynamic and variable (Hall et al 2006:225). Cook's (1991a, 1991b) notion of multicompetence has been criticised by many (Hall et al., 2006; De Angelis, 2007; Kecskés, 2009) as the definition is contradictory. Although Cook coined the term multicompetence in opposition to Chomsky's UG and ideal language speaker, he continues to follow the Chomskyan notion of competence (i.e. multicompetence in this sense is about linguistic knowledge) and ignores the conceptual system. Hall et al. (2006) considered Cook's approach to language competence as unrealistic, presenting it as stable and homogeneous across language speakers (Alptekin, 2010:98). Therefore, Hall and his colleagues propose a usage-based view claiming that "all language knowledge is socially contingent and dynamic, no matter how many language codes one has access to. The differences across users are then based not on the number of languages, but on the amount and diversity of experiences and use" (Hall et al., 2006: 229). Thus, in Hall at al.'s view, even monolinguals can be considered as multicompetent speakers. However, Kecskés (2009: 11) argues for the inadequacy of Hall et al.'s criticism saying that they ignore the fact that 'NOT ALL language knowledge of bi or multilingual speakers derives from social-cultural experience of the use of L2 or Lx" (emphasis in the original). Kecskés (2009) emphasizes that most of foreign language knowledge is the result of instructed language learning rather than coming from social experiences through language use. While Hall et al. (2006) see a direct link between the frequency and variety of communicative contexts and the range of forms and functions, Kecskés (2009) argues that language development and language use depend on more than just social interaction because L2 learners have restricted access to genuine situational contexts.

Alptekin (2010: 97), examining Cook's (2002, 2003, 2005, 2007) articles on multicompetence, observed that Cook himself started to criticise his previous definition of the term and his latest articles $(2005,2007)$ advocate for a Saussurean view of language rather than a Chomskyan focus on syntax. In this sense, it can be argued that Cook has gradually moved from a "static and reductionist view of language characterized by mentalist conceptions in order to put forth a perspective of multicompetence as a more dynamic construct" (Alptekin, 2010: 97). 
With their aim to provide a comprehensive definition of multicompetence, Mitchell et al. (2008: 7) propose an understating of multicompetence as a two-layered notion, encompassing the mental state and the language behaviour. They go back and extend Cook's definition, and adapt it to capture the dynamic capacity of multilingual people. Mitchell's research group (working within a European research project called LINEE $^{1}$ ) extends Cook's views of multicompetence to both sociolinguistics and education, and reaches the following working definition:

"[...] multicompetence, i.e. the knowledge of more than one language in the mind, is part of the individual capacity of the person and develops in interaction with his/her social or educational environment [...] Multicompetence, or multilingual competence, is thus at the same time a tool and a state and relates to the complex, flexible, integrative and adaptable behaviour which multilingual individuals display" (Mitchell et al. 2008:7).

According to this view, multicompetence represents not only the language knowledge of the multicompetent language users (a state of being multilingual) but also refers to the ability of these language users to deal efficiently with the languages at their disposal (a tool and a strategy in becoming multilingual), an ability that goes back to the notion of technique, expressed by Edwards and Dewaele (2007). Furthermore, Mitchell et al.'s attention paid to the social environment of the individuals entails a Vygotskian perspective also proposed by Alptekin (2010), according to which language development is viewed from the perspective of social activity. Mitchell et al. (2008) and Alptekin (2010), similarly to Hall et al.'s (2006) usage-based view, emphasize the role of social environment and interaction in the development of multicompetence. According to Alptekin (2010), multilingual speakers develop a set of conceptual patterns in order for them to be able to deal with the multiple and diverse communicative activities they engage in and due to this available set of different

\footnotetext{
${ }^{1}$ LINEE (Languages in a Network of European Excellence), EU FP6 grant nr. 028388
} 
patterns of language use and the cognitive flexibility to adjust to the different communicative styles and conventions, these language users can be considered multicompetent "in both linguistic and cultural terms" (Alptekin, 2010:100).

Mitchell et al.'s (2008: 7) definition also points at the role of education in the development of multicompetence, which is in line with Kecskés's (2009) argument, according to which foreign language learners hardly encounter authentic target language communicative contexts, thus a usage-based view and developing multicompetence through social interaction is not always enough. Kecskés (2009: 11) argues that in case of foreign language learning, where learners do not have real social communicative experience, these learners develop multicompetence by studying the language itself and by attempting "to make intelligent hypotheses about the social use of the code when required".

Kecskés (2009), similarly to Mitchell et al. (2008), arrives at a two-layered definition of multicompetence and of multilingualism in general. In his view, multilingualism means not only the knowledge of several languages but a restructured cognitive system (a two-level system), which bring about both quantitative and qualitative changes (see also Herdina and Jessner, 2002). In Kecskés's (2009: 15-16) definition, multicompetence can be defined as follows:

"[as] a dynamically changing state of the mind that is characterised by the development of one or more additional language faculties (NLF) ${ }^{2}$ and a qualitative change in the common cognition part of the $\mathrm{BLF}^{3}$ that serves as sociocultural background knowledge for the use of more than one linguistic code".

The short literature overview presented above shows the development of multicompetence from a contradictory definition drawing on the Chomskyan paradigm (Cook, 1991a, 1991b), followed by several adaptations (Dewaele and Pavlenko, 2003; Edwards and Dewaele, 2007), corrections (Mitchell et al. 2008) and criticisms (Hall et al., 2006; Kecskés, 2009). All studies on multicompetence agree on the dynamic and

\footnotetext{
${ }^{2}$ Narrow language faculty

${ }^{3}$ Broad language faculty
} 
ever-evolving nature of this complex mental state that, according to Jarvis and Pavlenko (2008: 17), "allows us to theorize the interaction between multiple languages in the speaker's mind as a natural and ongoing process and to understand why multilinguals may perform differently from monolinguals in all of their languages, including the L1".

Finally, in my understanding, the term multicompetence is not just a cover term constructed to avoid making differences between the infinite line of bilingual, trilingual, quadrilingual etc. linguistic competencies, but a dynamic construct referring to the complex and changing mental state of multilingual individuals and to their capacity to cope with the diverse linguistic forms and communicative activities. It stands for the cognitive flexibility that allows multilingual speakers to use a set of varied communicative strategies in order to adjust to the needs of the actual communicative context they are engaged in.

I believe the concept of multicompetence to be useful for describing the cognitive processes and the linguistic behaviour of learners who possess two or more languages. The concept of multicompetence has been widely used in TLA and multilingual education research as marking the initiative towards a holistic approach and a paradigm change that go against language isolation and focus on multilingualism, on how languages are used in a social context. Accepting Kecskés's (2009) perspective on the bipartite nature of multicompetence, involving not only language knowledge but also a reorganized conceptual system which brings about changes of quantitative and qualitative nature, my paper focuses on the linguistic behaviour of teachers and students in a foreign language classroom environment. Examining classroom language choice and the linguistic behaviour of classroom participants, it will be possible not only to observe the existing and visible variety of communicative strategies used by students and teachers, but also to evaluate these strategies for the way they might support the process of becoming multilingual.

\subsection{Multicompetence and the Dynamic Model of Multilingualism (DMM)}

As Grosjean (1996) has argued and as has been pointed out in section 2.1 above, there is a need for a holistic view of bilingualism (and consequently multilingualism) as the double (or multiple) monolingualism view is inadequate in the attempt to develop a realistic model of multilingualism. Multicompetence and the DMM represent 
alternatives to be used in multilingual education and research. As presented in section 2.1 above, multicompetence is a theoretical concept which describes multilingual learners' dynamic and complex cognitive state and their multiple language knowledge that enable them to use a set of communicative strategies and to be able to function in different social communicative environments. Thus, the term multicompetence can be understood as an approach to foreign language learning that helps us to understand and evaluate the role of language education in developing such a complex mental state. The Dynamic Model of Multilingualism developed by Herdina and Jessner (2002) employs system theory (or chaos theory) to construct a model of multilingual development, focusing on a previously neglected aspect, namely, language decline and language attrition. The DMM is presented as a continuously reorganising system that changes over time due to its two main factors: language maintenance and language loss.

Among several models of multiple language learning presented by Kresič (2012), the DMM model and the multicompetence approach represent the framework and theoretical basis of the present investigation. In this section I provide evidence about the complementary nature of these two theories despite the fact that the creators of the Dynamic Model of Multilingualism (Herdina and Jessner, 2002) strongly reject the similarity between multicompetence and the DMM.

First, it has to be noted that current work on multilingualism, and multicompetence in particular, has been mainly influenced by holistic ideas of bi- and multilingualism. Grosjean's 1985 work on the bilingual as a competent but specific bilingual speaker-hearer strongly influenced both Cook's concept of multicompetence and Herdina and Jessner's (2002) dynamic view of multilingual development and multilingual proficiency.

Moreover, the authors of both multicompetence and the DMM attempted to argue against Universal Grammar-based theories with more or less success - Cook's (1991a) holistic multicompetence approach being still criticised for its failure to reject the Chomskyan understanding of competence.

Cook indicates that, in terms of the relationship between the L1 and L2 in one mind, his concept "fits with the Dynamic Model of Multilingualism (Herdina and Jessner 2002) in trying to see the language system of the L2 user as a whole rather than as an interaction between separate language components" (Cook 2003: 11). 
While agreeing with Cook's holistic concept of multicompetence, Herdina and Jessner nonetheless point to a major difference between the two theories. They view Cook's model as involving two (or more) language systems that are unitary in relation to the DMM, where "the language systems involved can be interpreted as separate systems in that the systems as a whole have properties their parts cannot be shown to contain" (Herdina and Jessner 2002: 151). Whilst Herdina and Jessner assume similarly to Cook and Grosjean - that multilinguals cannot be measured by monolingual standards, they also claim that the language systems involved can be interpreted as separate systems. This means that, on the one hand, the DMM is separatist in interpreting the language systems involved but, on the other hand, assumes that the subsystems outlined interact with each other and influence each other within the complex dynamic system called multilingualism (Herdina and Jessner, 2002). Thus, the DMM model presents a contradiction between its authors' aim to understand the holistic nature of multilingualism and, at the same time, the practical need to break up the system into its parts for the purpose of building a model. According to Jessner (2008b: 273), DMM "focuses not on languages (L1/L2/L3/Ln) but on the development of individual language systems (LS1/LS2/LS3/LS4, etc.) forming part of the psycholinguistic system (...) language systems are seen as interdependent”. The dynamics and interaction between the language systems and the components of multilingual proficiency are reflected in Figure 2 below:

Figure 2: A dynamic systems perspective of multilingual proficiency (Jessner, 2008: 276).

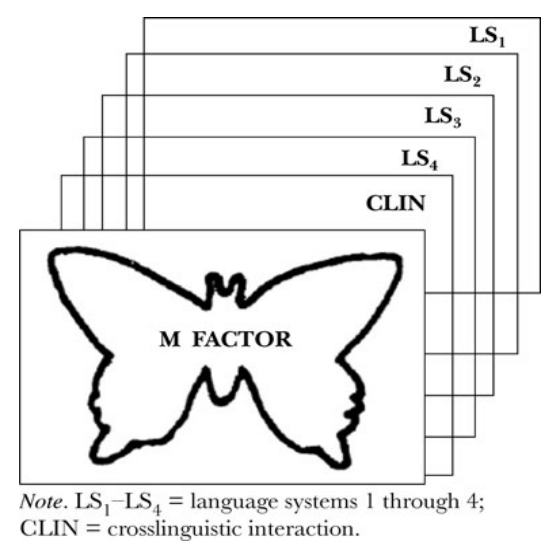

DMM, Herdina and Jessner's psycholinguistic model of multilingualism attempts to explain individual learner differences in language acquisition and implies 
that language is in constant flow, and so are the language systems in a multilingual, depending on the various factors involved in the language acquisition process (Herdina and Jessner, 2002). Furthermore, Jessner (2003) stresses the importance of timedependent variation in an individual's multicompetence. Accordingly, an individual's multilingualism is viewed "as a continuous process of adaptation to constantly changing (perceived) communicative requirements of the environment" (Jessner, 2003:241), allowing for variability and diversity in language development.

Examining the unitary versus separatist character of the two theories (multicompetence and DMM) above, it becomes evident that these contradictory perspectives are rooted in the different notions the two theories work with. While Cook uses the notion of language competence (meaning linguistic knowledge), the DMM works with the notion of language proficiency including not only linguistic knowledge but also the complex cognitive system of multilingual individuals.

The concept of language competence was introduced in linguistics by Chomsky (1965), the first to develop an explicit theory of it. According to him, linguistic competence is understood as "concerned with the tacit knowledge of language structure, that is, knowledge that is commonly not conscious or available for spontaneous report, but necessarily implicit in what the (ideal) native speaker-listener can say" (Chomsky, 1965:19).

Multilingual language proficiency is characterized as interaction between individual language systems and what has been called the multilingualism factor (Herdina and Jessner, 2002). This multilingualism factor is based on the changes in language awareness and language strategy development which evolve through increased exposure to language acquisition (Hufeisen, 2005: 35).

During the analysis of the two theories - multicompetence and DMM - two major differences can be identified, namely, the unitary versus separatist nature of the linguistic systems in the multilingual mind, and the different working notions of competence vs. proficiency.

In spite of these differences, there are many similarities that argue for the complementary nature of the two models.

First, both models are rooted in Grosjean's holistic approach to multilingualism and language learning. Cook's multicompetence model dates back to 1991, thus DMM is influenced by both Grosjean's and Cook's theories. 
Both multicompetence and DMM theories indicate a positive effect of bilingualism on further language learning - this positive effect being linked to metalinguistic awareness, language learning strategies and communicative ability, in particular in the case of typologically similar languages. In a number of projects, the concept of multicompetence has been applied - although quite often without drawing on the concept, or without being even aware of its existence - to multilingual learning contexts (Jessner, 2008: 362). These new approaches to multilingual education describe how to raise students' awareness of other languages in the classroom and in the school curriculum (Candelier, 2004), how to teach related languages, how to teach learning strategies and how to make use of prior linguistic knowledge in the classroom (see e.g. Hufeisen and Lindemann, 1998; Cenoz, Hufeisen and Jessner, 2003). Herdina and Jessner's (2002) dynamic system theory also argues that learning within this multilingual dynamic system involves a non-linear process and is dependent upon the interaction with existing knowledge.

$>$ Subsequent definitions of the concept of multicompetence suggest an interaction and mixing of the linguistic systems within the multilingual mind that lead to the DMM's interpretation of separate language systems. Even though the basic notion was coined by Cook, it was further developed by more researchers who tried to fill the concept with their own understanding. Thus, it became a dynamic, ever-evolving system (Dewaele and Pavlenko, 2003, Edwards and Dewaele, 2007), often explained by using the metaphors of blending colours and of a juggler. Cook's initial concept is often rejected and criticised (see Hall et al., 2006; Kecskés, 2009) because in his first attempts he could not escape from the Chomskyan paradigm of monocompetence as the norm. However, the term multicompetence seems viable as many researchers tried to improve it and, through its development, it became a complex notion referring not only to a dynamic usage-based construct, which involves not just a complex mental state with fluid and flexible linguistic systems, but also to multilinguals' capacity to cope with different communicative situations utilizing those linguistic systems that they have at their disposal. Since the Dynamic Model of Multilingualism was elaborated and explained in a specific and detailed manner, it leaves no room for further development or possible (mis)understandings. However, the 
first definition of multicompetence was so contradictory that its explanations and understandings use metaphors and embrace several different (psycholinguistic, usage-based sociolinguistic, non-usage based educational, etc.) perspectives.

This section has argued for the complementary nature of the two theories used as a framework for the present dissertation. I believe that both multicompetence and the DMM are useful concepts in interpreting data of studies into multilingualism as they contribute to a more realistic understanding of multilingual proficiency. The reason for choosing these two theories lies not only in their holistic approach to multilingualism but also in their focus on the skills and abilities the multilingual user develops (e.g. language learning, language maintenance, language management skills) due to the existence of a multilingual system.

Although Herdina and Jessner's (2002) dynamic systems construct is called a model - Dynamic Model of Multilingualism - it can be hardly interpreted as a model that allows measuring and testing. This holistic model of multilingualism with its complexity and all the interacting factors (the developmental effects of individual, social and instructional variables) make this model difficult to measure or test, rather it may be used as a valuable concept, an "adequate conceptual metaphor" (Jessner, 2008b: 270), that helps interpreting research findings. Hence, both multicompetence and the DMM will be considered as concepts or theoretical approaches that help to better understand multilingual interaction and multilingual language behaviour within the investigated classroom contexts.

The two theoretical concepts discussed in the present section of the dissertation represent examples of a new trend in the study of multilingual education. In line with this new trend researchers adopt a holistic approach and "shift from a cognitive to a social perspective" (Cenoz and Gorter, 2015). A more recent theoretical approach in the field of education is the so called "Focus on multilingualism", an approach proposed by Cenoz and Gorter (2011). This latter approach adopts a holistic perspective as well and aims at an itegrated language teaching and learning in order to activate all linguistic resources multilingual students have at their disposal. Focus on multilingualism "explores the possibility of establishing bridges between second/foreign language teaching at school and multilingualism in real-life communication, involving all the 
languages and multilingual discursive practices of speakers" (Cenoz and Gorter, 2015:8).

Apart from the holistic view these approaches adopt, they all claim that languages are not "isolated entities" (Cenoz and Gorter, 2015:7) and aim at softening boundaries between languages.

\subsection{Educational goals of the multicompetence and DMM frameworks}

The most important reason for selecting both multicompetence and DMM as frameworks for the present study lies in the common goals of the two theroretical approaches. The concept of multicompetence was constructed within the Second Language Acquisition (SLA) research field, thus empirical evidence has mostly focused on bilingual speakers so far. On the one hand, research on psycholinguistics and SLA tends to focus on defining what information is integrated or separated in the mind, and how and when knowledge is used or not used in the learning process. On the other hand, there has also been an increase of interest in the overall effects of bilingualism on cognitive development. Developing an alternative model of the language acquisition process, Herdina and Jessner (2002: 86-87) aimed to not only shift research focus towards multilingual speakers but also to "overcome the implicit and explicit monolingual bias of multilingualism research". The DMM model elaborated by them within the newly emerging field of Third Language Acquisition serves as an extension of SLA research and proposes that studies on language learning should turn their focus on the acquisition of three of more languages and the development of multilingualism.

Marked by different periods of time and constructed within different research fields, the two theories on multilingualism resemble each other in their goals concerning foreign language pedagogy and in shaping a new trend which adopts a holistic perspective on multilinguals and multilingual education.

The multicompetence idea has important implications for language teaching, which has often seen its task as making students as similar to native speakers as possible. Multicompetence is now starting to be utilized in books and articles on SLA and language teaching (see Cook, 2008; Ortega, 2009; Scott, 2009; Brown, 2013; Talebi, 2013; Cook, 2013; De Angelis, 2014; Wei, 2014; Otwinowska and De Angelis, 2014; Cenoz and Gorter, 2015). 
One of the most important contributions of the multicompetence theory is introducing the concept of the L2 user. Cook (2002, 2006, 2008, 2013) brought about some proposals concerning language teaching adjusted to the needs and the nature of an L2 user whom the author positions as belonging to a specific group different from the native speakers. By introducing the concept of the L2 user, Cook challenges the idea of the native speaker as a reference when teaching languages and argues that multilinguals develop a different type of competence (that he calls multicompetence) and therefore should not be compared to native speakers of a language. Cook's preference for the term L2 user also suggests his holistic view when looking at bilingual or multilingual language learners. The concept of the L2 user is similar to Haugen's minimal definition of bilingualism as "the point where a speaker can first produce complete meaningful utterances in the other language" (Haugen 1953:7) and to Bloomfield's comment "[ $t$ ]o the extent that the learner can communicate, he may be ranked as a foreign speaker of a language" (Bloomfield 1933:54).

Cook (2002) then, formulates some proposals for language teaching adopting a holistic approach. He argues that in contrast with traditional methods of language teaching, such as the Direct Method or the Audio-lingual method, the goal of language teaching should be achieving proficient L2 users who are able to use their linguistic repertoire in a variety of contexts. Therefore, in Cook's view language teaching should have the aim to support students in becoming multilingual, in developing their multicompetence that involves translation and codeswitching. Cook's (2002) proposal, that rejects assessing language learners compared to native speakers of the respective target language, has been recently underpinned by Cenoz and Gorter (2015) who also claim that expecting a native-like competence form language learners might result in a sense of failure and lack of self-confidence.

Adopting such a holistic approach, Cook (2002) also discusses the positive influence of non-native teachers on the learning process. He argues that proficient users of the target language have more advantages over native speakers because they speak the students' first language and can stand as a role model for successful language learning. The importance of giving real models (who share the native language of their students and have learned to speak English proficiently) to the students has already emerged in the 1980s. For example, Edge (1988) insisted on the importance of teachers who shared students' native language, their cultural and social background. In a later 
discussion about non-native speaker (NNS) teachers' advantages and disadvantages, Medgyes (1994, 2014) described six positive characteristics: (1) they provide a good learner model to their students; (2) they can teach language strategies very effectively; (3) they are able to provide more information about the language to their students; (4) they understand and even prevent the difficulties and needs of the students; (5) they are able to anticipate and predict language difficulties; and (6) in EFL settings, they can use the students' native language to their advantage. For what concerns language awareness, Barratt and Kontra (2000) confirmed that teachers who are native speakers of a language can often discourage learners since they are unable to profit from or to make useful comparisons and contrasts with the learners' first language. Additionally, according to Barratt and Kontra, NSs are often incapable of sympathizing with students and they are also unable to understand the learning process their students are going through. Árva and Medgyes' (2000) results validate those obtained by Barratt and Kontra (2000), showing that NNS English teachers have the advantage of understating the learning difficulties of their students. Finally, and most importantly, NNS teachers can be highly respected and even idolized by their students because they are successful role models and this fact motivates students (Lee, 2000). As Cook (2005: 57) explains, NNS teachers "provide models of proficient L2 users in action in the classroom and also examples of people who have become successful L2 users". That is, NNSs can demonstrate to their students what it is possible to do with a second language and they can also show their appreciation for that language and its culture (Moussu and Llurda, 2008: 322-323).

Focusing on classroom language use during foreign language teaching, Cook (1999) considers that the exclusive use of the target language within the language classroom is not advantageous as it excludes the existence of previously acquired languages also present in the students' mind. The multicompetence theory, instead, promotes a principled use of both the target language and students' other non-target languages. Cook (1999) supports the idea of non-target language use and his suggestion is based on efficiency principles - to use whatever language serves classroom goals best. Thus, a further proposal brought about by Cook $(1999,2001)$ is that the value of the L1 or any previously acquired languages in the classroom should be emphasized and the separation of language should be avoided. According to his view, a foreign language classroom should be a place where students can fully function with their total language 
system, using their whole linguistic repertoire. The theoretical concept of multicompetence thus highlights the importance of using non-target languages during foreign language classes and suggests that foreign language classrooms should create such a learning environment, where students can develop their whole multilingual language repertoire.

While multicompetence focuses on L2 users and stresses the importance of the L1 in the L2 learning process, the DMM - constructed within the field of TLA and multilingualism - focuses on multilingual speakers and the learning process of a third or additional language.

Focusing on the acquisition of a third language, the aim of TLA researchers is to emphasize the positive effect of bilingualism on the L3 learning process, where the learners' L1, L2 or any other previously acquired languages could serve as a tool for further language learning. Specifically, metalinguistic awareness is thought to enhance L3 language proficiency. Such assumptions are based on the outcomes of studies where research focused on vocabulary acquisition and lexical processing by monolingual and bilingual children (e.g. Munoz, 2000; Sanz, 2000; Allgäuer-Hackl and Jessner, 2013; Hofer, 2015; Jessner, Megens and Graus, 2016). According to the DMM, metalinguistic awareness is a key component of the multilingual factor and, thus, explains multilinguals' enhanced capacity to learn additional languages. Also, according to Sanz (2012), multilinguals' metalinguistic awareness, as a result of exposure to and literacy in two or more languages, provides learners with "a capacity to focus on form and to pay attention to the relevant features in the language input, thereby increasing the amount of intake (processed input)" (Sanz, 2012: 3939). Sanz (2012) also mentions heightened restructuring strategies, as a result of metalinguistic awareness, which lead to a quicker processing of new input as well. Bono (2011) promotes the idea of a strategic advantage provided by metalinguistic awareness, suggesting that the notion of metalinguistic awareness is mainly relevant in classroom contexts where interactions contain a high proportion of metalanguage.

These new approaches to multilingual education describe how to raise the learners' awareness of other languages in the classroom, how to teach related languages, how to teach learning strategies, and how to make use of prior linguistic knowledge in the classroom (see, e.g. Hufeisen and Lindeman, 1998; Cenoz, Hufeisen and Jessner, 2003; Cenoz and Gorter, 2011). 
Studies on multilingual education also argue that teachers must be proactive and flexible with their language of instruction (Wood, 2011:86), language teachers therefore should be multilinguals themselves, "not just native speakers teaching as if their leaners were, or were to become, native speakers" (Byram, 1998: 113). It is a principle of human cognition that learners rely on whatever they perceive as relevant to the task at hand and looking for similarities is a natural process in learning in general. According to Ringbom (2007: 5), "[t]he natural procedure in learning something new is to establish a relation between a new proposition or task and what already exists in the mind". During the language acquisition process, the most relevant piece of information for the learning task is likely to be the knowledge of other languages as well as the experience gained in acquiring such knowledge. Lasagabaster (2001) points out that multilingual learners may transfer the skills developed in all of their prior languages to another nonnative language, and this may improve their speed of acquisition, and possibly affect the route of acquisition as well.

Cummins (2001) also suggests that in sociolinguistic and educational contexts where comprehensible input in the target language is not available, and learners hardly use the target language outside the classroom, they can gain benefits from some teaching methods that complement for the lack of comprehensible input. Thus, the reactivation of prior language knowledge in the classroom, that is, to build on language systems which are already existent in the students' multilingual repertoire, is suggested to be of facilitative nature in language learning (Herdina and Jessner, 2002). And, at the same time, metalinguistic and metacognitive awareness will be fostered in the students, as argued by Jessner $(1999 ; 2001)$. In particular, the focus on the similarities between two language systems seems to be helpful in the language learning process. As Hufeisen (2005: 38-39) points out, the classroom teaching environment should incorporate the use of already acquired languages, translation and explicit language and cultural comparisons as these will result in more learner independence and faster progression. 


\subsection{The acquisition of a third language - an educational perspective}

Nowadays, it is a natural trend that children learn three or even more languages at school. Multilingual education is gradually becoming more and more popular in order to help and encourage multilingualism and multilingual development, either by introducing a foreign language - in most cases English - at an early age (kindergarten), or one or two second foreign languages in secondary school (Cenoz and Jessner 2009:121).

There is a range of reasons for the interest in third language acquisition, namely, practical, theoretical and empirical (Hammarberg 2009). The practical motives for TLA research are represented by the need to acquire more languages and by the increasing role of English as a lingua franca in Europe and throughout the world, which puts English in the position of a third language for a large number of bilingual speakers. The fundamental theoretical base for the study of third language competence, use and acquisition is the observation that people are "potentially multilingual by nature and that multilingualism is the normal state of linguistic competence" (Hammarberg 2009: 2). Given this assumption, Hammarberg (2009) claims that there is a need for an adequate theoretical framework of linguistic competence that would treat multilingualism as the norm. The empirical motives behind third language acquisition research are supported by researchers' aims to investigate the complexity of speakers' language competence and use, including the processes of language development, language maintenance and language loss and the way languages interact within the mind of the speaker. Hammarberg (2009) suggests that going beyond bilingualism and adopting a multilingual perspective, researchers can obtain a more complete picture of the language learning processes mentioned above and that they could focus more on the complexities of such cognitive abilities such as metalinguistic awareness, linguistic creativity, language learning and communication strategies.

Third language acquisition research developed first as internal to the field of second language acquisition (SLA), then it grew out of it as the separate research field of third language acquisition (TLA). In the need for differentiation, the definition of TLA is constructed in relation to SLA, with an emphasis on both quantitative and qualitative changes in language learning. Many authors dealing with TLA studies (Cenoz and Genesee, 1998; Cenoz and Jessner, 2000; T.Balla, 2013), share the opinion 
that multilingual acquisition and multilingualism are more complex than bilingualism and SLA, not only because the greater number of languages involved but also due to all "the factors and processes associated with SLA and bilingualism as well as unique and potentially more complex factors and effects associated with the interactions that are possible among the multiple languages being learned and the processes of learning them" (Cenoz and Genesee, 1998:16).

There is also more diversity and complexity in multilingual acquisition as compared to SLA if we consider other factors such as the age of acquiring different languages, the educational context and the sociolinguistic environment in which languages are learnt and the typological distance between languages. If we accept the integrated language system theory, it means that languages in one's mind are interconnected and dependent on one another and have mutual effect on one another. Then, from this integrated systems perspective, an increase in the number of languages, (i.e. adding one more language) means also a growth in the complexity of the system. More variables come into question and more connections are built, thus, not surprisingly, it leads to a qualitative change. In this way, learning a further language affects the overall linguistic system, creating new connections and relationships, and thus the entire linguistic system is restructured. Studies concerning multilingualism and the learning of languages other than the L2 had a major effect on the shaping of this particular field, however, according to several researchers (e.g. Hall and Ecke 2003, Cenoz 2001, De Angelis 2007, Jarvis and Pavlenko, 2007, Herdina and Jessner, 2000 etc.) TLA carries some specific features connected to multilingual development that differentiates it from SLA.

Herdina and Jessner (2000) provide a clear distinction of the terminology currently used in TLA studies. According to these authors, multilingualism can be considered as a phenomenon including bilingualism as a possible form, but it mostly refers to languages acquired after a second one. They present some representative features of third language acquisition which involve non-linearity, language maintenance, individual variation, interdependence and quality change. Non-linearity in language acquisition is defined as the process of language development which does not follow a linear route but includes phases of speed in acquisition and phases of discontinuation or "retardation" (Herdina and Jessner, 2000:87). Language maintenance is strongly related to non-linearity, meaning that leaners have to struggle and make 
efforts in order to maintain their proficiency level in the languages they know. Being a multilingual naturally involves more maintenance effort, as there are more languages to be preserved. The third defining characteristic of TLA is individual variation which stands for all the internal and external factors leaners may be affected by and the interaction of these factors. Interdependence addresses the existence and interaction of all the languages in the learners' linguistic repertoire. All the languages a learner may know operate at the same time, and they are considered as a whole unit, as one system, or as two or more languages in one's mind - as the multicompetence perspective would define it. The last feature mentioned by Herdina and Jessner (2000) is quality change which embraces all the above mentioned characteristics, pointing out that an additional language changes the whole system by creating new connections, new schemes of interdependence, brings about more effort from the learners' part not only language learning but also language maintenance efforts and new experiences.

Multilingual acquisition is a complex and dynamic process. Herdina and Jessner (2002:75) define multilingual proficiency as "dynamically interacting linguistic subsystems which themselves do not necessarily represent any kind of constant but are subject to variation", which also includes what the authors call the M[ultilingualism]factor. The latter refers to the properties of a multilingual system such as multilingual awareness, multilingual monitoring, language maintenance effort and multilingual learning strategies related to the prior language knowledge the speaker can rely on.

Learning a third or additional language involves acquiring certain skills and competences connected to the process of language learning and language maintenance (Herdina and Jessner, 2000; Safont Jorda, 2005). Therefore, we may assume that acquiring an additional language enhances the development of internal language processing mechanisms and language use as well.

\subsubsection{Factors that influence the acquisition of a third language}

As argued above, there are significant differences - both quantitative and qualitative - between acquiring a second vs. a third language. Scholars in the TLA research field, in the need for differentiation between SLA and TLA, have been focusing on the acquisition process and on factors that influence this process of language learning. In the present section I provide an account of how different 
researchers have attempted to classify the factors affecting the acquisition process of a third language. As I will show in the following paragraphs, the list of factors composed by several different researchers may overlap; however, they differ in their degree of elaboration.

Odlin (1989) differentiates between structural (i.e. language related) and nonstructural factors (such as motivation, class size, individual traits, such as level of proficiency, language aptitude, first language literacy and linguistic awareness) that influence language acquisition. He goes beyond the contrastive analysis hypothesis and its conceptualizations of L1 influence by taking into account the above mentioned additional, non-language related factors that also interact with linguistic transfer. Among the language related factors Odlin (1989) mentions semantic, syntactic and pronunciation differences in the language structures and the way these differences affect the foreign language acquisition process. The non-structural factors comprise individual characteristics and Odlin's aim is to emphasize the importance of these non-structural factors in the acquisition process and transfer phenomena. Motivation plays a major role since highly motivated language learners will probably learn more and faster even if there are a great number of structural differences between their target and non-target languages. Class size, according to Odlin (1989), may also have an important effect because of the individual attention learners can get. The individual differences mentioned above are all considered to have major effects on language development and success in foreign language learning. Odlin (1989: 135) emphasizes that a "high degree of literacy in one's native language can increase the likelihood of positive transfer in recognizing cognate vocabulary".

Cenoz (2001) compiles a list of seven factors including psychotypology (the learners' perception of the linguistic distance between the language to be acquired and the languages present in their linguistic repertoire), level of proficiency (both in the target language and his/her other languages), context of acquisition, language mode (introduced by Grosjean, 1998 and referring to monolingual or bilingual contextual situations), foreign language effect (based on Meisel, 1983 and further elaborated by Hammarberg, 2001 as well as De Angelis and Selinker, 2001) concerning the use of an L2 or any other languages than the L1 as the source of cross-linguistic influence), age, and recency of use. In a more recent publication Cenoz and Gorter (2015:2) complete the list of influencing factors with the characteristics of the languages involved - 
meaning their status, use in society and educational contexts - and the sociolinguistic environment in which language learning takes place including the linguistic landscape of the given educational context. Moreover, the authors also mention factors related to language pedagogy as the intensity of language instruction, the age languages are introduced at schools and teachers' teaching methodology.

A more recent list by De Angelis (2007) includes all the factors mentioned by Cenoz (2001), complementing the list with exposure to foreign language environment and order in which the languages were acquired. Jarvis and Pavlenko's list (2007: 174) includes five main factors, namely, linguistic and psycholinguistic factors, cognitive, attentional and developmental factors, factors related to cumulative language experience and knowledge, factors related to the learning environment, and, finally, factors related to language use.

The psycholinguistic factor contains further components, such as cross-linguistic similarity, language use, frequency, recency and salience, as well as markedness and prototypicality, and, last, linguistic context (Jarvis and Pavlenko, 2007:175). Cognitive, attentional and developmental factors are further subdivided into cognitive maturity, developmental and universal processes of language acquisition, cognitive language learning abilities and attention to and awareness of language (Jarvis and Pavlenko, 2007:190). Finally, the third factor, related to cumulative language experience and knowledge includes components like age, length, frequency and intensity of language exposure, length of residence, general level of proficiency and number and order of acquired languages (Jarvis and Pavlenko, 2007:197).

Perhaps the most finely elaborated list is provided by Hall and Ecke (2003). These authors also compiled a list of five main factors that are subdivided in further categories. The first is the learner factor containing individual learner variation with components like psychotypology, metalinguistic awareness, motivation, attitude, age, learning style and strategy use and degree of anxiety. Learning factors are subdivided into factors such as acquisition order and time-course of learning, the proficiency and fluency achieved in each language involved, the amount of exposure to and use of each language, the recency of exposure and use, "L2 status", the learning context (instructional, natural, etc.), the size of the vocabulary and the type of $\mathrm{bi} /$ multilingualism. The language related factor is concerned with the type of languages involved, the degree of formal relationship between them, typological distance, the 
historical distance, the degree of contact and the type of writing systems. The category of event factors refers to the situations in which the language is actually used, that is, language mode (monolingual/bilingual), language control, style (formal/informal), tasktype, interlocutor, degree of monitoring, processing direction (comprehension/production), and modality (written/spoken). The last factor is called the word factor and includes the relevant features of the words involved specifically in the learning process, that is, the degree of formal similarity with other languages from the learner's linguistic repertoire (phonological/orthographic), the number of formally similar words in other languages (neighbourhood density), the degree of frame (lemma) similarity and the number of similar words, the degree of concept similarity and the number of conceptually similar words, the degree of combined similarity (indirect and true cognates), content vs. function word status, abstractness vs. concreteness, frequency, frequency of competitors, recency of exposure or use, and, finally, completeness of representation.

As we can see, the authors cited above have defined a great number of categories and further divided them into subcategories in order to account for all possible factors that represent a multitude of influences causing TLA to be a field that is rather challenging to research. The factors listed by the different authors overlap and some of the factors that occur repeatedly are the most researched ones as well. In order to have a comprehensive and clearer overview, below I provide a table listing all the factors discussed above which have been noted as influential in the process of third language acquisition.

Table 1. Overview of factors influencing third language acquisition

\begin{tabular}{|lll|}
\hline \hline Author/s & Factors & \\
\hline Odlin (1989) & Structural & Non-structural \\
\cline { 2 - 3 } & Semantics & Learner personality \\
& Syntax & Age \\
& Pronunciation & Literacy \\
& & Level of proficiency \\
& & Aptitude \\
& & Linguistic awareness \\
\hline Cenoz (2001) & Psychotypology \\
& Level of proficiency \\
& Context of acquisition \\
\hline \hline
\end{tabular}




\begin{tabular}{|c|c|c|}
\hline Cenoz and Gorter (2015) & \multicolumn{2}{|c|}{$\begin{array}{l}\text { Language mode } \\
\text { Foreign language effect } \\
\text { Age } \\
\text { Recency of use } \\
\text { Language status } \\
\text { Use of language in society and education } \\
\text { Sociolinguistic environment } \\
\text { Linguistic landscape } \\
\text { Intensity of language instruction } \\
\text { Teachers' teaching methodology }\end{array}$} \\
\hline De Angelis (2007) & \multicolumn{2}{|c|}{$\begin{array}{l}\text { Language distance } \\
\text { Level of proficiency } \\
\text { Recency of use } \\
\text { Exposure to a non-native language environment } \\
\text { Order of acquisition } \\
\text { Formality of context }\end{array}$} \\
\hline \multirow{4}{*}{$\begin{array}{lll}\text { Jarvis } & \text { and } & \text { Pavlenko } \\
(2007) & & \end{array}$} & Major factors & Sub-factors \\
\hline & $\begin{array}{l}\text { Linguistic factors and } \\
\text { psycholinguistic } \\
\text { factors }\end{array}$ & 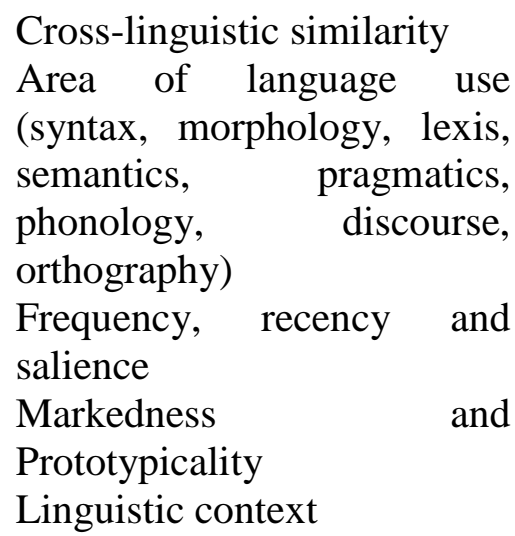 \\
\hline & $\begin{array}{l}\text { Cognitive, attentional } \\
\text { and developmental } \\
\text { factors }\end{array}$ & $\begin{array}{l}\text { Cognitive maturity } \\
\text { Developmental and universal } \\
\text { processes of language } \\
\text { acquisition } \\
\text { Cognitive language learning } \\
\text { abilities } \\
\text { Attention to language } \\
\text { Language awareness }\end{array}$ \\
\hline & 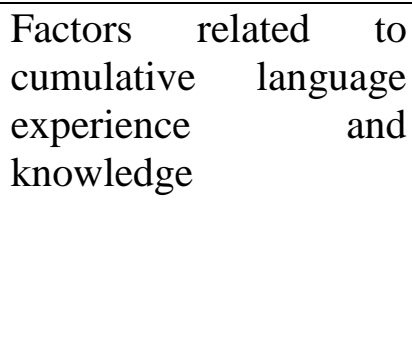 & $\begin{array}{l}\text { Age } \\
\text { Frequency and intensity of } \\
\text { language exposure } \\
\text { Length of residence } \\
\text { General level of proficiency } \\
\text { Number and order of } \\
\text { acquired languages }\end{array}$ \\
\hline
\end{tabular}




\begin{tabular}{|c|c|c|}
\hline & $\begin{array}{l}\text { Factors related to the } \\
\text { learning environment }\end{array}$ & $\begin{array}{lll}\text { Formal or } & \text { naturalistic } \\
\text { exposure } & & \end{array}$ \\
\hline & $\begin{array}{l}\text { Factors related to } \\
\text { language use }\end{array}$ & $\begin{array}{l}\text { Interlocutor, level of } \\
\text { formality, task type }\end{array}$ \\
\hline \multirow[t]{5}{*}{ Hall and Ecke (2003) } & Major factors & Sub-factors \\
\hline & Learner factor & $\begin{array}{l}\text { Psychotypology } \\
\text { Metalinguistic awareness } \\
\text { Motivation } \\
\text { Attitude } \\
\text { Age } \\
\text { Learning style } \\
\text { Strategy use } \\
\text { Degree of anxiety }\end{array}$ \\
\hline & Learning factors & $\begin{array}{l}\text { Order and time-course of } \\
\text { learning } \\
\text { Proficiency and fluency in } \\
\text { each language involved } \\
\text { Amount of exposure and use } \\
\text { of each language } \\
\text { Recency of exposure and use } \\
\text { L2 status } \\
\text { Learning } \\
\text { (formal/natural) } \\
\text { Size of vocabulary } \\
\text { Type of bi/multilingualism }\end{array}$ \\
\hline & Language related factor & $\begin{array}{l}\text { Type of languages involved } \\
\text { Degree of formal relationship } \\
\text { between the languages } \\
\text { Typological distance } \\
\text { Historical distance } \\
\text { Degree of contact } \\
\text { Type of writing system }\end{array}$ \\
\hline & Event factors & $\begin{array}{l}\text { Language mode } \\
\text { (monolingual/bilingual) } \\
\text { Language control } \\
\text { Style (formal/informal) } \\
\text { Task type } \\
\text { Interlocutor } \\
\text { Degree of monitoring } \\
\text { Processing direction }\end{array}$ \\
\hline
\end{tabular}




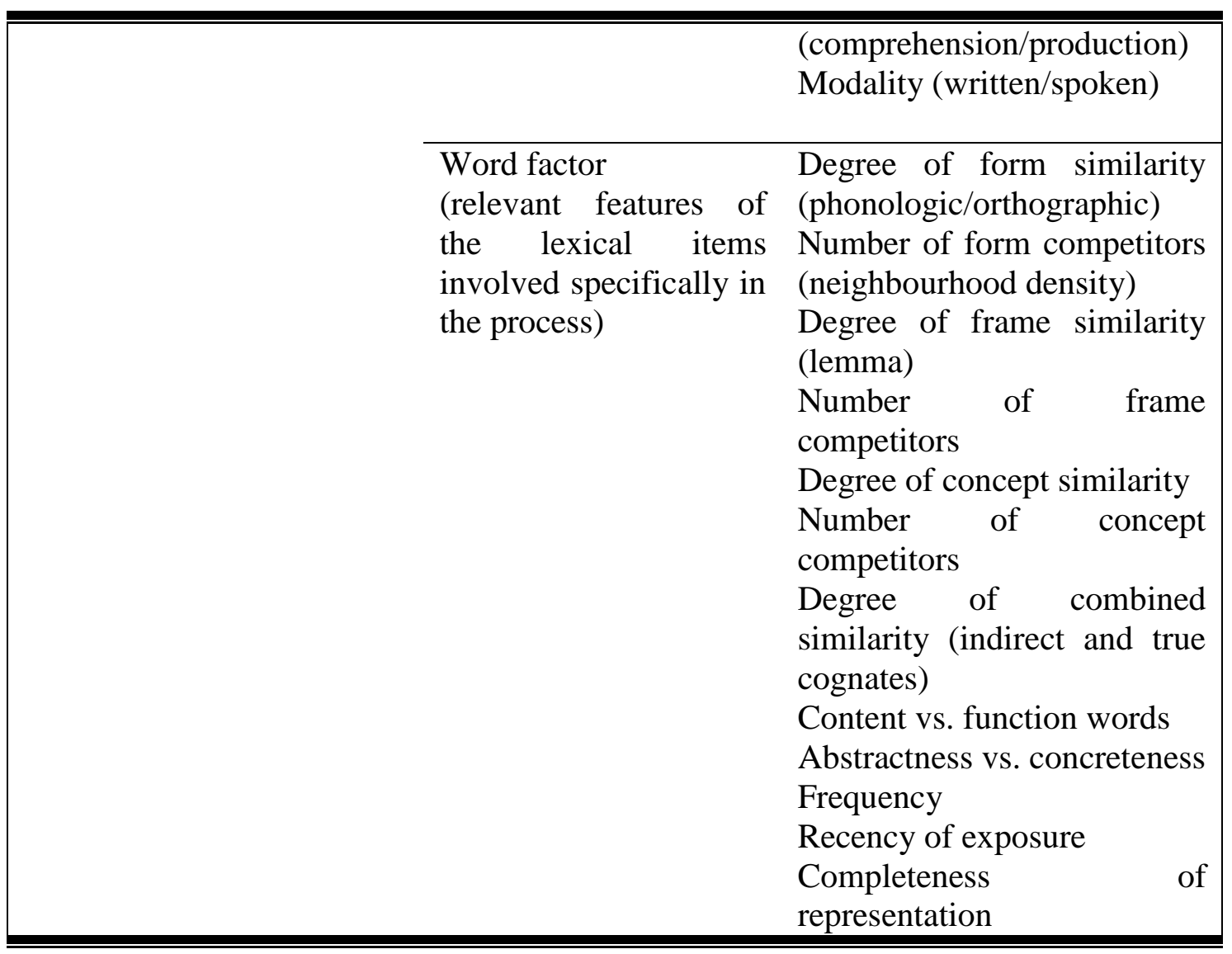

The comprehensive table above lists the factors that influence the acquisition of a third language as defined by the different authors. There is vast number of factors affecting foreign language learning although some major, overlapping factors can be traced. Hall and Ecke's (2003) major factors indicate the areas which need to be considered and from where an influence should be expected, namely, factors related to individual learner differences, factors related to learning, the languages themselves, context of interaction and some characteristics of the specific lexical items that can be influential in the learning process. All the factors defined by other researchers fit into Hall and Ecke's (2003) five major categories.

It is beyond the scope of the present study to account for all the factors listed above; however, by investigating current EFL teaching trends and the use of non-target languages during EFL classes, the paper reveals how factors like second language exposure and the language mode adopted by teachers and schools affect EFL teaching and learning. Moreover, the interviews with students focus on their beliefs and attitudes regarding the use and usefulness of non-target languages in language acquisition and thus interviews reflect also on factors such as psychotypology and language awareness. 


\subsubsection{Cross-linguistic influence in third language acquisition}

In the present section I describe one of the main factors that influence third language acquisition, namely, cross-linguistic influence, that is, the effect of prior language knowledge on the acquisition of an additional language.

Cross-linguistic influence (CLI), a term coined by Sharwood-Smith and Kellerman in 1986 has been the common concept used for "phenomena such as transfer, interference, avoidance, borrowing, and L2-related aspects of language loss" (Sharwood-Smith and Kellerman, 1986:1). In the case of third language acquisition the issue becomes much more complex and TLA studies show that the role of non-native languages are of greater importance than it was originally thought of. Research on multilingualism involves a lot of studies investigating language transfer. Recently, the discussions of codeswitching in the classroom have made this issue more apparent. For example, Lüdi (1986:242) highlights that codeswitching phenomena can occur in the case of language learners as a compensatory strategy, but it can also characterise competent bilingual speakers' communication as well. Therefore, Jessner (2003:49) argues that transfer phenomena salient during third language production should be analysed from a holistic, multilingual perspective and she proposes a common framework, offered by the DMM - "an umbrella term for all the existing transfer phenomena" - which includes not only transfer and interference, mostly studied in SLA, but also codeswitching and borrowing, mostly studied in bilingualism research. For what regards transfer and interference, it is difficult to provide a clear definition since the definitions of the two terms overlap in most cases. While Weinreich (1953:1) uses the term interference for "instances of language deviation from the norms of either language which occur in the speech of bilinguals as a result of their familiarity with more than one language", Odlin (1989: 27) uses the term transfer to account for the influence "resulting from similarities and differences between the target language and any other language that has been previously (and perhaps imperfectly) acquired" (see also Ellis, 1997). One difference that can be traced between the two terms lies in their connection with prior linguistic influence in the target language. Interference is usually assigned to have a negative connotation, referring to negative transfers, i.e. learner errors rooted in prior linguistic knowledge. Odlin (1989: 36-41) broadened the definition of transfer by including positive transfer which has a facilitative effect on the 
target language acquisition process, thus, transfer has a neutral connotation being used for both positive and negative transfer. Odlin (1989) also explains that in language contact situations (and here he refers to situations when speakers do not share the same languages and they need to communicate) a phenomenon called code mixing arises, meaning the combination of the languages involved. According to Odlin (1989), code mixing can have two forms: borrowing and code-switching.

The proposed term is that of cross-linguistic interaction (CLIN), which is also intended to "cover another set of phenomena such as non-predictable dynamic effects which determine the development of the systems themselves and are particularly observable in multilingualism" (Jessner 2003:49). Contrary to the Contrastive Analysis Hypothesis which dominated CLI research for many decades and concentrated on leaner errors, the umbrella term CLIN, developed by TLA researchers, focuses on the interaction of at least three languages in the multilingual's mind. Apart from the larger number of languages involved and their combinations, the interaction of these languages in the learners' minds leads to changes in the whole linguistic system resulting in different skills and abilities, such as metalinguistic awareness and metacognitive strategies which can play an important role in the third language acquisition process. Thus, CLIN is considered to be both qualitatively and quantitatively different from the CLI concept (Veronique 2010).

The results of the studies on cross-linguistic influence in multilingual acquisition and Jarvis and Pavlenko's (2007) comprehensive work on the types of linguistic transfer indicate that the phenomenon occurs on all levels of the linguistic subsystems, namely, it can be traced on the level of phonetics and phonology, morphology, syntax, and lexis. The "influence of word knowledge in one language on a person's knowledge or use of words in another language" (Jarvis and Pavlenko, 2007) seems to be the most visible type of cross-linguistic influence. Therefore, most L3 studies concentrate on the lexical level, where traces of non-target information are mostly overt and easily recognizable. It appears that both L1 and L2 play a role in transfer to the L3 on the lexical level, though this may be dependent on whether we consider the transfer of form or meaning (Foote 2009:95). Ringbom $(1987,2001)$ differentiates between transfer of function words and content words, and he brings evidence that function and form are transferred from L2, while meaning and content from L1. Ringbom (2001) states that transfer of meaning (i.e. when an authentic target language word is used with a meaning that reflects 
semantic influence of a corresponding word in another language) can only occur from the L1 or a highly proficient L2, in any case, the most fluent language. Formal transfer occurs from the source or base language perceived as the most similar to the target language, and it can result in morphophonological errors (false friends, i.e. formal similarity but partial or no semantic identity), blending words from two or more languages, and unintentional lexical borrowing.

In Tremblay's (2006) categorization there are two types of CLI on the lexical level, namely, lexical inventions and language shifts. Tremblay (2006: 112) uses Dewaele's (1998: 471) definition to describe the meaning of lexical inventions, according to which lexical inventions include words "which are morpho-phonologically adapted to the TL but which are never used by native speakers". Lexical inventions refer to such categories as loan translations, semantic extensions, cognates, hybrids, blends and relexification. Language shifts, in contrast with lexical inventions, are not intended to be used for communication in the target language. The categories discussed here were identified by Williams and Hammarberg (1998) and include the following: edit (referring to instances of self-repairing or turn-taking), meta (comments on performance or requests for help), insert (the use of other language to overcome lexical gaps) and "without identified pragmatic purpose" (WIPP), which appear to be slips of the tongue (Tremblay 2006:112-113).

The findings of some studies point to the fact that there are several factors that affect cross-linguistic influence. One of the most discussed factors is linguistic similarity or distance (Odlin, 1989; De Angelis, 2007; Kellerman, 2001; Cenoz, 2001; Jessner, 2008; Jarvis and Pavlenko, 2007 etc.), together with perceived linguistic similarity, that is, psychotypology (Williams and Hammarberg, 1998; De Angelis, 2007; Jarvis and Pavlenko, 2007).

The broadest category of factors is discussed by De Angelis (2007) in her book Third or additional language acquisition. Research concerning multilingualism and cross-linguistic influence has already identified a number of factors that influence learners' strategy to rely on previously learned languages and the factors that limit the type and amount of influence on the target language. A number of these factors is important in explaining both native and non-native language effects, while others are more specific to multilinguals' language production processes. De Angelis (2007:21) examines the following factors with reference to non-native language influence or 
cross-linguistic influence: (a) language distance; (b) target language proficiency and source language proficiency; (c) recency of use; (d) length of residence and exposure to a non-native language environment; and (f) formality of context. In what follows I will briefly discuss about these factors that have an effect on cross-linguistic influence.

a) Language distance:

There is wide agreement among researchers that transfer is most likely to occur between languages that are closely related to one another rather between languages that are distantly related (Cenoz, 2003, 2005; Cenoz and Valencia, 1994; Clyne, 1998; De Angelis, 2005; De Angelis and Selinker, 2001; Dewaele, 1998; Ecke, 2001, 2003; Ringbom, 1987, 2001, 2005; Williams and Hammarberg, 1998 etc.). The notion of language distance usually refers to objective and formal similarities or distances between languages or language families. Languages which are relatively close to each other are more likely to be activated simultaneously due to their similarities at the lexical and morphological levels (Cenoz 2005:2). However, there is a further distinction present in the literature with respect to language distance, that is, the notion of perceived language similarity or distance, also called psychotypology. This is the distance that learners recognize to exist between languages that may or may not correspond to the distance that actually exists between them.

The notion of psychotypology was coined by Kellerman in the 1970s when he identified the importance of learners' perceptions of language distance with a study on idiomatic expressions conducted with Dutch L1 learners of English as an L2. As already mentioned, multilinguals familiar with related and unrelated languages are generally argued to be most influenced by the languages perceived to be the closest to the target language. However, learners perceive language similarity and distance at different levels and "may rely on their prior knowledge depending on how they judge the overall level of closeness between languages, or the similarity of some features of components of two or more languages" (De Angelis 2007: 23). Moreover, it has been shown that multilinguals generally select and rely on one of their languages as their source of crosslinguistic influence (Ringbom, 2001; De Angelis, 2007).

Language relatedness and perceived linguistic similarity are important in the study of language acquisition and multilingual language production. Nevertheless, Williams and Hammarberg (1998) have claimed that relatedness is only one of the factors that determine which language becomes the learners' main source of 
information, and, thus, they propose other factors to be taken into consideration as well. As it has been previously stated, learners choose one of their languages as the base language, but the selection process does not exclusively rely on language relatedness, but the L2 status, recency of use and proficiency level are also influencing factors in deciding upon the source language. The main source becomes the language which qualifies the best in these four conditions.

b) Language proficiency

In the literature on cross-linguistic influence, proficiency is discussed with regard to proficiency in the target language vs. proficiency in the source language. In relation to proficiency in the target language, most studies show that cross-linguistic influence is more likely to occur at earlier stages of development, when learners' knowledge in the target language is weak, and there is a greater need to fill knowledge gaps (Ringbom 1986, Odlin 1989, Williams and Hammarberg 1998). With respect to proficiency level in the source language, it has been shown that transfer occurs not only from a nonnative language a speaker is proficient in (Williams and Hammarberg 1998) but also from non-native languages which the speaker knows less (De Angelis 2005). This suggests that there is no need for a high proficiency level in order for transfer to occur: De Angelis (2007: 34) states that one or two years of formal instruction are enough to affect target language production and development.

c) Recency of use:

The recency of use factor refers to how recently a language was last used. Among others, Williams and Hammarberg (1998) believe that a language recently used has an influence on target language production. However, in the literature there are a number of studies that show instances of transfer from languages that have not been used for a long period of time (De Angelis 1999, De Angelis and Selinker 2001).

d) Exposure to language:

Exposure to a non-native language and order of acquisition - as shown by Dewaele's 1998 study, cited in De Angelis (2007: 37-38) - may determine the amount and type of cross-linguistic influence that occurs in a third or additional language.

e) Formality of context:

Up to the present point, there is only one study that has empirically examined the influence of formality on multilinguals' performance. The study was conducted by Dewaele (2001), who compared high school students' performance in formal and 
informal situations. His aim was to examine whether the formality of the communicative situation led to more effective monitoring of the speech output. The result of the analysis was that those students who were interviewed in a more formal situation produced less mixed speech than those learners who were interviewed informally, possibly due to the increased monitoring activity during the formal situation.

Research on multilingual acquisition has shown that first language transfers are less influential than typological similarity between the languages regardless of when they are learned, and also that bilingualism has a positive effect on the acquisition of additional languages (Cenoz, 1997; Molnár, 2010c; Singleton and Little, 2005; Ó Laoire and Singleton, 2009). Researchers have shown that "expert" language learners have greater flexibility in switching strategies and increased communicative competence, being more sensitive and responsive to the needs of their interlocutors (Cenoz and Genesee 1998:26).

Although there is a lot more to investigate and learn about the contexts and strategies that facilitate language learning, the fact that cross-linguistic transfer occurs, remains unquestionable. Study results bring evidence that "a child who acquires his/her basic literacy or numeracy concepts in one language can transfer these concepts and knowledge easily to her second or third or other later-acquired languages" (Tucker 1998:11-12).

In line with the above research results and evidence, we can formulate the need that multilingual education should exploit the presumed benefits of bilingualism by designing curricula and classroom activities that help multilingual learners use their previous linguistic knowledge and strategies to learn additional languages.

\subsubsection{Research foci within the TLA field}

The present section provides a brief outline of the research areas within the field of Third Language Acquisition in order to be able to identify the position of the present study within this particular field of research.

Scholars have mainly focused on the role of previously learned languages in language production and comprehension (see studies of codeswitching, Williams and Hammarberg, 1998; T. Balla, 2011; for receptive multilingualism studies, see ten Thije and Zeevaert, 2007) and on the presumed advantages of bilinguals over monolinguals in 
learning an additional language (Bild and Swain, 1989; Cenoz 1997, 2008; Cenoz and Genesee, 1998; Sanz, 2000; Molnár, 2010a, 2010b). Historically, most empirical studies carried out within the field of TLA focus on the structure of the mental lexicon, foreign language pedagogy and sociolinguistics.

Further narrowing down the areas of multilingual research, studies concerning multilingual education and foreign language acquisition view the following research groups: (1) early trilingualism (the study of children growing up with three languages from birth), (2) bilingual children learning an L3 (in many cases English), (3) immigrant communities, monolingual individuals learning an L2 and then an L3. Despite the fact that third language acquisition is still in its infancy, various studies have been conducted, particularly within the European setting, that focus on the acquisition of English by bilingual speakers (Byram and Leman, 1990; Hoffman, 2000; Safont Jorda, 2005).

Focusing on the European context, research adopting an educational perspective has been carried out in three main European areas, namely Finland (Björklund and Suni, 2000), Friesland (Ytsma, 2000) and Spain (Cenoz and Valencia, 1994; Lasagabaster, 1998, 2000, 2005; Muňoz, 2000; Cenoz and Gorter, 2014; Portolés and Martí, 2017); however, with the gradual growth of the TLA field more and more studies are being conducted including other European regions and countries, such as Poland (Komorowska, 2014; Cybulska and Borenić, 2014), Croatia (Čajko, 2014; Cybulska and Borenić, 2014), Austria (Csire and Laasko, 2014), France (Clark and Lamoureux, 2014). All the studies quoted above report the positive effects of bilingualism in third language acquisition. Despite the fast growing empirical studies conducted in various European contexts, still the vast majority of research adopting an educational and psycholinguistic perspective comes from the Spanish context focusing on the acquisition of English by Basque-Spanish or Catalan-Spanish bilingual learners (Cenoz and Valencia, 1994; Lasagabaster, 2000; Muňoz, 2000; Sanz, 2000; Safont Jordà, 2005; Cenoz and Gorter, 2014;).

Cenoz and Valencia's 1994 study suggests that bilingualism has beneficial effects for achieving an optimal degree of multilingual competence. Cenoz and Valencia (1994) compared Spanish monolingual and Spanish-Basque bilingual university students in their success in learning English. English-fluency tests were given to both native Spanish speakers and Spanish-Basque bilinguals who had studied 
English between 4 and 9 years. All other influential factors (intelligence, age, motivation, and English exposure) eliminated, bilingualism in Spanish and Basque was a strong predictor of English fluency. Those who were fluent in more than one language were more successful at learning English. Spanish and Basque are relatively dissimilar and genetically unrelated languages. There is also an unequal relationship between how widely Basque is used in comparison to Spanish, since Spanish-Basque bilinguals typically encounter more situations where Spanish is useful.

In order to examine how bilingualism may influence L3 acquisition with variable differences between L1 and L2, Sanz (2000) replicated Cenoz and Valencia's findings comparing Spanish-Catalan bilinguals to Spanish monolinguals. Spanish and Catalan are both Romance languages, and Catalan has a wider use when compared to Spanish than Basque. Controlling other influential factors (such as exposure and motivation), Spanish-Catalan bilinguals were more successful at learning English than Spanish monolinguals (all of them high school juniors). Focusing on the Basque country, Lasagabaster (2000) found not only that bilingualism had beneficial effects on third language learning but that the presence of three languages in the curriculum is seen as a promoter of metalinguistic competence.

Considering current research, it makes sense to assume that bilingual learners will acquire an additional language faster and more efficiently than monolinguals. Current research on third language acquisition that focuses on cognitive and developmental processes has shown the advantage of bilinguals over monolinguals as described by Lambert's hypothesis (1990:212): “...bilingualism provides a person with a comparative, three-dimensional insight into language, a type of stereo linguistic optic on communication that the monolingual rarely experiences."

The present study concerns the multilingual development of bilingual young learners in Transylvania, Romania. In the present literature on multilingual acquisition we can find a truly great amount of data on bilingual children learning an L3 in European minority language contexts, however, these studies cluster around a few places or regions - the Basque country (Cenoz and Valencia, 1994; Cenoz and Gorter, 2014; Muňoz, 2000), Catalonia (Sanz, 2000) and South Tyrol (Jessner, 2006). There is almost no data to be found regarding Eastern-European bilingual communities such as the Hungarian minority groups living in countries neighbouring Hungary. 
Adopting an educational perspective to third language acquisition research although different from studies carried out in the Spanish context by Cenoz and Valencia (1994), Munoz (2000), and Sanz (2000), the present study focuses on Transylvanian Hungarian bilingual learners' acquisition of English as their first foreign language.

\subsection{The most obvious sign of multilingual language use: Codeswitching}

Research on codeswitching in educational settings refers mostly to bilingual classes. Earlier studies on codeswitching were carried out in the United States and focused on linguistic minority children enrolled in bilingual education programmes and the use of children's L1 (mainly Spanish) in such contexts (see Ovando and Collier, 1985; Ramirez, 1980; Wong Fillmore and Valadez, 1986). These first studies carried out on codeswitching in the school context used quantitative and functional analysis to measure the amount and functional distribution of L1 and L2 use during classroom activities. After the 1980s studies on bilingual classroom language use have been undertaken in other multilingual contexts as well such as Canada, Africa, Asia and Europe (Martin-Jones, 1995). These studies mainly focused on codeswitching patterns between students' L1 and the language of instruction with the aim to reflect upon issues related to ideology and the influence of language policies upon education.

In the TLA literature, codeswitching is considered to be an inherent and salient feature of multilingual communication. According to many researchers in the field of multilingualism and multilingual education codeswitching is "the most distinctive behaviour" of multilinguals ( $\mathrm{Li}$ and $\mathrm{Wu}, 2009$; Cenoz and Gorter, 2015) and a salient feature of multilingual communication and reflect students' competence in more than one language (Safont Jorda, 2005:36).

In the present study I look at the phenomenon of codeswitching in a different environment: the foreign language classroom. As the purpose of this study is to investigate EFL classroom language use and the way teachers' and learners' multilingualism is incorporated in language instruction, the best way in which nontarget language use can be discovered, I believe, is through observation of codeswitching during foreign language instruction. 
In a discussion of foreign language classrooms, we have to mention that multilingual communication in this kind of setting is "multilingual" due to the fact that the classroom is constituted for the teaching and learning of a foreign language. The sense in which the switching from the language of instruction to the target language and back can be designated as "codeswitching" is also in need of specification. Meisel (1989) defined code mixing as the intertwining of two grammatical systems, while codeswitching was considered to be part of the pragmatic competence of bilingual or multilingual individuals. For the terms mixing or switching to be meaningful, there must be at least two separate entities to mix that can be identified. Here we have to go back to the discussion presented in section 2.2, where the notion of multicompetence and DMM were explained. Both DMM and the later understandings of multicompetence argue for a set of linguistic sub-systems which are flexible, dynamic and interact with each other. Thus, codeswitching and code-mixing may be considered as a visible output of these interactions of languages and language sub-systems within the multilingual mind.

As I have already mentioned, the notion of codeswitching in the language classroom was first discussed in bilingual educational settings for minority children in the United States and the focus was rather on preserving L1 and identity than on acquiring second language (Edmondson, 2004). Furthermore, discussions in the literature concerning codeswitching between students' L1 and the language of instruction do not deal with foreign language classroom either, but with the teaching of different school subjects (mathematics, history, etc.) in immersion programmes (e.g. Byram, 2000). The case of the foreign language classroom is clearly distinctive. Cook offers a simple but useful definition of codeswitching applicable for this context: "going from one language to the other in midspeech when both speakers know the same languages" (Cook, 1991a: 63). This definition is roughly matched by that of Milroy and Muysken (1995: 7) as "the alternative use by bilinguals of two or more languages in the same conversation". Both definitions can be confusing and are disputed, as we can ask, for example, whether in the foreign language classroom the participating speakers in fact know the same languages, or what 'in the same conversation' means in the context of classroom teacher-student interaction (Dégi, 2014). A more recent definition given by Lin (2008: 273) states that classroom codeswitching refers to "the alternating use of more than one linguistic code in the classroom by any of the classroom participants". 
Lin (2008) differentiates between code-mixing (intra-clausal/sentential) and codeswitching (inter-clausal/sentential). What regards the present paper, it will use the term codeswitching as an umbrella term for both intra- and inter-sentential language alternations.

For what regards reserachers' attitudes towards the occurrence of codeswitching in educational settings, there are both positive and negative opinions expressed. Negative attitudes to codeswitching focus on repair strategies and emphasize learners' incomplete target-language knowledge. Adopting a sociolinguistic and ethnography of speech perspectives, Martin-Jones $(1995,2000)$ has carried out extensive research on classroom codeswitching and has demonstrated how widespread this phenomenon is and what a wide variety of purposes it can serve. It may, for example, look at how languages are used in social contexts outside the classroom; serve as an inclusive strategy where students are of varying language competences; serve to encourage students' acquisition of a second, third or additional language by ensuring that they understand at least part of what is said without difficulty; and have a purpose in pedagogic discourse structuring (Gardner-Chloros, 2009:159).

Similarly, Cleghorn (1992) shows how teachers in science classes in Kenya present and explain their lessons more effectively when they do not stick to an Englishonly instruction policy. Merritt et al. (1992) list four major factors which account for codeswitching in the classroom: (a) official school policy, (b) cognitive concerns, (c) classroom management concerns, and (d) values and attitudes about the appropriate use of the languages in society at large. Research studies also show that codeswitching and the flexible use of languages in the classroom can serve a number of important educational and communication functions (Cenoz and Gorter, 2015: 63) and help the teacher to be more effective in carrying out his/her roles in the classroom - directing attention, giving instructions, involving shyer students (Gardner-Chloros, 2009:160).

Current research in the field of multilingual education shows that alternated, flexible and integrated use of languages within the language classroom is beneficial for language learning (Garcia and Li, 2014; Jones and Lewis, 2014; Cenoz and Gorter, 2015). Investigations of codeswitching in foreign language classrooms focus mainly on learner initiated codeswitching patterns and refer to learners' inefficiency in foreign language production (Bentahila, 1983; Poulisse, 1997; Dewaele, 2001; Poulisse and Bongaerts, 1994). Similarly, Lüdi (2003) points out that students use their first language 
as a compensation strategy to get around communicative stumbling blocks. However, in practice it is more difficult to differentiate between codeswitching "born of necessity" and "more discourse-oriented" and identity related codeswitching, which develops as higher level of fluency is attained (Gardner-Chloros, 2009: 175).

Macaro (2014: 14) differentiates between two types of classrooms regarding the functions of codeswitching occurences: (1) classrooms where codeswitching is used only for making comparisons among languages or to explain lexical items and grammar rules of the target language (2) and communicative classrooms, where codeswitching has a communicative purpose, such as topic switch, socializing or expressing emotions. Macaro (2014: 20-21) also suggests that investigating codeswitching in foreign language classrooms is worth only if there is at least a balanced use of L1 and the target language, or the target language is used predominantly during classroom interactions and the goal of the lesson is that of teaching communication in the target language.

New trends in the study of multilingual education also deal with the notion of translanguaging. The term translanguaging was first coined by Cen Williams in 1994 under the Welsh term trawsieithu and it meant a pedagogical practice in Welsh schools where two languages were used within the same lesson (students were asked to read in Welsh and write in English). There is a growing number of studies that have taken up the term translanguaging and therefore the term has developed and it is employed not only in educational contexts but all areas of multilingualism to refer to the complex and flexible language practices of multilinguals (Garcia and Lin, 2016).

Scholars using and working with the term translanguaging argue that translanguaging is different from codeswitching because the latter concept entails the alternation of two languages as separate codes while translanguaging assumes that multilinguals have only one complex linguistic repertoire from which they select what is needed or appropriate (Gorter and Cenoz, 2015). Although the term translanguaging is considered as epistemologically different from the term codeswitching I believe the two terms are closely related in that they refer to the use of more than one language, to "the ability of multilingual speakers to shuttle between languages, treating the diverse languages that form their repertoire as an integrated system" (Canagarajah, 2011).

For my purposes in this paper, the point at issue is that the use of two or more languages in the foreign language classroom is a special case of codeswitching and whether one wishes to accept or reject this term is a matter of terminological preference 
or theoretical stance. In the course of this paper I will speak about codeswitching accepting Edmondson's use of the term as "any use of more than one language in a discourse segment or sequence of discourse segments by one or more classroom participants, either turn-internally or turn-sequentially" (Edmondson, 2004: 157). Moreover, examining multilingual classrooms, where classroom participants share at least three languages and thus codeswitching may occur in more combinations than L1 and L2, I believe that, contrary to Macaro's (2014) argument concerning the type of classrooms worth examining, all foreign language classrooms regardless of the aim of the lesson (teaching grammar vs. teaching communicative competence) may provide valuable data on current practices in foreign language pedagogy and thus they are worth investigating.

\subsubsection{Use of non-target languages during foreign language instruction: empirical research on classroom codeswitching}

Codeswitching during foreign language lessons has been a much debated topic in the last decade not only from the part of researchers but it means a major concern for teachers as well. Teachers mostly try to avoid and prevent the occurrence of codeswitching as they believe it has a negative effect on language acquisition; students, on the other hand, try to find ways to use their mother tongue while still participating and succeeding in the foreign language classroom. Levine (2011:4) emphasizes the contradictory relationship between the existent aims of foreign language education creating a target-language environment by using exclusively the target language within the classroom - and the poor educational system which offers only a low number of teaching hours where learners can get in contact with the target language. A number of scholars (Cook, 2001; Kramsch, 1998, 2000; Turnbull and Dailey-O'Cain, 2009; Garcia and Li, 2014; Cenoz and Gorter 2011, 2013, 2015; Canagarajah, 2013; Cummins, 2007; Swain and Lapkin, 2013) have already contested the monolingual norms applied to the foreign language classroom and concerning the ways in which "teachers understand the artificial microcosm" (Levine, 2011: 4) of the foreign language classroom. The worst is that the use of the L1 is stigmatized and prohibited; teachers often us the L1 relatively little as they convey a minimum or no pedagogical value to the use of the L1 (Macaro, 2001). Due to the limited number of foreign language classes, teachers try to use the 
target language exclusively; however, they seem to neglect the fact that the language classroom is a multilingual environment where teachers' and students' complete linguistic repertoire is present (Cook, 1999, 2001; Kramsch, 1998; Levine, 2003, 2005). If multicompetence and dynamic system theories are taken into account, then all the languages of the learners' linguistic repertoire interact and are involved in the language learning process. Thus, ignoring the role of non-target languages means to avoid not only previous empirical findings done in this area but also to neglect an important part of the foreign language learning process and students' previous language knowledge and language learning experiences. Thus, Levine (2011:5) points out that "the time is ripe for the development of a principled, multilingual approach to language classroom communication".

Contrary to previous studies arguing for the prohibition of learners' first language(s) during foreign language teaching, currently many researchers (see Cook, 2001; Swain and Lapkin, 2000, Levine, 2011; Cummins, 2007; Voicu, 2012) claim that the L1 or any other previously learnt language can function as "a cognitive tool" (Dailey-O'Cain and Liebscher, 2009: 131) that supports foreign language acquisition, and these claims lead them to argue for "some sort of principled alternation" (DaileyO'Cain and Liebscher, 2009: 131) between target and non-target language use in the foreign language classroom. Macaro (2001:545) suggests a "theory of optimality for the use of codeswitching by the teacher". Elsewhere, he defines the optimal use of codeswitching as "optimal use is where codeswitching in broadly communicative classrooms can enhance second language acquisition and/or proficiency better than second language exclusivity" (Macaro, 2009:38). The TARCLINDY research project (Macaro, 1997) included surveys and interviews about teachers' beliefs and attitudes with regard to first language use. The findings showed three distinct personal theories: (a) exclusive use of target language labelled by the author as virtual position and it is rooted in the input and interaction theories of the 1980s and 1990s, according to which learners should be provided with the maximum input and output opportunities in the target language; (b) use of the target language as much as possible without perfect learning conditions is called by the author maximal position, and (c) the value of the non-target language use which is thought to enhance learning stands for the optimal position (Macaro, 2009:35-36). Macaro's (2009) optimality theory needs to be addressed carefully. First, it refers only to classes where the focus is on developing 
communicative competence in the target language. Second, he does not give anything like a prescription of how to reach optimality in L1 use but rather relies on broad generalizations saying that an optimal use of codeswitching is up to teachers' judgement, and considering non-target language use as valuable in any way already means an optimal position. Thus, Macaro's (2009) optimality theory can be interpreted by teachers in any way, their judgements and understanding being filtered by their own attitudes towards non-target language use.

Earlier studies of classroom codeswitching usually focused on quantifying and categorizing classroom first language use. Such studies (e.g. Wing, 1980; Guthrie, 1984; Duff and Polio, 1990) conclude that most instructors used the target language a great deal of the time, though there was a difference between the linguistic and communicative functions of the codeswitches. Later studies focused on both teacher and student language use, however, the findings did not show much alternation, the instances of non-target language use were relatively scarce. Nzwanga (2000:104) points out that even if the use of non-target languages was forbidden by the teachers, they still appeared during the foreign language teaching. He found that codeswitches were most likely to occur during pair or group work (among the students), before a quiz or during (teachers') presentations. Levine (2003) was also interested in the amount of target vs. non-target language use and contexts of use for both teachers and learners, based on self-assessments. Self-reports regarding estimated target and non-target language use and the attitudes toward and beliefs about it were then compared with the reality of actual classroom observations. The results of the survey on the estimative use of languages show that the target language was used most by teachers when speaking to students, less by students when speaking with their teachers, and even less overall when students spoke with other students. Bailey (2011) conducted a study on university students' perception and attitudes regarding codeswitching and the use of L1 during EFL classes. His findings show that language anxiety and perceived competence have a large impact on students' attitudes towards codeswitching. Students with high language anxiety and low perceived competence had more favourable attitudes towards their teacher's codeswitching practices.

Turning from a quantitative analysis of the amount of codeswitching instances towards a more sociocultural perspective of language use, Anton and DiCamilla (1999) investigated the discourse functions of the languages used during foreign language 
teaching. The authors concluded that non-target language use provides, through collaborative dialogue, an opportunity for target language acquisition to take place (Anton and DiCamilla, 1999:237). In a similar way, Swain and Lapkin (2000) investigated the ways learners make use of non-target languages to complete target language tasks.

Further studies on English vocabulary acquisition in China provide evidence that the use of non-target languages enhances target language vocabulary acquisition and conclude that banning non-target languages from the foreign language classroom may reduce the "cognitive and metacognitive opportunities available to learners" (Turnbull and Dailey-O'Cain, 2009:10).

A case study carried out at a university in the United Kingdom addresses the issue of the use of English as a lingua franca (ELF) in mediating the learning of a third language. Ife (2008) was interested in the type of language that should be used for classroom interactions that requires a language level beyond the learners' current ability, such as classroom management, learner inquiry or task instructions. The study was conducted using the method of classroom observation, where interaction was recorded, transcribed and analysed. The goal of the author was to find out the extent of English as a lingua franca used. She thus examined ELF use in the provision of input, in metalinguistic commentary, in classroom management and in classroom interaction, whether between teacher and learners or among learners themselves. The results show that the dominant classroom discourse was target language discourse and ELF was relatively little used, but it was used by both teachers and learners for specific functions and it clearly served as a useful form of scaffolding for the learning process (Ife, 2008: $83)$.

An observational study of English classrooms in primary schools in Hungary focused on the teachers' use of Hungarian (Nagy and Robertson, 2009). Nagy and Robertson's (2009) study shows that contrary to the language policy which prescribes the maximum use of the target language, teachers' educational practice involves a wide use of the first language. Other studies also confirm the extensive use of first language during English lessons (see also Lugossy, 2003; Nikolov, 1999). Apart from a quantitative analysis of the amount of L1 used, the author carried out an in-depth analysis regarding the activity types and their relation to the highest/lowest use of L1. Results show that L1 occurs when language use departs from the routine (see also 
Nikolov, 2000) and becomes unpredictable, spontaneous, or when social norms within the classroom have to be reinforced. Functions of L1 codeswitching relate to comments, ensuring understanding, translating new words, giving instructions and encouragement (Nagy and Robertson, 2009: 82).

Nagy (2009) focused on language use in EFL classes in primary school in Hungary. Her research examines the use of the target language and learners' mother tongue in 16 English classes in the $4^{\text {th }}$ grade. Research results show that L1 was used mainly for giving information, asking questions and giving instructions. The author also points out that elementary teachers used more L1 than intermediate teachers, though there were teachers who did not fit this pattern; therefore, she concludes that the level of students and teachers' beliefs might influence the amount of L1 use during EFL lessons.

Thompson and Harrison (2014) analysed 40 videotaped lessons to examine the frequency and reasons for using English and Spanish. Their results point out that most L1 switches were used in case of class administration, explaining grammar, translations, giving instructions and explaning the assigments, checking comprehension and establishing relationships.

Codeswitching carried out by students is often assumed to be evidence showing lack of proficiency in the target language. When codeswitching occurs on the part of teachers who have both authority and ability to speak the target language, these codeswitching phenomena are considered to serve important functions in the acquisition process in that they mediate language learning and mark different aspects of meaningmaking within the classroom. From the perspective of sociocultural theory, the use of non-target languages helps learners to establish intersubjectivity, or arrive at a shared perspective regarding the task at hand (Dailey-O'Cain and Liebscher, 2009). The authors differentiate between discourse-related and participant-related functions of codeswitching, where discourse-related codeswitching includes instances of metacomments, or students indicating a problem in understanding. Participant-related codeswitching includes activities that correspond to the preferences of either the person performing the switch or his/her fellow conversation participants (Dailey-O'Cain and Liebscher, 2009:137).

Levine (2009) suggests that teachers should raise learner awareness concerning the role of non-target languages in foreign language communication and learning. The author proposes that raising awareness does not mean to consciously control the 
codeswitching during talk-in-interaction but first to de-stigmatize codeswitching and to teach and discuss some purposes of codeswitching in conversation. At the same time, teachers' experiences and numerous studies show that regardless of whether the teacher uses the target language most of the time, and whether or not the teacher forbids the use of non-target languages, students in fact still use their first language in many ways when they communicate in the classroom. Yet, simply allowing the use of non-target languages during classroom communication is neither sufficient nor pedagogically sound (Levine, 2009: 160). Ó Duibhir and Cummins (2012) also emphasize that the use of non-target languages can be more efficient if teachers drew learners' attention to crosslinguistic similarities and differences. Moreover, a flexible use of the languages during language teaching has been considered beneficial by many scholars (Garcia and Li Wei, 2014; Jones and Lewis, 2014; Cenoz and Gorter, 2015).

Levine's (2009:160-162) proposal for curriculum design and classroom affordances includes teaching students the terminology and concepts regarding multilingualism and codeswitching, developing teaching units dealing with multilingual individuals and communities in the target language culture, performing discourse analysis of multilingual speech with students, developing classroom surveys to assess and evaluate the role of non-target languages and code choice practices.

In line with Ringbom (2007), who states that looking for similarities and establishing connections between previous and new knowledge is part of the natural learning process, Paradowski (2008: 515) also argues that "learning invariably proceeds by relating new facts to the already familiar". Similarly, Voicu (2012) states that drawing comparison and relying on similarities and differences between English and the learners' mother tongue can be "a very enriching experience" and that it could "enhance acquisition" (Voicu, 2012: 214). As we could see in the sections above, previous knowledge and experience are a fundamental part of the foreign language learning process. Thus, it proves to be necessary that learners' previous linguistic knowledge and language learning experience be actively used and exploited by the teacher. As languages are interacting within the learners' linguistic repertoire, learning is thought to be more efficient if teachers raise their learners' awareness about the similarities and differences between languages (Cummins, 2007; Hall and Cook, 2013). "Drawing on the learner's L1 (or another mastered language) and showing comparisons and contrasts between this and the target mirrors, facilitates, and accelerates the processes which 
occur independently in his/her mind. The role of pedagogic intervention is unquestionable, as transfer of operations from the L1 to the FL usually requires additional correction and clarification" (Paradowski, 2008:515; see also Boócz-Barna, 2010).

\subsection{Teachers' beliefs on language teaching}

Another important question is related to teachers' belief set. What are the factors that influence or shape teachers' beliefs? Several studies, (Debreli, 2012; Gutièrrez Eugenio, 2017; Bailey et al. 1996) that focused on teachers' and teacher trainees' beliefs, report that most pre-service teachers have strong beliefs about language teaching and learning even before they start their teacher training module. These findings show that teachers' beliefs about language teaching and learning derive from their own experiences as language learners. Other studies (Borg M., 2005; Borg S. 2006; 2015; Urmston, 2003) conclude that teacher training can barely change teachers' pre-existing beliefs and that teachers' own language learning experiences have a greater impact on their beliefs than teacher training (see also Otwinowska, 2013). However, there are research findings (Cabaroglu and Roberts, 2000) showing that teacher training courses do have an influence on teachers' existing beliefs - not in changing these beliefs but in reshaping the order and importance of such beliefs. Abdi and Asadi (2015) provide a list of five sources for teachers' beliefs, namely: teachers' experience as language learners, experience from teaching, their own personality, experience based on the community - including school, parents, local society, and education or researchbased principles (see also Gilakjani and Sabouri, 2017).

Teachers' belief regarding the use of non-target languages in the classroom is yet another important issue to discuss. As Gutièrrez Eugenio (2017: 52) states, teachers' beliefs "act as a filter" and thus determine teachers' classroom behaviour and teaching practice. Adopting Mohamed's (2006: 21) definition, teachers' beliefs refer to a "complex, inter-related system of often tacitly held theories, values and assumptions that the teacher deems to be true, and which serve as cognitive filters that interpret new experiences and guide the teacher's thoughts and behaviour". Teachers' beliefs have a great impact on their pedagogical decisions and language behaviour during the language 
classes, therefore research is needed in order to better understand what happens in the classroom. Studies related to teachers' first language use during second or foreign language lessons range from classrooms where the first language is officially banned but still present in classroom interactions (e.g. Littlewood and Yu, 2011), to classrooms where a balanced and flexible use of languages is promoted (e.g. Carless, 2008) and classrooms where translations and codeswitching is encouraged and employed (Kim, 2011). All studies bring evidence that learners' first language is used and occurs within EFL classrooms even in contexts where it is strongly discouraged (Hall and Cook, 2013; Hlas, 2016). Hall and Cook (2013) conducted a large scale international study where they investigated teachers' attitudes and beliefs regarding non-target language use within EFL classes. Their results show a paradox between teachers' reported first language practices and activities in the classroom and teachers' general attitude towards language use. While most teachers reported on using learners' L1 when explaining grammar, vocabulary, maintaining discipline or developing rapport, they suggested that they try to exclude or to limit L1 language use. Hall and Cook's 2013 conclusions also support Macaro's 2009 findings, namely, that English is "predominant but not necessarily the only language in the classroom" (Hall and Cook, 2013:17). De Angelis (2011) also conducted an international study where 176 high school teachers were asked about their beliefs concerning the role of previously learnt languages and the use of learners' home language (in case of immigrant children). The results of the aforementioned study show that teachers generally encourage learners to use their first language though not within the classroom as respondents thought first language use might hinder target language acquisition. A small scale study conducted by Håukas (2016) in Norway analysed teachers' beliefs about multilingualism and explored the use of multilingual pedagogical approaches in the third language classrooms. The results of focus-group discussions with 12 teachers of French show that teachers consider multilingualism in general as a positive asset and students' previous language knowledge is thought to be helpful in establishing links between the languages involved. However, the author also concludes that teachers do not tend to reflect on previous language learning experiences and do not seek collaboration with teachers of other languages in order to enhace students’ multilingualism (Håukas, 2016:14). 


\subsection{Chapter summary}

The present chapter started with a discussion of the two main theoretical concepts - multicompetence and the Dynamic Model of Multilingualism (DMM) - that provide the framework of this research.

Regarding multicompetence, I have outlined the development of the notion from being strongly influenced by the Chomskyan paradigm of monocompetence as the norm to becoming a usage-based concept for a dynamic, flexible and complex linguistic system that also denotes the communicative ability of multilingual language users to handle effectively the languages they have within their linguistic repertoire.

The DMM, similarly to multicompetence, has been inspired by Grosjean's holistic view of bilingualism and refers to the development and interaction of individual linguistic subsystems that constitute the multilingual speakers' psycholinguistic system. Even if some differences can be traced between the two models (due to the different background and time) they still represent common goals and ideals concerning foreign language pedagogy. Both models propose a different view of the multilingual language learner and try to overcome the monolingual perspective still persisting in pedagogy and instructional aims. The two models also stress the importance of previously acquired languages and the exploitation of these languages during foreign language instruction.

As the present dissertation focuses on minority bilinguals acquiring a third language, I have considered it necessary to discuss some of the relevant issues found in the field of TLA. A more detailed account is provided with regard to cross-linguistic influence, as a factor influencing third language acquisition.

Finally, the last sections of the present chapter have dealt with codeswitching, the use of non-target languages during foreign language instruction and teachers' beliefs about language teaching and the use of non-target languages in the classroom. These phenomena have been discussed separately, and previous empirical research has been presented as the paper focuses on exploring classroom interaction and codeswitching within the EFL learning environment.

The theoretical models and empirical research presented in this chapter show a clear need for education to reassess the instructional goals suitable for today's multilingual society and to modify language curricula in order to incorporate activities systematically promoting multilingual language awareness. This empirical research is 
necessary in order to explore the ways how multilingualism is reflected in the current foreign language teaching pratices in this Eastern-European minority educational context and to explore those specific educational contexts which favour a holistic, dynamic and flexible use of the multilingual repertoire. 


\section{Background: Multilingualism within the Hungarian community in Transylvania}

As has been outlined in the Introduction and the previous chapter in detail, the aim of the present dissertation is to explore EFL classroom interaction within the Transylvanian school context in order to investigate the ways in which teachers' and students' multilingualism is incorporated in this specific minority foreign language education context and to evaluate classroom language use based on the theories presented in the previous chapter. One might ask why I have chosen to carry out such an investigation in Transylvania. The answer is manifold.

First, literature on third language acquisition is abundant with studies concerning Basque-Spanish or Catalan-Spanish minority bilinguals learning English as a third language, however, there are no studies whatsoever with regards to Eastern European minority bilinguals learning a third language. Thus, I felt the need to draw the attention to Hungarian/Romanian bilinguals from Transylvania.

Second, Transylvania, as an autochthonous minority region, ${ }^{4}$ is also a strongly multilingual setting, which offers a suitable context for research in multilingualism.

Third, Transylvania is my home region, the place where I was raised, educated and where I still live, and this way I have an insider position regarding not only access to data and institutions but also in terms of insight and understanding.

The present chapter provides an overview on the Transylvanian Hungarian community focusing on the relevant historical background, the educational system with special focus on language learning and an account of the language repertoire of Hungarian/Romanian bilingual students. This chapter also deals with the types of multilingualism that schools promote and the students' and educational stakeholders' perceptions on multilingualism and attitudes to the languages offered by schools.

\footnotetext{
${ }^{4}$ The term autochthonous refers to a minority group that is native to a particular region and their status as autochthonous minorities "is a result of incorporation into another sovereign unit through the change of borders after major conflicts” (Malloy, 2013: 16).
} 


\subsection{General overview}

This section of the dissertation provides general information regarding the Hungarian community in Romania focusing on demographic data, a brief historical overview, relevant language policy issues, and the educational system, with a special focus on language learning. The main reason behind giving a general presentation of the minority Hungarian situation is to provide a frame and a context within which the investigation was carried out and within which the results will and should be interpreted.

\subsubsection{Demographic characteristics}

According to Horváth and Scacco (2001: 243) "Romania presents a fascinating case for the study of multi-ethnic communities". Romania's total population involves more than $10 \%$ of ethnic minorities, and there can be identified around twenty different minority groups proving the multicultural and multilingual nature of the country. Hungarians represent the largest ethnic and linguistic minority groups in Romania (Horváth and Scacco, 2001: 243).

According to the 2011 census, the entire population of Romania is $20,121,600$ of which $1,227,600(6.5 \%)$ are Hungarians, and $11.1 \%$ of the population are members of ethnic minority groups (National Institute of Statistics, 2013:5). "In 1930, at the time of the first post-Trianon census, the proportion of nationalities other than Romanian was 22.15\%" (Benő and Szilágyi N. 2005: 134). The percentage of ethnic minority population decreased gradually between 1930 and 2011, from $22.15 \%$ in 1930 to $11.1 \%$ in 2011. In 2011, the Hungarian population constituted the majority of the population in two counties located in Transylvania, namely, Harghita/Hargita ${ }^{5}$ (85.2\%) and Covasna/Kovászna (73.7\%); however, there are four other counties where there is a high proportion of Hungarian population: Mureş/Maros (38.1\%), Satu Mare/Szatmár

\footnotetext{
${ }^{5}$ Throughout this dissertation I provide both the official Romanian and traditional Hungarian versions of place names.
} 
(34.7\%), Bihor/Bihar (25.3\%) and Sălaj/Szilágy (23.3\%) (National Institute of Statistics, 2013:5).

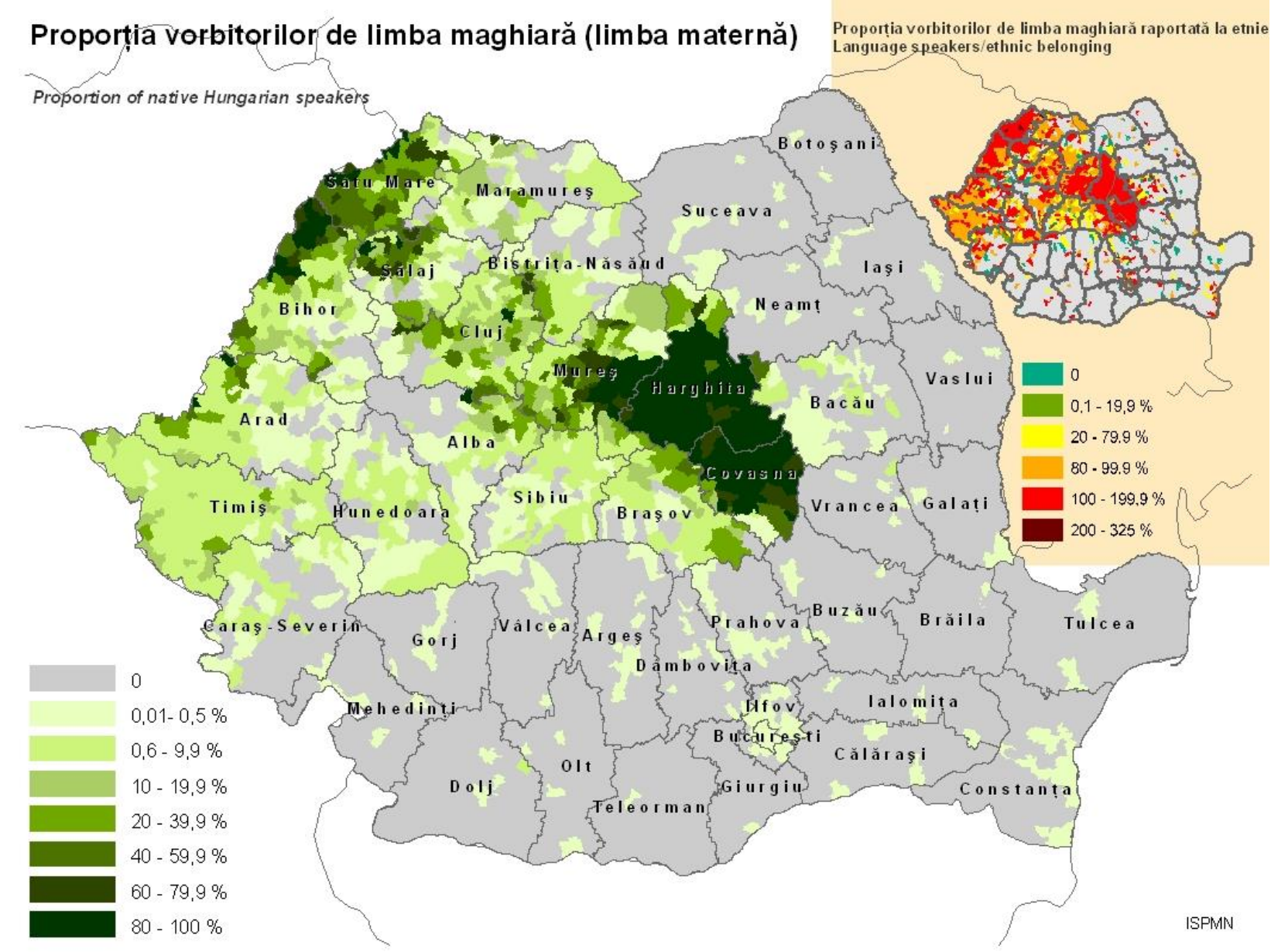

Figure 3. Proportion of native Hungarian speakers in Romania

(source: http://www.ispmn.gov.ro/maps/county/etnii-2011_maghiar)

Census data (National Institute of Statistics, 2013:5) show that there has been a decrease in number not only in the case of Hungarian minority population but the entire population of Romania since the last census, in 2002 (21,680,974 in 2002 and $20,121,641$ in 2011).

The persistent decrease in the number of Hungarians is due to three factors: a low birth rate, emigration, and assimilation (Benő and Szilágyi N. 2005: 136). In the 1990s the rate of emigration among Hungarians was relatively greater than in the whole population. Besides emigration, the large number of ethnically mixed marriages greatly affected the process of assimilation and consequently led to the decrease of the 
Hungarian minority population (Benő and Szilágyi N. 2005: 137). Also as a consequence of urbanization and industrialization the number of townspeople increased and led to a change in the ethnic composition of the towns and cities of Transylvania.

In terms of the linguistic environment it can be noted that a great number of Hungarians in Romania are numerically in a minority in their locality. As has been previously mentioned, there are only two counties (Harghita/Hargita and Covasna/ Kovászna) where the Hungarian minorities constitute the local majority. In minority environments the use of the Hungarian language is limited. It can also be assumed that in these localities the influence of Romanian is more intensive due to the local Romanian majority population, and the domains of usage of Hungarian are more restricted.

\subsubsection{The Romanian educational system}

Article 2 of the most recent Law on Education (Official Gazette of Romania, 2011: 1), adopted on 1 January, 2011, and effective as of 9 February, 2011, indicates that the main objective of the education in Romania is "the free, integral and harmonious development of the individual and the development of an autonomous personality for active citizen participation in society, social inclusion and employability" (UNESCO-IBE, 2012, para.1). According to Article 2, the state provides equal access to all levels of education without any discrimination, idea also supported by Article 32 of the Constitution of Romania (1991: 199), saying that public education is free and persons belonging to national minorities have the right to learn their mother tongue and are also guaranteed to be taught in these languages.

Until 1999 compulsory education comprised eight years. However, in 2003, Law no. 268/2003 (Official Gazette of Romania, 2003) introduced a ten-year compulsory education programme also supported by Article 16 of the Law on Education (Official Gazette of Romania, 2011: 3) consisting of four years of primary education (grades 14), another four years of secondary education (grades 5-8) and two years of high school or vocational school education (grades 9-10).

The structure and organization of the educational system can be seen in Table 2 below: 
Table 2. The structure of the Romanian educational system

\begin{tabular}{|c|c|c|c|c|c|c|c|c|}
\hline Age & $\begin{array}{l}\text { Type of } \\
\text { education }\end{array}$ & Grade & ISCED & \multicolumn{4}{|c|}{ Educational level } & $\begin{array}{l}\text { Qualification } \\
\text { level }\end{array}$ \\
\hline \multirow[t]{5}{*}{$>19$} & \multirow[t]{8}{*}{$\begin{array}{l}\text { Post- } \\
\text { compulsory }\end{array}$} & & \multirow[t]{2}{*}{6} & \multirow{2}{*}{\multicolumn{2}{|c|}{$\begin{array}{l}\text { Post-university } \\
\text { education } \\
\text { Doctorate }(\mathrm{PhD})\end{array}$}} & \multirow{4}{*}{\multicolumn{2}{|c|}{$\begin{array}{l}\text { University and } \\
\text { post-university } \\
\text { education }\end{array}$}} & \multirow{4}{*}{ the } \\
\hline & & & & & & & & \\
\hline & & & \multirow[t]{2}{*}{5} & \multirow{2}{*}{$\begin{array}{l}\text { University } \\
\text { education }\end{array}$} & MA & & & \\
\hline & & & & & BA & & & \\
\hline & & & 4 & $\begin{array}{l}\text { Post high } \\
\text { education }\end{array}$ & school & $\begin{array}{l}\text { Post- } \\
\text { educ }\end{array}$ & $\begin{array}{l}\text { secondary } \\
\text { ation }\end{array}$ & 3 \\
\hline 18 & & 13 & 3 & High school & High sc & hool & Upper & 3 \\
\hline 17 & & 12 & & upper-cycle & upper cy & & $\begin{array}{l}\text { secondary } \\
\text { education }\end{array}$ & \\
\hline 16 & & 11 & & & $\begin{array}{l}\text { Complet } \\
\text { year }\end{array}$ & & & 2 \\
\hline 15 & Compulsory & 10 & 2 & High school & School & & Lower & 1 \\
\hline 14 & & 9 & & & $\begin{array}{l}\text { Arts } \\
\text { Trades }\end{array}$ & & $\begin{array}{l}\text { secondary } \\
\text { education }\end{array}$ & \\
\hline 13 & & 8 & & & & & & \\
\hline 12 & & 7 & & Lower secc & ndary $\mathrm{sc}$ & hool & & \\
\hline 11 & & 6 & & (Gymnasium & & & & \\
\hline 10 & & 5 & & & & & & \\
\hline 9 & & 4 & 1 & Primary scho & & & Primary & \\
\hline 8 & & 3 & & & & & education & \\
\hline 7 & & 2 & & & & & & \\
\hline 6 & & 1 & & & & & & \\
\hline 5 & & & 0 & & educ & ation & Pre-school & \\
\hline 4 & & & & (kindergarten & & & education & \\
\hline 3 & & & & & & & & \\
\hline
\end{tabular}

Foreign language education and acquiring communicative competence in foreign languages is listed as the second key skill in the national education curriculum (art. 68, Law on Education, 2011) after the acquisition of Romanian language and mother tongue, in case of minority groups. Thus, it can be said that teaching and learning a foreign languages has a considerable role in the Romanian educational system. Based on the curriculum framework for compulsory education (The new national curriculum of Romania, 2000), the development of multilingualism is ensured by the introduction of one or two foreign languages as compulsory school subjects. Romanian students study two foreign languages, usually English and French, where English is introduced in grade 3, while French is introduced as the second foreign language in grade 5. 
According to the Eurostat data on teaching languages at schools in Europe (2012), more than $80 \%$ of the students in grades 5-8 learn two or more foreign languages (Key data on teaching languages at schools in Europe, 2012: 62). As far as high school education is concerned, the Eurostat publication states that Romania is one of the countries where nearly all students learn at least two languages. English is reported to be the most widely learnt foreign language; however; Romania is one of the few countries in Europe reporting significant increase in the number of students learning two foreign languages (Key data on teaching languages at schools in Europe, 2012: 66). After English, French and German are the most widely taught foreign languages in Romania. English is taught in 2-3 hours/week from grade 3 (age 8-9) and the second foreign language (mostly French or German) is taught in 2 hours/week from grade 5 (age 10-11). However, during primary education (grades 5-8), there is a differentiation between Romanian vs. minority students. Romanian students learn two compulsory foreign languages beside their mother tongue, while Hungarian students learn Romanian, a compulsory foreign language and the second foreign language is marked as optional and is taught according to the school board decisions (The new national curriculum of Romania, 2000).

The above mentioned EACEA document, Key data on teaching languages at schools in Europe (2012), contains a section on teaching guidelines referring to foreign language teaching and claims that more target language input increases students' proficiency. Therefore, it says that '[o]ne way to increase pupils' exposure to foreign languages is to make sure that the target language is used during language lessons both by teachers and pupils" (Key data on teaching languages at schools in Europe, 2012: 12). However, the 2017 edition of the aforementioned document does not include such guidelines.

Van der Perre (1994:10), a European science and educational policy expert, proposed that "the promotion of language learning [...] should be compulsory for entry into and for exit from higher education" throughout Eastern and Central Europe. The Romanian Ministry of Education accepted this proposal and students have to demonstrate competency in one international language in order to pass the Baccalaureate exam and be admitted to higher education. Foreign language evaluation within the Romanian Baccalaureate exam follows the Common European Framework of Reference for Languages (CEFR, 2001) and uses the six language levels from A1 to C2 (Pierson and Odsliv, 2012: 10). 
Focusing on Hungarian minority students and their language instruction at school it can be said that they learn their mother tongue and the state language from kindergarten, and foreign languages which are introduced from the third grade (if not in kindergarten already) (Dégi, 2012). At primary level (grades 1-4), Romanian, the state language, is taught from textbooks especially designed for minority students; however, in lower and upper secondary education it is taught from the same textbooks that are developed for native speakers, following the same norms and requirements. The first foreign language, English, is introduced in grade 3 (2-3 hours/week) and the second foreign language in grade 5 ( 2 hours/week). Yet learning a second foreign language is not compulsory for minority students because learning their mother tongue means an "extra" four hours for them in the national curriculum.

Nevertheless, discussions with school principals and teachers revealed that minority students - or their parents - choose learning a second foreign language as an optional course provided by the school curriculum (Dégi, 2009). It is worth noting, though, that the type of languages chosen as a second foreign language differs from nationality to nationality. In most cases, where the school offers German and French as second foreign languages, Hungarian children choose German while Romanian children choose French (Dégi, 2009). Apart from these four languages, students also learn Latin in grade 8, and if they choose Philology or Social Sciences as a specialization, they have one hour per week of Latin in high school as well. Consequently, by the time students reach their Baccalaureate exam at the age of 18 or 19 , they already have knowledge in at least three or four languages. Table 3 below comprises the number of hours allocated weekly for the learning of languages. 
Table 3. Numbers of hours allocated for each language during compulsory education, based on the Romanian national framework curriculum (The new national curriculum.

Romania, 2000)

\begin{tabular}{|c|c|c|c|c|c|c|c|c|c|c|}
\hline \multirow[t]{2}{*}{$\begin{array}{l}\text { Curricular } \\
\text { area/discipline }\end{array}$} & \multicolumn{10}{|c|}{$\begin{array}{l}\text { Number of weekly periods in each grade (compulsory } \\
\text { education) }\end{array}$} \\
\hline & 1 & 2 & 3 & 4 & 5 & 6 & 7 & 8 & 9 & 10 \\
\hline $\begin{array}{l}\text { Mother tongue } \\
\text { (HU) }\end{array}$ & $\begin{array}{l}7- \\
8\end{array}$ & $\begin{array}{l}7- \\
8\end{array}$ & $\begin{array}{l}5- \\
7\end{array}$ & $\begin{array}{l}5- \\
7\end{array}$ & 5 & 4 & 4 & 4 & 4 & 3 \\
\hline Romanian & 4 & 4 & 4 & 4 & 5 & 4 & 4 & 4 & 4 & 3 \\
\hline $\begin{array}{l}\text { First foreign } \\
\text { language } \\
\text { (=English) }\end{array}$ & - & - & $\begin{array}{l}2- \\
3\end{array}$ & $\begin{array}{l}2- \\
3\end{array}$ & $\begin{array}{l}2- \\
3\end{array}$ & $\begin{array}{l}2- \\
3\end{array}$ & $\begin{array}{l}2- \\
3\end{array}$ & $\begin{array}{l}2- \\
3\end{array}$ & $2-3$ & $2-3$ \\
\hline $\begin{array}{l}\text { Second foreign } \\
\text { language (only } \\
\text { optional for } \\
\text { Hungarians) } \\
\text { (=German/French) }\end{array}$ & - & - & - & - & 2 & 2 & 2 & 2 & 2 & 2 \\
\hline Latin & - & - & - & - & - & - & - & 1 & $\begin{array}{l}1 \\
\text { (only } \\
\text { Philology and } \\
\text { Social } \\
\text { Sciences } \\
\text { specializations) } \\
\end{array}$ & $\begin{array}{l}1 \\
\text { (only } \\
\text { Philology and } \\
\text { Social } \\
\text { Sciences } \\
\text { specializations) } \\
\end{array}$ \\
\hline
\end{tabular}

Within the present section on the Romanian educational system, I believe it is important to briefly discuss the type of primary and secondary schools. In Transylvania ${ }^{6}$ there are three types of schools: (a) Hungarian minority schools which resemble a typical monolingual school; the language of instruction for content subjects is exclusively Hungarian and children learn Romanian, English and most often German as compulsory language subjects; (b) Romanian schools are again monolingual schools with instruction exclusively in the state language; and (c) what I call 'mixed-type' schools, meaning one educational institution including two separate sections, one with Romanian language of instruction and one with Hungarian language of instruction. Mixed-type schools should be understood and treated differently from bilingual schools as these schools do not involve the teaching of school subjects in two languages; rather they function as two parallel monolingual institutions in a shared building. In most cases the two sections have their own teaching staff, though there are exceptions, when for budget issues some of the subjects such as sports, arts or languages are taught by the

\footnotetext{
${ }^{6}$ The three types of schools refer only to education in the Romanian-Hungarian relation, as there are also a few schools with other minority language education, such as German, Slovak, Serbian and Ukrainian.
} 
same teacher in both sections. Yet another exception in the case of mixed-type schools is represented by vocational schools, where certain specializations are offered only in Romanian, therefore we can encounter a number of Hungarian students in the Romanian section (but the language of instruction is the same as for homogeneous Romanian classes (Dégi, 2012: 653).

\subsection{Transylvanian students' linguistic repertoire}

In order to provide a more comprehensible picture of the investigated context, it is necessary to enumerate briefly the characteristics and most common aspects of the Transylvanian minority students' linguistic repertoire. It is impossible and also beyond the scope of the present section to take into consideration every instance of possible individual variation regarding students' language repertoire. Nevertheless, a general overview can offer valuable insight and can contribute to a better understanding of the setting under study.

As has been mentioned at the beginning of Chapter 2, Transylvania is an autochthonous minority region, and if we accept multilingualism to mean the ability of individuals or groups of individuals to use more than one language in their everyday lives, then Transylvania is a strongly multilingual region, which offers a suitable context for research in multilingualism.

The previous section discussed Romania's educational system with a special focus on the Hungarian minority community, emphasizing that by the age of 18 or 19 , Hungarian-Romanian bilingual learners already have knowledge in four languages. These languages are Hungarian (L1), Romanian (L2), English (L3), German/French (L4), and we can also mention Latin (L5) since all learners in Romania learn at least two years of Latin (in the $8^{\text {th }}$ and $12^{\text {th }}$ grades).

Looking more closely at the language repertoire of Transylvanian Hungarian students, we can notice that their mother tongue, Hungarian, is different genetically and typologically from all the other languages they might further learn in a school context. All the languages provided by the school curricula include inflectional Indo-European, Romance or Germanic languages that are different from minority students' agglutinative and Finno-Ugric mother tongue. Thus, researchers and language teachers 
might ask the following question: when learning foreign languages, which language(s) do the students use as their base language, and which language(s) can help these learners in the process of acquiring a third, fourth or additional language?

Section 2.2.1 mentioned several factors that influence third language acquisition (for a comprehensive overview see Table 1); however, T. Balla (2013: 1) notes that "from the point of view of third language learners, cross-linguistic influence seems to be one of the most decisive phenomena". Linguistic similarities and differences between the languages present in one's linguistic repertoire can occur at all levels from phonology to lexis and syntax, but perceived similarity also plays an important role in observing and relating new target language elements to those already known.

If we accept T. Balla's (2013) suggestion concerning the major role of crosslinguistic influence in the third language acquisition process, then I propose looking at the position and role of the Romanian language in the learning process of English as a foreign language.

Taking into consideration that the Hungarian mother tongue of the learners is not linguistically similar or genetically close to the target language (English), let us examine the students' second language, Romanian - a language of Indo-European origin with an extensive proportion of Latin based vocabulary - which is closer to English.

In what follows, the Romanian language is examined as a possible base language in in learning English. I believe the Romanian language could serve as a 'bridge-language' between Hungarian-Romanian bilingual students' mother tongue and the target foreign language, English. Thus, below I provide a closer look at the status of the Romanian language, taking into account the factors that have an effect on crosslinguistic influence (linguistic and perceived language distance, language proficiency, recency of use, exposure to the language and formality of context) and have been listed in section 2.2.2.

First of all, there are linguistic similarities between the two languages (e.g. Romanian, like English, is an SVO language; it has the schwa, ə, the passive, grammatical gender, and many cognates on the lexical level, etc.). Secondly, beyond the similarities and differences between these languages in a linguistic sense, it is important to highlight language learners' own perceptions as well. 
As has been mentioned before, Romanian is an Indo-European language of the Romance branch, while English is an Indo-European language of the Germanic branch of the language family. However, if we look at the lexical level, numerous cognates ${ }^{7}$ can be found in both English and Romanian due to the fact that both languages contain a large number of words of Latin origin. If we consider language typology, then Romanian is again closer to English than the students' mother tongue. A study by Iațcu (2005) emphasizes the role of Romanian in learning English for Hungarian-Romanian bilingual children. Comparing Hungarian and Romanian students' progress in the acquisition English, Iațcu (2005) noticed that Hungarian students in primary level education learn English at a slower pace than their Romanian peers, and Hungarian learners carry a stronger accent of their mother tongue while speaking the target language. The author attributes this difference, on the one hand, to the fact that Hungarian minority learners begin studying both Romanian and English at an early age shortly one after the other, and on the other hand, to the structural similarity of the two languages. Romanian is a Romance language, having cognates in other European languages, while Hungarian is a Finno-Ugric language, genetically and typologically similar to no other language spoken in its vicinity it in Central Europe. Iațcu (2005) further emphasizes that in spite of the preliminary differences noticed during lower level primary school, later, in high school, Hungarian and Romanian students show the same level of competence and proficiency. The author considers this progress to be a result of a more conscious and thorough study of English from the part of Hungarian learners which helps them to overcome their "initial handicap" in a short period of time (Iațcu 2005: 1095).

Other studies, by Molnár (2010a, 2010b, 2010c), also focus on HungarianRomanian bilingual learners' ability to recognize cognates and false cognates while learning English vocabulary. Her results show that Hungarian-Romanian bilinguals did better on the cognate tests than their monolingual Hungarian peers; however, the best results were achieved by monolingual Romanian learners. The results of the study reveal not only the benefits of bilingualism when learning a third language but also the facilitative effect of L2 and L3 linguistic similarities. Moreover, in a retrospective

\footnotetext{
${ }^{7}$ I use the term cognate as defined by Montelongo et al. (2009: 2), namely, "words that are orthographically, semantically and syntactically similar in two languages".
} 
interview carried out with Hungarian-Romanian bilingual students, learners confirmed using and relying on their L2, Romanian more frequently than on their L1, as they perceive it to be closer to the target language (Molnár, 2010b: 158).

As far as psychotypology (i.e. how learners perceive the similarity between two languages) is concerned, there are studies which focus on learners' beliefs and what language they rely on when learning English. A study reveals that HungarianRomanian bilingual learners name Romanian as the language they most frequently rely on and consider Hungarian, their mother tongue, useless in this respect (Molnár, 2010a). Another paper shows the results of student interviews, where learners say that Romanian means a help for them in learning English and translating between the two languages as "the words resemble each other" (Dégi, 2010: 307).

Some other factors of cross-linguistic influence besides linguistic typology and psychotypology are related to the learning process of other available languages, such factors as the formality of the learning context, exposure to the language, and language proficiency. Considering Romanian from these perspectives, we can assert that the formality of the learning context is given, as it is learned from the first grade (if not already in kindergarten), when children start school, and it is taught three to six hours a week throughout at least ten years (in a compulsory fashion for all). However, it needs to be mentioned that the methodology of teaching Romanian to Hungarian children is similar to the teaching of Romanian as a mother tongue. Instead of teaching children how to communicate in the language, what is taught in fact builds upon the assumption that learners come to school with some previous language knowledge (which is not always the case), and, thus, children learn about the grammatical system and literary works (Dégi, 2008: 181) instead of more practical and communicative aspects of the language.

The 'exposure to the language' factor proved to be a key element among other factors concerning cross-linguistic influence. As has already been mentioned above, institutionalized education presupposes an extracurricular exposure to the language, outside the school context - a need which is not always met. The degree of exposure to the state language of minority Hungarians varies from one locality to the other, depending on the size and proportion of the local minority population. Furthermore, this exposure to the language strongly affects the language proficiency of the learners. As institutionalized education is based on an assumed, already acquired language 
knowledge deriving from exposure and contact with the language, it is mostly successful if the aforementioned contact with the language is not only available but also put into practice.

Finally, the sociolinguistic status of Romanian language should be mentioned. As discussed in section 3.1.3 above, Romanian is the only official language of the state. However, the findings of a study by Fenyvesi (2012: 49), among $7^{\text {th }}-8^{\text {th }}$ vs. $11^{\text {th }}-12^{\text {th }}$ grade students in minority schools from three Hungarian regions outside Hungary, show that there is a "[...] very negative rating of the majority language. Romanian, in Transylvania: its speaker's status and solidarity traits have been ranked most negatively among all speakers".

All in all, what we can see so far about the situation of the Romanian language in the repertoire of Hungarian minority learners is that from the perspective of language typology, psychotypology and formality of learning context it would certainly count as the most possible source language regarding the learning process of English L3. Nevertheless, the Romanian language also faces some obstacles from the point of view of teaching methodology, language proficiency and, most importantly, its sociolinguistic status.

Figure 2 below summarizes the relationship and position of Romanian among the factors affecting cross-linguistic influence in third language learning based on the discussion above. 
Figure 2. Factors favouring and opposing Romanian as the source language in learning

\section{L3 English}

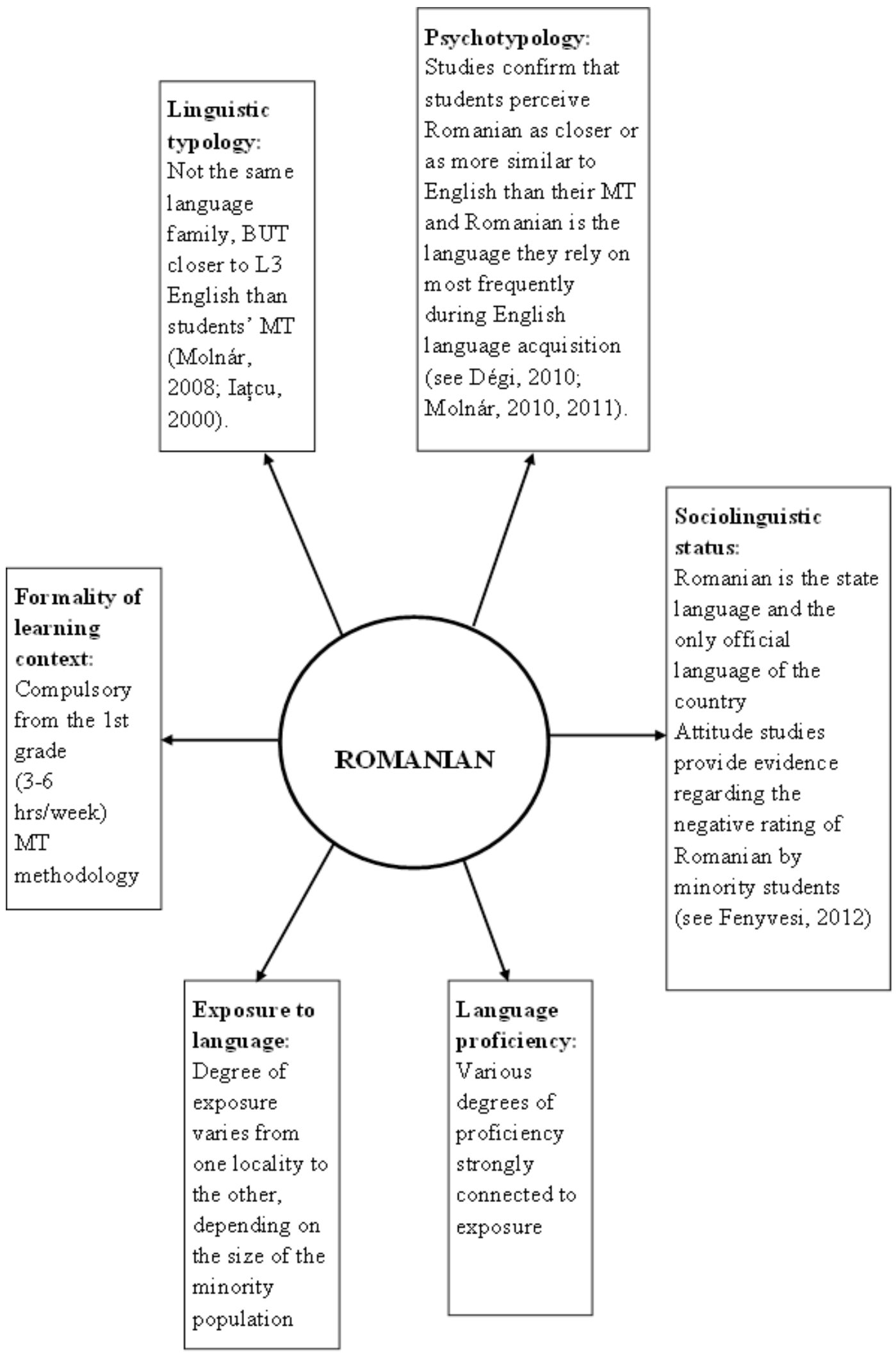




\subsection{Types of multilingualism promoted and language attitudes}

The present section of the dissertation aims to provide further background information on the research context in which the study was conducted. Previous sections of this chapter introduced demographic (3.1.1) and historical (3.1.2) characteristics of the region, linguistic rights (3.1.3) as represented in the country's language policy, the educational system (3.1.4) with a special focus on minority education and language learning, and a general overview of the linguistic repertoire (3.2).

In order to have a clearer understanding of the multilingual nature of the region, the present section refers to previous research conducted, by myself, within the LINEE (Languages In a Network of European Excellence) project in 2008 and 2009. I believe including this prior study into the dissertation adds valuable data regarding the way multilingualism is perceived and defined by school principals, teachers and students. Educational stakeholders' and learners' views concerning multilingualism may affect foreign language education, thus, it is necessary to provide a brief overview regarding this matter.

It should be noted that the results of this small scale study refer only to one county in Transylvania, thus findings cannot be generalized. However, the specific county where data was collected represents one of the counties participating in the larger study for the purpose of the dissertation.

The results come from a total of 26 semi-structured interviews conducted with teachers $(\mathrm{N}=20)$ and students $(\mathrm{N}=6)$ from six high schools from Mureș/Maros county, Transylvania. Interviewees were mainly of Hungarian origin $(\mathrm{N}=19)$; however, 7 Romanian native-speaker teachers also participated in the research. The interviews were conducted either in Hungarian or Romanian, according to the interviewee's preferences, and the length of each recording ranges from 30 to 60 minutes.

In what follows, my aim is to give an account of students' and teachers' beliefs about multilingualism and make connections with the trends found in the literature about this concept. As has already been mentioned, multilingualism is not a new phenomenon in Europe. Even though homogeneous monolingual nation-state views prevailed in the 19th century and during the communist era in Eastern Europe, today's complex, heterogeneous societies cannot function according to the monolingual 
linguistic norm. As formulated in a previous paper, "it is the multilingual competencies of citizens which serve as the most appropriate means of engaging with the new challenges facing Europe's linguistically and culturally complex societies" (Dégi, 2012: 654). People, especially young ones, appreciate more and more the value of being multilingual (Franceschini, 2009); however, interview results do not reach an agreement regarding the extent to which an individual is required to speak the languages in his/her linguistic repertoire in order to be considered multilingual. One frequently encountered opinion within the interviews with teachers and students is that a multilingual is "one who has more mother tongues or speaks more languages at mother tongue proficiency". At the same time, respondents also share the opinion that "Hungarians should first of all deepen their proficiency in their own language and culture and know the rest of the languages only at a user level”.

\subsubsection{Multilingualism perceived by foreign language learners}

Students' future career prospects, their attitudes towards language learning and languages in general represent key factors in motivation, language learning effort and success. Interviews carried out among students reflect that these students have positive attitudes toward multilingualism. Every student participating in the study believes that multilingualism is important and they often quote the well-known Bulgarian proverb, the more languages you know, the more persons you are. Based on the interview results with students, we can formulate a general definition for multilingualism, namely, that it means knowing or speaking more languages. Nevertheless, a closer look at the interview data allows us to detect a range of different ideas and beliefs concerning multilingualism.

Answers given to the interview question on the possible meaning of multilingualism vary from more general to more detailed and specific ones. Besides mentioning the Bulgarian proverb, students refer to either practical or some abstract benefits of multilingualism. From a practical point of view, multilingualism is considered as a resource in international communication and contact with people abroad. One student mentions a more general, a more abstract advancement brought 
about by multilingualism, namely, multilingual people are wiser and have greater culture.

Along the benefits generated by multilingualism, interview respondents also reflect on the language proficiency level of multilingual individuals. One of the student interviewees expresses her uncertainty regarding the expected language proficiency level of multilinguals and says the following:

(1) [A többnyelvüség] azt hiszem normálisan azt jelentené, hogy valakinek több anyanyelve van, vagy legalább anyanyelvi szinten beszéli ezeket a nyelveket.

"I think [multilingualism] would normally mean that somebody has more than one mother tongue, or at least speaks these languages at a mother tongue level."

Interview extract (1) above provides an example of the issue concerning levels of proficiency in other languages, i.e. languages besides the mother tongue. The student reflects the well-known monolingual perspective (see Bloomfield 1935), according to which the multilingual person is required to have a native-like control in all his/her languages. Thus, the student later hesitates to call herself multilingual, and answers my question on whether she considers herself a multilingual person saying: 'Talán igen, de nem vagyok megelégedve a román és angol tudásommal', "Maybe yes, but I am not satisfied with my Romanian and English knowledge". This perception of incomplete multilingualism appears with another student as well, in the sense that he considers himself 'részben többnyelvü', "partly multilingual" because he 'több nyelvet is tanulhatnék', "could learn more languages". According to the above interview data incompleteness is either due to lack of knowledge and competence in one language or the lack of a desired number of languages in an ideal language repertoire. Such a perspective of incomplete or partial multilingualism assumes that multilingualism is an idealized end-state and those who have not reached it cannot be considered "true or full multilinguals" (Dégi, 2012:656).

Interview data reflect students' positive attitudes towards multilingualism, though their understanding of the term is heavily influenced by the monolingual perspective of the ideal and balanced language user. 


\subsubsection{The educational stakeholders' views on multilingualism}

Educational stakeholders' (teachers' and principals') perception of multilingualism represents another important question in language pedagogy. Therefore, the small scale study on multilingualism introduced above included interviews with teachers (some of who are also school principals) to find out the number and types of foreign languages taught in schools and to examine teachers' beliefs regarding the importance of these languages. A general outcome of the interviews is the widely popular practice of schools to offer only three or four foreign languages. Interviews confirm the general experience that schools are dominated by certain foreign languages while other languages are excluded from the linguistic marketplace of the schools.

Interview data confirm Eurostat statistical data on Romania presented in section 3.1.4 above concerning the type of foreign languages offered by schools. Thus, English, German and French are languages with the highest numbers of learners. Although the National Curriculum (2000) does not specify the type of languages to be taught as a first or second foreign language, interview data together with the Eurostat statistical data show that English is the first foreign language followed by French and German. One of the school principals points out the following:

(2) A francia és még a német is háttérbe szorul az angol miatt, legalább is ebben a régióban. A szülök kérésére minden gyerek angollal kezd, és ötödik osztályban jön a német többnyire. Egyre kevesebben választják már a franciát.

"French and even German are pushed aside because of English, at least in this region. On the demand of the parents every child starts with English and then in 5th grade German comes mostly. Fewer and fewer choose French".

Another school principal also points out the important role played by parents in the foreign language palette offered by educational institutions.

(3) Se remarcă engleza totuși, ca limbă de cea mai mare circulație europeană și nu numai. În consecință foarte mulți părinți doresc ca copii lor să învețe limba engleză și o învață, și noi trebuie să răspundem la această dorință. 
"English is remarkable as the most widely spoken language in Europe and not only. As a result, many parents want their children to learn English and they do learn English, and we have to respond to this need".

As interview extracts (2) and (3) above show, English is the first foreign language in schools and is offered and encouraged by schools to satisfy the parents' needs.

In addition to schools' language offers, interview questions focused also on teachers' attitudes towards these languages and the perceived importance of the languages taught. When asked about the importance of each language, teachers' answers were grouped around the idea of instrumentality of the languages (see Dörnyei and Ushioda, 2009) and each language was placed at some point on the instrumentality scale. Among the 20 teachers interviewed in 6 different schools there was only one respondent whose answer showed a negative attitude towards English based on the idea that English is not a beautiful language.

Teacher interview data reflect the general usefulness of English, and teachers often connect the English language to an international context using phrases such as it is wide spread in the world, is spoken everywhere and interviews also express the requirement for learning English if someone wants to succeed beyond our borders.

In contrast with the international level, in a national context, the state language (Romanian) is considered to be the most important language. Hungarian mother tongue teachers emphasize that minority students have to learn and know Romanian if they plan to stay and find a job in the country (Dégi, 2012). Vocational school teachers expressed their struggle and effort to spend more time and give extra lessons for their students in order to teach them the necessary technical terminologies in both Hungarian and Romanian.

Interview extract (4) below reflects the attitudes of such a vocational school teacher, who expresses the idea that foreign languages are linked to international study or career opportunities whereas in a national context, Romanian becomes the most important language.

(4) [A románt] el kellene sajátítani alapszinten a megélhetéshez és a munkához. Másrészt viszont sok vélemény van olyan, hogy nem annyira fontos, hiszen ott van 
Európa, tehát inkább egy angol, egy francia, de hát ez azokra vonatkozik szerintem, akik tovább akarnak tanulni, elsösorban, hogy ott tudjanak érvényesülni az egyetemeken, és kevésbé azokra, akik elmennek mondjuk téglát rakni.

"[Romanian] should be acquired at a basic level for making a living and for work. On the other hand, there are many opinions that [learning Romanian] is not so important as there is Europe, so English or French is more important, but I think this concerns those who want to continue their studies, in the first place, to be successful there at the universities, and is less important for those who go to lay bricks in construction".

Teacher interview results have shown that English is not only the most required language by parents but it is also the most important language in teachers' opinions. While English is described as the language that can lead to international success, learning French, for example, is mentioned by one respondent as good for the sake of learning languages without any practical benefits attached to it (see interview extract (5) below).

(5) Mondtam a gyerekeknek is, hogy mindenképpen az angol van elsö helyen. A franciára pedig úgy gondoljunk, hogy egy jó dolog egy másik nyelvet megtanulni.

"I told the children that English is in the first place anyway. We should think about French as a good thing that we can learn another language".

Clearly, the steady growth of English as a lingua franca plays an important role in the development of multilingualism; nevertheless, some teachers regard this rapid spread of English as unfair and incorrect, as articulated in interview excerpts (6) and (7) below.

(6) [...] sajnálom, hogy a francia annyira háttérbe szorult. Vannak kollegáim, akik évekig franciát tanítottak aztán át kellett térjenek angolra, mert egyszerüen nem volt elég óraszámuk.

"[...] I am sorry for French being so pushed aside. I have colleagues who had taught French for years, and then they had to turn to English simply because they didn't have enough classes to teach". 
(7) Az angol az a nyelv, amely sikerhez vezet, de lehet igazságtalanul a többi nyelvvel szemben, föleg a franciával, és nem gondolom, hogy ez helyes.

"English is the language that leads to success, but perhaps it is unfair to other languages, especially French, and I do not think this is right".

Teachers' feelings regarding the "unfair" spread of English are also shared by other people and researchers, who assume that the spread of English might be a threat to multilingualism (House, 2003: 556). Yet, House $(2002,2003)$ argues for the contrary by accepting Hüllen's (1992) distinction between language for communication and language for identification. According to House (2003), English as a lingua franca serves as a "communicative instrument" (2003:559) and is just one element of the linguistic repertoire that multilinguals have at their disposal. Similarly, other researchers (Cenoz and Jessner, 2000; Hoffmann, 2000; Soler, 2007) have also argued that the spread of English in Europe does not entail the death of multilingualism. Their arguments are based on the hybridity framework ${ }^{8}$ which suggests that multilingual speakers adapt their language according to their needs, thus a language can be used to express identity or just as a communicative instrument. In spite of the doubtful opinions of teachers connected to the unfair spread of English, the increased demand for and acquisition of English means the development of what is called "multilingualism with English" (Hoffman, 2000: 3) rather than the elimination of multilingualism.

\subsubsection{Types of multilingualism identified}

The last two sections, based on the results of a small scale study, have been meant to contribute to a better understanding of the research context by providing insights into students' and teachers' attitudes and beliefs towards multilingualism and the languages taught in schools. The present section aims to conclude these two sections by identifying and constructing patterns or types of multilingualism as present in the interview data.

\footnotetext{
8 "the hybridity hypothesis, is based on the thesis that there is no pure or authentic culture distinct from others and claims the need for a synthesis of diverse cultural forms" (Soler, 2007: 26).
} 
Multilingualism in a broad sense, i.e. speaking/knowing more languages, has gained a definitely positive evaluation on both the students' and teachers' part. Although multilingualism as such is considered to be highly functional, several patterns of social and individual multilingualism can be traced along the interviews.

As has been mentioned before, the National Curriculum (2000) does not include any language policy regarding the types of foreign languages to be taught in schools. The only specifically named language that is compulsory for all students is Romanian Language and Literature, the other languages being generally mentioned under the names of Mother Tongue and Literature, Foreign Language 1 and Foreign Language 2.

Therefore, the language offer of the school is decided on by the school board and parents' preferences. In such contexts teachers' attitudes towards languages are key factors in promoting different languages in schools.

The main perspective on the basis of which types of multilingualism are categorized is motivation. Teacher interview results can be grouped into two categories based on motivation for language learning: (a) learning languages for pleasure, intrinsic motivation, and (b) learning languages in order to advance in career or further studies, extrinsic motivation.

In second language motivation research, Gardner and Lambert (1972) introduced the terms instrumental and integrative (see also Dörnyei and Ushioda, 2009) in order to differentiate between learners' motives behind language learning. According to these authors (Gardner and Lambert, 1972; Dörnyei and Ushioda, 2009) integrative motivation refers to the positive attitudes and feelings towards the target language group, while instrumental motivation stands for the potential practical benefits of language proficiency. Analysing the interviews with students and teachers, clear distinctions can be traced regarding the type of languages that fall into the instrumental vs. the integrative categories of motivation.

As discussed in connection with interview excerpt (5) above, English falls into the category of instrumental motivation. Interviews with teachers reflect the way English is considered to be useful and important with regards to international communication, mobility, future career and learning prospects.

These beliefs about English as having the highest instrumentality are in line with the attitudes of the rest of the European population mentioned in the report on multilingualism of the European Commission in 2007: 
"90 percent of all pupils in secondary education in the EU are now learning English [...] it confirms earlier findings, according to which 71.1 percent of those questioned believed that EU citizens should be able to speak a language in addition to their mother tongue, and roughly the same percentage -69.4 percent - thought that this language should be English." (European Commission, 2007: 7)

"The appeal English holds for young people is a well-researched topic. However, what is perhaps even more important is that for a variety of reasons many policymakers and decision-makers - including parents - firmly believe that all that children at the beginning of the 21 st century need to acquire is a good command of English.” (European Commission, 2007: 8-9)

In contrast, interviews with teachers also illustrate the integrative motivation behind learning French. Thus, based on the two categories of motivation we can identify two types of multilingualism: (a) career-multilingualism and (b) multilingualism for pleasure.

Furthermore, it is important to note that instrumental motivation characterizes not only English but the Romanian language as well. While teachers stress the importance and usefulness of English on an international level, on a national level, Romanian is thought to be the most useful language in achieving success in one's career. As a result, the previously mentioned career-multilingualism can be understood at an international and the national level.

While the present section of the dissertation has shed light on important and interesting aspects related to multilingualism and the attitudes towards languages taught in school contexts, there are certain limitations that need to be taken into account.

It has focused on a phenomenon that is a very extensive and major one, i.e. multilingualism; yet, this complex phenomenon could be studied only from a rather narrow empirical perspective here. The selection of a particular setting and the limited number of interviews naturally bring forth many limitations as far as the generalization of the results is concerned. 


\subsection{Chapter Summary}

The aim of the present chapter has been to argue in favour of the appropriateness of the setting and to provide a context within which the present research should be interpreted. The chapter presented an overview of the Transylvanian Hungarian community with a special focus on the linguistic and educational situation.

The role of the first section in this chapter has been to present the demographic data and some relevant language rights and historical issues that help contextualize the present day situation. Demographic data shows that Hungarians constitute the largest ethnic minority group in Romania and are concentrated in several counties like Harghita/Hargita, Covasna/Kovászna, Mureș/Maros, Satu Mare/Szatmár, Bihor/Bihar and Sălaj/Szilágy. For the research for the thesis was conducted in two counties, namely Mureș/Maros and Harghita/Hargita. While in Harghita/Hargita county Hungarians represent the majority of the population, in Mureș/Maros county there is a high number of Hungarians in the population but their proportion is only $38.1 \%$ of the total population. Historical data outline the major events and issues that led to the present minority status of Hungarian people. As far as language language rights are concerned, although the Constitution grants minorities the right to preserve, develop and express their linguistic identities, it also states that Romania is a unitary state with a single official language, i.e. Romanian.

This chapter includes a section concerning the Romanian educational system with a specific focus on language teaching in order to provide an insight into the educational and school context in which the research was carried out. In this section I discuss how the teaching of the mother tongue is slowly adjusted in number to Romanian language teaching and that Hungarian children are relieved from learning a second foreign language - it is not compulsory - because of the mother tongue "burden". However, Hungarian students still choose the second foreign language (usually German) as an optional course provided by the school curricula. Thus, by the age of 18-19 they have been learning five languages already.

Section 3.2 of the present chapter provides a closer look at the linguistic repertoire of minority Hungarian learners and examines the role of the second language, Romanian, in learning English. Analysing the relationship between the factors of crosslinguistic influence introduced in section 2.2.2, it could be concluded that from the 
perspective of language typology, psychotypology and formality of context, Romanian would certainly count as the most possible and valuable source language regarding the learning process of English L3. Nevertheless, factors like Romanian teaching methodology, language proficiency and sociolinguistic status create an obstacle that hinders the use of Romanian as a language that could foster the English language acquisition process.

The last section (3.3) presents a previously conducted small scale study regarding students' and educational stakeholders' perspective on multilingualism and how these opinions and views affect foreign language education. On the basis of interview data it could be concluded that both students and teachers favour multilingualism, however, their understanding of the term proves a strong monolingualist view, according to which perfect language knowledge is necessary for individuals to be considered as multilinguals. It could also be seen that the first foreign language (a general term used in the national school curricula) is equated with English and other foreign languages tend to lose their ground because of the English dominance. English is the language that is thought to lead to international educational and career success. Other foreign languages, e.g. French, are only learnt for pleasure. It is also worth noting that career-multilingualism includes not only international multilingualism involving English but also national or local multilingualism involving Romanian for those who plan to stay and work in the country. 


\section{Methodology: An empirical study of EFL classroom interaction from a multilingual perspective}

As is discussed in Chapter 1 above, multicompetence and Third Language Acquisition are relatively new concepts which have been introduced to turn the existent monolingual view in language acquisition research into a holistic multilingual one and to offer alternative perspectives in the analysis of multilingual individuals and their complex linguistic system.

The idea for the present investigation is rooted in the examination of these two concepts and the language teaching suggestions offered by the researchers dealing with both multicompetence and TLA (e.g. Cook, 2003, 2006, 2008; Herdina and Jessner, 2002; Jessner, 2006; Hufeisen, 2005). Being familiar with the multilingual linguistic situation of the Transylvanian minority context under study, and realizing the lack of foreign language education research done in this geographical region, I felt the need to examine how current foreign language teaching practices in this sociolinguistic setting allow for the adoption of a multilingual language education methodology. Thus, the present dissertation aims to investigate and describe, through classroom-based empirical research, the ways in which teachers' and students' multilingualism is incorporated in foreign language (FL) instruction and to evaluate classroom language use based on the theories and literature on multilingual approach to language teaching. Teachers' beliefs about teaching and learning have also been considered since they have a central role in the actual classroom teaching practices (Farrell and Filion-Tomenson, 2014; Haukas, 2016; Dégi, 2016). Moreover, students' attitudes and beliefs regarding multilingualism and multiple language use during foreign language classroom instruction complemented the data, providing more insight into the possible need for and acceptance of a multilingual perspective in language education.

As has been already discussed in section 2.1 , the term multicompetence was introduced with the aim to stress the importance of those techniques and strategies that represent the basis of multilingual speakers' linguistic behaviour. It is difficult to list and name all the strategies used during the acquisition of a second language and these strategies become even more complex as language learning includes more and more languages (Biró, 2011: 78). Many researchers (e.g. Lasagabaster, 1998; Munoz, 2000; 
Cook, 2003; Cummins, 2001; Jessner, 2008 etc.) agree that a bilingual learner acquires a third language in a different way than how monolingual learners and bilinguals develop new strategies, by comparing and contrasting the languages in their linguistic repertoire, and they are characterized as more flexible in changing learning strategies. Apart from a more developed metalinguistic and cognitive capability, lexical knowledge and a less conservative learning method, bilinguals also benefit from their previous language learning experiences (Kemp, 2009).

As we could see in Chapter 2, previously acquired language competencies play a significant role in additional language learning, as the learner acquires and develops further techniques and expands his/her knowledge regarding his/her own learning types (Boócz-Barna, 2010). In line with other researchers, I believe that language learners cannot fully exploit the benefits of their previous language knowledge, thus, the aim of third language teaching would be to develop language awareness so that learners could transfer previously acquired knowledge and strategies into the third language learning process.

As mentioned in section 2.4 above, codeswitching and second language transfer is a sign of learners' multicompetence and the aim of foreign language teaching should be to transform previous knowledge and competencies into manageable resources through reflection and awareness raising.

In line with the above mentioned discourses present in the TLA literature and multilingual education studies, the dissertation focuses on the English language instruction of Hungarian-Romanian bilingual students in Transylvania and the way current practices in English L3 teaching profit (or not) from bilingual students' existing language competencies and language learning experiences. Investigating classroom language use the research focused on teachers' and students' language use, especially on codeswitching instances and the extent to which non-target language use is oriented towards the development of language awareness and conscious reflection upon linguistic similarities.

In this chapter of the dissertation I present and discuss the design of the empirical investigation in detail. The following sections provide a description of the research questions and methodology, before turning to the results and discussion of the findings in chapter 5 . 


\subsection{Research questions}

The wider scope of the present study is to examine current English foreign language teaching practices in Transylvanian high schools and explore the possible tendencies of adopting a multilingual approach in language teaching. Observations of classroom teaching practices complemented by teacher questionnaires and student interviews are discussed in relation to educational discourses and suggestions present in TLA and multilingual pedagogy research.

On the one hand, studies concerning multicompetence and the acquisition of a third language (e.g. Lasagabaster, 1998; Munoz, 2000; Cook, 2003; Cummins, 2001; Jessner, 2008; Boócz-Barna, 2010; Cenoz and Gorter, 2014 etc.) advocate the positive influence of multilingualism and previous language learning on further language acquisition processes and suggest that third language teaching should build upon students' prior linguistic knowledge and language learning experiences and to use these as resources to enhance students' language awareness and reduce their language acquisition time and effort. On the other hand, several foreign language acquisition studies investigating the use of L1 in foreign language classes (Nzwanga, 2000; Macaro, 2001, 2009; Levine, 2009, 2011; Ife, 2008; Hall and Cook, 2013) mention that the use of the L1 is stigmatized and prohibited and teachers use students' L1 as little as possible since they associate little pedagogical value with it. The contradiction between multilingual educational and psycholinguistic research and the findings of foreign language teaching studies shows a lack of communication between researchers and language teachers or perhaps a faster change in research trends that are hard to follow in actual teaching practices. The present research, thus, examines foreign language teaching in order to see how far actual practices are from the pedagogical suggestions of researchers and whether some good practices can already be identified.

In order to cope with these objectives and to make them operative in data collection and analysis, I propose to seek answers to three groups of research questions:

1. In order to describe how multilingualism is manifested in EFL classrooms we need to answer the following questions regarding the linguistic behaviour of the participants: 
1.a Which languages are used during an EFL class?

1.b When and for what pedagogical functions are these languages used?

1.c By whom and with whom are these languages used?

2. Previous research on teacher language use shows that teachers try to avoid the use of the L1 during EFL classes (Nzwanga, 2000; Macaro, 2001, 2009; Levine, 2009, 2011; Ife, 2008), and they are more concerned with native-like pronunciation which they think students are unable to replicate (Némethné Hock, 2007: 81-82). However, many classroom observation studies (Nikolov, 1999, 2000; Lugossy, 2003; Nagy and Robertson, 2009; Hlas, 2016) show that teachers' educational practices involve a wide use of students' first language. Moreover, studies concerning native and non-native teacher differences emphasize the advantages of non-native speaker language teachers based on the fact that they can profit from students' native language (Barratt and Kontra, 2000; Medgyes, 1994, 2014). Thus, the next question will focus on teachers' beliefs about language use in the EFL classroom and their linguistic behaviour:

2.a What kind of linguistic behaviour (monolingual vs. multilingual) is used and encouraged by teachers during an EFL class?

2.b Are there any explicit or implicit rules concerning language use during the EFL class? (i.e. How does the teacher control targeted language mode? Does the teacher allow the use of other languages in an EFL classroom?)

3. Several sections of chapter 2 argued for the importance of previous linguistic knowledge and language learning experience in the foreign language learning process, and section 2.2.1 presented several factors influencing the acquisition of a third language, of which the effects of cross-linguistic interaction have been considered one of the major factors. Moreover, several researchers (see Ringbom, 2007; Paradowski, 2008) state that learners look for similarities and try to establish connections between previous and new knowledge as part of their natural learning process. Thus, the following research questions focus on 
learners' beliefs regarding the use of other languages during foreign language learning and the type of languages students consider as helpful in learning English:

3.a What are the students' opinions about multiple vs. monolingual language use in the EFL classroom?

3.b Why do students consider the use of other languages during EFL classroom an asset in learning English?

3.c What are the languages that are viewed to help students in learning English?

\subsection{Research design}

In the present dissertation I adopt a case study approach, with two overall goals in mind. First, to provide a comprehensive picture of the way multilingual students and teachers interact during foreign language classes and the way they think about using non-target languages during the course of foreign language teaching and learning. Second, to contribute to the field of third language acquisition and complement previous research findings with data on Transylvanian Hungarian-Romanian bilingual learners.

Flyvbjerg (2011: 301) claims that it is safer and better to adopt a common-sense definition of a case study research and, thus, he uses the definition of the MerriamWebster's dictionary, according to which a case study is "an intensive analysis of an individual unit (as a person or community) stressing developmental factors in relation to environment". The intensive analysis conveys a detailed and rich in-depth analysis of a unit and provides a more complete view. This idea is also shared by Cohen et al. (2007: 253) who assert that case studies examine and provide information about "complex, dynamic and unfolding interactions of events, human relationships and other factors in a unique instance". Both definitions stress the importance of studying people and events in interaction within a specific context.

The investigation presented in this paper is, however, a special type of case study, namely, an educational case study. This means that a set of specific events or programmes or a particular institution or classroom is the focus of the study. Kormos 
(2004: 25) emphasizes that the aim of such studies is not to arrive at some general conclusion but to understand and describe a situation in its context and from the subjects' perspective. Educational case studies obviously focus on educational events embedded in their natural context and require the collection of sufficient data that allows for tracing significant features of the particular case and for creating credible and valid interpretations of what is found. Researchers conducting case studies need to adopt a critical approach in the research and findings or arguments must be connected to other relevant studies in the literature in order to construct a good argument (Bassey, 1999: 61).

The present study will be a case study in four senses. First, because it involves the collection and recording of data about a specific case - English foreign language classes in five high schools from Transylvania. Second, because it is based on a real-life context (Yin, 1994:13), observing the characteristics of an individual unit. Third, because it adopts classroom observations, questionnaires and interviews as the main data collection techniques and, thus, it relies on different sources of evidence which are combined to arrive at a triangulation method enhancing the validity of the findings. And fourth, because it is built on theoretical concepts to guide the data collection and analysis and is also connected to other relevant research in the literature as pointed out by Bassey (1999).

In the following sections I will provide a detailed description of the setting (4.2.1), of the research participants (4.2.2) and of the procedure (4.2.3), including a section for the description of the research instruments (4.2.3.1-4.2.3.4). The last part of the Research design (4.2) section gives a detailed account regarding the research procedure and the steps of fieldwork, from contacting participants to the description of the data collection processes.

\subsubsection{Setting}

The schools where data collection was carried out were selected on the basis of several considerations with regard to the size of the minority population and the school types identified at the end of section 3.1.4 above.

For the purposes of this study, data was collected in two counties and three localities within these two counties. One county is Mureș/Maros, where $38.1 \%$ of the 
population is of Hungarian ethnicity (National Institute of Statistics, 2012: 2). However, the county is divided into two parts. As the county is situated between Harghita/Hargita and Cluj/Kolozs counties, the percentages of minority Hungarian population vary according to which part of the county we look at. In the eastern provinces of the county, which are situated closer to Harghita/Hargita county in the Sovata Valley, Hungarians form more than $85 \%$ of the population (Iatcu 2005:1093). In the provinces closer to Cluj/Kolozs the percentage of Hungarian population is lower.

The selected two localities were Târgu Mureș/Marosvásárhely and Luduş/Marosludas. The first is a big town (municipality) with a population of 134,290 , of which $42.8 \%$ are of Hungarian ethnicity (National Institute of Statistics, 2012: 14). The other town is much smaller, with a population of 15,328 , of which $23.2 \%$ belong to the Hungarian minority (National Institute of Statistics, 2012: 14).

Târgu Mureș/Marosvásárhely has several high schools including grammar schools and vocational schools specializing in different areas of study (economics, engineering, chemical engineering, agriculture etc.). I chose two schools from this locality, one grammar school (or theoretical high school) and one vocational school specializing in transportation technology, telecommunications and electrical engineering. The two schools were chosen on the basis of convenience sampling, i.e. their willingness to cooperate. I contacted more schools within the city and those who agreed to cooperate or where I had acquaintances who helped me to be allowed to collect data were selected.

In the smaller town, Luduș/Marosludas, I contacted one high school, the only one in the town. It is called Industrial School Group, a name given to several schools after the reorganization of the educational specializations after 1992. Thus, this school group includes both theoretical high schools and vocational schools.

Harghita/Hargita county is one of the two counties where the Hungarian minority population constitutes the local majority, and it is the county with the highest concentration of Hungarians in the country. Harghita/Hargita county has a Hungarian population of $86.4 \%$ (National Institute of Statistics, 2013: 2). Here, I chose the town Miercurea Ciuc/Csíkszereda (a municipality), which is a middle-sized or rather small town with a population of 38,966 , of which $78.5 \%$ are of Hungarian ethnicity (National Institute of Statistics, 2012: 8). Miercurea Ciuc/Csíkszereda has one Romanian grammar school and one Hungarian grammar school, the rest being vocational schools 
specializing in different subject areas like economics, woodworking, construction etc. I chose two schools from this town. One is a Hungarian grammar school, the most prominent high school in the county, while the other is considered the second best high school in the town. This latter school also bears the name Economic School Group and comprises both theoretical and vocational specializations.

In both counties I chose a grammar school (a school with Hungarian as the language of instruction in both cases) and one vocational school or school group which belongs to the mixed type school. As explained in section 3.1.4 above, there are three types of schools in Romania, i.e. Hungarian schools (where Romanian is just a school subject), Romanian schools, and mixed type schools (with both Hungarian and Romanian sections, at least in some specializations).

The aim of choosing a Hungarian and a mixed type school in each locality was to compare foreign language education in the two types of schools and to see if greater exposure to the state language, Romanian, has any effect on EFL classroom interaction.

\subsubsection{Subjects}

The main purpose of the study, as mentioned above, is to examine English foreign language teaching practices and the use of non-target languages during these classes in order to trace the presence of multilingualism and the possible tendencies towards a multilingual approach in EFL education. The study explores the linguistic behaviour of both teachers and students within the EFL classroom context. The research includes the investigation of ten EFL classes from five different schools in Transylvania: one industrial school group ${ }^{9}$ in Luduș/Marosludas; one grammar school and one vocational school in Târgu Mureș/Marosvásárhely; and one grammar school and one economic school group in Miercurea Ciuc/Csíkszereda.

The industrial school group in Luduş/Marosludas is a recently renovated building located in the city centre among some blocks of flats. The institution was founded in 1966 and today it has more than one thousand students and 70 teachers. The

\footnotetext{
${ }^{9}$ The School Group (in Romanian: Grup Școlar Industrial; in Hungarian: Iskolaközpont) is a name given to several schools after the reorganization of the educational specializations after 1992. Thus, this school group includes both theoretical high schools and vocational schools.
} 
school offers education in humanities, sciences and technology in 7 profiles including mathematics, natural sciences, philology, electrical installation, mechatronics, repair and maintenance services and textile industry. The language of instruction is predominantly Romanian, except in the natural sciences profile where there is a separate class with Hungarian language instruction.

The grammar school in Târgu Mureș/Marosvásárhely has been partly renovated and it is located in the city centre. It is a prestigious school founded in 1557 . The present building was constructed in Hungarian Art Nouveau style in 1909. The grammar school was founded by the Reformed Church and in 1960 it became a mixed type school offering profiles with Hungarian and Romanian languages of instruction. Since the 2005-2006 academic year it has been functioning again as a Hungarian school. The school has more than 1,100 students and 89 teachers. The school offers a varied range of profiles where sciences (social sciences, natural sciences, mathematics and informatics) are in most of the cases paired with languages (e.g. social sciences and intensive English/German, natural sciences and intensive English/German/Italian, mathematics and intensive English).

The vocational school in Târgu Mureș/Marosvásárhely is located in an old building in the outskirts of the town. It was founded in 1966 as a technical school providing vocational training in car manufacturing. At present the school has a total of 708 students and 58 teachers. The school offers education in the technical and services domain including profiles such as: telecommunications engineer, transport engineer, auto electrician, aesthetics and hygiene and hair stylist. Education is offered in both Romanian and Hungarian.

The grammar school in Miercurea Ciuc/Csíkszereda is again a prestigious high school founded by the Franciscans in Șumuleu Ciuc/Csíksomlyó in the middle of the $17^{\text {th }}$ century. However, the present building located in Miercurea Ciuc/Csíkszereda was completed in 1911. It is located close to city centre on the way to Șumuleu Ciuc/Csíksomlyó. The renovation of the building started in 2010 and was completed recently. It is a Hungarian school with about 750 students and 47 teachers. It offers education in a number of profiles such as mathematics and informatics, natural sciences, social sciences and philology.

The economic school group in Miercurea Ciuc/Csíkszereda was founded in 1970 as a vocational school in economics and it was located in 
Gheorgheni/Gyergyószentmiklós. The school was moved to Miercurea Ciuc/Csíkszereda in 1985 and it functioned within the Industrial school no. 2 until 1993, when it became a separate institution. The building was renovated in 2006. It is one of the most populated schools in the county with about 1,200 students and 85 teachers. As an economic school group, the school offers four types of education: theoretical (similarly to grammar schools), vocational, vocational night school, and postgraduate. The school offers training and qualification in economic activities technician, tourism technician, business activities technician, contracts and acquisition technician, event organizer, accountant and cook.

Student participants of this study are Hungarian-Romanian bilingual minority students in grade 12, their last year of high school, with their age ranging from 18 to 19. There are several reasons for choosing students of this age group. First, they have been learning English for at least 7-8 years (some of them even 11 or 12) plus one additional foreign language. Second, I considered it important to bear in mind that I would make interviews with them and for students of the age of 18 or above, I did not need parental consent, which made the data collection procedure easier. This issue, as trivial as it might seem, is a very problematic one, in fact. Relying on my previous experiences and on what teachers told me, carrying out an interview with a student presents no problem, but when contacted for consent, parents immediately tend to become suspicious and to see the potential interview as harmful and threatening, so gaining parental consent would most likely have caused great difficulties.

Classroom observation necessarily included the teachers of the ten classes visited ( $n=7$ teachers), however, a questionnaire survey was carried out including all the English language teachers from the visited schools $(n=16$ teachers) since I was interested in finding out whether there are any shared beliefs regarding EFL teaching and the use of non-target languages among the teachers of the same institution. Classroom observation included ten classes in five schools and a total of 231 students. However, I have to point out that the number of students is given according to the number of students enrolled in the particular classes, whereas their actual number varied from one visiting occasion to the next due to absences.

Following classroom observations, the study included interviews with 14 students from the total 10 classes. In each class I asked students to volunteer for an interview and, thus, one or two students offered to participate in the research. 
Table 4 below comprises the list of subjects investigated during the different phases of the fieldwork.

Table 4. A summary of subjects used for the study

\begin{tabular}{|c|c|c|c|c|c|c|}
\hline Date & School & Participants & $\begin{array}{l}\text { Teacher } \\
\text { Questionnaire }\end{array}$ & $\begin{array}{l}\text { Classroom } \\
\text { observation }\end{array}$ & $\begin{array}{l}\text { Student } \\
\text { interview } \\
\text { (post- } \\
\text { observati } \\
\text { onal) }\end{array}$ & $\begin{array}{l}\text { Teacher } \\
\text { interview } \\
\text { (post- } \\
\text { observatio } \\
\text { nal) }\end{array}$ \\
\hline \multirow[t]{2}{*}{$\begin{array}{l}\text { February } \\
2009\end{array}$} & \multirow{2}{*}{$\begin{array}{l}\text { Industrial school } \\
\text { group (mixed) } \\
\text { Luduș/Marosludas } \\
\text { Mureș/Maros }\end{array}$} & Teacher & 2 & 1 ( 2 classes) & - & - \\
\hline & & Student & - & $\begin{array}{l}38(2 \\
\text { classes }) \\
\end{array}$ & 2 & - \\
\hline \multirow[t]{2}{*}{$\begin{array}{l}\text { January and } \\
\text { February } \\
2009\end{array}$} & \multirow[t]{2}{*}{$\begin{array}{l}\text { Grammar school } \\
\text { (HU) } \\
\text { Târgu Mureș/ } \\
\text { Marosvásárhely } \\
\text { Mureș/Maros }\end{array}$} & Teacher & 5 & 2 (3 classes) & - & - \\
\hline & & Student & - & $\begin{array}{l}72(3 \\
\text { classes })\end{array}$ & 5 & - \\
\hline \multirow[t]{2}{*}{$\begin{array}{l}\text { March and April } \\
2009\end{array}$} & \multirow{2}{*}{$\begin{array}{l}\text { Vocational school } \\
\text { (mixed) } \\
\text { Târgu Mureş/ } \\
\text { Marosvásárhely } \\
\text { Mureș/Maros }\end{array}$} & Teacher & 3 & 2 (2 classes) & - & - \\
\hline & & Student & - & $\begin{array}{l}44(2 \\
\text { classes })\end{array}$ & 2 & - \\
\hline \multirow[t]{2}{*}{$\begin{array}{l}\text { October and } \\
\text { November } \\
2011\end{array}$} & \multirow{2}{*}{$\begin{array}{l}\text { Grammar school } \\
\text { (HU) } \\
\text { Miercurea } \\
\text { Ciuc/Csíkszereda } \\
\text { Harghita/Hargita }\end{array}$} & Teacher & 4 & 1 ( 2 classes $)$ & - & 1 \\
\hline & & Student & - & $\begin{array}{l}53(2 \\
\text { classes })\end{array}$ & 3 & - \\
\hline \multirow{4}{*}{$\begin{array}{l}\text { January and } \\
\text { February } \\
2012\end{array}$} & \multirow{2}{*}{$\begin{array}{l}\text { Economic school } \\
\text { group (mixed) } \\
\text { Miercurea } \\
\text { Ciuc/Csíkszereda } \\
\text { Harghita/Hargita }\end{array}$} & Teacher & 2 & 1 (1 class) & - & 1 \\
\hline & & Student & - & 24 (1 class) & 2 & - \\
\hline & \multirow[t]{2}{*}{ Total } & Teacher & 16 & $\begin{array}{l}7(10 \\
\text { classes })\end{array}$ & - & 2 \\
\hline & & Student & - & $\begin{array}{l}231(10 \\
\text { classes) }\end{array}$ & 14 & - \\
\hline
\end{tabular}




\subsubsection{Data collection methods}

Adopting a case study approach, the present paper investigates the specific case of the English foreign language teaching class in five schools. The research relies on several data collection methods in order to provide a more detailed picture and a more thorough understanding of the case.

Mixed method research is defined by Johnson and Onwuegbuzie (2004:17) as "the class of research where the researcher mixes or combines quantitative and qualitative research techniques, methods, approaches, concepts or language into a single study". The main principle of this type of research is that researchers collect multiple data and this mixture leads to better results and strengthens the study. As Dörnyei (2007:45) states, using mixed method research is fortunate as it brings out the best of both quantitative and qualitative methods and improves the validity of the results through the "convergence and corroboration of the findings" (but see also Riazi and Candlin, 2014).

Researchers using case studies believe that in order to understand a case it is required to perform an in-depth analysis of the emerging patterns and their interactions with the larger context (Sturman, 1997: 61), thus, such studies are mainly associated with observation and interviewing. To facilitate this process, primarily qualitative methods are used, although quantitative methods are not ruled out either. The main methods I have adopted in this study are observation, interviewing and the use of questionnaires.

The first step in a research procedure consisted in developing field relations and establishing contact with the subjects of the study. As mentioned in section 4.2.2 above, five schools have been contacted in three localities from two different counties in Transylvania.

The research procedure involved different time periods. First, in the year 2009 data was collected in Mureș/Maros county in the two localities described above - Târgu Mureș/Marosvásárhely and Luduș/Marosludas (see Table 4 above). Then, between autumn 2011 and spring 2012, further data was collected in Miercurea Ciuc/Csíkszereda, Harghita/Hargita county (see Table 4 above).

The two research sites differ in the way access was gained into schools. Data collection in Mureș/Maros county was carried out while I was still working as a 
researcher in the European FP6 research project LINEE (Languages In a Network of European Excellence). Thus, the project leader from the University of Szeged wrote an official letter to school principals where she asked for permission to carry out research in their schools (a sample letter can be found in Appendix 1a and its English translation in Appendix 1b). After gaining the principals' consent, I was introduced to the English teachers of the schools. However, in Miercurea Ciuc/Csíkszereda, gaining access to schools proved to be more complicated. As the project had ended in 2010, the official letter was written by the University of Sapientia, where I teach (see Appendix 2a and $2 b)$. A further problem was that the letter could not be presented directly to school principals but had to be pre-approved by the County School Inspectorate. When I presented my research aims and the letter was signed and stamped by the Inspectorate, I could address the school principals, who introduced me to the English teachers of that particular school. After I had presented my plans concerning the research to be carried out, I asked the teachers for their cooperation. I decided to inform the teachers that I would examine classroom language use in general, without mentioning the exact methods I would use to examine these. I also had to reassure the teachers that I was not interested in students' achievement or in different pedagogies and methodologies, hoping that they would not change their daily classroom practices because I of my presence. Thus, teachers were selected according to convenience sampling, on the basis of volunteering to help me in conducting this research. Prior to the actual data collection phase I discussed with the teachers the types of data I needed, and they agreed to provide me with those data (questionnaires and interviews for teachers) and offered their help in collecting the data (classroom observation).

As mentioned at the beginning of the present section (4.2), for the purpose of this study a triangulation of data collecting methods was used. Thus, data include questionnaires with EFL teachers, audio recorded (Mureș/Maros county), video-taped (Harghita/Hargita county) and transcribed naturally occurring classroom interaction, as well as audio-recorded and transcribed post-observational interviews with students and teacher interviews (in Miercurea Ciuc/Csíkszereda).

The following sections offer a justification for the main methods adopted and the perspective I take within each, drawing upon various theories to argue their appropriateness for the present study. 


\subsubsection{Questionnaires}

The data collection procedure was designed to include several steps. The first step was handing out the questionnaires to the EFL teachers $(n=16)$ in order to gain insight into the way language teachers perceive their language use in the classroom, and to get a more "official" side of the situation under study.

Questionnaires designed for teachers follow a structured form and include 21 questions altogether. The first set of questions (questions 1-6) include questions regarding the social background of the teachers such as age, gender, mother tongue, years of teaching English etc. Question 7 is a general multiple choice question on teachers' perceptions concerning their language use during EFL teaching. Questions 821 are about teachers' language use in specific pedagogical situations such as greetings, classroom administration, grammar explanation, explaining or translating unknown lexical items, asking and responding to student questions, socializing teacher talks in and outside the classroom. Each question is provided with pre-coded answers using a rating scale related to the frequency of using different languages. The rating scale includes five categories and ranges from never to always. In this case teachers had to mark with an $\mathrm{X}$ the most appropriate answer. Finally, the last item of the questionnaire allowed teachers to make comments regarding their or the students' language use and comments on the questionnaire (see a copy of the questionnaire in Appendix 3).

Questionnaires were administered after establishing contact with the teachers from each school and obtaining their agreement about their cooperation in the research. I visited teachers in school breaks and gave them printed copies of the questionnaire which they filled in immediately during the break in my presence. The presence of the researcher might be helpful in that it allows subjects to ask for clarifications in case of uncertainties, and the researcher's presence might elicit a better response rate and ensure that all questions are answered.

Questionnaires provide, thus, information regarding the social background of the teachers involved and their perception regarding the frequency of target and non-target language use during EFL classroom interaction. 


\subsubsection{Observations}

Naturalistic observation for case study research is very important since it offers the researcher access to social situations to study in their natural state, and to provide detailed information on events and informants (Denscombe, 1984). Observation gives an insight into what people actually do that might differ from what they say (Robson, 2002: 310), and the researcher can observe directly and 'live' the social situations. An important issue regarding observations is the extent to which the observations are structured or unstructured. Quantitative approaches to data collection and analysis usually have a more rigorous structure and require pre-defined categories, while qualitative observation is much more unstructured. As Adler and Adler (1994: 381) argue, "qualitative observation [...] follows the natural stream of everyday life" with the logic that the categories for describing the data will emerge later, probably in the analysis stage (Punch, 1998). As Patton (1990:202) suggests qualitative data obtained from observation allows the researcher to gain better insight and understand the situation that is being analysed and described.

For the purpose of the present research audio and video-recorded classroom observations were carried out in order to look at the linguistic behaviour of both teachers and students paying special attention to the use of non-target languages (codeswitching phenomena) during the EFL classroom. As mentioned above, a structured observation would have meant the use of pre-set categories and previously defined hypotheses to be validated. The observation method used in this study, however, lies between the structured and unstructured types of observation methods, thus, falling into a category called "semi-structured observation" (Cohen et al., 2007: 397). According to Cohen et al. (2007: 397), semi-structured observations are somewhat pre-planned, but data is collected in a less "predetermined or systematic manner" and contrary to structured observations where the researcher knows in advance what to look for, in semi-structured observations they define the emerging patterns after the data is collected.

Classroom observation and audio/video recordings of the EFL classes constituted a next step in the data collection procedure. According to Mackey and Gass (2005), observations are considered to be useful methods for collecting "in-depth information about such phenomena as the types of language, activities, interactions, 
instruction and events that occur in second and foreign language classrooms" (Mackey and Gass, 2005: 186-187). As has been previously mentioned, data collection fell into two different time periods. This is important to mention when discussing observation techniques since the second part of data collection shows some improvements compared to the earlier data collection process. While in the first period - in Mureș/Maros county - classroom observations consisted of the audio-recording of one or two English classes per visited classroom, during the second phase - in Harghita/Hargita county - I tried to overcome the "observer's paradox" (Labov, 1972: 209) or "the Hawthorne effect" (Mackey and Gass, 2005: 151) by using a time-series design (Mellow et al., 1996), which has been shown to reduce the Hawthorne effect as students and teachers begin to feel more comfortable and natural about being observed. According to this design, I spent three weeks in each class, being present, video-taping and audio-recording every English class they had during that period of time (2-3 classes per week). However, my aim was not to conduct a longitudinal study as the purpose of the research does not focus on the changes brought about by time. The time-series design enabled students and teachers to get accustomed to my presence in the class and the fact of being videotaped. Thus, for the detailed analysis of the data, only the last two recordings in each class are considered.

When observing a classroom in addition to using mechanical means of recording the lesson, I also made field notes where I wrote down the thoughts and perceptions I had at the time of observing (e.g. class size, class decoration, discipline etc.).

A pilot study of classroom observation was carried out between December 2008 and January 2009 to test the quality of the recordings. During this trial stage, I used a digital voice recorder that I placed on the teachers' desk or one of the front student desks, while I was sitting in the back and taking notes on the organization of the setting, and also writing down what students were saying in the back of the classroom (since their voices were not recorded well with my recorder). What I have learned from this experience is that voice recorders are not good enough to capture the voices of the whole class and that the students in the back of the classroom also provided valuable data worth recording. After consulting with a sound technician I was given three suggestions to solve this problem - the first was to use a sensitive, boom microphone that would capture the whole interaction inside a classroom. However, this solution was almost impossible to realize, as it would have required special microphones placed on 
the ceiling, an audio-mixer, and also technicians to set all these up. This solution would not have been only prohibitively expensive, but the size of the recording apparatus would have inevitably distracted students and teachers alike. The two other options were to either use several audio recorders that would entail listening to and transcribing the same event several times or use a video-recorder, which captures speech better than most audio-recorders. The first data collection phase was completed using several digital voice recorders (between 4 and 6, depending on the size of the class). However, this method turned out to be very time consuming when it came to transcribing data.

Thus, although the aim of the research does not require video-taping, it seemed to be the most time- and money-efficient procedure to follow during the second phase of data collection. This method was also piloted in advance by videotaping two language classes in October 2009. Although videotaping turned out to be the best method, I also placed three audio-recorders in each row of desks, thus gaining good quality data. The idea of having both video- and audio-recordings comes from Camilleri (1996: 95), who looked at language practices - more specifically code switches - in secondary classrooms in Malta. Her project involved micro-ethnographic observation in classrooms, audio- and video-recorded lessons, and informal interviews with teachers. Other studies on classroom code switching draw on participant observation, field notes and audio-recordings of classroom interaction (Martin-Jones, 1995: 90-111).

\subsubsection{Interviews}

Qualitative interviewing is considered one of the most effective tools along observation in case study research (cf. Hammersley, 1992; Fontana and Frey, 1994) and one of the most common and powerful ways to understand people (Fontana and Frey, 1998: 48). Interviews can allow researchers to examine certain phenomena that cannot be observed directly, such as learners' perception and attitudes in this case. Interviews, thus, can complement observations. While observations focus on people's behaviour and actions, interviews can reveal people's views and attitudes, and this way they can uncover feelings, thoughts, views and conceptions. As Jones (2003: 258) argues, "in order to understand other persons' construction of reality, we would do well to ask them". 
In my study interviews represent the main methodological tool for exploring students' views and perceptions on their multilingualism and the usefulness of other languages during foreign language learning. Of all the various types of interviewing one-to-one, group, structured, semi structured, and unstructured interviews - I have used one-to-one, semi-structured interview approaches that allow space for interviewee feelings, initiate discussion and "produce rich and valuable data" (Punch, 1998: 178). This approach plays an essential role in studying students' beliefs regarding the importance of non-target languages and how students actually perceive their own language use. Furthermore, interviews are used in the case of teachers as well to discuss and to check their own understanding of the patterns of classroom language use and to verify my analysis of the classroom recordings.

Interviews, however, are said to exhibit some weaknesses, mostly because they are based on what people claim, so subjects may not report their honest opinions but only what they consider to be politically correct, or they might say what they think they are expected to believe, rather than what they actually believe. However, Edwards (1983) asserts that often what people believe or claim can be more important than what they actually do. Although we can hardly ever answer the question whether a person is telling what he/she really thinks or not, from my perspective interviews still constitute an important source of data to be considered.

Conducting semi-structured interviews constituted the next stage of the fieldwork. I conducted semi-structured post-observational one-to-one interviews and one paired interview with students (who were paired based on their personal preferences) to explore their perception of language use during the EFL class and their perspectives on their own language use and language learning. According to the norms of semi-structured interviews, a set of possible questions were listed with the purpose to guide the interview. The content, wording or the order of the prepared questions was adjusted to the interview context. The list of guiding questions includes a set of questions related to the learners' language background. The second group of questions is aimed at classroom language use and the way students perceive and evaluate the use of non-target languages during EFL classroom instruction. The last part of the interview questions referred to students' self-reflections on some of the strategies they might use, for example, when they encounter a new lexical item, when they have to translate, or when they need to write a composition (for possible questions see Appendix 4). The 
interviewees were selected based on convenience sampling, namely, students who volunteered to do the interview. I asked 1-2 students per classroom, which means a total of 14 interviews (see Table 4 above). The interviews were carried out in Hungarian, the students' mother tongue.

Student interviewing was piloted in January 2009, when interviews were carried out with primary school students related to their views on multilingualism (results presented in section 3.2).

Except for one interview situation, students were interviewed individually. As a result, interview data consist of 12 individual interviews and one paired interview. The reason behind conducting paired interview is student preferences - one pair of students from the grammar school in Târgu Mureș/Marosvásárhely volunteered to take part in the interview but asked me to let them come together.

Finally, semi-structured post-observational interviews were carried out with the two teachers from Miercurea Ciuc/Csíkszereda to discuss and to check their own understanding of patterns of language use in the lessons and to verify my analysis of the classroom recordings. The need for a post-observational interview was clear after completing the first data collection phase, transcribing all classroom observations and realizing that there were classroom events where a clarification of events or choice would have helped. Thus, the second data collection period was further improved by planning and carrying out post-observational interviews with teachers. These interviews, though limited in number $(\mathrm{n}=2)$, provided me with valuable complementary data on classroom language use.

\subsubsection{Validity and reliability}

Validity means the truth value or correctness of the findings (Davies, 1998), to the soundness of the research methods and constructs, or, as House (1980: 25) states, "to the quality of being well founded on fact, or established sound principles, and thoroughly applicable to the case or circumstances". Validity and reliability have been traditionally associated with the more objective quantitative approaches to research, according to Punch (1998), who also notes that qualitative research has been the target of much criticism in these aspects in reaction to this dominant view. Observation, for 
example, has been heavily criticized as lacking validity, since it heavily depends on the interpretation provided by the researcher (Adler and Adler, 1994). It has also been criticized as lacking reliability, since it is more likely to be accurate for the sample group under study and unverified for extension to a larger population.

However, what these criticisms fail to consider is that there are other ways to conceive of validity in a qualitative inquiry related to the nature of the activity itself rather than comparison with quantitative inquiry. House (1980), for example, notes that the grounds for validity claims in qualitative inquiry are different from those in quantitative research. For House (1980), credibility - the match between the findings and the experience of participants and audience - is an important criterion in addition to the accuracy of the findings (House, 1980:253). Denzin (1989) takes a similar view in proposing the notion of "credibility" instead of validity, and, in turn, dependability ${ }^{10}$ instead of reliability, as more appropriate concepts for qualitative inquiry. What both these authors recognize is that, in qualitative inquiry, subjective experience is central to understanding the phenomena being researched, and that what is required to ensure validity are procedures that cross check findings (such as, for instance, triangulation or audit trail, cf. Guba and Lincoln, 1981) and providing a rich description in context (Geertz, 1973). Rather than trying to eliminate bias, the task is to achieve a greater consciousness of one's partialities and see how they impact upon the data and the researcher.

Similarly, to ensure stronger reliability in qualitative inquiry, strategies such as cross checking with participants, observing systematically, and repeating methods under varying conditions have been outlined (Davies, 1999). In this study, I have adopted the following procedures: the provision of a thick description of context, the triangulation of data and methods, and the use of post-observational interviews to check my understanding and clarify uncertainties with research participants.

\footnotetext{
${ }^{10}$ Dependability is defined as a notion similar to reliability that can be achieved through a process of auditing. Research data and research methods are examined by others to assure that the research process is logical land well-documented. Besides outsider examiners self- criticism and reflexivity also assure dependability (Morse et al., 2002)
} 


\subsection{Data Analysis}

As has been mentioned in the various sections of the previous chapter on the research design, three kinds of data have been collected in order to address the research questions, namely, questionnaire data, audio and video classroom recordings, and postobservational interview recordings.

The analysis of the data has included both quantitative and qualitative methodologies, given the nature of the data collected. As regards the questionnaires, they are analysed quantitatively by describing the frequencies and patterns of teachers' certain beliefs and perceived language behaviours during EFL classes.

In order to analyse the recorded classroom interaction, both quantitative and qualitative means of data analysis are used. Quantitative data analysis regarding classroom observations focuses on the number of occurring codeswitching phenomena in the course of the English lessons observed based on an utterance count method. The utterance count method was used to determine the distribution of the target and nontarget languages within EFL classroom interaction. Some methods estimating the number of languages used during language classroom instruction are the use of 5-15 second samplings (see Duff and Polio, 1990; Macaro, 2001, 2009), utterance counting (Polio and Duff, 1994) or word counting (Rolin-Ianziti and Brownlie, 2002). The utterance count method, chosen for the present study, has one problem, namely, that it does not count for the length of utterances. In order to overcome this obstacle, a differentiation was made between word or phrase length utterances and sentence length utterances or more. This analysis was carried out in order to be able to answer research question 1a, referring to the type of languages used during the EFL classroom. As a second step, a functional analysis was done focusing on the use of non-target languages by both teacher and students. The instances of non-target language use were identified and coded according to their functions. This analysis was carried out in order to be able to answer research questions $1 \mathrm{~b}$ and $1 \mathrm{c}$, regarding the functions of non-target languages and the users of these languages (who speaks to whom). A qualitative analysis followed using teacher questionnaires, classroom recording transcripts, post-observational interviews with teachers and students in order to answer research questions 2 and 3, regarding teachers' and students' beliefs and attitudes towards the use of non-target 
languages during EFL classroom interaction. As is typical with qualitative data analysis, the transcription and coding of the data are already part of the analysis procedure.

Thus, the analysis of classroom interactions consists of three phases. The first step has been to transcribe the recordings, followed by their organization into a manageable and analysable base of information. As the amount of audio data is enormous, content analysis was used to identify common ideas and emerging patterns throughout the data and, thus, classroom recordings have not been transcribed verbatim. As has been mentioned already, I spent three weeks in each class to get students and teachers accustomed to my presence and to the fact of being video-taped. Thus, I consider it to be logical to run a content analysis of the recordings and not to transcribe them word by word, while the last two recordings in each class were transcribed in full and analysed on a turn by turn basis.

There are several ways of coding classroom interaction and what the best choice is, I believe, depends on the nature of the interaction, the theoretical framework and the research questions. As the aim of the study is to track codeswitches (non-target language use) and their functions in the classroom discourse, a "broad" transcribing method of the recorded data has been applied. According to Du Bois et al. (1993:4546), broad transcriptions include the most basic transcription information, namely, speaker labels, the words spoken, hesitations, laughter, pauses, truncated words and uncertain hearings. When working with conversational data, the speakers' turns as well as speech overlap, which also needs to be indicated. Once recordings were transcribed, I began analysing the data by searching for patterns and explaining the logic of the interaction. Coding involves making decisions about how to classify or categorize particular pieces or parts of data. As I am particularly interested in the language use and linguistic behaviour of teachers and learners, the transcripts were analysed for codeswitching instances. In this case, coding meant identifying patterns of language use, where the codes were not pre-set or ready-made - instead, custom-made coding schemes emerged from the data itself based on the observations. This type of coding, when the schemes emerge from the data rather than being decided on and pre-imposed prior to the data being collected or coded is called 'open coding' (Mackey and Gass, 2005:241). The coding phase was followed by the actual analysis, when comparisons between different emerging patterns were made and interpretations provided (for examples of transcription and coding, see Appendix 5). 
A discourse analysis approach is used in this paper to investigate classroom interaction, which "allows researchers to gain insight into what is being accomplished in a particular classroom interaction that takes place in a specific social context" (McKay, 2006: 105). The value of classroom discourse analysis is that, unlike coding systems that record only whether or not the L1 or other languages are used in the classroom or not, classroom discourse analysis can demonstrate the purposes why these languages are used and thus to reach conclusions about language use. The most widely used frameworks for the analysis of classroom discourse are the following: conversation analysis and ethnography of communication (Rampton et al., 2002; McKay, 2006).

From the existent qualitative approaches to discourse analysis I have chosen the ethnography of communication approach, which "recognizes the influence of culture and social realities in seeking to find holistic explanations for meaning and behaviour" (McKay, 2006:102). Lazarton (2002, cited in McKay, 2006:102-103) points out that the main difference between conversation analysis and ethnography of communication is that the latter considers transcribed interactional data as "just one source of information that should be considered in documenting cultural practices" taking into consideration also the use of interviews, field notes and other data in the study. Using the approach of ethnography of communication as a basis, I have looked at the classroom event, taking the actions in sequence on a turn-by-turn basis. Each codeswitch is counted, also differentiating between the length of the switches, as has been mentioned above, (word/phrase vs. sentence length vs. longer) and labelled with a code that describes its function (meaning clarification, eliciting, metalinguistic comment, task instructions, evaluation, telling off etc.). Relying on the ethnography of communication method, I have got answers not only as to the number of code switches during an English class, but I can also draw conclusions about the purpose of using a certain language, or why a certain language is preferred in some situations.

As regards the third type of data, the interview recordings, these have followed the same three-phase analysis procedure, being transcribed, coded and then analysed. Interviews serve the purpose of gaining more information on the language use of the learners, but also exploring their own views and perceptions on their multilingualism and language use.

All in all, the aim of the study is to describe the ways in which multilingualism in general and non-target language use in particular is present in the EFL classroom, 
through analysing natural classroom interaction and teachers' and students' discourses on language use during EFL classes. The focus is not solely on the number of codeswitches that occurred during a class, but on the purpose of these switches (i.e. why do participants switch from one language to another in certain situations). The question is whether knowledge of languages other than the target language is exploited or remains unexploited. Questionnaires give a theoretical, a more "official" picture about language use in the classroom, while classroom observations give insights to what is actually happening in the classroom. Finally, the interviews provide answers to my "why" questions connecting all questions and data.

In what follows I report on the findings of the empirical investigation carried out among Transylvanian Hungarian minority high school learners and their English teachers, as described in section 4.2.1 above. Sections 4.1-4.2.4 have presented the research questions and details regarding the design and methodology used in the present study. In this last section, the research questions will be treated, one after the other in order, in order to facilitate the understanding of the specific subject groups involved, the methodology used, and the research areas investigated. 


\section{EFL classroom language use}

The present chapter of the dissertation attempts to answer the first research question regarding students' and teachers' linguistic behaviour during EFL classes. The section explores the language use of students and their English teachers based on teachers' accounts regarding their language use (through a questionnaire survey), on natural classroom interaction (through classroom observation), and on students' perception (through interviews) concerning language use in the EFL classroom. Combining the different data collection methods allows for a more detailed and probably more accurate description of linguistic behaviour during EFL classes.

The present chapter focuses on the type of languages used within English as a foreign language class on the amount and purpose of occurring codeswitching.

If we understand multicompetence as the capacity of individuals to deal efficiently with the languages at their disposal and to see that this capacity develops in interaction and becomes more complex as the input is more complex, then foreign language classes should represent an appropriate setting where such complex input is provided to enhance students' development towards becoming multicompetent language users.

Adopting a multilingual perspective in foreign language education also means taking into account the presence of other previously learnt languages and exploiting the benefits of previous language knowledge and language learning experiences.

Taking into consideration the principles of the two theoretical concepts multicompetence and the DMM - presented in Chapter 2, it becomes clear that both suggest the existence of a constant interaction and mixing of the linguistic systems within the multilingual mind. Thus, neglecting learners' non-target languages during foreign language instruction would mean adopting a monolingual perspective in the language classroom and would also mean a denial of the existence of other languages in the students' minds.

According to the multicompetence perspective, a foreign language classroom should be a place where the language learners can fully function with their total 
language system, and it stresses the importance of previously learnt languages in the foreign language learning process (Cook, 2005).

Moreover, third language acquisition studies (cf. section 1.3) argue that learning a third or additional language is both quantitatively and qualitatively different from second language acquisition, and these distinctions are attributed to some complex factors and effects associated with the interaction of the language systems in the speakers' mind and with the experience gained from previous language learning. One of the most important factors influencing third language acquisition is cross-linguistic influence, i.e. the effect of prior language knowledge on the acquisition of an additional language. Therefore, codeswitching is considered to be a salient feature of multilingual speech, and many scholars argue that the L1 or any other previously learnt non-target language can be beneficial and aid foreign language learning. Studies conducted within the TLA field conclude that non-target language use during foreign language classes enhances target vocabulary acquisition (Macaro, 2009), it may be used as a form of support or scaffolding for better understading (Ife 2008), and, by raising students' awareness concerning the role of non-target languages, it facilitates and accelerates processes which occur independently in their minds (Paradowski, 2008).

Bearing in mind the theoretical considerations and the results of recent studies in the field of foreign language education and learning, the present section of the dissertation aims to explore and describe current foreign language teaching practices with a special focus on the linguistic behaviour of language teachers and students. Describing EFL classroom language use allows us to identify current trends and tendencies in English foreign language education and exploring the present local situation helps pointing out lacks that should be compensated and corrected as well as good practices that should be encouraged.

As mentioned in the previous chapter on data collection methods, classroom language use is explored using a triangulation of data collecting methods, namely, teacher questionnaires, classroom observation and student interviews. In what follows, I present the results of questionnaires, classroom recordings and interviews separately, and then I provide an overall discussion of these results. 


\subsection{EFL classroom language use according to the teacher questionnaire}

As described in section 4.2 above, fieldwork for the present study was conducted in two counties, three localities and five schools, and a total of ten different classes were studied. The questionnaire for teachers was administered not only to teachers whose English classes I visited but also to their colleagues teaching in the same school.

A total of 16 teachers completed the questionnaire, of whom 15 were female and one male. Regarding their age, most teachers were between 20-39 years of age $(n=12)$, one teacher was between 40 and 49, and 3 other teachers were between the ages of 50 and 59. For what regards their nationality and mother tongue, most teachers were Hungarian $(n=11)$, however, there were also 5 Romanian teachers who filled in the questionnaire. Looking at the nationality and mother tongue of their students, it can be observed that all five Romanian teachers teach in mixed classes, where they teach both Romanian and Hungarian students, and there is one Hungarian teacher who teaches in a mixed class. The rest of the Hungarian teachers $(n=10)$ teach exclusively Hungarian students.

The first question on classroom language use asked teachers about their predominantly used language during an EFL class. The answers show great variation which depends not only on the teachers' mother tongue. Of the 10 teachers who have Hungarian mother tongue and teach exclusively Hungarian students, only three use predominantly English for classroom interaction. Five teachers consider using both English and Hungarian in the course of English language classes. What is important to note is that there are two Hungarian mother tongue English teachers, teaching exclusively Hungarian students who use predominantly three languages during EFL classes, namely, English, Hungarian and Romanian.

The questionnaire revealed that teachers use English for greeting students and this is also the language they expect from students to greet them in. Only two of the 16 teachers professed to using both English and Hungarian for greetings. As regards the discussion of organizational matters in class, the situation becomes more layered. Only 5 teachers stated that they use only English for discussing management matters, while the others use English and their own mother tongue to discuss such matters in class. 
Questions 11 to 17 referred to the content of language teaching and are related to such educational situations like giving explanations, explaining/translating unknown vocabulary, asking and responding to questions, and, finally, group work. Apart from three situations - giving explanations, translating and making connections (lexical/grammatical) with languages other than the target language - teachers prefer using exclusively or mostly English. As regards asking and answering questions, most $(n o=14)$ teachers respond to students' questions in the target language, even if the respective question was addressed in the student's or teacher's mother tongue. Furthermore, when students answer the teacher's question using their own (or the teacher's) mother tongue, they are usually $(n o=15)$ asked to repeat their answer in the target language. In the case of small group activities, teachers require the students to use only English as a working language.

However, it is worth looking at Question 14, referring to the type of languages (Hungarian, Romanian or other) teachers make connections with during teaching English vocabulary or grammar. Only two teachers professed to using only English and making no connections whatsoever with other languages. The majority of the teachers who filled in the questionnaire marked at least one other language used for pointing out similarities and differences. Most Hungarian teachers $(n=9)$ use both the Hungarian and Romanian languages to establish lexical and/or grammatical connections between English and the respective language, the exceptions being only two Hungarian teachers who avoid the use of Romanian in teaching English. Romanian teachers mostly use their mother tongue to make connections with the target language, though there are two teachers who named French as the language used to make connections with English.

The last four items of the questionnaire (Questions 18-21) focused on activities building student-teacher relations and reflected on teacher language use while joking, disciplining, talking about informal topics, and carrying out teacher-student interaction outside the language classroom. Results show that half $(n=8)$ of the teachers tend to use only English in the course of joking with and telling off students, while the other half use both the target language and their own mother tongue in these situations. Nevertheless, talking about informal things and outside classroom interaction is marked by almost exclusive mother tongue language use. Only one Romanian mother tongue teacher, aged 50-59, said they used only English during outside-classroom interactions. 
Table 5 below offers an overview of language use based on the teacher questionnaire results.

Table 5. Overview of EFL classroom language use based on the teacher questionnaire results

\begin{tabular}{|llll|}
\hline $\begin{array}{l}\text { Educational } \\
\text { activity }\end{array}$ & $\begin{array}{l}\text { HU } \\
\text { teacher/HU } \\
\text { students } \\
(\text { no=10) }\end{array}$ & $\begin{array}{l}\text { HU } \\
\text { teacher/mixed } \\
\text { students } \\
\text { (no=1) }\end{array}$ & $\begin{array}{l}\text { RO } \\
\text { teacher/mixed } \\
\text { students } \\
\text { (no=5) }\end{array}$ \\
\hline Greeting & $\mathrm{EN}$ & $\mathrm{EN}$ & $\mathrm{EN}$ \\
\hline $\begin{array}{l}\text { Management } \\
\text { matters }\end{array}$ & $\mathrm{EN+HU}$ & $\mathrm{EN}$ & $\mathrm{EN+RO}$ \\
\hline Explanations & $\mathrm{EN+HU}$ & $\mathrm{EN+HU}+\mathrm{RO}$ & $\mathrm{EN+RO}$ \\
\hline $\begin{array}{l}\text { Vocabulary } \\
\text { translation }\end{array}$ & $\mathrm{HU}+\mathrm{RO}$ & $\mathrm{HU}+\mathrm{RO}$ & $\mathrm{RO}$ \\
\hline Connections & $\mathrm{HU}+\mathrm{RO}$ & $\mathrm{HU}+\mathrm{RO}$ & $\mathrm{RO}+\mathrm{FR}$ \\
\hline Questions & $\mathrm{EN}$ & $\mathrm{EN}$ & $\mathrm{EN}$ \\
\hline Group work & $\mathrm{EN}$ & $\mathrm{EN}$ & $\mathrm{EN}$ \\
\hline Joke/telling off & $\mathrm{EN+HU}$ & $\mathrm{EN}+\mathrm{HU} / \mathrm{RO}$ & $\mathrm{EN}+\mathrm{RO}$ \\
\hline $\begin{array}{l}\text { Informal/outside } \\
\text { classroom }\end{array}$ & $\mathrm{HU}$ & $\mathrm{HU}$ & $\mathrm{RO}$ \\
\hline
\end{tabular}

The questionnaire results presented above reflect teachers' own perceptions regarding language use within the English foreign language classroom. The results showed no differences regarding the age, teaching experience or the locality of the teachers. However, some distinctions are to be found in relation with the teachers' mother tongue.

As the visited schools were of Hungarian and mixed types, both Hungarian and Romanian mother tongue English teachers within the respective educational institution were involved in the research. The visited schools differ in the way they employ English language teachers. The two Hungarian schools employ Hungarian teachers to teach English, while the mixed type schools employ both Hungarian and Romanian nationality teachers. In the case of the mixed type schools visited, where there are classes with Hungarian language of instruction and classes with Romanian language of 
instruction, ${ }^{11}$ it could be observed that Hungarian mother tongue English teachers are assigned to teach Hungarian sections, while Romanian sections are taught by Romanian mother tongue teachers.

As the context and the participants' linguistic background suggest, in the case of mixed type schools greater variety of languages is involved, namely, the target language, English, Romanian and Hungarian. Although I assume the presence of at least three languages due to participants' linguistic background, it does not mean that the presence of Hungarian language is mentioned by Romanian teachers. Romanian being the language of the majority, people belonging to this linguistic/ethnic group usually do not speak Hungarian, which is the minority language and, in our case, the students' mother tongue. In the same vein, Hungarian schools or the Hungarian classroom context neglect the use of the Romanian language, though, as presented in chapter 3.2 above, it would certainly count as the most appropriate source language regarding the learning process of English as a third language. Thus, taking a closer look at the questionnaire results, we can clearly see that teachers of Romanian ethnicity use non-target languages such as Romanian and French, whereas the use of Hungarian is chosen only under question number 17 of the questionnaire regarding required language use from students during group work.

As it is true in larger social contexts that societal multilingualism does not necessarily entail individual multilingualism, it is also valid for the Transylvanian schools visited, where the presence of three languages in the classroom does not mean that all participants of the language classroom have all three languages in their linguistic repertoires.

Apart from these differences marked by the ethnic origin of the teachers, the results show a common tendency regarding language use during certain teaching activities. Thus, it can be stated that teachers use only English for greetings, asking and answering questions, and they require exclusive use of English during group work activities. However, Hungarian and Romanian (and in certain cases French) are used during talking about informal matters, classroom management related interactions,

\footnotetext{
11 In Romanian these two types of classes are called 'sections' (in Romanian: secțiune) and in what follows I will also use the term section (e.g. Hungarian section) meaning classes with a specific language of instruction.
} 
maintaining of class discipline, joking and teaching activities such as giving explanations, translating vocabulary unfamiliar to students and making connections (pointing out lexical and/or grammatical similarities and differences) between the target and non-target languages.

Based on the teacher questionnaire results, it can be concluded that (a) 7 out of 10 Hungarian teachers who teach exclusively Hungarian students reported using nontarget languages during EFL classes; (b) classroom language use is influenced by the teachers' mother tongue; (c) the use of non-target languages during EFL classes depends on the educational focus, namely, (d) these non-target languages are used for conveying meaning (explanations, making connections between languages, translation), maintaining discipline and for informal talks.

Teachers' answers show that the L1 or previously learnt languages (Romanian, French) are being used during EFL lessons which is in accordance with the results of current research studies (Lugossy, 2003; Nagy and Robertson, 2009; Hall and Cook, 2013; Hlas, 2016). According to Hall and Cook (2013) there is an emerging trend to reevaluate and recognize the value of students' mother tongue during foreign language classes. Previous studies on the use of non-target languages in foreign language lessons (Nagy and Robertson, 2009; Nzwanga, 2000; Ife, 2008; Levine, 2011; Hall and Cook, 2013; Thompson and Harrison, 2014; Hlas, 2016) point out different pedagogic functions related to the use of other languages (ususally referring to learers' mother tongue) which can be included in three major categories, such as instructional (e.g. conveying meaning, explanations, translation), managerial (e.g. classroom management, task instructions), and affective (e.g. building teacher-learner rapport, maintaining discipline).

Teacher questionnaire results reflect the use of non-target languages for similar functions; however, it was surprising that only 8 respondents (out of 16) marked using non-target languages in case of joking and telling off students. Moreover, questionnaire results show a discrepancy between teachers' language mode and teachers' control over students' language mode. On the one hand, teachers use both English and their mother tongue for a number of reasons listed above, while, on the other hand, they require exclusive target language use from students - students are expected to use only English during group work or to ask questions in English. In spite of such requirements, learners are also multilingual, thus, it seems inevitable for them to use other languages as well 
during English language classes. As one teacher comments at the end of her questionnaire:

(8) A diákok hajlamosak automatikusan magyarra váltani és néhányan reflexböl románt használnak angol helyett (és ezek magyar diákok).

"Students tend to automatically switch back to their mother tongue and some of them have the reflex of using Romanian instead of English (these are Hungarian students)."

The comment above suggests that even if the teacher requires only target language use, students cannot forget the other languages they have in their minds. The use of Romanian instead of English by Hungarian-Romanian bilingual students is a good illustration of Hammarberg's assumption $(1998,2001)$ regarding the foreign language effect or the L2 status: Romanian and English are perceived by students as different from their L1, and, thus, Romanian is perceived as a foreign language similarly to English.

However, based on the multilingualism literature, which argues for interaction among the languages in the students' minds and proposes an integrated language teaching method (see Jessner, 2008; Cenoz and Gorter, 2015), it is safe to say that such target-language only requirement stands in contrast with the new developments. From the perspective of multicompetence and the Dynamic Model of Multilingualism previously acquired languages have beneficial effects on further language learning processes (see Chapter 2) and, thus, the use of prior linguistic knowledge as a resource in language learning is recommended. Questionnaire results present teachers' perspectives on their own language use and the language mode they require from their students, according to which teachers mostly employ a bilingual - target language and mother tongue - language mode during EFL teaching, however reported language use during teacher talk is different from expected language use during student talk. . Literature on the use of non-target languages during language classes also highlights that previously acquired languages should be used in a systematic way, comparing and constrasting language systems, in order to draw students' attention to the crosslinguistic similarities and differences (Ringbom, 2007; Paradowski, 2008; Boócz-Barna, 2010; Ó Duibhir and Cummins, 2012; Hall and Cook, 2013). Thus, simply using or allowing the use of non-target languages is not sufficient (Macaro, 2009; Levine, 2009). There were only two questionnaires filled in by Hungarian mother tongue English teachers, who 
reported using three languages within the EFL classroom. Their responses show that these two Hungarian teachers use Hungarian for classroom management purposes, translations and outside-classroom communication, and they also use Romanian for translations and to point out similarities between Romanian and English during grammar explanations. Bearing in mind the ideas behind the concepts of multicompetence and DMM, the reported EFL teaching practices of these two Hungarian teachers stand as an example of good practice that recognizes the value of previous language knowledge and fosters multicompetence by allowing the use of the students' full linguistic repertoires.

\subsection{EFL classroom language use according to classroom observation recordings}

As discussed in detail in section 4.2, classroom observation involved a total of ten different classes from the five schools visited. It was already mentioned that data collection in the two counties (Mureș/Maros and Harghita/Hargita) was carried out in two different time periods, and the data collection methods were improved in the case of the latter period compared to the former.

One the one hand, fieldwork in Mureș/Maros county was carried out in 2009, when three schools were visited. Classroom observation data consist of audiorecordings from seven classes of five English teachers.

On the other hand, classroom observation in Harghita/Hargita county was performed between October 2011 and February 2012 in two schools. In this case, data collection methods were improved in a way that both video- and audio-recordings were made, and the time spent in each class was longer (three weeks). Thus, classroom observation data from Harghita/Hargita county consists of 21 video- and audio-recorded English classes. However, as it was mentioned in section 4.2.3.2 above, the longer time period spent in these classes was meant to create a familiar atmosphere, where both teacher and student participants got used to my presence and that of the technical equipment brought into the classroom. Therefore, the detailed analysis of classroom observations carried out within the present study refer to the last two English lessons in each visited class $(n=6)$.

Classroom audio- and video-recordings were transcribed and following an open coding they were analysed both quantitatively - counting the number of occurring 
codeswitching phenomena, also differentiating between the length of codeswitching (words/phrases or sentence length or more) - and qualitatively, analysing them on a turn-by-turn basis and identifying the purposes and functions of the codeswitching phenomena (i.e. meaning clarification, eliciting, metalinguistic comment, task instruction, evaluations, telling off, etc.). Classroom language use patterns were traced in each setting, to examine patterns and functions of codeswitching by teachers and students, and to document the extent and nature of metalinguistic commentary, especially any contrastive discussion (i.e. comparing features of any of the languages available).

Table 6 below lists the codeswitching functions identified during the observed EFL classes and provides an example for each function.

The present study aims to investigate the presence of multilingualism in foreign language teaching practices, and, as the codeswitching phenomenon is considered to be a salient feature of multilingual communication, I believe that observing codeswitching instances during foreign language classes represents the best way to examine the multilingual nature of these classes. Moreover, as discussed in section 2.2, both DMM and multicompetence theories argue for the existence of dynamic and interacting linguistic systems, and, thus, codeswitching may be considered as a visible output of this linguistic interaction in a multilingual's mind.

The research setting in which the present study was carried out represents a special case because classroom participants share at least three languages and in this way codeswitching may occur in several different combinations, and the language present in the classroom may get different functions as well.

Taking into consideration the whole range of data collected in all five schools, I arrived at a general overview regarding language use, where three types of classes can be differentiated - a class in a Hungarian school taught by a Hungarian mother tongue English teacher, a class in a mixed type school (cf. section 3.1.4) taught by a Hungarian mother tongue English teacher, and a class in a mixed type school taught by a Romanian mother tongue English teacher. A general overview of classroom language use in the three types of classes looks like as presented in Table 6 below. 
Table 6. Overview of EFL classroom language use concerning the three types of classes

\begin{tabular}{|l|l|l|}
\hline $\begin{array}{l}\text { Hungarian school/HU teacher } \\
\text { (teacher n=3, class n=5) }\end{array}$ & $\begin{array}{l}\text { Mixed school/HU teacher } \\
\text { (teacher n=2, class n=3) }\end{array}$ & $\begin{array}{l}\text { Mixed school/RO teacher } \\
\text { (teacher n=2, class n=2) }\end{array}$ \\
\hline $\begin{array}{l}\text { Teacher language use: ONLY } \\
\text { ENGLISH }\end{array}$ & $\begin{array}{l}\text { Teacher language use: English } \\
\text { and Hungarian }\end{array}$ & $\begin{array}{l}\text { Teacher language use: English } \\
\text { and Romanian }\end{array}$ \\
\hline $\begin{array}{l}\text { On-record student language use: } \\
\text { English mainly and some } \\
\text { informal matters in Hungarian }\end{array}$ & $\begin{array}{l}\text { On-record student language use: } \\
\text { English, Hungarian and } \\
\text { Romanian }\end{array}$ & $\begin{array}{l}\text { On-record student language use: } \\
\text { English, Romanian }\end{array}$ \\
\hline $\begin{array}{l}\text { Student-student interaction: } \\
\text { Hungarian }\end{array}$ & $\begin{array}{l}\text { Student-student interaction: } \\
\text { Hungarian }\end{array}$ & $\begin{array}{l}\text { Student-student interaction: } \\
\text { Hungarian }\end{array}$ \\
\hline
\end{tabular}

\subsubsection{Classroom observation data from Mureș/Maros county}

The seven audio-recorded English classes from Mureș/Maros county come from one Hungarian grammar-school and two mixed type vocational schools. As was mentioned in section 5.1 above, vocational schools employ both Hungarian and Romanian mother tongue foreign language teachers, thus, in the case of the mixed type schools visited in Mureș/Maros county, lesson observations included English classes of both Hungarian $(\mathrm{n}=2)$ and Romanian $(\mathrm{n}=1)$ mother tongue teachers. As was mentioned previously, recorded classroom interaction was transcribed and analysed for the number and functions of the occurring codeswitching phenomena.

In what follows I will give a general account of language use in the English classes from Mureș/Maros county, which I then complement by a table containing the numbers and the functions of the codeswitching instances, and, finally, discuss further the functions and purposes of codeswitches, providing examples as well.

As regards English classes in the Hungarian school $(n=3)$, classroom language use is dominated by the almost exclusive use of the target language. English lessons were of a communicative nature as the aim of these lessons was to prepare students for their English oral exam at the end of the semester (e.g. discussion about the role of luck versus hard work in one's life). From the point of view of teacher talk, there are no instances of codeswitching on the part of the teacher during any of the classes observed. Concerning student talk, it is mostly characterized by target language use, except for one instance in which the teacher cannot turn off the heating and asks students if they know what might be wrong. One of the students offers an explanation in Hungarian triggering the following reaction on the part of the teacher: 
(9)

$<$ Something is wrong with the tap and the teacher asks why she cannot turn it off>

T: but I've been using it FOR YEARS

S: igen, de elzárták, amikor lefertötlenitették az osztályt

T: Can't you speak English?

$S: N o$

T: NO? <laughter> So it is very very hot in here so some disinfectant has been used on it and is not working

" $<$ Something is wrong with the tap and the teacher asks why she cannot turn it off $>$

T: but I've been using it FOR YEARS

S: Yes, but it was turned off when the classroom was disinfected

T: Can't you speak English?

S: No

T: NO? <laughter> So it is very very hot in here so some disinfectant has been used on it and is not working"

Extract 9 above shows one of the very few instances of codeswitching initiated by students. It refers to an informal, off-task discussion between a teacher and her students, while the students try to explain to the teacher why she might have difficulties turning off the heating in the classroom. Though, the discussion is not related to task, the teacher does not allow the use of non-target languages during the English classroom. The teacher sounds authoritarian and rather harsh in the way she reacts and urges students her students to use the target language. First, she reacts with a question asking if the students cannot speak English, then she repeats the student's Hungarian explanation using English. The teacher's reaction of 'Can't you speak English?' shows not only her requirements of monolingual language use during the EFL class but also her authority regarding EFL classroom language use. The way she phrases the question 'Can't you speak English?' may also reflect the teachers' multilingual identity and possibly her lack of the appropriate register in English.

As could be seen from extract 9, the teacher tries to create an exclusive target language environment most probably to provide sufficient target language input for her students. Repeating the student's Hungarian explanation in the target language suggests that the aim of the teacher was not only to urge students to use only English but to provide support and help them in formulating their asnwers in the target language. 
Scaffolding on the leaner's L1 explanation reflects the teacher's pedagogical aim, i.e. to provide target language input and make use of the off-task situation to teach new vocabulary, however her reaction sounds authoritarian and controlling. Prohibiting first language use within the foreign language classroom has been criticized by several researchers (Cook, 2001; Macaro, 2001; Levine, 2011; Cenoz and Gorter, 2015) who argue for maintaining the multilingual nature of the language class. Multicompetence and DMM theories presented in chapter 2 of the present study also point out that the different languages within the students' linguistic repertoire interact and despite being banned, students' previous languages cannot be deactivated and therefore, students might rely on their full linguistic repertoire. By translating the learner's L1 comment, the teacher expresses that she understood the learner's L1 message but as the aim of the lesson is to improve students' oral language competences she contributes to the language learning process by providing an English translation of the L1 comment.

Classroom interaction, however, is more varied in the case of the mixed type schools, regardless of whether they have a Hungarian or a Romanian teacher of English. Analysing English classes recorded in the mixed type school with a Romanian teacher show variety not only in the languages used but also the functions and purposes for which these codeswitching phenomena are used. The teacher has a lot of trouble concerning discipline and an important number of codeswitching instances occur when the teacher scolds her students. The English lesson observed in the class of the Romanian mother tongue English teacher focused on learning how to write a "for and against" essay. At the beginning of the lesson they revise the simple present and present continuous tenses that they learnt during the previous lesson. Here the focus is on the accurate use of these two tenses.

(10)

S: An action in progress in the moment of the speech/

T: In the moment of speaking, da? / I'm writing right now/ Bagi is speaking right now/Sandor is talking to Szabi right now/So Iza and Eniko are eating/These are actions that take place right now/ okay?/ And they are (.) <laughter > okay so/ Sandor dragă ce ți-am spus când ai intrat în clasă/ pliscu' închis/ Toată ora/ Ne-am ințeles? / Tu nu tre' să scoți absolut ABSOLUT nici o vorbă/ Nici un sunet/ Nici un mormăit/NIMIC/ Ai priceput?/ (.) Da/ Până n-ai venit o fost liniștel

S: dar nu pot să fac așal

T: Liniște!/ Poți să-nchizi și te rog muzical ((???)) în afară de foame așa-i? Okay/

What's the difference between present simple and present continuous?/ 
"S: An action in progress in the moment of the speech/

T: In the moment of speaking, yes?/ I'm writing right now/ Bagi is speaking right now/ Sandor is talking to Szabi right now/ So Iza and Eniko are eating/ These are actions that take place right now/ okay?/ And they are (.) <laughter> okay so/ Sandor dear, what did I tell you when you entered the classroom/shut up/during the whole class/Do you understand?/You don't have to speak AT ALL/Not a sound/Not a murmur/ NOTHING/ Do you understand?/ (.) Yes/ It was quiet until you came/ S: But I can't do it this way/

T: Quiet!/ Can you also turn off the music/ ((???)) besides you are hungry, is that right? Okay/ What's the difference between present simple and present continuous?/"

Extract 10 above shows an example of teacher's and students' metalinguistic discussion concerning the use of the Present Continuous tense in the target language. The teacher uses discourse markers such as okay and bun "good" (in Romanian) in both English and Romanian (see also extract 11 below) to signal boundaries between different pedagogical activities. The teacher can switch from one language to the other. As extract 10 shows, metalinguistic comments and example sentences are given in the target language, while disciplining and scolding students (affective responses) are in Romanian. After the teacher scolds the respective student using Romanian, she marks the end of her monologue saying okay and turns back to the metalinguistic discussion in English.

The teacher uses Romanian for eliciting example sentences from students and requires the translation of these sentences from English to Romanian. The teacher then gives a Romanian sentence which has to be translated into English. Thus, besides telling off students, the other two most frequent code switches are related to meaning making, clarification, student elicitation and task instruction.

T: Acum timpurile astea vi le-am dat ca să le puteți folosi corect în vorbire/ Să nu vă mai aud persoana a treia singular fără s/ Sa nu vă mai aud că He go He eat și așa mai departel Neapărat nu uitați de s/ Ne-am ințteles?/ Și să nu mai folosiți în orice compunere He is going He is leaving every day/Că nu-i corect/ Ne-am ințeles?/ Bun/ Today's lesson is going to be a writing lesson (.) < the teacher tells the title while she writes it on the blackboard> For and against writing (.)essay/ Do I have to translate this into Romanian?/

S: yes

T: Eseuri pro și contra/ (.)Eseuri pro și contra/ Considering the title could you guess some themes of essays?/(.) Nah nimic?/ Luându-vă după titlu puteți să ghiciți cam ce fel de eseuri trebuie să scrieți?/ 
"T: Now, I gave you these tenses to use them correctly when you speak/I don't want to hear anymore third person singular without an s/ I don't want to hear He go He eat and so on/ Don't forget about the s/ Do you understand? And don't use in your essays He is going He is leaving every day/ Because it's not correct/ Do you understand?/Good/

Today's lesson is going to be a writing lesson (.) < the teacher tells the title while she writes it on the blackboard> For and against writing (.)essay/ Do I have to translate this into Romanian?/

S: yes

T: For and against essays/ (.) For and against essays/ Considering the title, could you guess some themes of essays?/(.) Come on, nothing? Considering the title, could you guess what kind of essay do you have to write?/"

Extract 11 above shows an example of grammar explanation in Romanian intertwined with drawing students' attention and warning them about the correct use of the verbs in third person singular. The turn ends with good, a marker for discourse shift and the teacher turns to the title of the current lesson writing it up on the blackboard. The teacher checks meaning understanding by asking students if she has to translate the title into Romanian. On student request, the teacher translates the title of the lesson and she is eliciting answers from students regarding some essay topics. As she gets no response, the question is repeated in Romanian as well.

As opposed to extract 10 above, extract 11 shows an example where the teacher uses Romanian (her L1 and the students' L2) for metalinguistic comment, however, in this case, the metalinguistic discussion carries an affective meaning, as the teacher points out some of the students' mistakes and warns them to use the Present Simple and Present Continuous tenses correctly in the future. The teacher's lengthy monologue rather sounds as the telling off quoted in extract 10 above - the teacher keeps saying ' $\mathrm{I}$ don't want to hear.../don't forget/don't use' telling learners how not to use the target language and to stop making mistakes. Similarly to extract 10, the teacher uses 'good' as a discourse marker in Romanian and turns to the topic of the new lesson. The last part of the extract gives some example of how the teacher uses Romanian in order to facilitate meaning and understanding of the task.

Students' language use includes - beside English and Romanian - Hungarian and, at one instance, Italian as well. Hungarian language use is related to meaning check or meaning confirmation. When students use Hungarian they always address each other, as the teacher cannot speak Hungarian. The single instance of Italian language use occurred during clarifying the task instruction and marked a language play, a form of 
ludic language and a source of humour in the class. The students' attitude of showing off, probably caused by my presence, attracted a negative and cynical reaction on the part of the teacher:

T: Păi da, asta este idea/ Și atât trebuie să-mi scrieți/ V-am zis că nu-mi trebuie să copiați că doar nu v-am dat copierel (.) Un exercițiu asemănător am făcut când am făcut descrierea unui text și v-am dat manualele să citiți Paradise Tour/ Așa-i?!

$S: D a l$

T: Nah/

S: ((???)) capisci/

T: Capisci/ Bravo/ Ești un geniu/

S: Știu

"T: Well yes, that's the idea/ and that's what you have to write/ I've told you, you don't have to copy as I didn't asked you to copy/(.) We did a similar exercise when we had the description of a text and I gave you the books to read Paradise Tour/ Is that right?/

S: Yes/

$\mathrm{T}: \mathrm{Nah} /$

S: ((???)) capisci/

T: Capisci/ Bravo/ You are a genius/

S: I know"

The EFL classroom in the mixed type school with a Romanian mother tongue English teacher presented a multilingual learning environment, where teacher talk and teacherstudent interaction were marked by the alternating use of English and Romanian. Student off-task interaction is marked by the use of Hungarian, the students' mother tongue. As the example extracts 10,11 and 12 above show, the teacher uses the target language for metalinguistic discussion and providing examples regarding the tenses learnt, to introduce the topic of the new lesson and for task instruction. Within the same EFL lesson, the teacher uses Romanian in case of affective utterances such as disciplining (extract 10), expressing irony (extract 12) and warning students about the correct use of the Present Simple and Present Continuous tenses. Moreover, Romanian is used for meaning clarification in case of task instruction and elicitation (extracts 11 and 12).

The variety of linguistic resources presented above are due to the specific learning context in which students and the teacher do not have the same mother tongue, but they do share a language that facilitates them in the EFL teaching and learning process. I believe that the use of Romanian language is present because that is the 
teacher's mother tongue, and it represents the single common non-target language shared by all classroom participants. The use of the students' mother tongue, although present in the classroom setting, is somewhat restricted to the students' off-task interaction because the Romanian mother tongue English teacher does not speak this language, and, thus, she cannot exploit this language for the benefit of the target language instruction.

Furthermore, it is worth considering whether the above presented multilingual context created by the teacher meets the criteria of multilingual approach in teaching presented in Chapter 2. Although both multicompetence and DMM theories suggest the alternated and flexible use of languages within the foreign language classroom is beneficial for the language learning process, these theories also highlight that non-target languages should be used in a principled way. Therefore, the teacher's lengthy monologue on how not to use the target language might not serve the purposes of acquiring multicompetence. Extract 11 above represents an example of a multilingual context created by the teacher, proving indeed an alternated and flexible use of the languages involved, nonetheless it cannot be considered as a good practice of constructive multilingualism, but an overuse of the classroom lingua franca.

Finally, English classroom interaction in the mixed type school with a Hungarian teacher is marked by an intensive use of non-target languages, mainly due to the nature of the classes visited. As lessons visited in this school applied the GrammarTranslation teaching method, focusing on reading out loud and translating a text from the students' textbook, most of the code switches are related to translation, meaning clarification/confirmation and evaluation.

However, it is interesting to note that during the time when the teacher was checking for absences, one of the students answered in French, again an example of language play and spurce of humour, probably because of the researcher's presence in the class. However, in this case the teacher completely ignored the student's comment.

<The teacher checks the absent students, students keep talking>

T: Pap Levente

S: Jelen

T: Bács Timea

S: present

<teacher continues reading out the names>

T: István 
S: Je suis ici

T: Ok what did we have for today?/

" $<$ The teacher checks the absent students, students keep talking $>$

T: Pap Levente

S: present

T: Bács Timea

S: present

<teacher continues reading out the names>

T: István

S: I am here

T: Ok what did we have for today?/"

Another interesting case represents an instance when a student signals that she is facing some problems with translating a part from the text, and after the teacher's encouraging words in Hungarian she does the translation into Romanian. The teacher repeats the same word in Hungarian and they continue translating the text.

S: Annyi pénze van, hogy errr (.)/

T: Eltörölhetnél a harmadik világ/

S: Ha akarnál nem tudom ezt jól

T: dehogynem, csak nyugodtan

(...)

S: imprumut

T: adósság/Eltörölhetné a harmadik világ/

S: adósságát, ha akarnál

"S: He has enough money to errr (.)/

$\mathrm{T}$ : abolish/ the third world/

S: if he wanted/ I don't know this well

T: Of course you do, go on

$(\ldots)$

S: debt (RO)

T: debt/ He could abolish the third world's/

S: debt if he wanted/"

In the extract above, the student uses the Hungarian language to inform the teacher about her uncertainty regarding the equivalent of a word from the English text they were translating. The teacher replies in Hungarian and encourages the student. The student gives the Romanian equivalent of the given word which is then translated by the teacher into Hungarian. The student repeats the Hungarian word and continues the translation activity. 
In case of this class from a mixed type school from Mureș/Maros county we can speak about a special case of instructional setting. Although the classroom can be characterised as multilingual due to the presence of English, Hungarian and Romanian languages, it cannot be considered a multilingual communication environment.

The topic of the lesson was 'money'. As an introduction to the lesson, the teacher asked students if they knew any slang words or idioms related to money. The initial brainstorming activity was followed by a reading activity, when students had to read the text out loud and translate it. The reading activity was followed by a vocabulary exercise including some adjectives and adverbs (confound, ardently, determined, competitive etc.). Then another reading activity followed with the same instructions, students had to read it aloud and translate it. Each student was assigned a part of the text to read and translate.

Due to the predominant use of translation activities, codeswitching instances are most frequently related to this activity. Hungarian is also used by the teacher to give instructions and to discipline as shown in extract 15 below.

S: 〈reading from the book>

T: Okay/ Now translate/ És asszem Ottó kezdi/

S: Mit?/

T: Fordítani/ De csak azért mert igen jól esztek/

S: Már nem eszünk/

T: Akkor László/ (.) Közösen Babival, igen/translate (...) Józsi

S: Hajózta/ Körülhajózta a/

"S: < reading from the book $>$

T: Okay/ Now translate/ and I guess Ottó will start/

S: What?/

T: the translation/ only because you are having a good time eating/

$\mathrm{S}$ : We are not eating anymore/

T: Then László/ (.) together with Babi, yes/translate (...) Józsi

S: Sailed/ Sailed around the/"'

Extract 15 above shows that the teacher uses both English (now translate) and Hungarian (És asszem Ottó kezdi, "I guess Ottó will start") for giving instructions and she uses Hungarian to scold students (De csak azért mert igen jól esztek, "only because you are having a good time eating"). 
Classroom observation extracts 9-15 above presented examples of EFL classroom language use and behaviour from different schools in Mureș county. The three different schools visited differ in their EFL learning environment. The lesson observed in the Hungarian grammar school resembles Macaro's (2009) virtual position label regarding teachers' attitudes, according to which learners should be provided with the maximum input and output opportunities in the target language. The teacher's language use can be characterised by exclusive target language use and a monolingual mode of language use, however her translation of the learner's Hungarian comment proves her multilingualism. Extract 9 also illustrates that monolingual target language environment is achieved by teacher control and authority. Contrary to the Hungarian grammar school, mixed type schools show a greater variety in the languages present and thus can be characterised as being more multilingual. However, mixed type school classes differed according to the mother tongue of the English language teacher. The lesson of the Romanian mother tongue English teacher showed a frequent use of Romanian as this was the only shared non-target language of the classroom participants (the lingua franca of the respective classroom community). During this lesson, students' mother tongue (Hungarian) was also present; however, as the teacher did not speak this language, it was restricted to student-student off-task interactions. The teacher encountered a lot of discipline problems, thus, the use of Romanian was frequent in case of disciplining. Nevertheless, Romanian was also used for meaning clarification of task instructions and for expressing irony.

The lesson in the mixed type school with a Hungarian mother tongue English teacher represented another specific case due to the teachers' instructional methods which involved mostly reading and translating texts from the English textbook. Therefore, the most frequent codeswitching instances are related to these translation activities.

EFL classes with the mixed type schools can be considered multilingual when we look at the number of languages that appear during the English lesson (English, Romanian, Hungarian, even French and Italian) and the frequent codeswitching instances either due to problems of classroom organization and discipline or as a result of the Grammar-Translation teaching method applied by the teacher. However, if we look at the educational goals of the two theories presented in Chapter 2 we can see that non-target languages present during the EFL class are not used in a principled way as 
suggested by Cook $(1999,2001)$ and the extensive Romanian monologue of the teacher in extract 11 does not seem to enhance students' multilingual competence or their metalinguistic awareness.

As it was presented earlier in this section, a quantitative analysis of codeswitching instances was carried out. Transcribed classroom recordings were analysed looking at the number of occurring codeswitches, and they were coded according to their function in the EFL classroom. Thus, Table 7 below presents an account of the languages used during EFL teaching and the purposes for using these languages.

Table 7. Uses of different languages during EFL classes in the monolingual Hungarian school and the mixed type vocational school with details regarding the functions and numbers of code switching phenomena (Mureș/Maros county)

\begin{tabular}{|c|c|c|c|c|}
\hline Type of school & Teacher/students & Functions of CSW & $\begin{array}{l}\text { Unit of CSW: } \\
\text { Word/phrase }\end{array}$ & $\begin{array}{l}\text { Unit of CSW: } \\
\text { Sentence/more }\end{array}$ \\
\hline \multirow{3}{*}{$\begin{array}{c}\text { Monolingual } \\
\text { Hungarian }\end{array}$} & Teacher (HU) & Meaning related & - & - \\
\hline & \multirow[t]{2}{*}{ Students (HU) } & Meaning related & 2 & 1 \\
\hline & & Informal discussion & 1 & 1 \\
\hline \multirow{24}{*}{$\begin{array}{c}\text { Bilingual } \\
\text { (mixed school) }\end{array}$} & \multirow[t]{8}{*}{ Teacher (RO) } & Meaning related & 7 & 5 \\
\hline & & $\begin{array}{l}\text { Metalinguistic } \\
\text { comment }\end{array}$ & 2 & 8 \\
\hline & & Grammar explanation & - & 14 \\
\hline & & Eliciting & 14 & 30 \\
\hline & & Task related & 8 & 18 \\
\hline & & $\begin{array}{c}\text { Organizational } \\
\text { discussions (windows, } \\
\text { absences etc.) }\end{array}$ & 1 & 9 \\
\hline & & Making discipline & 11 & 32 \\
\hline & & Evaluation/feedback & 6 & 8 \\
\hline & \multirow{5}{*}{$\begin{array}{l}\text { Students } \\
\text { (HU) }\end{array}$} & Meaning related & 5RO/1IT/1HU & $7 \mathrm{RO} / 3 \mathrm{HU}$ \\
\hline & & Task related & - & $4 \mathrm{RO} / 1 \mathrm{HU}$ \\
\hline & & Off-task interaction & $8 \mathrm{HU}$ & $5 \mathrm{RO} / 13 \mathrm{HU}$ \\
\hline & & $\begin{array}{c}\text { Organizational } \\
\text { discussion }\end{array}$ & $5 \mathrm{RO}$ & $4 \mathrm{RO}$ \\
\hline & & $\begin{array}{l}\text { Response to teacher's } \\
\text { eliciting }\end{array}$ & $8 \mathrm{RO}$ & $5 \mathrm{RO}$ \\
\hline & \multirow[t]{6}{*}{ Teacher (HU) } & Meaning related & 31 & 2 \\
\hline & & Eliciting & 8 & 1 \\
\hline & & Task related & 6 & 1 \\
\hline & & Telling off/discipline & - & 2 \\
\hline & & Evaluation/feedback & 12 & 1 \\
\hline & & $\begin{array}{c}\text { Translating unknown } \\
\text { vocabulary }\end{array}$ & 24 & 4 \\
\hline & \multirow{5}{*}{$\begin{array}{l}\text { Students } \\
\text { (HU) }\end{array}$} & Meaning related & $14 \mathrm{HU}$ & $2 \mathrm{HU}$ \\
\hline & & Task related & $7 \mathrm{HU}$ & - \\
\hline & & Off-task interaction & - & $1 \mathrm{HU}$ \\
\hline & & $\begin{array}{c}\text { Organizational } \\
\text { discussion (checking } \\
\text { presence) }\end{array}$ & $1 \mathrm{FR}$ & \\
\hline & & Translation & $23 \mathrm{HU} / 1 \mathrm{RO}$ & $36 \mathrm{HU}$ \\
\hline
\end{tabular}




\begin{tabular}{|l|c|c|c|c|}
\hline \multirow{2}{*}{} & & $\begin{array}{c}\text { Signalling } \\
\text { problem/difficulties }\end{array}$ & $1 \mathrm{HU}$ & $1 \mathrm{HU}$ \\
\cline { 3 - 5 } & Offering to do task & $1 \mathrm{HU}$ & $1 \mathrm{HU}$ \\
\hline
\end{tabular}

Table 7 above draws a clear picture regarding the number of codeswitching phenomena and the pedagogical functions attributed to these codeswitches.

The most striking difference can be observed between the monolingual Hungarian and the mixed type schools. The number of instances showing a codeswitching phenomenon is minimal in case of the monolingual Hungarian school. On the part of the teacher there are no codeswitches whatsoever, her teacher talk being characterized by what is called only-English language behaviour. In the case of students a few occurrences of codeswitching can be observed with the purpose of clarifying and confirming meaning and related to informal, off-task discussion within the English class.

While in the case of the monolingual Hungarian school there were scarcely any instances of codeswitching (only 5, all of them student-initiated), in the case of the mixed type schools codeswitching occurred more frequently and several pedagogical functions can be attached to them. Table 7 shows that teachers in both mixed type schools use two languages during English language instruction - the target language and their mother tongue. However, students' language use in these classes proves to be more varied - using non-target languages like Hungarian (their mother tongue) and Romanian. Moreover, in both classes there were some instances (about one per class) when students used other foreign languages - Italian and French - mainly to show off, behaviour that might have been provoked by my presence in the classroom.

Regarding the discourse functions of teacher initiated codeswitching instances, it can be stated that these are closely connected to teachers' pedagogical activities and are in line with the larger pedagogical purpose of the lesson, but students' behaviour and classroom management can have a great influence on teachers' linguistic behaviour.

As Table 7 demonstrates, in the class taught by the Romanian teacher, teacher talk is dominated by codeswitching related to elicitation techniques $(n=44)$ and maintaining discipline in the classroom $(n=43)$. The class of the Romanian teacher in one of the mixed type schools is also the class where most codeswitching within student talk is connected to off-task interaction $(n=26)$ in both Hungarian and Romanian. 
The English lesson taught by the Hungarian teacher is strongly marked by the educational goal of the lessons observed, i.e. translating two texts from the textbook. Thus, codeswitching instances within teacher talk are connected to meaning clarification $(n=33)$, translating unfamiliar lexical items $(n=24)$ and translating whole sentences $(n=4)$. During this lesson codeswitching within student talk is also related to meaning clarification $(n=16)$ and translation $(n=60)$, of which there is one occasion of codeswitching to Romanian (see also extract 14).

All in all, mixed vocational schools show not just a higher number of code switching instances but also a greater variety of functions attributed to the different codeswitches. As it is clearly visible in the table above, the monolingual Hungarian grammar school is characterised by monolingual target language classroom environment, where there are no codeswitching instances in the teacher talk. The use of non-target languages (in this case only Hungarian is present) appear only in students' communication and are mainly used for meaning clarification and informal discussion.

However, lessons visited in the two mixed type schools allowed the presence of more languages besides the target language, and these non-target languages are assigned different discourse functions within the EFL class. Apart from meaning related codeswitches we can also find some metalinguistic comments in Hungarian or Romanian, grammar explanations, and elicitation techniques, organizational and disciplinary functions. The lessons observed in the two mixed type schools gave examples of codeswitching phenomena not only in the student talk as in the case of the monolingual Hungarian grammar school but also in the teacher talk.

Figure 4 below focuses only on the two mixed type schools visited and shows the same results as Table 7 , in a more visual way. 
Figure 4. Numbers and functions of codeswitches present in the mixed type EFL classrooms

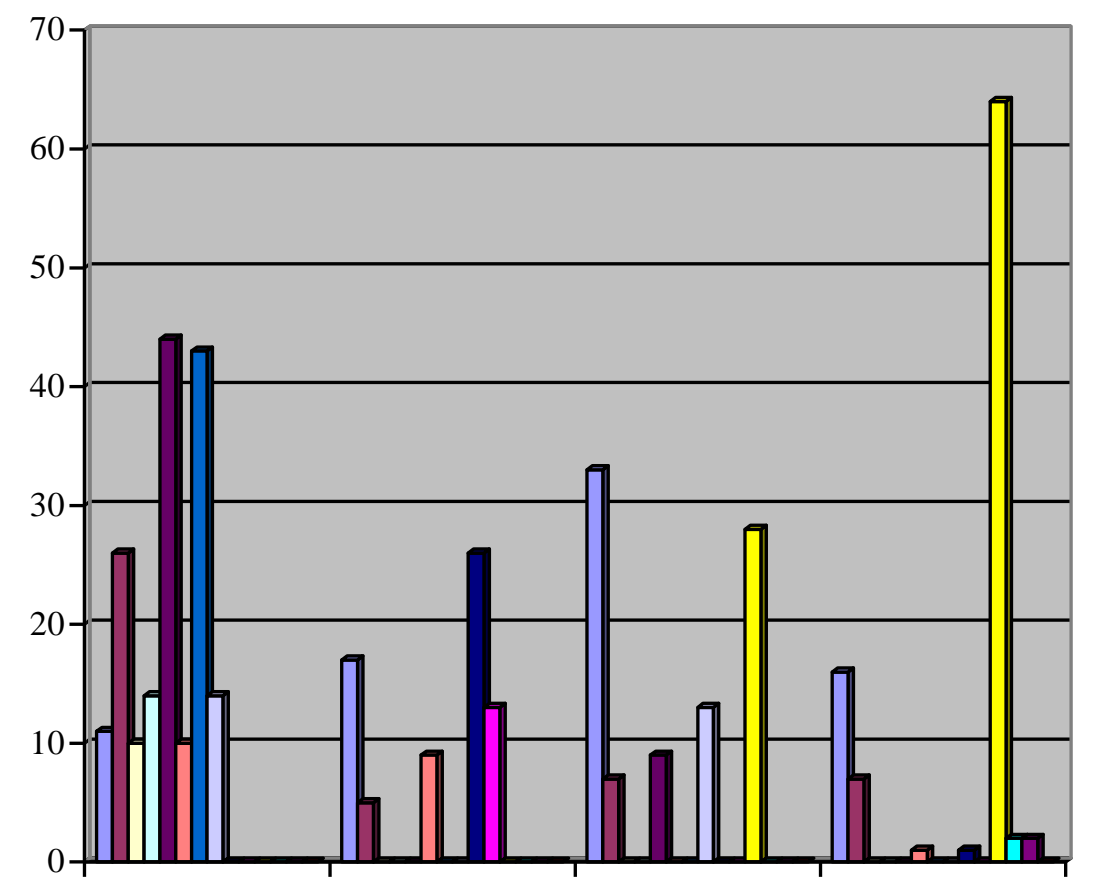

$\square$ Meaning

$\square$ Task

口Meta-comment

$\square$ Grammar expl.

$\square$ Elicitation

口Organizational

$\square$ Discipline

口Evaluation/feedback

O Off-task

$\square$ Response to elicitation

$\square$ Translation

口Problem signal

$\square$ Offer to do task

anformal
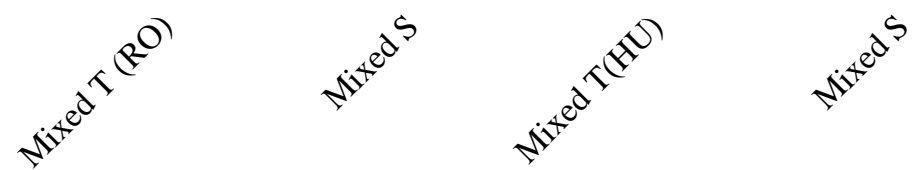

Data presented above on the number of languages and codeswitching instances encountered, show that English lessons within the observed mixed type schools can be called multilingual classes as they involve the use of more languages and teachers' talk can also be characterised by the use of multiple languages. While in the monolingual Hungarian grammar school English classes are mainly monolingual as well, teachers adopting a target language only teaching approach, in the mixed vocational school the language of the classroom resembles the multilingual nature of the school - though such multilingual practices are not carried out in a principled way or as a planned teaching strategy in order to enhance multilingualism and language awareness of the learners.

Classroom interaction data gathered in three schools from Mureș/Maros county gives evidence for the presence of multilingual speech during EFL classroom, though the type of the school and the mother tongue of the teacher affect not only the type of 
languages used but also the frequency of codeswitching within the lesson. Data above also brings several examples of pedagogical functions concerning classroom codeswitching. Though there is a wide range of discourse functions attached to the codeswitching instances, classroom management and the overall goal of the English lesson shapes the frequency of these codeswitching functions.

\subsubsection{Classroom observation data from Harghita/Hargita county}

After a detailed description of EFL classroom language use in the visited schools from Mureș/Maros county, further classroom observation data will be presented concerning Harghita/Hargita county. As it was mentioned in section 4.2 and at the beginning of the present section, two schools were visited in this county, both schools having their location in Miercurea Ciuc/Csíkszereda. The transcribed video- and audio-recordings of classroom interactions were analysed similarly to data gathered in the schools from Mureș/Maros county, as previously presented in this section. Thus, in what follows I provide a general account of the classes visited presenting the number and functions of codeswitching and giving examples.

As presented in Table 4, 21 audio and video-recordings were collected from Miercurea Ciuc/Csíkszereda in three different classes involving two different teachers, one teacher from a Hungarian monolingual grammar school and one teacher from a mixed type school. As was mentioned in section 4.2, I spent three weeks in each school as suggested by Mellow et al. (1996), with the aim to reduce or even overcome "the Hawthorne effect" (Mackey and Gass, 2005: 151) so students and teachers would get accustomed to my presence in the classroom. The number of classes visited in Mureș/Maros county was 7, therefore, only the last two recorded English lessons were fully transcribed $(n=6)$ to adjust their number to the transcribed recordings from Mureș/Maros county, and the other recordings $(n=15)$ were analysed for content and identifying trends and tendencies.

The English classes visited at the monolingual Hungarian grammar school in Miercurea Ciuc/Csíkszereda were conducted by the same teacher, thus from the perspective of linguistic behaviour these classes follow the same pattern. All English classes focused on communication and speaking skills. The teacher prepared the topics in advance and handed them out to the students on a piece of paper. The teacher used 
whole class and group discussions and walked around the class and among the student groups to check on their language use (they were required to use English during group discussions as well) and provided them help in case students did not know a word in English. Codeswitching in these classes was present in a reduced number of occasions, the most frequent situations being related to meaning clarification and translating a few unknown vocabulary items.

T: I'm not so sure I understand what you mean/

S: immunrendszer/

T: Oh, their immune system/

$S$ : Yes, the immune system

"T: I'm not so sure I understand what you mean/

S: immune system/

T: Oh, their immune system/

S: Yes, the immune system/"

Extract 16 is an example of a situation when the teacher signals a need for clarification and the student responds in Hungarian. The teacher repeats the words in English and begins her turn with a marker of understanding $O h$. The student then accepts the teacher's answer and they arrive at a common agreement, the student repeats the words in English.

T: I would like you to tell me something about endangered species, animals becoming extinct, poaching, which you know what it is (.) poaching, everybody knows that, last year we learnt quite a lot about it./What kind of hunting/poaching

S: orvvadászat

T: illegal hunting/okay, something else, nuclear plants, pollution, air pollution/okay, good.

"T: I would like you to tell me something about endangered species, animals becoming extinct, poaching, which you know what it is (.) poaching, everybody knows that, last year we learnt quite a lot about it./What kind of hunting/poaching

S: poaching

T: illegal hunting/okay, something else, nuclear plants, pollution, air pollution/okay, good." 
Extract 17 shows an example when the teacher stops during task instruction as she wants to ensure that students have understood the word poaching and gives them clues to be able to contextualize the time they learnt it and that it is related to hunting. The teacher's English explanation and contextualization clues are successful and one of the students gives the Hungarian equivalent of the respective word. The meaning, illegal hunting is repeated by the teacher and the task instruction continues.

The Hungarian language was also used by this teacher during classroom management activities at the beginning of the lesson. For instance, before starting the English lesson the teacher discussed with the students about some organizational matters related to a trip (how much money students needed to bring and the extent to which going on that trip was compulsory).

S: Van, aki nem akar jönnil

T: kötelezö tevékenység és az lenne a lényeg, hogy utolsó kiránduláson mindenki ott legyen/Okay/Can we start?

"S: There are some who don't want to come/

$\mathrm{T}$ : it is an obligatory activity and it would be important that everybody should be there on the last trip/Okay/Can we start?"

Extract 18 is taken from a discussion at the beginning of the English lesson. The discussion was related to the organization of the last class excursion, and it was conducted in Hungarian. The teacher closes the Hungarian discussion by using a discourse marker okay signals not only topic shift but also language shift.

In case of group work activities students used the target language but whenever they had to discuss or clarify something regarding the topic they switched back to Hungarian or raised their hands and asked the teacher for the English equivalent of a certain vocabulary item.

S: It is a box in which you put different things that err (.) people might be curious about in the future (.) and this box is err (.) elásva <student turn towards the teacher> elásva T: these might be dug

S: these might be dug and after I don't know ten or twenty years you go back and see which things you put there 
"S: It is a box in which you put different things that err (.) people might be curious about in the future (.) and this box is err (.) dug <student turn towards the teacher> dug T: these might be dug

S: these might be dug and after I don't know ten or twenty years you go back and see which things you put there"

Extract 19 shows an example when a student tries to explain what a time capsule is to his classmates and requires the help of the teacher in translating a Hungarian word into English. The teacher gives the necessary lexical item which is then repeated by the student and the student continues his explanation.

The observed lessons of the teacher in the Hungarian grammar school reflected an almost exclusive use of the target language, similarly to the lesson observed in the Hungarian grammar school in Mureș/Maros county. However, in case of the English lesson recorded in Mureș/Maros county there were no codeswitching instances within teacher-talk and student talk could also be characterized by minimal use of codeswitching $(n=5)$. The teacher from the grammar school in Miercurea Ciuc/Csíkszereda used Hungarian language for informal discussions at the beginning of the class, strictly separated from the target language activities. During the EFL lesson, Hungarian was used by students most frequently to ask for the translation of unknown vocabulary items (extract 19) or as a response to the teacher's meaning clarifying questions (see extract 17). It should be noted, however, that there is no Hungarian language use on the part of the teacher during target language teaching. Moreover, as shown in extract 17, the teacher repeats the student's Hungarian equivalent for the word poaching by using the English phrase illegal hunting. Although the teacher's requirements regarding classroom language use are not explicit and overt as in the case of the grammar school teacher in Mureș/Maros county (see extract 9), the teacher controls classroom language mode by her monolingual language behaviour.

The mixed type school from Miercurea Ciuc/Csíkszereda showed many similarities to those visited in Mureș/Maros county. The classes observed in this mixed type school involved more codeswitching instances and both Hungarian and Romanian were used as non-target languages during the EFL classroom. English lessons focused on all four language skills, i.e. reading, writing, speaking and listening. Teacher initiated codeswitches included translating unknown vocabulary items, often asking students to think first of the Romanian equivalent of the word and then try to figure out its meaning. The English teacher of the mixed type school, who participated in the 
study, is of Romanian nationality; however, he has some knowledge of Hungarian as well. The Romanian teacher's knowledge of Hungarian proved to be a useful asset, as he could understand his students better and could help them overcome their lexical gaps during communication.

S1: Ce înseamnă deficiency in these nutrients?/

T: Try to translate it into Romanian, the words are just like in Romanian/

S1: $\operatorname{errr}(\ldots)$

S2: deficit?/ [deficiency?]

T: Da, și ce inseamnă deficit?/ [Yes, and what does deficiency mean?/]

S2: hiányosság, hiány/ [deficiency, lack]

S1: lack of something?/

T: Yes, that's it/

"S1: What does deficiency in nutrients mean?/

T: Try to translate it into Romanian, the words are just like in Romanian/

S1: $\operatorname{errr}(\ldots)$

S2: deficiency?

$\mathrm{T}$ : Yes, and what does deficiency mean?

S2: deficiency, lack

S1: lack of something?/

T: Yes, that's it/"

Extract 20 is an example of meaning clarification, initiated by the student using Romanian, the teacher's mother tongue. The teacher encourages his students to think of a translation in Romanian as the words resemble each other (drawing students' attention to English-Romanian cognates). Although the student cannot come up with an answer, he gets peer assistance, another student gives the Romanian word and translates it into Hungarian. The first student now understands the word and gives an English synonym for it, approved by the teacher. The extract above shows not only a good example of teacher and peer assisted meaning making, but also creates a context where the teacher can draw students' attention to the existence of cognates and encourages them to find these words in the students' previously learnt languages other than their mother tongue.

T: Yes, you can see her here and what do we know about her so far/ she is an athletel yes athletel doing what/

$S:$ four hundred 
T: four hundred meters / four hundred meters hurdle/ do you know this?/ athletic garduri/ patru sute metri garduri/ futás az atlétikában, rúdon kell átugrani/ proba atletical

S: gátfutás

T: good/ what is her best/ her best personal record? Júlia could you

S: 54

" T: Yes, you can see her here and what do we know about her so far/ she is an athlete/ yes athlete/ doing what/

S: four hundred

T: four hundred meters / four hundred meters hurdle/ do you know this?/ athletic hurdles/ four hundred meters hurdle / running in athletics, they have to jump over rods/ an athletic event/

S: hurdle

T: good/ what is her best/ her best personal record? Júlia could you

S: 54"

Extract 21 is an example when the Romanian mother tongue English teacher from the mixed type school in Miercurea Ciuc/Csíkszereda initiates codeswitching to both Romanian and Hungarian in order to explain the meaning of hurdle. First he translates it into Romanian then gives a Hungarian explanation. Even though the teacher's proficiency in Hungarian is not enough to translate the word hurdle into this language, he succeeds in explaining the word. The teacher success is marked by the response of a student who provides the Hungarian equivalent of the word. The teacher then closes the meaning clarification discussion by the discourse marker good and continues to elicit further answers from students regarding the topic of the lesson.

T: You use the passive when the person who does the action is not important or it is unknown/a magyarban nem nagyon használatos, ha jól tudom, ott többes szám van/ Javítják az utat/deci mai bine gândiți în românește că structura e la fel/ Casa a fost construită în 1890/The house was built in 1890/vedeți că și ordinea e la fel?

"T: You use the passive when the person who does the action is not important or it is unknown/it is not really used in Hungarian, if I know it well, the plural is used/The road is being repaired/so it's better to think in Romanian as the structure is the same/The house was built in 1890/The house was built in 1890/can you see the word order is the same?"

Extract 22 presents a metalinguistic comment initiated by the teacher. The teacher uses both Hungarian and Romanian to draw students' attention to the use of the passive 
constructions. The teacher gives a Hungarian sentence which could be translated into English using the passive voice, and he points out that Hungarian language does not use the passive voice. In addition, he recommends that students think in Romanian and provides a Romanian sentence and its English translation to show to students that passive constructions in English and Romanian follow a similar pattern and even word order.

As mentioned before, EFL lessons observed in the mixed type school in Miercurea Ciuc/Csíkszereda are similar to those English classes that were visited in the mixed type schools in Mureș/Maros county. However, it needs to be pointed out that while in Mureș/Maros county the participating Romanian mother tongue English teacher could not speak Hungarian (her students' mother tongue), the Romanian teacher in Miercurea Ciuc/Csíkszereda had some Hungarian knowledge and this way, he could use Hungarian for clarifying meaning and explaining grammar (metalinguistic comment). Moreover, EFL lessons observed in the mixed type school in Miercurea Ciuc/Csíkszereda contain metalinguistic comments not only related to the correct use of certain grammatical constructions but also involve the comparison of all three languages (English, Romanian and Hungarian).

The quantitative analysis of codeswitching instances are presented in Table 8 below.

Table 8. Uses of different languages during EFL classes in the monolingual Hungarian school and the mixed type vocational school with details regarding the functions and numbers of code switching phenomena (Harghita/Hargita county)

\begin{tabular}{|c|c|c|c|c|}
\hline Type of school & Teacher/students & Functions of CSW & $\begin{array}{l}\text { Unit of CSW: } \\
\text { Word/phrase }\end{array}$ & $\begin{array}{l}\text { Unit of CSW: } \\
\text { Sentence/more }\end{array}$ \\
\hline \multirow[t]{5}{*}{$\begin{array}{c}\text { Monolingual } \\
\text { Hungarian }\end{array}$} & Teacher (HU) & $\begin{array}{l}\text { Outside lesson frame } \\
\text { (informal discussion) }\end{array}$ & - & 14 \\
\hline & \multirow[t]{4}{*}{ Students (HU) } & $\begin{array}{l}\text { Outside lesson frame } \\
\text { (informal discussion) }\end{array}$ & - & 6 \\
\hline & & Meaning related & 8 & 2 \\
\hline & & Off-task interaction & - & 3 \\
\hline & & $\begin{array}{c}\text { Group discussion of } \\
\text { task }\end{array}$ & 19 & 7 \\
\hline \multirow{7}{*}{$\begin{array}{c}\text { Bilingual } \\
\text { (mixed school) }\end{array}$} & \multirow[t]{7}{*}{ Teacher (RO) } & Meaning related & 11 & 8 \\
\hline & & $\begin{array}{l}\text { Vocabulary } \\
\text { translation }\end{array}$ & $8 \mathrm{RO} / 2 \mathrm{HU}$ & - \\
\hline & & $\begin{array}{l}\text { Metalinguistic } \\
\text { comment }\end{array}$ & 3 & $18 \mathrm{RO} / 1 \mathrm{HU}$ \\
\hline & & Grammar explanation & - & 9 \\
\hline & & Eliciting & 5 & 7 \\
\hline & & Task related & - & 12 \\
\hline & & $\begin{array}{c}\text { Classroom } \\
\text { management }\end{array}$ & - & 6 \\
\hline
\end{tabular}




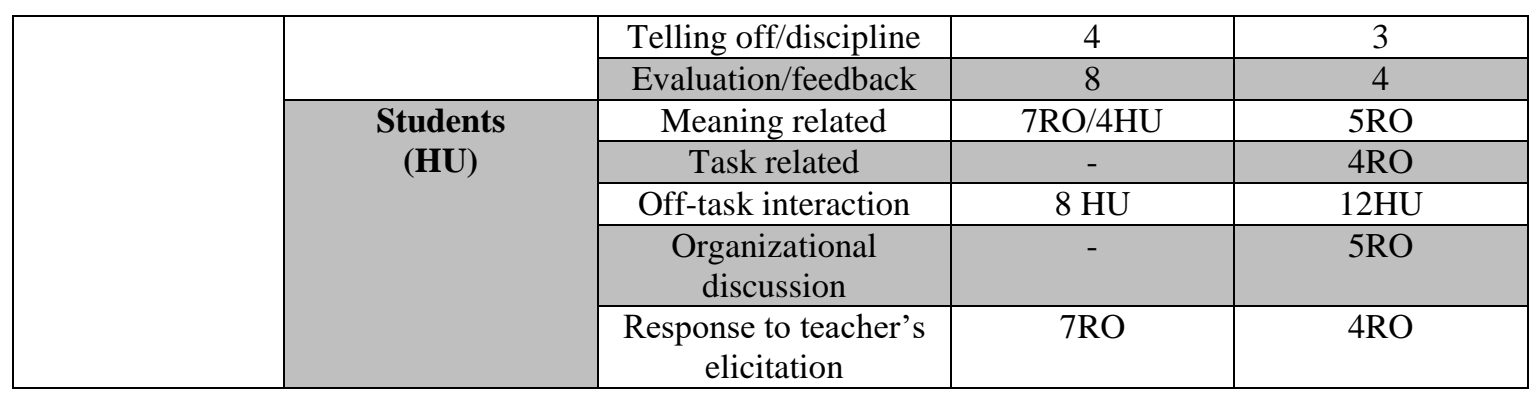

Table 8 presents the different languages present during the EFL classes observed in the two schools visited in Miercurea Ciuc/Csíkszereda. Results show similar tendencies to those found in Mureș/Maros county regarding the linguistic behaviour of classroom participants. While EFL classes in the monolingual school in Miercurea Ciuc/Csíkszereda involve the use of the target language mainly, the mixed school involves two non-target languages, Romanian and Hungarian.

Teacher's codeswitches in the monolingual school are limited to informal discussions at the beginning of the lesson (see extract 18) set outside the lesson frame. In these classes student-talk is characterised by a bilingual English-Hungarian language mode. Student initiated codeswitches appear, on the one hand, when students address the teacher and ask her to translate a Hungarian word into English; on the other hand, Hungarian is used when students are organized into small groups and they have to discuss about some topics given by the teacher. Although the teacher requires the use of English during group discussions and walks around the class to check students' language use, students tend to use Hungarian $(n=26)$ when they lack the necessary English vocabulary or when the discussion becomes heated. Applying Macaro's (2009) terms for teacher attitudes during communicative language classes, we can say that in case of EFL classes in the monolingual school in Miercurea Ciuc/Csíkszereda the teacher adopts a maximal position meaning that she uses the target language as much as possible, however the learning context cannot be characterized by exclusive target language use.

With regard to the mixed type school, one salient feature of teacher talk is the use of the Hungarian language, even though the teacher's mother tongue is Romanian. While most of his codeswitching involves Romanian, Hungarian is also used in case of translating unknown vocabulary and giving metalinguistic comments. The majority of codeswitches have the pedagogical function of providing metalinguistic comments $(n=22)$ and clarifying meaning $(n=19)$. In these classes students use Hungarian, their 
mother tongue, in case of off-task interaction among themselves $(n=19)$, but studentteacher interaction is characterised by a more frequent use of Romanian $(n=12)$ and the presence of some Hungarian words $(n=4)$. In spite of the fact that we cannot speak about a communicative language classroom in Macaro's (2009) terms, I believe his label of optimal position can be used to describe the EFL classrooms in the mixed type school visited in Miercurea Ciuc/Csíkszereda. Though Macaro's (2009) optimality theory needs to be addressed carefully - as it refers only to classes where the focus is on developing communicative competence in the target language and he relies on broad generalizations saying that an optimal use of codeswitching is up to teachers' judgement - combined with the theories and educational goals presented in Chapter 2 I suggest that the term optimal can be used to describe non-target language use of the teacher. The teacher did not only rely on non-target languages (Romanian and Hungarian) to ensure discipline or to organize the lesson, but he compared and contrasted these languages in order to draw students' attention upon the existing lexical and grammatical similarities and built on students' existing language systems.

Data from both counties reflect that while teacher talk in the two monolingual grammar schools visited can be characterised by monolingual target language use during English foreign language classes, teachers observed in the mixed type schools use non-target languages (Hungarian and/or Romanian) for example to translate unknown lexical items, clarify meaning, explain grammar, provide metalinguistic comments and make discipline.

Student talk is characterized by the use of the target language and two non-target languages (Romanian and Hungarian), though off-task and peer-group interactions are conducted in Hungarian.

Although data come from a total of 5 schools, results from both counties show the same tendency, according to which English teachers from monolingual grammar schools $(n=2)$ use exclusively the target language and require a monolingual language mode from their students. They control students' language behaviour overtly (manifested verbally, see extract 9) or covertly (through modelling monolingual language use). Even though these teachers' linguistic repertoire comprises all non-target languages also present in the students' repertoire, these other languages are not taken into account and are not exploited in the foreign language classroom. Teachers' linguistic behaviour in the context of monolingual grammar schools shows a target 
language only ideology in foreign language teaching. This ideology is not necessarily specific to the region of Transylvania, as a study by T. Balla and Dégi (in press) shows that teachers in monolingual grammar schools in Hungary have the same ideology and tendency to use target language only during EFL teaching.

In contrast to this, results from both counties show that in mixed type schools $(n=3)$, whether the teacher is Hungarian or Romanian, teachers use and even encourage a more varied use of the languages for a wider range of pedagogical purposes. Data collected in mixed type schools bring evidence for students' multicompetent language use, involving other non-target languages than their mother tongue in the process of English language acquisition.

One of the most visible differences can be observed between the two Romanian mother tongue English teachers. While the Romanian teacher in Mureș/Maros county uses only English and her mother tongue during the English classes, the Romanian teacher from Miercurea Ciuc/Csíkszereda uses both his mother tongue and the students' mother tongue in the course of his English lessons. The present distinction might be attributed to the different demographic characteristics of the two localities, Miercurea Ciuc/Csíkszereda representing a special setting where the minority Hungarian population constitutes the local majority, thus the Romanian teacher has acquired some knowledge of Hungarian. His knowledge of the students' mother tongue proved to be helpful during his EFL teaching activities, not only in case of meaning construction and co-construction shown in extracts 20 and 21, but also in case of comparing and contrasting the languages present in students' linguistic repertoire (extract 22).

\subsection{EFL classroom language use according to student interviews}

In addition to the data presented in the previous sections on teachers' perspectives concerning classroom language use and on natural classroom interaction, semistructured interviews were conducted with one or two volunteering students from each class in order to supplement data gained from the questionnaires (see 5.1) and classroom observation (see 5.2).

The interview questions were designed to provide data for research questions 1 and 3, namely, on classroom language use and students' beliefs regarding the usefulness and help of other languages when learning English as a third language. The interviews 
conducted with the students were structured around the following questions: What languages do you speak during the English lesson? What languages does the teacher use during an English class? In what language does your teacher give you the task instructions? What language do you use to ask the teacher and your classmates questions? What language do you use with your classmates when you have to work in small groups? If you haven't done your homework, what does your teacher say and in what language?

The interviewed subjects' perceptions confirm the validity of the classroom observation data. The interviewees' statements vary according to the classroom interactions observed, and differ according to the type of school and the mother tongue of their English teachers.

Interviewees with a Hungarian teacher say that English and Hungarian are used during the lessons and explanations are generally given in Hungarian and the examples in English.

Interviewer: Milyen nyelveket szoktatok használni órán?

Interviewee: A nyelvtant például magyarul magyarázzák el nekünk, a példamondatok angolul vannak.

"Interviewer: What languages do you usually use during an English class?

Interviewee: Grammar for example is explained to us in Hungarian, the example sentences are in English."

Besides grammar explanations, students also mention the use of Hungarian and Romanian in case of translation activities. Translation was predominant in the lesson of the Hungarian teacher in one of the mixed type schools (see section 5.2). The student interviewee from this class mentions the use of two non-target languages, Hungarian and Romanian. According to this student, non-target languages are used during translation activities.

Interviewer: Milyen más nyelveket használtok angol órán belül?

Interviewee: A magyart, és a románt is egyszer-egyszer.

Interviewer: Azt mire használjátok? 
Interviewee: Amikor nem tudjuk lefordítani magyarra, könnyebb románra, egyszerübb. Amikor forditunk órán, ha románul jut eszünkbe a szó, románul mondjuk.

"Interviewer: What other languages do you use during an English class?

Interviewee: Hungarian, and from time to time Romanian as well.

Interviewer: For what do you use it?

Interviewee: When we cannot translate something into Hungarian, it is easier to translate into Romanian. When we translate during the lesson, if the word comes to our mind in Romanian, we say it in Romanian."

The interviewee, as shown in extract 24, points out that Romanian is used during translation activities in cases when students cannot translate the given phrase or sentence into Hungarian. The student respondent also mentions that during translation activities Romanian lexical items are used when ' $a$ word comes to our mind in Romanian'.

English learners from the mixed type schools, whether they have a Romanian teacher or not, commented that in case of translation exercises or text/word translations they turn to the Romanian language saying that it is easier because the words are similar.

Könnyebb nekem angolról románra fordítani, mert könnyebben megtalálom a szó értelmét, magyarra pedig nehezebb, mert könnyebb angolról románra, mert hasonlítanak a szavak.

"It is easier for me to translate from English into Romanian, because I can find the meaning of the word more easily, it is harder into Hungarian, because it is easier from English into Romanian, because the words are similar."

According to interview extracts 24 and 25, Hungarian and Romanian have complementary roles within classroom translation activities. As discussed in section 3.2, the students' Hungarian native language does not show linguistic similarities with either Romanian (their second language) or English (their first foreign language). Romanian, on the other hand, is typologically closer to English than the students' Hungarian mother tongue, and many similarities can be traced between them, mainly on the lexical level. Extract 25 shows that students perceive the lexical similarities between the Romanian and English languages and supports previous findings (see Molnár, 2010a, 2010b) as it reveals that the interviewee relies on Romanian during translation. While 
translating English texts into Hungarian is considered to be 'harder', translating into Romanian is 'easier' due to the perceived lexical similarities.

Contrary to the above mentioned language behaviour in classes with Hungarian teachers, the two students from the monolingual schools stated that their teachers speak only English and they discuss the topics in English.

A tanárnö angolul beszél csak, angolul mondja el, hogy ö ahhoz a témához mit írna, vagy angolul kérdez minket.

"The teacher speaks only in English, she tells us in English what she would write on that topic, or she asks us in English."

Interview extracts 23-26 are provided as examples to support classroom observation results. Classroom recordings showed that teachers in the Hungarian monolingual grammar schools use exclusively the target language and require a monolingual, target language only language mode from the part of their students. Students interviewed from these classes also point out that teachers use only English. All lessons visited in the classrooms of these two teachers focused on developing students' speaking skills and involved communicative classroom activities like small group discussions or whole class debates. Therefore, during these classes I did not observe any pedagogical activities related to grammar.

On the other hand, lessons observed in the mixed type school involved reading activities and the teacher used the grammar-translation method extensively. Students read a text from their textbooks and translated it. In this case, classroom observation data contain codeswitching instances with translation purposes. However, student interviewees, when asked about the languages used during English lessons, recalled instances of both translation activities and grammar explanations.

Students who have Romanian teachers assert that the teacher usually gives explanations in Romanian and sometimes in English, and in case of misunderstandings or unclarities, teachers allow time for the better students to explain the matter to their peers in their mother tongue.

A tanárnö elmagyarázza románul, van amikor angolul, de van amikor csak románul és ha mégsem értjük akkor a jobb tanulók lefordítják. 
"The teacher explains it in Romanian, sometimes in English, but there are occasions when only in Romanian, and if we still don't understand it, then the better students translate it."

Extract 27 also supports classroom observation results showing that Romanian is used as a non-target language. It needs to be pointed out that the observed classroom involved Hungarian mother tongue students. Thus, the students' words 'if we still don't understand it' gain more sense. For Hungarian students, Romanian is their second language and this way their language competences may vary and they might not understand everything the teacher explains to them. Therefore, one meaning clarification strategy mentioned by the interviewee in extract 27 is the use of Hungarian. 'Better students' refers to students with higher language competences in Romanian and/or English, who explain the respective matter to their peers using the Hungarian language.

All students agree that receiving explanations in Hungarian or Romanian is beneficial as they understand things better.

Jó, ha magyarul magyaráznak. Olyan szempontból jobb lenne, ha angolul magyaráznának, hogy több angol ragadna ránk, de magyarul jobban megértjük.

"It is good that they [=the teachers] explain things in Hungarian. It would be better from that point of view that we would pick up more English, but we understand things better in Hungarian."

Jobb, ha románul magyaráznak, nem tudom, nekem úgy könnyebb. Könnyebben felfogok dolgokat.

"It is better if they [=the teachers] explain things in Romanian, I don't know, it's easier for me. I can understand things more easily."

Extracts 28 and 29 refer to the use of non-target languages for explanation purposes. Students' opinions, expressed in these two sample extracts, are, unanimously, that explanations given in non-target languages are helpful, and they use adjectives like 'good', 'better' and 'easier' to describe their positive attitude towards the use of Hungarian and Romanian for explanations. As discussed in chapter 2 of the present paper, many scholars (e.g. Cook, 2001; Swain and Lapkin, 2000) argue that the L1 or 
any other previously learnt language can be beneficial in foreign language teaching as the use of these non-target languages provide further opportunities for target language acquisition to take place (Anton and DiCamilla, 1999). Whether students' native language or the target language is best for giving explanations is a practical issue, but one argument for using the L1 for explanations might be efficiency of understanding by the students.

Besides grammar explanation and translation activities, students from mixed type schools ask for clarification or ask task related questions in Hungarian or, in case of a Romanian teacher, in Romanian (pointing out the fact that only good students ask questions in English), and their questions are answered in the language in which they asked the question. Again, the two teachers in the monolingual schools represent exceptions as they require students to ask any questions they have in English, and if not, students are required to repeat their questions in the target language.

(30)

Interviewer: Ha nem értetek valamit órán, egy feladatot vagy valamit, azt milyen nyelven kérditek meg?

Interviewee: Magyarul

Interviewer: És magyarul is válaszolnak nektek?

Interviewee: Igen. Mindenki magyarul kérdez és sokszor meg is szólítanak a tanárok, hogy akkor kérdezzük angolul.

"Interviewer: If you don't understand something during the class, a task or something, in what language do you ask about it?

Interviewee: In Hungarian.

Interviewer: And do you get the answers in Hungarian?

Interviewee: Yes. Everybody asks in Hungarian and teachers tell us many times to ask in English."

Interviewer: Ha valamit meg akarsz kérdezni, azt hogy kérded meg?

Interviewee: Hát románul is meg angolul is, attól függ, hogy ha tudom, hogy kell kérdezni, azt megkérdem, de általában románul kérdeznek, csak egyes jobb tanulók kérdeznek angolul.

"Interviewer: If you want to ask something, how do you ask it?

Interviewee: Well, in Romanian and English, it depends on whether I know how to ask it in English, but usually they ask in Romanian, only some better students ask in English." 
Interview extracts 30 and 31 refer to the languages used by students when they ask clarification questions from teachers and to the languages used by the teachers to answer these questions. Students' language use, as the two extracts above show, is participant related, i.e. it is a non-target language adjusted to the teacher's mother tongue. The interviewee whose English teacher is Hungarian reports that students ask questions in Hungarian and the teacher also uses Hungarian to answer; however, the student points out that the teacher encourages them to ask in English. The interviewee in extract 31 is the student of the Romanian teacher in Mureș/Maros county and states that students from that class use Romanian and English for asking questions from the teacher. She also highlights that mostly Romanian is used, and only 'better' students use the target language to ask questions. In extracts 27 and 31 above students refer to "better students" when speaking about translations and meaning clarification among peers. This classification of better and worse students referring to the level of their language competence reminds me of the results of a previous study on multilingualism perceived by foreign language learners presented in Chapter 3 (3.3.1.) of the dissertation. Learners consider themselves as incomplete or partial multilinguals because they are not satisfied with their language competence or the number of languages they speak, a belief strongly influenced by the monolingual perspective of the ideal and balanced language user.

Student interviews support classroom observation findings when interviewees speak about using Hungarian during group activities; they discuss the task in Hungarian and write down the answers or report in English.

Interviewer: Ha csoportos feladatok vannak, akkor mi történik?

Interviewee: Hát magyarul beszéljük meg, és leírjuk angolul.

"Interviewer: What happens if you have to work in groups?

Interviewee: We discuss the matter in Hungarian, and then we write it down in English."

Interviewer: Egymás között milyen nyelven beszélgettek?

Interviewee: Magyarul, van amikor angolul is, de magyarul.

"Interviewer: In what language do you speak among yourselves?

Interviewee: In Hungarian, sometimes in English, but in Hungarian.” 
Extracts 32 and 33 reflect on student language use during group works. Students, as shown in the sample interview extracts above, use Hungarian during group discussion and then they write or report their answers in English. This strategy of collaborative dialogue in Hungarian for the purpose of solving a given task is against teachers' requirements to use the target language during these group discussions (see section 5.1). However, it is in line with previous findings (see Nzwanga, 2000) and recently developed pedagogical practices (such as translanguaging) which argue that codeswitching is a normal feature of multilingual language use when participants share at least two languages and should be developed systematically at school (Cenoz and Gorter, 2013; Jones and Lewis, 2014; Cenoz and Gorter, 2015). The term translanguaging, coined by Cen Williams (1994), refers to exactly such a practice when students receive or discuss information in one language and use another language to present, discuss or write a summary. Furthermore, as it was shown in extract 27, students' native language provides scaffolding for the students to help each other.

Analysing the semi-structured interviews carried out with volunteering students from the classes visited, I focused on that part of the interview which provided data on classroom language use and students' opinions about it.

Interview results, as shown in excerpts 23-33 above, confirm classroom observation results and verify my previous observation regarding the distinction between monolingual and mixed type high schools. It can be said that interview data validate previous classroom observation findings according to which teachers visited in the two monolingual high schools tend to use exclusively the target language during EFL lessons and require an exclusive target language mode from their students. Contrary to teachers' language mode control and linguistic behaviour, it could also be seen that students use their mother tongue for informal discussions, asking the target language equivalent of certain lexical items and to discuss or clarify information during group works. Interviews confirm the multilingual characteristic of English classes in mixed type schools, on the one hand, explanations are provided in the teachers' mother tongue and, in case of Romanian teachers, time is allotted for the Hungarian peertranslation of these explanations if needed and, on the other hand, students are encouraged and allowed to use Romanian during translation activities or when clarifying unknown vocabulary. 
Student discourses reveal that codeswitching to non-target languages is helpful and 'easier'. Explanations given in Hungarian or Romanian are better understood (see extracts 28 and 29), and translating English words or text into Romanian, rather than into Hungarian, is considered easier (see extracts 24 and 25).

Target language proficiency is a recurrent issue within student interviews. Several interviews point out the importance of good competence in the target language and suggest that students who have better target language competences use the language for wider communicative purposes. For instance, in extract 31, the interviewee points out that 'only better students' ask questions in English. Furthermore, extract 27 reflects that again 'better students' translate and help their peers in understanding the teacher's explanations in English or Romanian.

\subsection{Overall discussion}

The aim of the present dissertation is to investigate the ways in which multilingualism is incorporated in the English foreign language classrooms in five Transylvanian schools visited. Therefore, a multi-perspective analysis of classroom language use has been carried out focusing on instances of codeswitching and the factors that might influence the linguistic behaviour and code choice within the EFL classroom.

The first research question addresses the issue of classroom language use, more specifically, the number of non-target languages present within the EFL class, the subjects who use these languages and, finally, the purposes for which these languages are used.

The above mentioned multi-perspective analysis is based on teachers' perceptions of classroom language use (questionnaire results), on analysing actual classroom interaction (observation) and students' perceptions and opinions regarding this issue (interview results).

By combining all the results we can gain valuable insight into current English foreign language education to Hungarian minority students in the five Transylvanian schools visited.

The questionnaire designed for teachers focuses mainly on teacher talk and teacher initiated codeswitching during EFL classes, complemented by questions 
regarding teachers' requirements on students' language use in case of greeting, asking and answering questions or in case of group activities. Questionnaire results come from all English teachers of the visited schools $(n=16)$ and show three types of language modes, namely, monolingual language mode using only English, bilingual language mode using non-target languages besides English, and monolingual language mode using only their own (the teachers') mother tongue. Monolingual target language use comprises pedagogical situations like greeting, asking/answering questions, and this is the language mode teachers require from students in case of small group activities. Nontarget languages are said to be used mainly in case of classroom management activities, grammar explanations, maintaining discipline and metalinguistic comments (making connections with other languages).

Looking at the classroom observation results, the picture becomes more complex, as the recordings show not only teacher initiated codeswitching but also student initiated codeswitching occurrences. One salient distinction between the questionnaire results and classroom observation findings refers to classroom management and maintaining discipline which requires a bilingual language mode. In these two situations teachers' mother tongue, rather than exclusive target language, becomes the most frequently used language. Similarly, asking and answering questions do not follow an only English monolingual language mode, as reported by teachers in the questionnaires, but even teacher initiated codeswitching instances occur in case of questions, mainly in case of student elicitation. With regard to student initiated codeswitching, students usually ask their questions in the teacher's mother tongue, and the teacher answers students' questions using both English and his/her mother tongue. Moreover, the language required by teachers during group work activities, as expressed in the questionnaire, is exclusive target language use. However, looking at classroom observation data it becomes evident that students use their mother tongue for discussing tasks in a group, and they give their answers or report in English.

Finally, looking at student interview results, these findings reveal the validity of classroom observation results, asking and answering questions requires indeed a bilingual language mode, and students report using their mother tongue during group work. 
In order to have a clearer view on all three sets of data collection results, in what follows I will provide a table summarizing the results on language use with regard to certain pedagogical functions.

Table 9. Overview of languages used for different pedagogical purposes according to the three different data collection results

\begin{tabular}{|c|c|c|c|c|}
\hline & $\begin{array}{l}\text { TEACHER } \\
\text { QUESTIONNAIRE }\end{array}$ & \multicolumn{2}{|c|}{ CLASSROOM OBSERVATION } & $\begin{array}{l}\text { STUDENT } \\
\text { INTERVIEWS }\end{array}$ \\
\hline ONLY EN & $\begin{array}{l}\text { Greeting } \\
\text { Asking/Answering } \\
\text { questions } \\
\text { Group activities }\end{array}$ & \multicolumn{2}{|c|}{$\begin{array}{l}\text { All pedagogical activities in } \\
\text { monolingual grammar schools }\end{array}$} & $\begin{array}{l}\text { All pedagogical } \\
\text { activities in } \\
\text { monolingual } \\
\text { grammar schools }\end{array}$ \\
\hline \multirow{2}{*}{$\begin{array}{l}\text { CSW/ } \\
\text { NON- } \\
\text { TARGET } \\
\text { LG. USE }\end{array}$} & \multirow{2}{*}{$\begin{array}{l}\text { Organizational matters } \\
\text { Grammar explanations } \\
\text { Metalinguistic } \\
\text { comments/connections } \\
\text { with other languages } \\
\text { Maintaining discipline }\end{array}$} & Teacher initiated & Student initiated & \multirow[t]{2}{*}{$\begin{array}{l}\text { Asking/answering } \\
\text { questions }\end{array}$} \\
\hline & & $\begin{array}{l}\text { Organizational } \\
\text { matters } \\
\text { Meaning and } \\
\text { task related } \\
\text { Grammar } \\
\text { explanation } \\
\text { Metalinguistic } \\
\text { comments } \\
\text { Telling off } \\
\text { Asking/question } \\
\text { s/elicitation } \\
\text { Evaluation/feed } \\
\text { back }\end{array}$ & $\begin{array}{l}\text { Organizational } \\
\text { matters } \\
\text { Meaning and } \\
\text { task related } \\
\text { Answering/respo } \\
\text { nse to elicitation } \\
\text { Signalling } \\
\text { difficulties }\end{array}$ & \\
\hline $\begin{array}{l}\text { ONLY } \\
\text { HU/RO }\end{array}$ & $\begin{array}{l}\text { Informal matters } \\
\text { Outside classroom } \\
\text { interaction } \\
\text { Unknown vocabulary } \\
\text { translation }\end{array}$ & $\begin{array}{l}\text { Unknown } \\
\text { vocabulary and } \\
\text { whole text } \\
\text { translation }\end{array}$ & $\begin{array}{l}\text { Informal matters } \\
\text { Off-task } \\
\text { interaction } \\
\text { Group activities } \\
\text { Unknown } \\
\text { vocabulary and } \\
\text { whole text } \\
\text { translation }\end{array}$ & $\begin{array}{l}\text { Grammar } \\
\text { explanations } \\
\text { Group activities } \\
\text { Unknown } \\
\text { vocabulary and } \\
\text { whole text } \\
\text { translation }\end{array}$ \\
\hline
\end{tabular}

Differences among the three types of data reflect upon the differences between teachers' beliefs regarding an ideal foreign language classroom, while classroom observation data, confirmed also by student interviews, reveal the actual practices during EFL classrooms. Teacher questionnaire results present teachers' perceptions on their language use and language requirements, which reflect that, even though teachers use non-target languages for several pruposes (grammar explanations, vocabulary translation and maintaining discipline), they require an exclusive target language mode from their students. Classroom observation data together with student interviews show 
greater variety of languages and results lead to the existence of several factors which might influence classroom language use in the classrooms visited, namely, the English teachers' proficiency in the students' native language and the type of school (monolingual versus mixed).

Taking into account previous research results regarding the use of non-target languages during foreign language instruction (see section 2.4.1), teachers' exclusive target language use and language control from the monolingual grammar schools suggest that teachers' beliefs concerning non-target language use promote a monolingual approach to foreign language teaching without making references to or using the learners' previously acquired languages. However, as presented in chapter 2, multicompetence and third language acquisition studies point out the problematic aspects of this target language-only approach based on the assumption that the language classroom is a multilingual environment, and classroom participants have several nontarget languages in their linguistic repertoire which are all involved in the language learning process. Moreover, languages in the students' minds are interdependent and interact with each other; therefore, adopting exclusive target language use seems unattainable.

We can see that even if some teachers expect an only English monolingual language mode during group work, these other languages are still activated during an English class and codeswitching instances do occur, as found is previous studies (e.g. Macaro, 2009; Hall and Cook, 2013), which similarly conclude that learners' first language does appear during EFL classes even in contexts where it is "ostensibly discouraged" (Hall and Cook, 2013: 10). I think that the non-occurrence of codeswitching on the part of the visited non-native speaker teachers would be unnatural - and if this happens (as in the case of the two teachers from the monolingual grammar schools), then it may be motivated by teachers' language teaching beliefs. I believe that for specific pedagogic functions the switch to another code (HU/RO) is eminently justifiable, and arguably preferable. For instance, extract 21 presented a situation where the teacher used Romanian and Hungarian to explain the English word hurdle. Explaining such domain-specific word using the target language only would have required a greater amount of time and effort on the part of the teacher. Thus, in case of such words translation is preferable. Furthermore, extract 22 shows a situation when grammar (the use of the passive voice in English) is explained by using both Hungarian 
and Romanian, and comparisons among the three languages were made. As discussed in section 3.2, students' native language presents hardly any linguistic similarities with the target language and, thus, I believe, the teacher's instructional practice involving a comparison of English and Romanian passive constructions and his metalinguistic comment regarding the absence of such grammatical construction in the students' native language is justifiable. Teachers' use of non-target languages in case of grammar explanations might occur in order to foster more efficient understanding. This is supported by data from several student interviews (see extracts 23, 28 and 29), which show students' preferences for non-target language grammar explanations.

Findings resulting from the three types of data, i.e. questionnaires, classroom observation and interviews, reveal that there are two major factors that influence linguistic behaviour and code choice within the English foreign language classroom in the five Transylvanian schools visited.

One factor affecting classroom language use is the type of school that students attend. As it was discussed in section 3.1.4 regarding the Romanian educational system with a focus on minority Hungarian education, there are three types of schools, i.e. monolingual Hungarian, monolingual Romanian and mixed type schools that Hungarian students can typically choose from. As my interest was to explore the EFL instruction of Hungarian minority students in high schools, I chose monolingual Hungarian high schools and mixed type school groups or vocational schools as the setting for my study. Results on classroom language use revealed the difference between these two types of schools. Teachers observed in monolingual Hungarian high schools adopt a monolingual language mode, teachers' classroom practices bring evidence of a target language only approach to English foreign language teaching, even though both students and teachers have other non-target languages in their linguistic repertoire which might be useful in the English language learning process. To be more specific, Romanian (which is the state language and, in most cases, the language of the everyday environment of the students' lives) is shared by both teachers and students, and, as shown in section 3.2, from the perspective of language typology, psychotypology and formality of learning context, it would certainly count as the most useful base language in the English L3 learning process. Meanwhile, teachers observed in the three mixed type schools included in the research allow for a wider range of language use attributed not only to the variety of the linguistic background of the classroom participants but to a 
more multilingual approach in language teaching. Teachers in mixed type schools encourage the use of other non-target languages besides students' mother tongue and promote a multilingual language mode during English foreign language instruction.

The second major factor influencing participants' linguistic behaviour during EFL classroom interactions is the English teachers' proficiency in their students' native language. As has been previously discussed in the present chapter, the minority language (Hungarian) is rarely acquired by Romanian majority speakers. Thus, the presence of a Romanian teacher in the English language classroom naturally triggers Romanian language use and although three languages are present in the language classroom, it does not follow that every participant in the classroom speaks all three languages. However, classroom observation results showed situations where Romanian was present without the teacher being Romanian, and there were also examples of a Romanian teacher using Hungarian for meaning clarification and grammar explanation. These two latter examples can be attributed to the specific linguistic environment of the two settings. In the first example, the presence of Romanian in a classroom with no Romanian classroom participant, the setting is the small locality in Mureș/Maros county, namely Luduș/Marosludas, where the Hungarian minority population constitutes only $23.2 \%$ of the total population. Thus, the setting is characterized by a dominant Romanian language population and the Romanian language, which might explain the presence of the Romanian language in the English language classroom. The second example, showing the case of a Romanian teacher using Hungarian for meaning clarification, could be again explained by looking at the linguistic environment of the locality in question. The Romanian teacher lives and teaches in Miercurea Ciuc/Csíkszereda, a town where the Hungarian population constitutes the local majority (78.5\%). Thus, the fact that Hungarian represents the dominant language in the region might explain the Hungarian knowledge of the teacher which is exploited during EFL instruction. 


\section{Teachers' beliefs regarding EFL classroom language use}

Previous research on teacher language use has been discussed in section 2.4.1 and shows that there are teachers who try to avoid the use of the L1 during EFL classes (Nzwanga, 2000; Macaro, 2001, 2009; Levine, 2009, 2011; Ife, 2008) and that they are more concerned about native-like pronunciation, which they think students are unable to replicate (Némethné Hock 2007, 81-82). However, classroom observation studies from Hungary (Nikolov 1999, 2000; Lugossy, 2003; Nagy, 2009; Nagy and Robertson, 2009) show that teachers' classroom language use involves students' first language. Moreover, studies concerning native and non-native teacher differences emphasize the advantages of non-native speaker language teachers based on the fact that they can benefit from students' native language (Barratt and Kontra, 2000; Medgyes, 1994, 2014). This argument is further supported by authors in the multicompetence (Cook, 2002, 2006) and third language acquisition fields (Jessner, 2001; Herdina and Jessner, 2002; Hufeisen, 2005) who propose that students' bilingualism should be exploited, and prior linguistic knowledge should be used in foreign language instruction.

With the above mentioned research results in mind, in what follows teachers' beliefs and preferences regarding EFL classroom language use will be presented and analysed. The analysis focuses on teachers' expected and practiced linguistic behaviour and on the explicit or implicit rules used by teachers to control classroom language behaviour also reflecting upon the educational goals of using non-target languages during EFL classrooms.

The two framework models constituting the basis of the present research propose some common educational goals connected to foreign language instruction. Within the multicompetence framework, Cook (2002:335) proposes that foreign language teaching aims should be related to the foreign language user and not the native speaker of the respective language. Moreover, Cook (2002) states that foreign language users use the language for several different functions, such as translation and codeswitching and thus, he proposes that language instruction should incorporate these language uses.

Researchers of multicompetence (Cook, 2002), third language acquisition (Jessner, 2003, 2008; Hufeisen, 2005) and authors of current educational studies (Mckay, 2003; Barratt and Kontra, 2000; Lee, 2000) stress the importance of teachers as 
role models, according to which teachers should be successful users of the target language and not native speakers. Non-native speaker language teachers are believed to be more efficient not only because they provide a real role model, but they can also help students regarding learning strategies, they can understand and even anticipate learner difficulties, and they can use their students' mother tongue to their advantage. Thus, a further proposal is the use of non-target languages during foreign language instruction suggesting that the reactivation of prior language knowledge in the classroom has a facilitative effect on language learning (Herdina and Jessner, 2002; Cummins, 2007; Cenoz and Gorter, 2015).

In recent years, numerous scholars have emphasized the problematic aspect of the ways some teachers understand the foreign language classroom. One of these aspects is that a monolingual set of norms and ideals is assumed and applied to classroom practices (Cook, 2001; Kramsch, 1998, 2009; Turnbull and O'Cain, 2009), and little pedagogical value is attached to non-target languages if they are not totally banned (Macaro, 2001).

Opposing the monolingual views, many scholars (Cook, 1991, 2001; Kramsch, 1998; Levine, 2003, 2005; Cenoz and Gorter, 2015) have demonstrated empirical evidence that the language classroom is a multilingual environment and argued that denying the role of other languages than the target language means ignoring a significant part of the foreign language acquisition process and of the learners' personal experiences.

Student codeswitching instances during EFL teaching and learning is often assumed to signal lack of proficiency in the target language. On the other hand, teacher initiated codeswitching is considered to serve important functions in the acquisition process. Therefore, Levine (2009) suggests that teachers should raise learners' awareness concerning the role of non-target languages and to discuss the purposes of codeswitching during a conversation.

Examining teachers' beliefs about EFL classroom language use is important because they might influence teachers' pedagogic decisions and help understand what happens in the classroom. Previous studies on teachers' beliefs regarding non-target language use (De Angelis, 2011; Hall and Cook, 2013; Håukas, 2016) show a discrepancy between teachers' language practices during classes and their attitude towards language use. While most teachers say that they use their students' mother 
tongue to explain grammar, vocabulary or to maintain discipline, they also state that they try to limit or exclude the use of non-target languages (Hall and Cook, 2013). A more recent study by Håukas (2016) concludes that even if teachers believe previous language knowledge to be helpful, they do not make references to such crosslinguistic similarities.

In the context of the present study, teachers' beliefs and ideals about language use in the EFL classroom can be derived from the teacher questionnaire results, teachers' linguistic behaviour during EFL teaching and finally the two recorded teacher interviews from Miercurea Ciuc/Csíkszereda. Therefore, all data will be taken into account and analysed focusing on teachers' beliefs and their linguistic behaviour.

Previous data revealed that the two major factors influencing linguistic behaviour during EFL classes are school type and the mother tongue of the teachers (see chapter 5), therefore, it is necessary to further analyse these aspects. On the basis of the existing set of data we can identify several teacher types which might be affected by the linguistic environment to greater or lesser degree. According to the results on classroom language use ( 7 teachers and 10 classes), three main teacher types can be identified: (i) Hungarian teachers adopting a monolingual approach to EFL teaching, (ii) Hungarian teachers allowing and using a bilingual (English-Hungarian) language mode during EFL teaching, and (iii) Romanian teachers using a bilingual (English-Romanian) language mode during EFL teaching. These teacher types presented above show that English teachers, if they use any other language besides the target language, use their own mother tongue. These three teacher types can be influenced by the wider sociolinguistic context in which the school is situated. Such influence, be it a Romanian or Hungarian majority language environment, means an additional non-target language which is introduced to facilitate the acquisition process and the teaching activities. In the case of the mixed type school from Luduș/Marosludas, codeswitching to Romanian is initiated by the students to help the translation activity required by the teacher. The other example comes from Miercurea Ciuc/Csíkszereda, a Hungarian majority language environment, where the Romanian native speaker teacher initiates codeswitching to Hungarian in order to facilitate students' understanding of the grammatical structure explained. In both cases, codeswitching to a language other than the speaker's native language is introduced to foster success in certain classroom activities. Both codeswitching situations support multicompetence and third language acquisition 
theories, according to which languages in the speakers' mind are in interaction, and they all contribute to the language acquisition process.

Even though questionnaire results on teacher language use during English lessons clearly show the use of other non-target languages beside the teachers' mother tongue - in the case of Hungarian teachers, Romanian is mentioned, and in the case of Romanian teachers, French - this was not validated either by classroom observations or by student interviews. Grammar explanations, metalinguistic comments do appear, but the only non-target language present in these pedagogical situations is the teachers' mother tongue, which is used to explain English grammar in another, more accessible language. Connections with other languages and raising students' awareness regarding the similarities between the language systems was found only in the exceptional case of the Romanian teacher in Miercurea Ciuc/Csíkszereda, who facilitated meaning making process in case of grammar explanation and unknown vocabulary by drawing students' attention to the lexical and structural similarities between English and Romanian.

Questionnaire results demonstrate the beliefs and ideals of English language teachers concerning their classroom language use. According to these results, teachers use exclusive target language only in case of greetings and asking/answering questions, but during other activities they use both the target language and their mother tongue (grammar explanations, translations of unknown vocabulary items, making connections with other languages, making discipline and informal, outside classroom interactions). However, teachers require an exclusive use of English (in greeting, asking/answering questions, and group work). Extract 8, presented in section 5.1, reflects the teacher's personal observation of classroom language use and points out that students have "the mistaken reflex of using Romanian instead of English'. According to this extract, the teacher considers students' use of Romanian as a mistake and not a natural feature of multilingual speech. The word 'reflex' used by the teacher suggests that this phenomenon occurs frequently in case of her students, and that codeswitching to Romanian instead of using the target language is unconscious. Based on multicompetence and third language acquisition theories, students' languages in their linguistic repertoire are not compartmentalized but are in constant interaction. Furthermore, Williams and Hammarberg's 1998 study shows that speakers may assign different values to their languages, and thus, a second language, similarly to a third language, can have the value of a non-native language. This way, using Romanian 
instead of English can be considered a natural occurrence in case of multilingual speech production and not a 'mistake'. Extract 8 also supports empirical observations showing that even though teachers try to maintain a target language only approach (see teacher questionnaire results discussed in section 5.1 and classroom observation data in section 5.2), students' previously learnt languages still emerge in the language classroom, and these languages cannot be simply excluded.

Classroom observation data also brings evidence showing teachers' linguistic behaviour and the educational purposes of using non-target languages in the EFL classroom.

Extract 9 has already been presented in section 5.1 as an example of the only codeswitching instance initiated by students in the Hungarian monolingual grammar school in Mureș/Maros county. Extract 34 (originally presented as extract 9 in section 5.1) can also be analysed in this section, looking at the authoritarian way the teacher urges her students to use English.

$<$ Something is wrong with the tap and the teacher asks why she cannot turn it off>

T: but I've been using it FOR YEARS

S: igen, de elzárták, amikor lefertötlenitették az osztályt

T: Can't you speak English?

S: No

T: NO? <laughter> So it is very very hot in here so some disinfectant has been used on it and is not working

" $<$ Something is wrong with the tap and the teacher asks why she cannot turn it off $>$

T: but I've been using it FOR YEARS

S: Yes, but it was turned off when the classroom was disinfected

T: Can't you speak English?

S: No

T: NO? <laughter> So it is very very hot in here so some disinfectant has been used on it and is not working"

The extract grasps the only moment when students use their L1 in the English classroom. The teacher reaction to students' L1 use sounds rather harsh, however the phrase 'Can't you speak English' followed by the target language repetition of the student's Hungarian comment, can be interpreted as scaffolding on the learner's comment in the target language. This language situation reflects teacher's language 
choice and her preference regarding the language of the classroom. However, from an educational perspective such a language choice can be explained by the teacher's pedagogical aim to provide sufficient linguistic input for her students and to seize every opportunity (even in informal situations, outside the lesson frame) to teach new vocabulary.

Another example of teachers' almost exclusive target language use is provided by the example below. It is an example taken from the English lessons of the teacher from the Hungarian monolingual grammar school from Miercurea Ciuc/Csíkszereda. In this situation the teacher herself uses Hungarian; nevertheless, it was used at the beginning of a lesson, outside the lesson frame. Extract 35 (originally presented as extract 18 in section 5.1 above) is an example of teacher initiated codeswitching for informal, classroom management purposes.

S: Van aki nem akar jönni/

T: kötelezö tevékenység és az lenne a lényeg, hogy utolsó kiránduláson mindenki ott legyen/Okay/Can we start?

"S: There are some who don't want to come/

$\mathrm{T}$ : it is an obligatory activity and it would be important that everybody should be there on the last trip/Okay/Can we start?"

The informal talk (organizing a trip) was deliberately separated from the rest of the classroom activities as it was not part of the lesson. The fact that this talk is delimited from the rest of the lesson is shown by the discourse marker 'okay', followed by the instruction of the teacher 'can we start'. During English lessons, the teacher uses only English. Moreover, students' Hungarian clarification and meaning related questions are interrupted and translated into English as shown in extract 36 below.

S1: Hogy mondják, hogy=

T: $\quad=$ What is the English word for

S1: What is the English word for kiszolgáló (.)

S2: shop assistant

S1: shop assistant

T: so we need shop assistants 
"S1: What is the English word for =

$\mathrm{T}$ : $\quad=$ What is the English word for

S1: What is the English word for shop assistant (.)

S2: shop assistant

S1: shop assistant

T: so we need shop assistants"

Extracts 34, 35 and 36 above express the target-language-only preference of English teachers in Hungarian monolingual schools. Extract 34 shows the teacher's explicit and overt communication regarding her language preferences during the EFL lesson. Extracts 35 and 36 do not contain explicit expressions of the teacher's language preferences, however, the discourse markers separating informal discussions and the actual EFL lesson and the teachers controlling actions as she interrupts the Hungarian speech of the student, repeating it in English show the teacher's expectations regarding target language only classroom environment.

In contrast with these examples, English teachers visited in the mixed type schools show a more flexible approach towards language use and linguistic behaviour within the English lesson. On the one hand, teachers' own language use is characterized by (at least) bilingual, English-Hungarian/Romanian, speech; on the other hand students' are not prevented from using their other non-target languages present in their linguistic repertoire. In case of translation activities (common in case of the Hungarian teacher in the mixed type school from Luduș/Marosludas) students are encouraged to use Romanian as seen in extract 37 and 38 (presented originally as extracts 14 and 20, respectively, in section 5.1 above).

S: Annyi pénze van, hogy errr(.)/

T: Eltörölhetnél a harmadik világ/

S: Ha akarnál nem tudom ezt jól

T: dehogynem, csak nyugodtan

(...)

S: imprumut

T: adósság/ Eltörölhetné a harmadik világ/

S: adósságát, ha akarnál

"S: He has enough money to errr (.)/

$\mathrm{T}$ : abolish/ the third world/

$\mathrm{S}$ : if he wanted/ I don't know this well

$\mathrm{T}$ : Of course you do, go on

(...)

S: debt (RO) 
T: debt/ He could abolish the third world's/

S: debt if he wanted to/"

S1: Ce inseamnă deficiency in these nutrients?/

T: Try to translate it into Romanian, the words are just like in Romanian/

S1: $\operatorname{errr}(\ldots)$

S2: deficit?/

T: Da, și ce înseamnă deficit?/

S2: hiányosság, hiány/

S1: lack of something?/

T: Yes, that's it/

"S1: What does deficiency in nutrients mean?/

T: Try to translate it into Romanian, the words are just like in Romanian/

S1: errr (...)

S2: deficiency?

$\mathrm{T}$ : Yes, and what does deficiency mean?

S2: deficiency, lack

S1: lack of something?/

T: Yes, that's it/"

Both cases present situations of translation of an unknown English word and meaning making where students signal their lack of proficiency in translating or understanding specific vocabulary items. In extract 14 the student's hesitation and her negative selfevaluation regarding the ability to translate the English word loan is followed by the teacher's eliciting and encouraging words. Finally, the student comes up with the Romanian translation of the word, which is repeated in Hungarian by the teacher. The teacher accepts the Romanian translation and helps the student by providing the Hungarian translation of the word. In extract 38 the teacher acts more consciously, his aim being to raise students' awareness regarding the lexical similarity between English and Romanian. Thus, he encourages students to think primarily of the Romanian translation of the word calling students' attention that the English word is "just like in Romanian". One student comes up with the Romanian version of the English word and the Hungarian translation of it, which helps the first student to give an English synonym for the problematic word deficiency.

While both episodes, presented in extracts 37 and 38, indicate the flexible approach of the teachers regarding language use, only extracts 38 proves the teacher's aim to raise students' awareness regarding English-Romanian lexical similarities. 
In what follows, post-observational interview results carried out with the two teachers from Miercurea Ciuc/Csíkszereda are analysed. After conducting classroom observation recordings in the two schools, post-observational semi-structured interviews were carried out with the two English teachers. First we (the teacher and I) looked at one of the recordings, and then through reflective questions I asked the teacher about her linguistic behaviour and practices within the English lesson.

The teacher interview results show that teachers were aware of their language use and language behaviour within the English class, moreover, they proved a conscious behaviour which was explained in the course of the interview.

Analysing the interview with the Hungarian mother tongue English teacher from the monolingual school it became clear that even though her linguistic repertoire contains languages such as Hungarian, Romanian, English, German and a beginning level Italian, during her English classes she speaks only English.

T: Csak angolt használok, minél több angolt és kerülöm a magyar nyelv használatát (.) mint ott az órán is, inkább körülírom vagy szinonimát keresek angolul és azt próbálom megszoktatni velük, hogy ök is, ha nem tudják a szót, akkor magyarázzák el angolul. Órákon kívül, az iskolán kívül nem nagyon van lehetöségük angolul beszélni, ezért mindent megteszek, hogy a lehetö legtöbbet beszéljünk angolul és kerüljük a más nyelvek használatát.

"I use only English, as much English as possible, and I try not to use the Hungarian language (.) like in that class, I rather explain or find an English synonym and I try to make them get used to explaining words in English, if they don't know the exact word. Outside of English classes and the school, they don't really have the opportunity to speak English, that's why I do all I can to speak as much English as possible and to avoid to use of other languages."

The interview excerpt 39 above not only validates the teacher's observed language behaviour, but the teacher provides an explanation concerning her target language only approach to English foreign language teaching. She supports her language behaviour and control expressing her concern regarding the limited possibility of her students to use and speak the language. Thus, by offering students an English-only classroom context, the teacher wishes to provide them with possibilities to use the language, to maximize target language exposure. Yet, as previously discussed, the classroom context represents a multilingual environment in which classroom participants share a number 
of different languages. Moreover, the limited number of EFL classes per week (1-3) and the lingua franca context as noted by the teacher as well - 'they don't really have the possibility to speak English' - do not support the teacher's monolingual set of norms that she consciously applies.

The interview with the Romanian teacher from the mixed type school also proves that the teacher's linguistic behaviour and practice is conscious, and he deliberately designs his lesson so as to teach English in relation with other languages. He considers that students' rich linguistic repertoire (Hungarian, Romanian, English and French) is an asset for further language learning. As in the case of the Hungarian teacher, we (the teacher and I) watched the recording of one of his English lessons. He justifies his teaching practice stating that grammar explanations in Romanian and giving the Romanian equivalent of a grammatical term helps students arrange concepts in their minds (extract 40).

T: La gramatică dau tot timpul echivalentul în limba română, să le aranjeze ei puțin în minte și îi ajută să facă legăturile (.) aşa văd eu.

"In case of grammar I always give the equivalents in Romanian, for them to be able to arrange them a bit in their mind, and it helps them to establish the connections (.) That's how I see things."

Furthermore, on the basis of the student feedbacks, the Romanian teacher says that students are contented and even surprised when they hear how much similarity there is between the languages they know.

T: Fac legături mai mult cu limba română și cu franceza, îi mai întreb și pe ei cum ar fi, dacă văd că este ceva mai apropiat. Copii sunt încântați când aud că acest cuvânt este așa și în limba franceză (.) mai mult însă cu româna, cum ar fi 'obedient', avem și în limba română, sau 'persuade'. In cazul cuvintelor 'confortabil' și 'comfortable' discutăm dacă se scrie cu m sau n, cum e în limba română și cum e în englezăa. Multe legături aș fi putut face între limba germană dacă ar învăța, dacă ar fi făcut germană.

"I make connections mainly with Romanian and French, I usually ask them how it would be in the other language, if I can see that there is some connection. Children are contented when they hear that this word is similar to that in French (.) however, I make more connections with Romanian, as 'obedient', we have it in Romanian as well, or 'persuade'. In case of 'confortabil' and 'comfortable' we discuss if it is written with an $\mathrm{m}$ 
or n, how we write it in Romanian and how it is written in English. I could have made more connections with German if they learnt the language, if they had learnt it before."

The above interview extract shows the conscious teaching practice of the teacher as he points out similarities between the languages students know, brings examples of English-Romanian cognates, and he discusses the spelling of the word in each language. $\mathrm{He}$ is also aware of the typological similarities between English and German, however that school offers French as a second foreign language and, therefore, students have no German language knowledge.

The aim of the present section has been to reflect upon teachers' beliefs and preferences regarding language use in the EFL classroom, therefore teacher questionnaire data and classroom observation transcripts have been analysed focusing on these issues. Additionally, these results - already presented in chapter 5.1 and 5.2 before - have been complemented by the analysis of the two post-observational interviews carried out with the participant teachers from Miercurea Ciuc/Csíkszereda. The interview analyses were useful, in the sense that they validated my interpretations of the classroom observation results and they provided me with further explanations concerning teachers' language teaching approaches present in the EFL classrooms.

Teachers who prefer the exclusive use of the target language during English classes seem to follow the prevailing communicative language teaching method, which has been predominant since the 1970s (Appia, 2013), and suggests that in the interest of successful acquisition, target language alone should be used within the classroom - an idea that is accepted and favoured by the two teachers from the monolingual grammar schools visited. As the post-observational teacher interview results show, teachers support their view with the fact that students have limited possibilities to speak the target language outside school. Therefore, their aim is to provide sufficient input and a target language only learning context for students to ensure successful acquisition of the target language.

However, a number of recent studies in the field of education (Ife, 2008; Alptekin, 2010; Cummins, 2001) suggest that creating such monolingual, target language only microcosm of native speaker context deprives students from rewards and motivation because the target language has no immediate or intrinsic relevance to students' lives. In such contexts, where exposure to the target language is usually 
minimal or non-existent, target language students should benefit from other instructional strategies that facilitate the foreign language acquisition process and expand the impact of comprehensible input (Cummins, 2001: 70). Moreover, Alptekin (2010: 98) argues that for EFL learners who will use English mostly in lingua franca settings, a successful bilingual teacher, preferably one who knows the leaners' native language, would be more relevant, as such a role model will help develop students' social experience with English in various local and international contexts through a multicompetent perspective. Similarly, Ife (2008: 80) suggests that a method using target language only input has its disadvantages at the beginning and elementary levels, as it slows down the learning process, and it is not always well received by linguistically experienced learners who have already developed some metacognitive awareness and, as a result, seek rules and explanations.

Teachers who use non-target languages during their English classes were ecountered in mixed type schools. In the three mixed type schools visited, teachers not only used other languages besides English, but they also encouraged their students to use other languages for meaning making and, in one case, for contrasting languages. The educational goals formulated within the framework of the two theories (multicompetences and DMM) presented in chapter 2 highlight the importance of previously acquired languages in the language learning and teaching process and emphasize that teaching strategies focusing on linguistic similarities/differences and explicit cultural and language comparisons enhance learners' metalinguistic awareness and language learning strategies.

However, it needs to be pointed out that teacher initiated codeswitching occurences are not systematic as pointed out by several studies (Levine, 2011; Hall and Cook, 2013), but random, and in most cases non-target languages are used for meaning making and translation, rather than pointing at crosslinguistic similarities or to make references to other language systems. Moreover, some teacher initiated codeswitching instances simply suggest an overuse of the classroom lingua franca (see extracts 10, 11, 12) instead of using appropriate scaffolding. Therefore, the pedagogical aims of such multilingual language behaviour are questionable. 


\section{Learners' beliefs regarding the role of previously acquired languages in the foreign language learning process}

Several sections of chapter 2 argued for the importance of previous linguistic knowledge and language learning experience in the foreign language learning process, and section 2.2.1 presented several factors influencing the acquisition of a third language out of which the effects of cross-linguistic interaction have been considered as one of the major factors. Moreover, several researchers (see Ringbom, 2007; Paradowski, 2008) state that learners look for similarities and try to establish connections between previous and new knowledge as part of their natural learning process. Thus, the third research question focuses on learners' beliefs regarding the use of non-target languages during foreign language learning and the type of languages students consider as helpful in learning English.

Research on multilingualism argues that in contrast to monolinguals, multilinguals have a different knowledge of their previously acquired languages and a different kind of language awareness (Edwards and Dewaele, 2007; Jessner, 2006). Moreover, both theoretical concepts (multicompetence and the DMM) constituting the base of the present research indicate a positive effect of bilingualism on further language learning and this positive effect is linked to the learners' metalinguistic awareness and language learning strategies. In Jessner's (2006) definition regarding linguistic awareness we can find two sub-components, cross-linguistic awareness and metalinguistic awareness. While metalinguistic awareness resembles James's (1996) definition, cross-linguistic awareness means learners' unconscious or explicit realization that there are connections among the languages they know (see also Jessner, 2008; Aronin and Hufeisen, 2009). According to this definition, students' prior language learning experience facilitates learners to develop an enhanced linguistic awareness. Moreover, an experienced learner is considered to be more aware of the structural similarities and differences between languages, and he/she is able to expand his/her repertoire of language learning strategies (Jessner, 2008; Veronique, 2010).

Although new approaches to multilingual education describe how to raise students' awareness of other languages and how to make use of prior linguistic knowledge in the classroom (see e.g. Hufeisen and Lindemann, 1998; Cenoz, Hufeisen 
and Jessner, 2003; Cenoz and Gorter, 2014, 2015), there is still little evidence for teachers exploiting the relationships between languages in a systematic way. James (1996: 140) suggests that language awareness activities should connect the different languages in the learners' minds, and teachers should raise leaner awareness by using non-target languages (see also Levine, 2009). In line with these suggestions, Barratt and Kontra (2000) emphasize the value of non-native-speaker teachers who can encourage students by making useful comparisons and contrasts with the learners' other languages and thus help them to develop their metalinguistic awareness.

Bearing in mind the above mentioned language teaching proposals and the multicompetence and DMM theories discussed in chapter 2, the aim of the present chapter is to explore the learner's belief regarding the role of non-target languages in learning English as a third language.

In order to gain an insight into students' beliefs and language awareness, semistructured one-to-one and group interviews were carried out with students from the visited classes. Interview data come from 14 student interviews, each of which lasted between 30 and 45 minutes. For the purposes of the present chapter I will focus on those parts of the interviews which refer to learners' personal language use, their strategies during translation, reading or writing tasks, how they find the meaning of a word or whether any of their languages help them in their learning process.

As previous studies (Iațcu, 2000; Molnár, 2010a, 2010c; Dégi, 2010) have shown, in the case of Transylvanian Hungarian minority learners of English, Romanian can be considered as the most available source language in the acquisition of English, as it is typologically closer than their Hungarian mother tongue, and learners also perceive Romanian to be closer to English, especially regarding lexical items. Student interview results provide further evidence in the sense that 6 interview participants mentioned Romanian as resembling English not only on the lexical level but also on the level of syntax. Romanian language knowledge is mentioned as an asset concerning translation tasks, vocabulary learning, understanding and deducing the meaning of new words during reading activities, and, on the level of morphology, perfect and continuous tenses were mentioned.

Reflecting on students' strategies with regard to the understanding of new lexical items, interview results show that in all cases students' first attempt in understanding a 
new word consists in trying to deduce the meaning of the word from the context and from other languages.

Interviewer: Ha találkozol olyan szóval, amit nem ismersz, mit szoktál csinálni?

Student: Elöbb következtetek, ha nem megy, megnézem a szótárban.

Interviewer: Hogyan következtetsz?

Student: Van amikor emlékeztet valamire a szó, van, hogy hasonlít valamelyik más nyelvre, általában a románra, nagyon sok szó hasonlít a románra.

"I: If you come across a word you don't know, what do you do?

S: First, I try to deduce the meaning, if it doesn't work, I look it up in a dictionary.

I: How do you deduce the meaning?

S: Sometimes the word reminds me of something, or sometimes it resembles some other language, usually Romanian, a lot of words are similar in Romanian."

S: Amikor nem tudok egy szót, akkor mindig elkezdek gondolkozni, hogy ez milyen szóra hasonlít valami más nyelvben, vagy van olyan, hogy életemben nem találkoztam azelött azzal a szóval és mégis tudom mit jelent, mert hasonlít valamelyik másik nyelvre.

"When I don't know a word, I always start thinking, how is that word in another language, or there are times when I haven't seen that word before in my life, but I know what it means because it is similar to some other language."

While all students from the mixed type schools $(n=6)$ try to understand the meaning of a new word by looking for similar words in Romanian, the students from the monolingual schools $(n=8)$ make a general statement about their meaning making strategies (see interview extract 43 above), and try to figure out the meaning of a word by searching its equivalents in 'some other language'.

The most surprising observation for me was the difference between monolingual and mixed type school students' beliefs. Even though their linguistic repertoire contains the same languages (differences might occur in their fourth language: German or French), only 6 participants mentioned Romanian as a useful language which helps their English language acquisition. The monolingual school students do not mention their Romanian language knowledge at all, instead they refer to German, and the way their English knowledge helps them in acquiring German.

Chapters 5 and 6 argued for the existence of three determining factors regarding language use and code choice in the EFL classroom. These influencing factors were as follows: the school type (monolingual versus mixed), teachers' proficiency in the 
students' native language, and teacher's preferences (explicit or implicit) regarding classroom language use. According to these findings and the differences perceived in case of students attending a monolingual or mixed type school, we can presume that teachers' linguistic behaviour and the specific instructional setting (school type) have a great influence on students' beliefs regarding the role of non-target languages in learning English. In other words, all 14 students seem to have a higher or lower level of language awareness, but the selected source or base language might depend on the linguistic behaviour of the foreign language teacher and the schools' linguistic environment.

\subsection{Leaners' beliefs in mixed-type schools}

Out of the 14 interviewed students, those who have a greater exposure to the Romanian language - either by having a Romanian teacher or by attending a mixed type school in a Romanian majority language context - tend to be more aware of the linguistic similarities between Romanian and English. Whether their teachers drew their attention to the linguistic similarities between the two languages or not, these students recall the help of their Romanian language knowledge in a variety of learning situations, such as translating texts and understanding new words during reading activities and learning new vocabulary items.

Interview extracts 44-47 below show some examples of students' perceptions concerning the help of Romanian in learning English.

Könnyebb nekem angolról románra fordítani, mert könnyebben megtalálom a szó értelmét, magyarra pedig nehezebb, mert könnyebb angolról románra, mert hasonlitanak a szavak.

"It is easier for me to translate from English into Romanian, because it is easier to find the meaning of the word; into Hungarian it is more difficult, because it is easier from English into Romanian, because the words are similar."

Szerintem a román nyelv segít nekem leginkább az angol tanulásban, mert azt már régóta tanulom, és sok szó van az angolban, ami románul is ugyanúgy van. Most, hogy a líceumban franciát is tanulok, ott is a román segít. 
"I think Romanian helps me more in learning English because I have been learning it for a long time and there are a lot of words in English that are the same in Romanian. Now that I am learning French as well in high school, Romanian helps me there, too."

A román sokat segít az angol tanulásban, például amikor megtanultam románból az igeidöket, utána angolból egy kicsit románul is gondolkoztam és a románhoz hasonlitottam, amikor tanultam például a past continuous-t.

"Romanian helps a lot in learning English, for example when I learnt the tenses in Romanian, then in English I was thinking a bit in Romanian and I compared it to Romanian, for example when I learnt the past continuous."

Moreover, we can find situations when students point out that the strategies they use in target language reception (understand and figure out the meaning of unknown vocabulary items) or target language production were taught by their English teacher, who advised them to search for similar words in Romanian (see extract 47).

Az iskolában nem, de jártam angolból magánórákra és ott a tanárnő mindig azt mondta, hogy ha nem tudjuk magyarul a szót vagy angolul, akkor gondoljunk a románra és az tényleg segít, szoktam is alkalmazni, amikor nem tudok angolul egy szót, akkor gondolok románra.

"Not in school, but I had private English lessons and there the teacher always told me to think of Romanian when I don't know a word in English or Hungarian and that really helps, I use this when I don't know a word in English, then I think of Romanian.”

Interview extracts 44-47 above bring examples from the interview data of 6 students (out of the total 14 student interviewees), in which Romanian represents an aid in the case of vocabulary, due to the existing cognates - named by students as 'words that are similar'. It is interesting how cognates in the learner's L2 (Romanian) and L3 (English), mentioned as a resource already in section 3.2 of the present thesis, are noticed by the students and perceived as a useful strategy in foreign language learning. The perceived similarities between languages can represent further evidence for Ringbom's (2007: 1) statement that language learners when learning a new language tend to rely on their prior knowledge and connect new elements to whatever linguistic or other knowledge that they have. 


\subsection{Leaners' beliefs in monolingual high schools}

When asked the same questions, students from the monolingual high school spoke generally about the similarities between English and 'some other language' (see extract 43) or two students immediately recalled their German language learning experiences. Therefore, these students mention English as a source language in learning German, saying that English helps because tenses in English are more similar to German and there are a lot of cognates. These two students' awareness concerning English-German typological similarity might be influenced by their German language teacher, who does not speak Hungarian and the language of instruction during German classes is English (see extract 48 below). Students also reveal some of the teaching strategies used by the teacher who often draws comparisons between German and English.

A német tanárnö, aki nem tud magyarul csak angolul, elmagyarázza angolul a nyelvtant és az igeidöknél szokta mondani, hogy ez pont olyan, mint az angolban, mert magyarban nincsenek ilyen igeidök és úgy jobban megértjük. Segít ez a hasonlítgatás, mert a magyarban nincs ilyen, hogy plusquamperfekt angolban viszont van Past perfect és akkor van egy ilyen viszonyítási alap.

"The German teacher, who doesn't speak Hungarian, only English, explains to us the grammar in English, and in case of the tenses she says that this is the same as in English, because in Hungarian we don't have such tenses and we understand it better this way. This comparing helps because in Hungarian there is no such thing as plusquamperfekt but in English there is the Past perfect and we have some point of reference."

Moreover, the two students' linguistic awareness is reflected in their contrastive approach applied to their L3 English and L4 German, in the way they notice and discover lexical similarities between German and English vocabulary items and also draw my attention to the existence of false friends, 'words which have almost the same form but their meaning is completely different' (see extract 49).

Nagyon sok szó van az angolban, ami hasonlít a német szavakhoz. Ahogy többet kezdek tudni németböl, látom, hogy vannak olyan szavak, amelyeknek hasonló a kiejtésük és hasonlóan is irják, viszont vannak olyan szavak is, amelyeknek majdnem ugyanaz a formája viszont teljesen más a jelentése, mint a német 'bekommen', amit azt jelenti, hogy kapni és az angol 'become', ami viszont azt jelenti, hogy valamivé válni. 
"There are a lot of words in English that are similar to the German words. As I am getting to know more and more German, I can see that there are words that have similar pronunciation and similar spelling, but there are also words which have almost the same form but their meaning is completely different, like German 'bekommen', which means to get something, and English 'become' which means to grow or turn into something."

Interview extract 49 above shows the way students discover cognates and false friends while they learn two typologically close languages. Furthermore, one of the interview participants also reveals that she was able to discover false friends after getting to know the target language more. Her words bring further evidence to what has been described in section 2.3.2 regarding the effects on cross-linguistic influence. Williams and Hammarberg (1998) and DeAngelis (2007) all suggest that a certain language proficiency in both the target language and source language is necessary in order for cross-linguistic influence to take place. The student here also stresses that only as she became more fluent in the target language was she capable of discovering false friends.

Student interview results presented above suggest that in the course of the foreign language learning process students tend to rely on those languages in which they are more proficient or languages they are exposed to the most. Interview data brought further evidence that in the case of the five schools visited, language teachers's beliefs and preferences and the school context play an important role in the EFL classroom language use and students' perceptions regarding the role of non-target languages during English language acquisition. On the one hand, teachers from mixed type schools, who allow and practise multiple language use during the EFL lesson, enhance students' linguistic awareness and, as these students have a greater exposure to Romanian either because it is their teacher's mother tongue or because of the school context, they perceive Romanian as being typologically closer to English and have the tendency to rely on Romanian as a source language in learning English. On the other hand, teachers from monolingual Hungarian grammar schools set and maintain a monolingual target language only linguistic behaviour during EFL classes, therefore students from these classes do not even mention Romanian as aiding EFL learning even though Romanian is present in their linguistic repertoire. However, these students refer to their German language learning and the way their English L3 knowledge helps them in acquiring German L4. Students' linguistic awareness concerning EnglishGerman typological closeness is fostered by the German language teacher's teaching practices, according to which she compares English and German grammatical system. 
Interview extracts 44-49 above provide evidence not solely to the enhancing effect of using multiple languages during target language education but also show a certain degree of learners' linguistic awareness.

In the light of the interview findings concerning students' beliefs and perceptions on the role of previously acquired languages, teachers who apply teaching strategies focusing on comparing language systems seem to represent good practices and an optimal situation that enhances students' linguistic awareness in terms of the pedagogical proposals of multicompetence and DMM theories. Although non-target language use during the EFL classroom is in most cases non-systematic and does not serve an integrated language teaching approach (except for one case), greater exposure to Romanian language enhances to some extent students' awareness regarding the use of it in the acquisition process of English as a third language. 


\section{Conclusion}

The aim of the present study has been to explore English foreign language classroom interaction within the context of Transylvanian Hungarian minority education in order to investigate the extent to which teachers' and students' multilingualism is present in the classroom teaching and learning environment and to discuss and evaluate classroom language use based on the theoretical framework. Therefore, besides looking at the number of different languages that emerged within the observed EFL classroom contexts, the study has analysed both teachers' and students' beliefs and opinions regarding the use of previously acquired non-target languages during the EFL teaching and learning process.

Chapter 2 of the dissertation has presented two emerging theories that developed from the traditional SLA research field and argued for adopting a multilingual perspective not only in language acquisition research but also in foreign language education methodology. The two theoretical frameworks - multicompetence and the Dynamic Model of Multilingualism - offered the necessary background for the present research by providing arguments and support for the need to adopt a multilingual approach in language education. These theories, usually treated separately in the literature, co-construct a unique framework - a holistic perspective and a dynamic construct developed to best describe the complex language system of multilingual individuals. The common perspective of the two theoretical frameworks focuses on the linguistic behaviour of multilinguals claiming that they have a special ability to handle effectively several languages and language awareness to benefit from their previous language knowledge and language learning experiences while learning an additional language. Constructing a rather new picture of the language learner and striving to overcome the monolingual perspective still persisting in pedagogy and instructional aims, both theories propose some changes for current language teaching pedagogy that involve the importance of previously acquired languages and language learning experiences and the exploitation of these languages during foreign language instruction.

As the present dissertation focuses on minority bilinguals acquiring a third language, I have felt the need to summarize and present the relevant findings from the field of Third Language Acquisition, with a special focus on cross-linguistic influence. 
Finally, a separate section has been devoted to discussing classroom codeswitching (2.4) and the use of non-target languages during foreign language education (2.4.1).

The third chapter of the paper has provided an overview of the Transylvanian Hungarian community focusing on the relevant historical background, the educational system - especially issues regarding language learning - and the linguistic repertoire of Hungarian-Romanian bilingual students. A small scale study included in section 3.3 has offered further information regarding the types of multilingualism present in the research setting. The aim of the third chapter has been to provide the necessary contextual information in order to better understand the results of the study.

As the study has intended to examine EFL classroom interaction in order to investigate the ways in which multilingualism is present in the current foreign language teaching practices, several methods of data collection (classroom audio- and videorecordings, teacher questionnaires and interviews with both teachers and students) and a comparative content analysis of the data have been applied. Chapter 4 has provided a detailed description of the research setting and subjects as well as information regarding the methods of data collection and analysis.

The results obtained from different schools, teachers and students have been compared and contrasted in order to gain insight into the current EFL teaching practices and the ways these practices employ a multilingual approach to language teaching. Data has provided information not only about language use in EFL classes but also regarding teachers' beliefs about their educational practices, students' attitudes towards multiple language use and the roles that school types and teachers' language preferences play in shaping language use within the EFL classroom and learners' language awareness.

Concerning the type of languages used within an EFL classroom, the amount and purpose of occurring codeswitching phenomena (cf. research question 1), a multiperspective analysis of classroom language use has been applied - a teacher questionnaire, classroom observation, and student interviews - in order to achieve a detailed description of the English classes observed in five schools.

Results have shown that while teacher questionnaires, focusing mainly on teacher talk, present teachers' perception of their own language use, classroom observation data validated by student interviews have revealed the actual practices during EFL classrooms. Findings concerning classroom language use have shown that there are three major factors that influence linguistic behaviour and code choice within 
the English foreign language classroom, namely, the type of school or the school context, the English teachers' proficiency in the students' native language and teachers' beliefs and preferences regarding classroom language use. While EFL teaching in the two monolingual Hungarian grammar schools is characterized by a target language only, monolingual language mode, English language teaching in mixed type schools $(n=3)$ presents a more flexible approach towards non-target language use. With regard to the mother tongue of English language teachers, it should be mentioned that in mixed type schools Hungarian students might be taught English by a Hungarian or Romanian mother tongue teacher. The mother tongue of English teachers is an important issue when discussing language use in the EFL classroom. With Romanian being the language of the majority and the only official language of the country, Romanian native speakers rarely acquire the language of the minority. In this way, a Romanian mother tongue English teacher does not speak the (minority language) learners' mother tongue and the language of instruction is restricted to the target language and the teacher's mother tongue.

However, results have shown that the wider sociolinguistic context in which the particular school is situated may have an impact on EFL classroom language use in a way that the Romanian mother tongue teacher observed in a setting where minority language speakers constitute the local majority had some knowledge of students' native language and used it in the classroom in order to compare and contrast the language and to facilitate the acquisitional process.

In section 5.2 on teachers' beliefs regarding classroom language use, a metaanalysis of previous classroom observation findings and questionnaire results has been applied and complemented by two post-observational teacher interviews. Findings have suggested that things are not black and white. In the light of the literature and theoretical framework presented, a multilingual approach to language teaching, where students' full language repertoire is activated and teachers rely on and build upon students previously acquired language knowledge and language learning experiences enhances the acquisition process. Thus, it might suggest that exclusive target language lessons are bad, while allowing non-target language use is good.

If we have a closer look at the data, it can be seen that the presence or the use of non-target languages within the foreign language classroom does not automatically improve language learning or teaching. Macaro (2009) proposes that an optimal use of 
non-target languages enhances language learning. He uses the term optimal for the amount of non-target language use, however he says that optimality depends on the teachers' judgements and beliefs about teaching. Empirical classroom data collected reveals that teachers' judgement of optimal non-target language use might be placed on a continuum. One end of the continuum represents no use of other languages than the target language, while the other end of the continuum stands for the overuse of nontarget languages. Teachers' beliefs about teaching and learning have a great impact on how they judge optimal non-target language use. Teachers whose pedagogical aim is to maximize target language input use only English within the lesson, require the same language behaviour from their students and use translation as a scaffolding strategy. Yet, other teachers use non-target languages to ensure understanding and for meaning making within the EFL classroom. Especially, one teacher applies the use of non-target languages in a systematic, strategic way by comparing and contrasting language systems present in the learners' linguistic repertoire. Nonetheless, findings show language situations where non-target languages were extensively used even when other, more appropriate scaffolding strategies or target language use would have been more useful or productive.

Teachers' linguistic behaviour and the specific educational context have seemed to have an impact on learners' language awareness as well. Student interview results discussed in chapter 7 reveal that although each participant proved to have some degree of language awareness, the type of school and their English teachers' monolingual or flexible approach towards non-target language use within the EFL classroom influenced the way students selected the source language on which they rely during target language acquisition. Data from the five visited schools suggests that students of the monolingual grammar school $(n=8)$ ignore (or at least do not mention) the usefulness of their second language, Romanian, in their EFL learning process. Two of these students mention the benefits of knowing English in their German language learning. This results reminds us of Boócz-Barna's (2010) statement, according to which students are not capable of fully exploiting the benefits of their previously learnt languages on their own, and, thus, the role of language teachers would be to improve students' conscious perception of their language learning experiences and strategies and emphasize ways in which they can transfer and integrate these experiences into the current language learning process. On the other hand, all students from the mixed type schools $(n=6)$ refer to Romanian as the 
most useful language in acquiring English and point out the lexical similarities between the two languages. Thus, it is safe to conclude that in case of the visited classrooms the amount of exposure to a non-target language influences students' choice concerning the source language on which they rely on during foreign language learning.

Classroom observation conducted in $10 \mathrm{EFL}$ classes and student interview $(n=14)$ results have shown that non-target languages are mostly used for translation or explanation of unknown words, maintaining discipline, classroom management issues and grammar explanation. The use of non-target languages, however, is rather unsystematic, unplanned and does not serve the purpose of an integrated language teaching as described in the theoretical framework. Of the seven observed teachers, there was only one who used non-target language in order to compare the languages and facilitate the acquisition of the respective grammatical structure. Moreover, this was the only teacher who encouraged students to use their Romanian vocabulary knowledge when they had difficulties in the reception or production of an English text. Student interview results have also emphasized that learners of mixed type schools $(n=6)$ are more aware of the help Romanian language can offer even if their respective teachers do not use codeswitching with the aim to compare or contrast language structures or lexical items. This might suggest that a greater exposure to the Romanian language and the teachers' systematic use of contrastive approaches in language teaching can have a positive effect on learners' linguistic awareness.

As suggested by several researchers (e.g. Meissner, 2004; Boócz-Barna, 2010; Cenoz and Gorter, 2015), it is necessary to adopt a multilingual approach in foreign language instruction so that language learners can fully exploit the potentials offered by typological similarities between the languages, an idea that is missing in most of the EFL classrooms observed.

Research results support the idea that even if some teachers try to stick to the idea of separating languages in the class, these other languages are still activated during an English class and codeswitching instances do occur. Therefore, according to the literature on multilingual approach to language teaching, adopting exclusive target language behaviour does not aid the development of learners' metalinguistic awareness. However, teachers using non-target languages within the EFL classroom do not use these languages deliberately in order to support an integrative foreign language learning either. Thus, the present research points out, that teachers need to develop ways in 
which to promote multicompetence in the foreign language classroom, primarily by modelling and reflecting upon multiple language use and communication strategies themselves.

Overall, on the basis of these findings, I have suggested that instructional goals in language education should be reviewed and adjusted to the needs of today's multilingual society. If we accept the theory of multicompetence and the DMM regarding the existence of an integrated and dynamic linguistic system where all the languages in the speaker's mind interact with one another and that the acquisition of a third or additional language is different from learning a second language, then language education needs to move on from an additive view of multilingualism towards a more integrative one, where the prior linguistic knowledge of the students can be exploited in order to raise students' awareness regarding the similarities and differences among the languages they know and to help students develop further language learning strategies that are based on their previous language knowledge and language learning experiences.

Therefore, I suggest that the curriculum of teacher training programs needs to be revised so that future language teachers should learn about the pedagogical implications of multilingualism. Furthermore, such teacher training programs or professional development programs for in-service teachers should provide courses on third language learning and teaching in order to enable teachers to understand the learning process of their multilingual students and possibly to develop more efficient teaching strategies.

By studying EFL classroom language use in a Hungarian minority context, I wish to have contributed to the development of the newly emerging trend of softening boundaries between languages and integrated language teaching. Studies focusing on multilingual education (Cenoz and Gorter, 2011, 2015; Portoles and Martí, 2017) and integrated language teaching (Garcia and Li, 2014; Jones and Lewis, 2014; Cenoz and Gorter, 2015) stress the idea that students' whole linguistic repertoire should be activated and used during foreign language teaching and that teachers must be flexible regarding classroom language use (Wood, 2011). Several proposals are made in the literature for how the concept of multicompetence can be integrated into FL teaching (Cook, 1991a, 1992, 2002, 2005; Jessner, 2006, 2008), but there is a lack in FL classroom research that would apply multicompetence theory to studying EFL teaching and learning. Although so far the notion of multicompetence has mainly been known among SLA researchers, a tendency to integrate the main ideas of the theory into 
multilingual teaching has been noted by Jessner (2008). Research on multilingualism in education and, particularly, language teaching, might mean not only an advance in the field of SLA or TLA, but it may also contribute, on a more practical level, to the progress of teacher training by setting new aims for future work on language teacher education.

Furthermore, multilingualism and TLA studies that have been carried out mainly focus on subjects such as the Valencian community in Spain (Jorda, 2005); bilinguals in Germany acquiring English as a third language (Jessner, 1999, 2006, 2008); educational, sociolinguistic and psycholinguistic perspectives of multilingualism involving the Basque community in Spain (Cenoz and Jessner, 2000; Cenoz and Gorter, 2014, 2015), and Italian-German bilingual community in South Tyrol (de Angelis, 2007, 2011), but there are no studies involving Hungarian minorities. In this way the present study fills a gap for what concerns linguistic research on multilingualism in education in a Hungarian minority context.

\subsection{Limitations and future prospects}

As has been mentioned in chapter 4, the study was carried out in two counties of Transylvania and altogether ten classes were observed in five schools. For what concerns classroom observation, one or two English classes were recorded in each visited class from Mureș/Maros county ( $\mathrm{n}=7$ audio-recorded classroom observations), and I spent three weeks in each visited class in Harghita/Hargita county ( $\mathrm{n}=21$ audioand video-recorded classroom observations). In order to adjust the number of classroom observations in the two counties, only the last two recordings of the observed English classes $(n=3)$ were fully transcribed $(n=6)$. While students in the latter sample had the chance to get used to the presence of a researcher and of several recording gadgets in the classroom, participants from Mureș/Maros county did not have this possibility. Therefore, spending more time in the schools contacted from Mureș/Maros county would have helped to overcome the possible Hawthorne effect and would have provided me with a larger sample of data.

Furthermore, post-observational interviews carried out with the two participant teachers from Miercurea Ciuc/Csíkszereda has proved to be valuable in the sense that they provided me with not only a validation of my observational interpretations but 
teachers gave further explanations to support their linguistic behaviour within the EFL classroom. As data collection in Mureș/Maros county was carried out earlier, in 2009, unfortunately, I did not have a chance to contact those teachers again for such an interview. Conducting post-observational interviews with all teachers would have provided me with further data on teachers' linguistic behaviour and I would have gained a more thorough insight into their language teaching beliefs. Moreover, I believe that further studies should be conducted on teachers' beliefs regarding the use of non-target languages during foreign language classrooms, and such information might help us better understand what happens in the classroom.

Despite of the above mentioned limitations, I expect that data collected in the five Transylvanian schools and the results presented in the present paper constitute valuable contribution to the field of TLA and multilingualism and the study has brought sufficient arguments in order that Transylvanian minority third language acquisition be perceived as a research topic worth exploring. 


\section{References}

Abdi, Heidar and Asadi, Bahareh. 2015. A Synopsis of researches on teachers' and students' beliefs about language learning. International Journal on Studies in English Language and Literature, 3 (4): 104-114.

Adler, Patricia A. and Adler, Peter. 1994. Observational techniques. In: Denzin, Norman K. and Lincoln, Yvonna S. eds. Handbook of qualitative research. London: Sage Publications, 377-392.

Allgäuer-Hackl, Elisabeth, Jessner, Ulrike. 2013. Mehrsprachigkeitsunterricht aus mehrsprachiger Sicht: Zur Förderung des metalinguistischen Bewusstseins [Multilingual teaching from a multilingual perspective: To promote metalinguistic awareness]. In: Vetter, Eva ed. Professionalisierung für sprachliche Vielfalt. Perspektiven für eine neue Lehrerbildung. Baltmannsweiler: Schneider Verlag Hohengehren, 111-148.

Alptekin, Cem. 2010. Redefining multicompetence for bilingualism and ELF. International Journal of Applied Linguistics, 20(1): 95-110.

Antón, Marta and DiCamilla, Frederick J. 1999. Socio-cognitive functions of L1 collaborative interaction in the L2 classroom. The Modern Language Journal, 83(2): 233-247.

Árva, Valéria and Medgyes Péter. 2000. Native and non-native teachers in the classroom. System, 28: 355-372.

Auer, Peter and Li Wei. 2007. Introduction: Multilingualism as a problem? Monolingualism as a problem? In: Auer, Peter, Li Wei, eds. Handbook of multilingualism and multilingual communication. Berlin: Mouton de Gruyter, $1-12$.

Bailey, Ainsworth Anthony. 2011. Codeswitching in the foreign language classroom: students' attitudes and perceptions and the factors impacting them. Theses and dissertations. 514.

http://utdr.utoledo.edu/cgi/viewcontent.cgi?article=1535\&context=thesesdissertations. Access: 20 June, 2017.

Bailey, M. Kathleen, Bret Bergthold, Belinda Braunstein, Natasha Jagodzinski Fleischman, Matthew P. Holbrook, Jennifer Tuman, Ximena Waissbluth and 
Leslie J. Zambo. 1996. The language learner's autobiography: examining the “Apprenticeship of Observation". In: Freeman, Donald A. and Richards, Jack. C. eds. Teacher learning in language teaching. Cambridge: Cambridge University Press, 11-19.

Bakó, Rozália Klára, Ruxandra Noica, Razvan Stan and Alina Mungiu-Pippidi. 2006. Regions, minorities and European integration: A case study on Hungarians from Romania.

http://www.eliamep.gr/wpcontent/uploads/en/2009/03/romania_revised_-okedby-alina.doc. Access: 04 October, 2013.

Barratt, Leslie and Kontra H., Edit. 2000. Native-English-speaking teachers in cultures other than their own. TESOL Journal, 9(3): 19-23.

Bassey, Michael. 1999. Case study research in educational settings. Buckingham: Open University Press.

Bentahila, Abdelali. 1983. Motivations for code-switching among Arabic-French bilinguals in Morocco. Language and Communication, 3(3): 233-243.

Benő, Attila and Szilágyi N., Sándor. 2005. Hungarian in Romania. In: Fenyvesi, Anna, ed. Hungarian language contact outside Hungary: Studies on Hungarian as a minority language. Amsterdam: John Benjamins, 133-162.

Bialystok, Ellen. 2007. Language acquisition and bilingualism: Consequences for a multilingual society. Applied Psycholinguistics, 28 (3): 393-397.

Bild, Eva Rebecca and Swain, Merrill. 1989. Minority language students in a French immersion programme: Their French proficiency. Journal of Multilingual and Multicultural Development, 10(3): 255-274.

Biró, Enikő. 2011. Nyelvhódítás - domináns kétnyelvűek nyelvtanulási stratégiaválasztásai [Linguistic conquest - language learning strategies of dominant bilinguals]. In: Horváth, István and Tódor, Erika Mária, eds. Nyelvhasználat, tannyelv és két(több)nyelvü lét [Language use, language of instruction and being bi(multi)lingual]. Kolozsvár: Kriterion Könyvkiadó, 7186.

Björklund, Siv and Suni, Irmeli. 2000. The role of English as L3 in a Swedish immersion programme in Finland: Impacts on language teaching and language relations. In: Cenoz, Jasone and Ulrike Jessner, eds. English in Europe: The acquisition of a third language. Clevedon: Multilingual Matters, 198-222. 
Bloomfield, Leonard. 1933. Language. New York: Henry Holt.

Bloomfield, Leonard. 1935. Language. London: George Allen and Unwin.

Bono, Mariana. 2011. Crosslinguistic interaction and metalinguistic awareness in third language acquisition. In: De Angelis, Gessica and Jean-Marc Dewaele, eds. New trends in crosslinguistic influence and multilingualism research. Clevedon: Multilingual Matters, 25-52.

Boócz-Barna, Katalin. 2010. Az első idegen nyelvi transzfer vizsgálata a német mint második idegen nyelvet tanulók szókincs-elsajátításában [The investigation of L1 transfer in German as an L3 learners' vocabulary acquisition]. In: Navracsics, Judit, ed. Nyelv, beszéd, írás. Pszicholingvisztikai tanulmányok I [Language, speech and writing: Studies in psycholinguistics, I]. Budapest: Tinta Kiadó, 176-184.

Borg, Michaela. 2005. A case study of the development in pedagogic thinking of a preservice teacher. TESL-EJ, 9 (2): 1-30.

Borg, Simon. 2006. Teacher cognition and language education: research and practice. London: Continuum.

Borg, Simon. 2015. Researching teacher beliefs. In: Brian Paltridge and Aek Phakiti (eds.) Research methods in applied linguistics: a practical resource. London: Bloomsbury, 487-504.

Brown, Amanda. 2013. Multicompetence and second language assessment. Language Assessment Quarterly, 10(2): 219-235.

Burlingame, Patrick. 2004. Ethnic Hungarian minorities: Past, present, and future. In: Huszár, Ildikó, ed. Fulbright student conference papers. Academic years 2002/2003 and 2003/2004. Budapest: Hungarian-American commission for educational exchange, 49-60.

Byram, Michael. 1998. Cultural identities in multilingual classrooms. In: Cenoz, Jasone and Fred Genesee, eds. Beyond bilingualism: Multilingualism and multilingual education. Clevedon: Multilingual Matters, 96-116.

Byram, Michael, ed. 2000. Routledge encyclopedia of language teaching and language learning. London/New York: Routledge.

Byram, Michael and Leman, Johan, eds. 1990. Bicultural and trilingual education: The Foyer model in Brussels. Clevedon, England: Multilingual Matters. 
Cabaroglu, Nese and Roberts, Jon. 2000. Development in student teachers' pre-existing beliefs during a 1-year PGCE programme. System, 28: 387-402.

Čajko, Irena Horvatić. 2014. Developing metalinguistic awareness in L3 German classrooms. In: Otwinowska, Agnieszka and De Angelis, Gessica, eds. Teaching and learning in multilingual contexts: Sociolinguistic and educational perspectives. Clevedon: Multilingual Matters, 199-214.

Camilleri, Antoinette. 1996. Language values and identities: Code switching in secondary classrooms in Malta. Linguistics and Education, 8(1): 85-103.

Canagarajah, Suresh. 2011. Codemeshing in academic writing: Identifying teachable strategies of translanguaging. The Modern Language Journal, 95: 401-417.

Canagarajah, Suresh. 2013. Translingual practice: Global Englishes and cosmopolitan relations. Abingdon: Routledge.

Candelier, Michel, ed. 2004. Janua Linguarum: A gateway to languages. Kapfenberg: Council of Europe Publishing.

Carless, David. 2008. Student use of the mother tongue in the task-based classroom. ELT Journal, 62 (4): 331-338.

Center of Documentation and Information on Minorities in Europe - South East Europe (CEDIME-SE). 2001. Report on Minorities in South East Europe. Hungarians of Romania. http://www.greekhelsinki.gr/english/reports/CEDIME-ReportsMinorities-in-Romania.html. Access: 10 August, 2013.

Cenoz, Jasone. 1997. The influence of bilingualism on multilingual acquisition: Some data from the Basque country. In: Cabeza, Pereiro C., Lorenzo, Suárez A.M. and Rodríguez, Yánez X.P, eds. I Simposio Internacional sobre o Bilingüismo: Comunidades e individuos bilingües [First international symposium on bilingualism: Bilingual communities and individuals]. University of Vigo. Vigo, 21-25 October, 1997. 278-287. http://www.multilingualmatters.net/jmmd/018/0261/jmmd0180261.pdf. Access: 10 March, 2009.

Cenoz, Jasone. 2000. Research on multilingual acquisition. In: Cenoz, Jasone and Ulrike Jessner, eds. English in Europe: The acquisition of a third language. Clevedon: Multilingual Matters, 39-54.

Cenoz, Jasone. 2001. The effect of linguistic distance, L2 status and age on crosslinguistic influence in third language acquisition. In: Cenoz, Jasone, Britta Hufeisen and Ulrike Jessner, eds. Cross-linguistic influence in third language 
acquisition: Psycholinguistic perspectives. Clevedon: Multilingual Matters, 820 .

Cenoz, Jasone. 2003. The role of typology in the organization of the multilingual lexicon. In: Cenoz, Jasone, Britta Hufeisen and Ulrike Jessner, eds. The multilingual lexicon. Dordrecht: Kluwer Academic Publishers, 103-116.

Cenoz, Jasone. 2005. Learning a third language: Cross-linguistic influence and its relationship to typology and age. In: Hufeisen, Britta and Robert J. Fouser, eds. Introductory readings in L3. Tübingen: Stauffenburg Verlag, 1-11.

Cenoz, Jasone. 2008. The acquisition of additional languages. ELIA, 8: 219-224.

Cenoz, Jasone and Fred Genesee. 1998. Psycholinguistic perspectives on multilingualism and multilingual education. In: Cenoz, Jasone and Fred Genesee, eds. Beyond bilingualism: Multilingualism and multilingual education. Clevedon: Multilingual Matters, 16-32.

Cenoz, Jasone and Gorter, Durk. 2011. Focus on multilingualism: a study of trilingual writing. The Modern Language Journal, 95(3): 356-369.

Cenoz, Jasone and Gorter, Durk. 2013. Towards a plurilingual approach in English language teaching: softening the boundaries between languages. TESOL Quarterly, 47 (3): 591-599.

Cenoz, Jasone and Gorter, Durk. 2014. Focus on multilingualism as an approach in educational contexts. In: Blackledge, Adrian and Creese, Angela, eds. Heteroglossia as practice and pedagogy. Dordrecht: Springer, 239-254.

Cenoz, Jasone and Gorter, Durk. 2015. Towards a holistic approach in the study of multilingual education. In: Jasone Cenoz and Durk Gorter eds. Multilingual Education. Between language learning and translanguaging. Cambridge: Cambridge University Press, 1-15.

Cenoz, Jasone, Hufeisen Britta and Jessner Ulrike. 2003. Why investigate the multilingual lexicon? In: Jasone Cenoz, Britta Hufeisen and Ulrike Jessner, eds. The multilingual lexicon. Dordrecht: Kluwer, 1-11.

Cenoz, Jasone and Jessner, Ulrike eds. 2000. English in Europe: The acquisition of a third language. Clevedon: Multilingual Matters.

Cenoz, Jasone and Jessner, Ulrike. 2009. The study of multilingualism in educational contexts. In: Aronin, Larissa and Britta Hufeisen, eds. The exploration of multilingualism: Development of research on L3, multilingualism and multiple 
language acquisition. Amsterdam/Philadelphia: John Benjamins Publishing Company, 121-138.

Cenoz, Jasone and Valencia, Jose F. 1994. Additive trilingualism: Evidence from the Basque Country. Applied Psycholinguistics, 15: 195-207.

Chomsky, Noam. 1965. Aspects of the theory of syntax. Cambridge, MA: MIT Press.

Clark, Julie Byrd and Lamoureux, Sylvie A. 2014. Rethinking multilingualism: Complex identities, representations and practices of multilingual student teachers moving through plurilingual times in university French language teacher education programs. In: Otwinowska, Agnieszka and De Angelis, Gessica, eds. Teaching and learning in multilingual contexts: Sociolinguistic and educational perspectives. Clevedon: Multilingual Matters, 32-49.

Cleghorn, Ailie. 1992. Primary level science in Kenya: Constructing meaning through English and indigenous languages. International Journal of Qualitative Studies in Education, 5(4): 311-323.

Clyne, Michael. 1998. Managing language diversity and second language programmes in Australia. In: Wright, Sue and Kelly-Holmes, Helen, eds. Managing language diversity. Clevedon: Multilingual Matters, 4-30.

Cohen, Louis, Manion, Lawrence and Morrison, Keith. 1989. Research methods in education, $3^{\text {rd }}$ edn. London: Routledge.

Cohen, Louis, Manion, Lawrence and Morrison, Keith. 2007. Research methods in education, $6^{\text {th }}$ edn. London: Routledge.

Commision of the European Communities. 2007. Final Report: High level group on multilingualism.

Luxembourg. http://ec.europa.eu/education/policies/lang/doc/multireport_en.pdf. Access: 13 October, 2011.

Cook, Vivian. 1991a. Second language learning and language teaching. London: Arnold.

Cook, Vivian. 1991b. The poverty of the stimulus argument and multicompetence. Second Language Research, 7: 103-117.

Cook, Vivian. 1992. Evidence for multicompetence. Language Learning, 42(4): 557591. 
Cook, Vivian. 1997. The consequences of bilingualism for cognitive processing. In: de Groot, Annette M.B. and Kroll, Judith F., eds. Tutorials in bilingualism. Hillsdale, NJ: Lawrence Erlbaum Association, 279-301.

Cook, Vivian. 1999. Going beyond the native speaker in language teaching. TESOL Quarterly, 33(2): 185-209.

Cook, Vivian. 2001. Using the first language in the classroom. Canadian Modern Language Review, 57(3): 402-423.

Cook, Vivian. 2002. Portraits of the L2 user. Clevedon: Multilingual Matters.

Cook, Vivian. 2003. Effects of the second language on the first. Clevedon: Multilingual Matters.

Cook, Vivian. 2005. Multicompetence: Black hole or wormhole? Draft of write-up of SLRF paper.

http://homepage.ntlworld.com/vivian.c/Writings/Papers/SLRF.htm, Access: 28 January, 2008.

Cook, Vivian. 2006. The nature of the L2 user. Written draft of EUROSLA Plenary. http://homepage.ntlworld.com/vivian.c/Writings/Papers/EURO2006.htm, Access: 28 January, 2008.

Cook, Vivian. 2007. The nature of the L2 user. In: Leah Roberts, Ayşe Gürel, Sibel Tatar and Leyla Martı eds. EUROSLA Yearbook, 7: 205-220.

Cook, Vivian. 2008. Linguistic contributions to bilingualism. In: Jeanette Altarriba, Roberto R. Heredia, eds. An introduction to bilingualism: Principles and practice, London: Lawrence Erlbaum Associates, 245-264.

Cook, Vivian. 2013. Second language learning and language teaching. London: Routledge.

Cook, Vivian, Bassetti, Benedetta, Kasai, Chise, Sasaki, Miho and Takahashi. 2006. Do bilinguals have different concepts? The case of shape and material in Japanese L2 users of English. International Journal of Bilingualism, 10(2): 137-152.

Creese, Angela and Blackledge, Adrian. 2010. Translanguaging in the bilingual classroom: A pedagogy for learning and teaching? The Modern Language Journal, 94(1): 103-115.

Crump, Alison. 2013. Fostering multilingual spaces in second and foreign language classes: Practical suggestions. The Journal of Language Teaching and Learning, 3(2): 65-71. 
Csepeli, György, Örkény, Antal and Székelyi, Mária. n.d. The steadiness and transformation of national-ethnic identity. http://www.hhrf.org/kisebbsegkutatas/mr_02/cikk.php?id=1218. Access: 5 May, 2010.

Csire, Márta and Laasko, Johanna. 2014. L3, L1 or L0? Heritage-language students as third-language learners. In: Otwinowska, Agnieszka and De Angelis, Gessica, eds. Teaching and learning in multilingual contexts: Sociolinguistic and educational perspectives. Clevedon: Multilingual Matters, 215-231.

Cummins, Jim. 2001. Instructional conditions for trilingual development. International Journal of Bilingual Education and Bilingualism, 4(1): 61-75.

Cummins, Jim. 2007. Rethinking monolingual instructional strategies in multilingual classrooms. Canadian Journal of Applied Linguistics, 10: 221-240.

Cybulska, Katarzyna and Borenić, Višnja Kabalin. 2014. EFL teacher trainees and European goals of multilingualism and plurilingualism. A survey of attitudes in Poland and Croatia. In: Otwinowska, Agnieszka and De Angelis, Gessica, eds. Teaching and learning in multilingual contexts: Sociolinguistic and educational perspectives. Clevedon: Multilingual Matters, 75-97.

Dailey-O'Cain, Jennifer and Liebscher, Grit. 2009. Teacher and student use of the first language in foreign language classroom interaction: Functions and applications. In: Turnbull, Miles and Dailey-O'Cain, Jennifer, eds. First language use in second and foreign language learning. Bristol: Multilingual Matters, 131-144.

Davies, Charlotte Aull. 1998. Reflexive ethnography: A guide to researching selves and others. London: Routledge.

De Angelis, Gessica. 1999. Interlanguage transfer and multiple language acquisition: A case study. Paper presented at TESOL 1999, New York City.

De Angelis, Gessica. 2005. Multilingualism and non-native lexical transfer: An identification problem. International Journal of Multilingualism, 2(1): 1-25.

De Angelis, Gessica. 2007. Third or additional language acquisition. Clevedon: Multilingual Matters.

De Angelis, Gessica. 2011. Teachers' beliefs about the role of prior language knowledge in learning and how these influence teaching practices. International Journal of Multilingualism, 8 (3): 216-234. 
De Angelis, Gessica. 2014. A multilingual approach to analysing standardized test results: Immigrant primary school children and the role of languages spoken in a bi- /multilingual community. Intercultural Education, 25(1): 14-28.

De Angelis, Gessica and Larry Selinker. 2001. Interlanguage transfer and competing linguistic systems in the multilingual mind. In: Cenoz, Jasone, Britta Hufeisen, and Ulrike Jessner, eds. Cross-linguistic influence in third language acquisition: Psycholinguistic perspectives. Clevedon: Multilingual Matters, $42-59$.

Debreli, Emre. 2012. Change in beliefs of pre-service teachers about teaching and learning English as a foreign language throughout an undergraduate pre-service teacher training program. Procedia - Social and Behvioral Sciences, 46: 367373.

Dégi, Zsuzsanna. 2008. Language teaching in Transylvania: A promotion of multilingualism? In: Arnándiz, Otilia Martí and Safont Jordà, Maria Pilar, eds. Achieving multilingualism: Wills and ways. Universidad Jaume I: Castelló de la Plana, 279-292.

Dégi Zsuzsanna. 2009. „A született magyarnak a saját kultúrájában kellene mélyre hatni, a többit meg felhasználói szinten tudni...” Idegennyelvoktatáshoz füződő attitűdök a kisebbségi magyarok körében. [Native Hungarians should be proficient in their own culture and the rest should be at user level: Minority Hungarians' attitudes towards foreign language teaching]. In: Borbély, Anna, Vanconé Kremmer, Ildikó, and Hattyár, Helga, eds. Nyelvideológiák, attitüdök és sztereotípiák. [Language ideologies, attitudes and stereotypes] Budapest: Tinta Könyvkiadó, 507-513.

Dégi Zsuzsanna. 2010. Effects on the linguistic awareness of foreign language learners. Acta Universitatis Sapientiae. Philologica, 2(2): 299-312.

Dégi Zsuzsanna. 2012. Types of multilingualism explored in the Transylvanian school context. Jezikoslovlje, 13(2): 645-666.

Dégi Zsuzsanna and T. Balla Ágnes. 2012. (In press) Language choice in the foreign language classroom. Proceedings of the Conference Multilingualism in Europe in Budapest 25-26 March 2011. Budapest: L'Harmattan. 
Denscombe, Martyn. 1984. Interviews, accounts and ethnographic research on teachers. In: Hammersley, Martyn, ed. The ethnography of schooling: Methodological issues. Driffield: Nafferton Books, 105-128.

Denzin, Norman K. 1989. Interpretive interactionism. Newbury Park: Sage.

Dewaele, Jean-Marc. 1998. Lexical inventions: French interlanguage as L2 versus L3. Applied Linguistics, 19: 471-490.

Dewaele, Jean-Marc. 2001. Activation or inhibition? The interaction of L1, L2 and L3 on the language mode continuum. In: Cenoz, Jasone, Britta Hufeisen, and Ulrike Jessner, eds. Cross-linguistic influence in third language acquisition: Psycholinguistic perspectives. Clevedon: Multilingual Matters. 69-89.

Dewaele, Jean-Marc, and Pavlenko, Aneta. 2003. Productivity and lexical richness in native and non-native speech: A study of cross-cultural effects. In: Cook, Vivian, ed. The effects of the second language on the first. Clevedon: Multilingual Matters, 120-141.

Diószegi, László. 2009. The story of survival: The Hungarians of Romania 1919-1989. In: Dreisziger N, ed. Transylvania: Its past and present. Special Issue of Hungarian Studies Review, 36 (1-2): 65-84.

Dörnyei, Zoltán. 2007. Research methods in applied linguistics: quantitative, qualitative and mixed methodologies. Oxford: Oxford University Press.

Dörnyei, Zoltán, Ema Ushioda. 2009. Motivation, language identity and the L2 self. Clevedon: Multilingual Matters.

Du Bois, John W., Schuetze-Coburn, Stephan, Cumming Susanna and Paolino, Danae. 1993. Outline of discourse transcription. In: Edwards, Jane Anne and Lampert, Martin D., eds. Talking data: Transcription and coding in discourse research. London: Routledge, 45-87.

Duff, Patricia and Polio, Charlene. 1990. How much foreign language is there in the foreign language classroom? The Modern Language Journal, 74: 154-166.

Dumitrica, Delia Despina. 2002. Uniate /vs./ Orthodox: what lays behind the conflict? A conflict analysis. Journal for the Study of Religions and Idelology, 3: 99114.

Ecke, Peter. 2001. Lexical retrieval in a third language: Evidence from errors and tip-ofthe-tongue states. In: Cenoz, Jasone, Britta Hufeisen, and Ulrike Jessner, eds. 
Cross-linguistic influence in third language acquisition: Psycholinguistic perspectives. Clevedon: Multilingual Matters, 90-115.

Ecke, Peter. 2003. Tip-of-the-tongue states in a polyglot: A longitudinal case study. Paper presented at the Third Conference on Third Language Acquisition and Trilingualism, Tralee, Ireland, 3-5 September. http://www.laslab.org/tla2012/slides/Ecke.pdf Access: 7 September, 2010:

Edge, Julian. 1988. Natives, speakers and models. JALT Journal, 9: 153-157.

Edmondson, Willis. 2004. Code-switching and world-switching in foreign language classroom discourse. In: House, Juliane and Rehbein Jochen, eds. Multilingual Communication. Amsterdam/Philadelphia: John Benjamins Publishing, 155178.

Edwards, Malcom and Dewaele, Jean-Marc. 2007. Trilingual conversations: A window into multicompetence. International Journal of Bilingualism, 11(2): 221-242.

Edwards, Viv. 1983. Language in multicultural classrooms. London: Batsford.

Ellis, Rod. 1997. Second language acquisition. Oxford: Oxford University Press.

Farrell, Thomas S.C. and Filion-Tomenson, Barbara. 2014. Teachers beliefs and classroom practices: a case study of an ESL teacher in Canada. In: Said, Selim Ben and Zhang, Lawrence Jun eds. Language teachers and teaching. Global perspectives, local initiatives. New York: Routledge, 169-184.

Fenyvesi, Anna. 2012. Hungarian minorities in Romania, Slovakia and Serbia: Schoolchildren's attitudes to their languages (minority vs. majority languages vs. EFL) and teaching these languages in school. Finnisch-Ugrische Mitteilungen Band, 35: 35-55.

Flyvbjerg, Bent. 2011. Case study. In: Denzin, Norman K. and Lincoln, Yvonna S, eds. The SAGE handbook of qualitative research. Thousand Oaks: Sage Publications, 301-316.

Fontana, Andrea and Frey, James H. 1998. The interview: From structured questions to negotiated text. In: Denzin, Norman K. and Lincoln, Yvonna S, eds. Collecting and interpreting qualitative materials. Thousand Oaks: Sage Publications, 61107.

Fontana, Andrea, and Frey, James H. 1994. Interviewing: The art of science. In: Denzin, Norman K. and Lincoln, Yvonne S. eds. Handbook of qualitative research. Thousand Oaks: Sage Publications, 361-376. 
Foote, Rebecca. 2009. Transfer in L3 Acquisition: The Role of Typology. In: Leung, Yan-kit Ingrid ed. Third language acquisition and universal grammar, Clevedon: Multilingual Matters, 89-115.

Franceschini, Rita. 2009. The genesis and development of research in multilingualism. Perspectives for future research. In: Aronin, Larissa and Britta Hufeisen, eds. The exploration of multilingualism: Development of research on L3, multilingualism and multiple language acquisition. Amsterdam/Philadelphia: John Benjamins Publishing Company, 27-62.

García, Ofelia. 2009. Bilingual education in the $21^{\text {st }}$ century. Oxford: Wiley-Blackwell. García, Ofelia. 2013. Informal bilingual acquisition: Dynamic spaces for language education. In David Singleton, Joshua A. Fishman, Larissa Aronin and Muiris Ó Laoire, eds. Current multilingualism: A new linguistic dispensation. Berlin: Mouton de Gruyter, 99-118.

García, Ofelia and Li Wei. 2014. Translanguaging: language, bilingualism and education. New York: Palgrave Macmillan.

García, Ofelia and Lin, Angel M.Y. 2016. Translanguaging in bilingual education. In: García, Ofelia and Lin, Angel M.Y. eds. Bilingual and multilingual education (Encyclopedia of language and education, vol.5). Dordrecht: Springer, 117-130.

Gardner-Chloros, Penelope. 2009. Code-switching. Cambridge: Cambridge University Press.

Geertz, Clifford. 1973. The interpretation of cultures. New York: Basic Books.

Gilakjani, Abbas Pourhosein and Sabouri, Narjes Banou. 2017. Teachers' beliefs in English language teaching and learning: a review of the literature. English Language Teaching, 10 (4): 78-86.

GOHMA (Government Office for the Hungarian Minorities Abroad). n.d. The situation of Hungarians in Romania in 2006. http://www.hhrf.org/htmh/en/index.php?menuid=0404. Access: 5 May 2009.

Gardner, Robert and Lambert, Wallace E. 1972. Attitudes and motivation in secondlanguage learning. Newbury House Publishers.

Gorter, Durk and Cenoz, Jasone. 2015. Translanguaging and lingusitic landscapes. Linguistic Landscape, 1(1):54-74.

Gorter, Durk and Cenoz, Jasone. 2017. Language education policy and multilingual assessment. Language and Education, 31(3): 231-248. 
Grosjean, François. 1985. The bilingual as a competent but specific speaker-hearer. Journal of Multilingual and Multicultural Development, 6: 467-477.

Grosjean, François. 1996. Living with two languages and two cultures. In: Parasnis, Ila ed. Cultural and language diversity and the deaf experience. Cambridge: Cambridge University Press, 20-37.

Grosjean, François. 1998. Studying bilinguals: Methodological and conceptual issues. Bilingualism: Language and Cognition, 1: 131-149.

Grosjean, François. 2001. The bilingual's language modes. In: Nicol, Janet, ed. One mind, two languages: Bilingual language processing. Oxford: Blackwell, 1-22.

Guba, Egon G. and Lincoln, Yvonna S. 1981. Effective evaluation: Improving the usefulness of evaluation results through responsive and naturalistic approaches. San Francisco: Jossey-Bass.

Guthrie, Emily M.L. 1984. Six cases in classroom communication: a study of teacher discourse in the foreign language classroom. In: James P. Lantolf and Angela Labarca, eds. Research in second language learning: Focus on the classroom, Norwood, NJ: Ablex, 173-194.

Gutièrrez Eugenio, Esther. 2017. L3 teachers' beliefs about multilingualism in Europe. PhD Dissertation.

https://doktori.hu/index.php?menuid=193\&lang=EN\&vid=18309. Access: 15 August, 2018.

Hall, Christopher J. and Peter Ecke. 2003. Parasitism as a default mechanism in L3 vocabulary acquisition. In: Jasone Cenoz, Britta Hufeisen and Ulrike Jessner, eds. The multilingual lexicon. Dordrecht: Kluwer, 71-87.

Hall, Graham and Cook, Guy. 2013. Own-language use in ELT: exploring global practices and attitudes. London: British Council. https://www.teachingenglish.org.uk/sites/teacheng/files/C448\%20Own\%20Lan guage\%20use\%20in\%20ELT_A4_FINAL_WEB\%20ONLY_0.pdf. Access: 10 January, 2018.

Hall, Joan Kelly, Cheng An and Carlson T. Matthew 2006. Reconceptualizing multicompetence as a theory of language knowledge. Applied Linguistics, 27(2): 220-240.

Hammarberg, Björn. 2001. Roles of L1 and L2 in L3 production and acquisition. In: Cenoz, Jasone, Britta Hufeisen, and Ulrike Jessner, eds. Cross-linguistic 
influence in third language acquisition: Psycholinguistic perspectives. Clevedon: Multilingual Matters, 21-41.

Hammarberg, Björn. 2009. Processes in third language acquisition. Edinburgh: Edinburgh University Press.

Hammersley, Martyn. 1992. What's wrong with ethnography. London: Routledge.

Haugen, Einar 1953. The Norwegian language in America: A study in bilingual behavior. Philadelphia: University of Pennsylvania Press.

Håukas, Åsta. 2016. Teachers' beliefs about multilingualism and a multilingual pedagogical approach. International Journal of Multilingualism, 13 (1): 1-18.

Herdina, Philipp and Ulrike Jessner. 2000. The dynamics of third language acquisition. In: Cenoz, Jasone and Ulrike Jessner eds. English in Europe: The acquisition of a third language. Clevedon: Multilingual Matters. 84-99.

Herdina, Philipp and Ulrike Jessner. 2002. A dynamic model of multilingualism: Perspectives of change in psycholinguistics. Clevedon: Multilingual Matters.

Hlas, Anne Cummings. 2016. Secondary teachers' language usage: beliefs and practices. Hispania, 99 (2): 305-319.

Hofer, Barbara. 2015. On the dynamics of early multilingualism: A psycholinguistic study. Berlin: Walter de Gruyter.

Hoffman, Charlotte. 2000. The spread of English and the growth of multilingualism with English in Europe. In: Cenoz, Jasone, Ulrike Jessner eds. English in Europe: The acquisition of a third language. Clevedon: Multilingual Matters, $1-21$.

Hoffman, Charlotte. 2001. Towards a description of trilingual competence. The International Journal of Bilingualism, 5(1): 1-17.

Horváth, István and Alexandra Scacco. 2001. The characteristics of Romanian minority policy: From the unitary to the pluralistic fine-tuning minority policy in Romania. In: Anna-Mária Bíró and Petra Kovács, eds. Diversity in action: Local public management of multi-ethnic communities in Central and Eastern Europe. Budapest: LGI Books, 241-273.

House, Juliane. 2002. Developing pragmatic competence in English as a lingua franca, In: Knapp, Karlfried, Christiane Meierkord, eds. Lingua franca communication. Frankfurt am Main: Peter Lang, 245-267. 
House, Juliane. 2003. English as a lingua franca: A threat to multilingualism? Journal of Sociolinguistics, 7(4): 556-578.

House, Ernest R. 1980. Evaluating with validity. New York: Sage.

Hufeisen, Britta. 2005. Multilingualism: Linguistic models and related issues. In: Hufeisen, Britta and Robert J. Fouser eds. Introductory readings in L3. Tübingen: Stauffenburg Verlag, 31-46.

Hufeisen, Britta and Lindemann, Beate, eds. 1998. Tertiärsprachen.

Theorien, Modelle, Methoden. Tübingen: Stauffenburg.

Hüllen, Werner. 1992. Identifikationssprachen und Kommunikationssprachen. Zeitschrift für Germanistische Linguistik 20(3): 298-317.

Iațcu, Tatiana. 2005. Teaching English vocabulary to bilinguals: Hungarian Romanian (9-11 of age) with the help of Romanian, In: James Cohen, Kara T. McAlister, Kellie Rolstad, and Jeff MacSwan (eds.) ISB4: Proceedings of the 4th International Symposium on Bilingualism, Somerville, MA: Cascadilla Press, 1093-1104.

Iațcu, Tatiana. 2000. Teaching English as a third language to Hungarian-Romanian bilinguals, In: Cenoz, Jason, Ulrike Jessner eds. English in Europe: The acquisition of a third language. Clevedon: Multilingual Matters, 236-248.

Ife, Anne. 2008. A role for English as a lingua franca in the foreign language classroom? In: Eva Alcon and Maria Pilar Safont Jorda, eds. Intercultural language use and language learning. Dordrecht: Springer: 79-100.

James, Carl. 1996. A cross-linguistic approach to language awareness. Language Awareness, 5(3-4): 138-148.

Jarvis, Scott and Pavlenko, Aneta. 2007. Crosslinguistic influence in language and cognition. New York: Taylor \& Francis Inc.

Jessner, Ulrike. 1999. Metalinguistic awareness in multilinguals: Cognitive aspects of third language learning. Language Awareness, 3\&4: 201-209.

Jessner, Ulrike. 2003. The nature of cross-linguistic interaction in the multilingual system. In: Jasone Cenoz, Britta Hufeisen and Ulrike Jessner, eds. The multilingual lexicon. Dordrecht: Kluwer. 45-57.

Jessner, Ulrike. 2006. Linguistic awareness in multilinguals: English as a third language. Edinburgh: Edinburgh University Press. 
Jessner, Ulrike. 2008. Teaching third languages: findings, trends and challenges. Language Teaching, 41(1): 15-56.

Jessner, Ulrike. 2008. Multicompetence approaches to language proficiency development in multilingual education. In: Hornberger, Nancy ed. Encyclopedia of language and education. New York: Springer, 1552-1565.

Jessner, Ulrike, Megens, Manon and Graus, Stefanie. 2016. Crosslinguistic influence in third language acquisition. In: Rosa Alonso Alonso ed. Crosslinguistic influence in second language acquisition. Bristol: Multilingual Matters, 360400.

Jones, Bryn and Lewis Gwyn W. 2014. Language arrangements within bilingual education. In: Enlli Mon Thomas and Ineke Mennen eds. Advances in the study of bilingualism. Clevedon: Multilingual Matters, 141-170.

Johnson, Burke R. and Onwuegbuzie, Anthony J. 2004. Mixed methods research: A research paradigm whose time has come. Educational Researcher, 33 (7): 1426.

Jorda, Maria Pilar Safont. 2005. Third language learners: Pragmatic production and awareness. Clevedon: Multilingual Matters.

Jordan, Peter. 1998. Romania. In: Christina Bratt Paulston and Donald Peckham, eds. Linguistic minorities in central and Eastern Europe. Clevedon: Multilingual Matters, 184-223.

Kecskés, István. 2009. Dual and multilanguage systems. International Journal of Multilingualism, http://www.albany.edu/faculty/ikecskes/files/offpring\%20Kecskes\%20dual\%2 0and\%20multilanguage\%20systems.pdf, Access: 10 March, 2013

Kellerman, Eric. 2001. New uses for old language: cross-linguistic and cross-gestural influence in the narratives of non-native speakers. In: Cenoz, Jasone, Britta Hufeisen, and Ulrike Jessner eds. Cross-linguistic influence in third language acquisition: Psycholinguistic perspectives. Clevedon: Multilingual Matters. 170-192.

Kemp, Charlotte. 2009. Defining multilingualism. In: Aronin, Larissa and Britta Hufeisen, eds. The exploration of multilingualism: Development of research on L3, multilingualism and multiple language acquisition. Amsterdam/Philadelphia: John Benjamins Publishing Company, 11-26. 
Key data on teaching languages at school in Europe. 2012 http://eacea.ec.europa.eu/education/eurydice/documents/key_data_series/143en .pdf. Access: 02 April, 2014.

Kim, Eun-Young. 2011. Using translation exercises in the communicative EFL writing classroom. ELT Journal, 65 (2): 154-160.

Komorowska, Hanna. 2014. Analyzing linguistic landscapes. A diachronic study of multilingualism in Poland. In: Otwinowska, Agnieszka and De Angelis, Gessica, eds. Teaching and learning in multilingual contexts: Sociolinguistic and educational perspectives. Clevedon: Multilingual Matters, 19-31.

Kormos, Judit 2004. Az esettanulmány [Case study]. In: Kontráné Hegybiró, Edit and Kormos, Judit, eds. A nyelvtanuló: Sikerek, módszerek és stratégiák. [The language learner: Success, methods and strategies]. Budapest: Okker Kiadó, $25-30$.

Kramsch, Claire. 1998. The privilege of the intercultural speaker. In: Byram, Michael and Fleming, Michael, eds. Language learning in intercultural perspective: Approaches through drama and ethnography. Cambridge: Cambridge University Press, 16-31.

Kramsch, Claire. 2000. Second language acquisition, applied linguistics, and the teaching of foreign languages. The Modern Language Journal, 84(3): 311-326.

Kresić, Marijana. 2012. Crosslinguistic and intercultural strategies in models of multiple language learning. Conference presentation. $2^{\text {nd }}$ LINEE Conference, Dubrovnik, 4 May 2012.

Labov, William. 1972. Sociolinguistic patterns. Philadelphia: University of Pennsylvania Press.

Lambert, Wallace E. 1990. Persistent issues in bilingualism. In: Birgit Harley, Patick Allen, Jim Cummins and Merill Swain, eds. The development of second language proficiency, Cambridge: Cambridge University Press, 201-220.

Lasagabaster, David. 1998. Metalinguistic awareness and the learning of English as an L3. Atlantis, 20: 69-79.

Lasagabaster, David. 2000. Language learning and the development of metalinguistic awareness. Rassegna Italiana di Linguistica Applicata, 1(00): 103-116. 
Lasagabaster, David. 2001. The effect of knowledge about the L1 on foreign language skills and grammar. International Journal of Bilingual Education and Bilingualism, 4(5): 310-331.

Lasagabaster, David. 2005. Attitudes towards Basque, Spanish and English: An analysis of the most influential variables. Journal of Multilingual and Multicultural Development, 26: 296-316.

Laufer, Batia. 2003. The influence of L2 on L1 collocational knowledge and on L1 lexical diversity in free written expression. In: Cook, Vivian ed. Effects of the second language on the first. Clevedon: Multilingual Matters, 19-32.

Lazarton, Anne. 2002. Quantitative and qualitative approaches to discourse analysis. In: McGroarty, Mary ed. Annual Review of Applied Linguistics, 22: 32-51.

Lee, Icy. 2000. Can a nonnative English speaker be a good English teacher? TESOL Matters, 10(1): 19.

Levine, Glenn S. 2003. Student and instructor beliefs and attitudes about target language use, first language use, and anxiety: Report of a questionnaire study. The Modern Language Journal, 87(3): 343-364.

Levine, Glenn S. 2009. Building meaning through code choice in L2 learner interaction: a D/discourse analysis and proposals for curriculum design and teaching. In: Turnbull, Miles and Dailey-O'Cain, Jennifer eds. First language use in second and foreign language learning. Bristol: Multilingual Matters, 145-162.

Levine, Glenn S. 2011. Code choice in the language classroom. Bristol: Multilingual Matters.

Levine, Glenn S. 2014. Principles for code choice in the foreign language classroom: A focus on grammaring. Language Teaching, 47 (3): 332-348.

Li, Wei and Wu, Chao-Jung. 2009. Polite Chinese children revisited: creativity and the use of codeswitching in the Chinese complementary school classroom. International Journal of Bilingual Education and Bilingualism, 12(2): 193211.

Lincoln, Yvonna S. and Guba, Egon G. 1985. Naturalistic inquiry. Newbury Park, CA: Sage.

Lin, Angel M.Y. 2008. Code-switching in the classroom: research paradigms and approaches. In: Hornberger, Nancy ed. Encyclopedia of language and education. New York: Springer, 3464-3477. 
Littlewood, William and Yu, Baohua. 2011. First language and target language in the foreign language classroom. Language Teaching, 44 (1): 64-77.

Lüdi, Georges. 1986. Forms and functions of bilingual speech in pluricultural migrant communities in Switzerland. In: Fishman Joshua A. ed. The Fergusonian impact. Vol. 2: Sociolinguistics and the sociology of language. Berlin, New York and Amsterdam: Mouton de Gruyter, 217-236.

Lüdi, Georges. 2003. Code-switching and unbalanced bilingualism. In: Jean-Marc Dewaele and Alex Housen and Wei Li, eds. Bilingualism: Beyond basic principles. Clevedon: Multilingual Matters, 174-188.

Lugossy, Réka. 2003. Code-switching in the young learner classroom. In: Andor, József, Horváth, József and Nikolov, Marianne, eds. Studies in English theoretical and applied linguistics. Pécs: Lingua Franca Csoport, 300-309.

Macaro, Ernesto. 1997. Target language, collaborative learning and autonomy. Clevedon: Multilingual Matters.

Macaro, Ernesto. 2001. Analysing student teachers' code-switching in foreign language classrooms: theories and decision making. The Modern Language Journal, 85(4): $531-548$.

Macaro, Ernesto. 2009. Teacher use of code-switching in the L2 classroom: exploring 'optimal' use. In: Turnbull, Miles and Dailey-O'Cain, Jennifer eds. First language use in second and foreign language learning. Bristol: Multilingual Matters, 35-49.

Macaro, Ernesto. 2014. Students' strategies in response to teachers' second language explanations of lexical items. The Language Learning Journal, 42(1): 14-32.

Mackey, Alison and Gass, Susan M. 2005. Second Language Research: Methodology and Design. London: Lawrence Erlbaum Associates.

Makoni, Sinfree and Pennycook, Alastair. 2007. Disinventing and reconstituting languages. In: Makoni, Sinfree and Pennycook, Alastair eds. Disinveting and reconstituting languages. Clevedon: Multilingual Matters, 1-41.

Malloy, Tove H. (ed.) 2013. Minority issues in Europe: Rights, concepts, policy. Berlin: Frank \& Timme GmbH.

Martin-Jones, Marilyn 1995. Code-switching in the classroom: Two decades of research. In: Milroy, Lesley and Muysken, Pieter, eds. One speaker, two 
languages. Cross-disciplinary perspectives on code-switching. Cambridge: Cambridge University Press, 90-111.

Martin-Jones, Marilyn. 2000. Bilingual classroom interaction: A review of recent research. Language Teaching, 33(1): 1-9.

McKay, Sandra Lee. 2003. Toward an appropriate EIL pedagogy: Re-examining common ELT assumptions. International Journal of Applied Linguistics, 13 (2): $1-22$.

McKay, Sandra Lee. 2006. Researching second language classrooms. London: Lawrence Erlbaum Associates.

Medgyes, Péter. 1994. The non-native teacher. London: Macmillan.

Medgyes, Péter. 2014. The native/nonnative conundrum revisited. In: Medgyes, Péter and József, Horváth, eds. Studies in honour of Marianne Nikolov, Pécs: Lingua Franca Csoport, 176-185.

Meisel, Jürgen M. 1983. Transfer as a second-language strategy. Language and communication, 3 (1): 11-46.

Meisel, Jürgen M. 1989. Early differentiation of languages in bilingual children. In: Kenneth Hyltenstam and Loraine Obler eds. Bilingualism across the lifespan: Aspects of acquisition, maturity, and loss. Cambridge: Cambridge University Press, 13-40.

Meißner, Franz-Joseph. 2004. Transfer und transferieren: Anleitungen zum interkomprehensionsunterricht [Transfer and transferring: A guide in teaching intercomprehension]. In: Horst G. Klein and Dorothea Rutke eds. Neuere Forschungen zur europäischen Interkomprehension [New research for the European intercomprehension]. Aachen: Shaker Verlag, 39-66.

Mellow, Dean J., Reeder, Kenneth and Forster, Elisabeth. 1996. Using time-series research designs to investigate the effects of instruction on SLA. Studies in Second Language Acquisition, 18: 325-350.

Merritt, Marilyn, Cleghorn, Ailie, Abagi, Jared O. and Bunyi, G. 1992. Socialising multilingualism: Determinants of code-switching in Kenyan primary classrooms. Journal of Multilingual and Multicultural Development, 13(1/2): $103-121$.

Milroy, Lesley and Muysken, Pieter. 1995. Introduction: Code-switching and bilingualism research. In: Milroy, Lesley and Muysken, Pieter, eds. One 
speaker, two languages: Cross-disciplinary perspectives on code-switching. Cambridge: Cambridge University Press, 1-15.

Mitchell, Rosamond, Ioannidou, Elena, Dal Negro, Silvia, De Angelis, Gessica, Varcasia Cecilia and Cortinovis, Enrica 2008. Traditional pedagogic cultures in foreign language education and the need for multicompetence. LINEE: Final Report of Work Package 8. Access on www.linee.info. 02 April, 2014.

Mohamed, Naashia. 2016. An exploratory study of the interplay between teachers' beliefs, instructional practices and professional development. Auckland: University of Auckland. $\mathrm{PhD}$ dissertation. https://www.asian-efljournal.com/Thesis_Naashia.pdf. Access: 10 January, 2018.

Molnár, Timea. 2010a. Rolul L2 în achiziţionarea L3: o comparaţie a competenţei lexicale a elevilor unilingvi vs. bilingvi [The role of the L2 in learning an L3: A comparison of monolingual vs. bilingual learners' lexical competence]. In: Horváth István and Tódor Erika Mária, eds. Limbă, identitate, multilingvism şi politici educaţionale [Language, identity, multilingualism and educational policies]. Cluj-Napoca: Editura Institutului pentru Studierea Problemelor Minorităţilor Naţionale, 141-164.

Molnár, Timea. 2010b. Cognate recognition and L3 vocabulary acquisition. Acta Universitatis Sapientiae Philologica, 2 (2): 337-349.

Molnár, Timea. 2010c. Second language versus third language vocabulary acquisition: a comparison of the English lexical competence of monolingual and bilingual students. Toronto Working Papers in Linguistics, 33. http://twpl.library.utoronto.ca/index.php/twpl/article/view/6893/12728, Access: 7 September 2013

Montelongo, Jose A.; Hernández, Anita C and Herter, Roberta J. 2009. Transparency ratings for Spanish-English cognate words. Cal Poly Digital Repository: http://digitalcommons.calpoly.edu/cgi/viewcontent.cgi?article=1035\&context= lib_facAccess: 08 April, 2014

Morse, Janice M., Michael Barrett, Maria Mayan, Karin Olson, and Jude Spiers. 2002. Verification strategies for establishing reliability and validity in qualitative research. International Journal of Qualitative Methods, 1(2): 13-22.

Moussu, Lucie and Llurda Enric. 2008. Non-native English-speaking English language teachers: History and research. Language Teaching, 41(3): 315-348. 
Muharata, Goro and Muharata Yoshiko. 2008. V. Cook's multicompetence and its consequences for SLA research and L2 pedagogy. Research reports of the Department of International Studies (Kochi University), 9: 109-128. http://souls.cc.kochi-u.ac.jp/?\&rf=3429. Access: 5 May, 2009.

Muñoz, Carmen. 2000. Bilingualism and trilingualism in school students in Catalonia. In: Cenoz, Jasone and Ulrike Jessner eds. English in Europe: The acquisition of a third language. Clevedon: Multilingual Matters. 157-178.

Nagy, Krisztina. 2009. English language teaching in Hungarian primary schools with special reference to the teachers' mother tongue use. University of Stirling: The Stirling Institute of Education, PhD dissertation.

https://dspace.stir.ac.uk/bitstream/1893/1688/1/Nagy\%20K\%20PhD\%202009. pdf. Access: 11 November, 2017.

Nagy, Krisztina and Robertson, Daniel. 2009. Target language use in English classes in Hungarian primary schools. In: Turnbull, Miles and Dailey-O'Cain, Jennifer eds. First language use in second and foreign language learning. Bristol: Multilingual Matters, 66-87.

National Institute of Statistics (Romania). 2013. Rezultatele definitive ale recensământului populației și al locuințelor - 2011 (caracteristici demografice ale populaţiei) [Final results of the census - 2011 (demographic characteristics)]. $\quad$ http://www.recensamantromania.ro/wpcontent/uploads/2013/07/REZULTATE-DEFINITIVE-RPL_2011.pdf. Acces: 23 September, 2013.

National Institute of Statistics. 2012. Comunicat de presă privind rezultatele preliminare ale recensământului populației și al locuințelor - 2011 în județul Mureș [Press release regarding the preliminary results of the census - 2011 from Mureș county http://www.mures.insse.ro/phpfiles/Comunicat_presa_rez_preliminare_Mures_ RPL-2011.pdf. Access: 6 October, 2013.

National Institute of Statistics. 2013. Comunicat de presă privind rezultatele finale ale recensământului populației și al locuințelor - 2011 (caracteristici demografice ale populației) în județul Harghita [Press release regarding the preliminary results of the census - 2011 (demographic characteristics) from Harghita county 
http://www.harghita.insse.ro/phpfiles/Comunicat\%20de\%20presa.pdf. Access: 6 October ,2013.

National Institute of Statistics. 2012. Comunicat de presă privind rezultatele preliminare ale recensământului populației și al locuințelor - 2011 în județul Harghita [Press release regarding the preliminary results of the census - 2011 from Harghita county ].. http://www.harghita.insse.ro/phpfiles/ComunicatDATE_PROVIZORII_RPL_2011_JUD_HR.pdf. Access: 6 October, 2013.

The new Romanian national curriculum. 2000. http://www.seeeducoop.net/education_in/pdf/new_nation_curric_rom-rom-enl-t06.pdf, Access: 16 January, 2011

Key data on teaching languages at schools in Europe. 2012. http://eacea.ec.europa.eu/education/eurydice/documents/key_data_series/143en .pdf, Access: 22 June 2013

Common European framework of reference for languages: Learning, teaching, assessment. 2001. http://www.coe.int/t/dg4/linguistic/source/framework_en.pdf, Access: 9 September, 2008

Némethné Hock, Ildikó 2007. Hungarian teachers' classroom language use. In: Sheorey, Ravi and Kiss-Gulyás, Judit, eds. Studies in applied and theoretical linguistics. Debrecen: Kossuth Egyetemi Kiadó, 75-95.

Nikolov, Marianne. 1999. Classroom observation project. In E. Fekete, Hajnal, Major Éva and Marianne Nikolov, eds. English language education in Hungary, Budapest: The British Council, 221-246.

Nikolov, Marianne. 2000. Kódváltás pár- és csoportmunkában általános iskolai angolórákon. [Codeswitching in pair and group-work in the primary English lessons]. Magyar Pedagógia, 100: 401-422.

Nzwanga, Mazemba Anatole. 2000. A study of French-English codeswitching in a foreign language college teaching environment. Unpublished doctoral dissertation, Ohio State University. https://etd.ohiolink.edu/ap/10?0::NO:10:P10_ACCESSION_NUM:osu124837 8598, Access: 2 February, 2009

Odlin, Terence. 1989. Language transfer: Cross-linguistic influence in language learning. Cambridge: Cambridge University Press. 
Ó Laoire, Muiris and Singleton, David. 2009. The role of prior knowledge in L3 learning and use: Further evidence of psychotypological dimensions. In: Aronin, Larissa and Britta Hufeisen, eds. The exploration of multilingualism: Development of research on L3, multilingualism and multiple language acquisition. Amsterdam/Philadelphia: John Benjamins Publishing Company, 79-102.

Ortega, Lourdes. 2009. Understanding second language acquisition. London: Hodder Education.

Otwinowska, Agnieszka and De Angelis, Gessica, eds. 2014. Teaching and learning in multilingual contexts: Sociolinguistic and educational perspectives. Clevedon: Multilingual Matters.

Otwinowska, Agnieszka. 2013. Does multilingualism influence plurilingual awareness of Polish teachers of English? International Journal of Multilingualism, 11(1): 97-119.

Ovando, Carlos J. and Collier, Virginia P. 1985. Bilingual and ESL classrooms: Teaching in multicultural contexts. New York: McGraw Hill Book Company.

Paradowski, Michał. 2008. Corroborating the role of L1 awareness in FL pedagogy. In: 33rd International LAUD Symposium: Cognitive approaches to second/foreign language processing: Theory and pedagogy. Essen: Linguistic Agency University of Duisburg-Essen, 515-580.

Patton, Michael Q. 1999. Enhancing the quality and credibility of qualitative analysis. Health Services Research, 34(5): 1189-1208.

Pavlenko, Aneta. 2003. 'I feel clumsy speaking Russian': L2 influence on L1 in narratives of Russian L2 users of English. In: Cook, Vivian, ed. Effects of the second language on the first. Clevedon: Multilingual Matters, 32-62.

Pierson, Cheri and Odsliv Megan. 2012. Perspective and Trends on education in Romania: A country in transformation. International Journal of Humanities and Social Science, 12(2): 5-13.

Portolés, Laura and Martí, Otilia. 2017. Translanguaing as a teaching resource in early language learning of English as an additional language (EAL). Bellaterra Journal of Teaching \& Learning Language \& Literature, 10(1): 61-77. 
Poulisse, Nanda. 1997. Language production in bilinguals. In: Anette M. B. de Groot and Judith F. Kroll, eds. Tutorials in bilingualism: Psycholinguistic perspectives. Mahwah, NJ: Lawrence Erlbaum Associates, 201-224.

Poulisse, Nanda and Bongaerts, Theo. 1994. First language use in second language production. Applied Linguistics, 15(1): 36-57.

Punch, Keith F. 1998. Introduction to social research: Quantitative and qualitative approaches. London: Sage.

Ramirez, Arnulfo G. 1980. Language in bilingual classrooms. The Journal for the National Association for Bilingual Education, 4(3): 61-79.

Rampton, Ben; Roberts, Celia; Leung, Constant; Harris, Roxy. 2002. Methodology in the analysis of classroom discourse. Applied Linguistics, 23(3): 373-392.

Riazi, Mehdi A. and Candlin, Christopher N. 2014. Mixed-methods research in language teaching and learning: Opportunities, issues and challenges. Language Teaching, 47 (2): 135-173.

Ringbom, Håkan. 1986. Cross linguistic influence and the foreign language learning process. In: Sharwood Smith, Michael and Eric Kellerman eds. Cross-linguistic influence in second language acquisition. New York: Pergamon. 150-162.

Ringbom, Håkan. 1987. The role of the first language in foreign language learning. Clevedon: Multilingual Matters.

Ringbom, Håkan. 2001. Lexical transfer in L3 production. In: Cenoz, Jasone, Britta Hufeisen, and Ulrike Jessner, eds. Cross-linguistic influence in third language acquisition: Psycholinguistic perspectives. Clevedon: Multilingual Matters, $59-69$.

Ringbom, Håkan. 2005. L2-transfer in third language acquisition. In: Hufeisen, Britta and Robert J. Fouser, eds. Introductory readings in L3. Tübingen: Stauffenburg Verlag. 71-83.

Ringbom, Håkan. 2007. Cross-linguistic similarity in foreign language learning. Clevedon: Multilingual Matters.

Robson, Colin. 2002. Real world research: A resource for social scientist and practitioner-researchers. Oxford: Blackwell.

Rolin-Ianziti, Jeanne and Brownlie, Siobhan. 2002. Teacher use of the learners' native language in the foreign language classroom. The Canadian Modern Language Review, 58 (3): 403-426. 
Sanz, Cristina. 2000. Bilingual education enhances third language acquisition: evidence from Catalonia. Applied Psycholinguistics, 21: 23-44.

Sanz, Cristina. 2012. Multilingualism and metalinguistic awareness. In: Chapelle, Carol A. ed. The encyclopedia of applied linguistics, Oxford: Wiley-Blackwell, 3933-3942.

Scott, Virginia M. 2009. Double talk: Deconstructing monolingualism in classroom second language learning. Upper Saddle River, NJ: Prentice Hall.

Selinker, Larry. 1972. Interlanguage. International Review of Applied Linguistics 10:209-231.

Sharwood Smith, Michael and Eric Kellerman. 1986. Cross-linguistic influence in second language acquisition: an introduction. In: Kellerman, Eric and Michael Sharwood-Smith, eds. Crosslinguistic influence in second language acquisition, Oxford: Pergamon, 1-9.

Singleton, David and Little, David. 2005. A first encounter with Dutch: Perceived language distance and language transfer as factors in comprehension. In: Hufeisen, Britta and Robert J. Fouser, eds. Introductory readings in L3. Tübingen: Stauffenburg Verlag, 101-109.

Sindik, Joško and Božinović, Nikolina. 2013. Importance of foreign languages for a career in tourism as perceived by students in different years of study. Tranzicija, 15 (31): 16-28.

Soler, Eva Alcón. 2007. Linguistic unity and cultural diversity in Europe: implications for research on English language and learning. In: Soler, Eva Alcón and Safont Jordà, Maria Pilar, eds. Intercultural language use and language learning, Dordrecht: Springer Netherlands, 23-40.

Splosky, Bernard. 2004. Language policy. Cambridge: Cambridge University Press.

Stenhouse, Lawrence. 1988. Case study methods. In: Keeves, John P. ed. Educational research, methodology, and measurement: An international handbook, $1^{\text {st }} \mathrm{edn}$. Oxford: Pergamon, 49-53.

Sturman, Andrew. 1997. Case study methods. In: Keeves, John P. ed. Educational research, methodology, and measurement: An international handbook, 2nd edn. Oxford: Elsevier Science Ltd, 61-66.

Swain, Merrill and Lapkin, Sharon. 2000. Task-based second language learning: The uses of the first language. Language Teaching Research, 4: 253-276. 
Swain, Merrill and Lapkin, Sharon. 2013. A Vygotskian sociocultural perspective on immersion education: the L1/L2 debate. Journal of Immersion and Content Based Education, 1: 101-129.

Talebi, Seyed Hassan. 2013. Cross-linguistic Transfer (from L1 to L2, L2 to L1, and L2 to L3) of Reading Strategies in a Multicompetent Mind. Journal of Language Teaching \& Research, 4(2): 432-436.

T. Balla, Ágnes. 2013. The perceived role of L2 English in the process of learning L3 German. Romanian Journal of English Studies, 10(1): 62-76.

ten Thije, Jan D. and Zeewaert, Ludger eds. 2007. Receptive multilingualism. Amsterdam: John Benjamins Publishing Co.

Thompson, Gregory and Harrison, Katie. 2014. Language use in the foreign language classroom. Foreign Language Annals, 47 (2): 321-337.

Tremblay, Marie-Claude. 2006. Cross-linguistic influence in third language acquisition: the role of L2 proficiency and L2 exposure. CLO/OPL, Vol. 34: 109-119.

Tucker, Richard G. 1998. A global perspective on multilingualism and multilingual education. In: Cenoze, Jasone and Genesee, Fred, eds. Beyond bilingualism: Multilingualism and multilingual education. Clevedon: Multilingual Matters, $3-16$.

Tullock, Brandon and Fernández-Villanueva, Marta. 2013. The role of previously learned languages in the thought processes of multilingual writers at the Deutsche Schule Barcelona. Research in the Teaching of English, 47 (4): 420 441.

Turnbull, Miles and Dailey-O'Cain, Jennifer eds. 2009. First language use in second and foreign language learning. Bristol: Multilingual Matters.

UNESCO-IBE. 2012. World data on education. http://www.ibe.unesco.org/fileadmin/user_upload/Publications/WDE/2010/pdfversions/Romania.pdf, Access: 14 March, 2014

Urmston, Alan. 2003. Learning to teach English in Hong Kong: the opinions of teachers in training. Language and Education, 17 (2): 112-137.

Van der Perre, J. 1994. Higher education and an evolving Europe. In L. Barrows, ed. CEPES papers on higher education. New York: UNESCO, 7-17.

Veronique, Daniel. 2010. Cross linguistic influence (CLIN) in L2/L3 acquisition. The dynamics of transfer. 
http://www.eva.mpg.de/lingua/conference/2010_summerschool/pdf/course_mate rials/Veronique_session6.pdf, Access: 23 October, 2011.

Voicu, Cristina-Georgiana. 2012. Overusing mother tongue in English language teaching. Cultural and Linguistic Communication, 2 (3): 212-218.

Wei, Li. 2014. Translanguaging knowledge and identity in complementary classrooms for multilingual minority ethnic children. Classroom Discourse, 5(1): 1-18.

Weinreich, Uriel. 1953. Languages in contact: Findings and problems. New York: Linguistic Circle.

Williams, Sarah and Björn Hammarberg. 1998. Language switches in L3 production: Implications for a polyglot speaking model. Applied Linguistics, 19(3): 295333.

Wing, Barbara H. 1980. The languages of the foreign language classroom: A study of teacher use of the native and target languages for linguistics and communicative functions. Columbus, $\mathrm{OH}$ : Ohio State University $\mathrm{PhD}$ dissertation.

https://etd.ohiolink.edu/!etd.send_file?accession=osu1230737833\&disposition =inline. Access: 23 October, 2011.

Wong Fillmore, Lily and Valadez, Concepcion. 1986. Teaching bilingual learners. In: Wittrock, Merlin C. ed. Handbook of research on teaching. New York: Macmillan Publishing Company, 648-685.

Wood, Jamison 2011. Third language acquisition: Spanish-speaking students in the Latin classroom. Teaching classical languages, 2(2): 81-92.

Yin, Robert K. 1994. Case study research: Design and methods, $2^{\text {nd }}$ edn. London: Sage. Ytsma, Jehannes. 2000. Trilingual primary education in Friesland. In: Cenoz, Jasone, Ulrike Jessner eds. English in Europe: The acquisition of a third language. Clevedon: Multilingual Matters, 222-236. 


\section{Appendix 1a.}

\section{Sample official letter to school directors}

Stimate domn director,

Szeged, 2008. 10. 22.

Vă contactez cu rugămintea ca dumneavoastră să permiteţi ca o persoană, Dégi Zsuzsanna, din grupul de cercetători aflat sub coordinarea mea să vă viziteze şi să contacteze profesorii de limba engleză. Cu acordul Dvs. şi al profesorilor am dori să observăm câteva lecţii de engleză şi să facem câteva interviuri cu copii.

Grupul de cercetători funcţionează în cadrul Facultăţii de Litere a Universităţii din Bolzano, Italia şi Universitatea din Szeged, făcând parte dintr-un proiect al unui consorţiu, care înglobează câte o universitate din 9 ţări europene şi care cercetează varietatea lingvistică prezentă în ţările europene.

Proiectul are numele de LINEE (Languages in a Network of European Excellence).

Acesta se referă, pe de o parte la grupul de programe de cercetare ştiinţifice din „reţeaua preferenţială" din Uniunea Europeană, pe de altă parte la scopul principal al colaborării: cercetarea coherentă şi interdisciplinară a varietăţii lingvistice din Europa.

Din acest cadru general, grupul nostru cercetează relaţia dintre varietatea lingvistică şi învăţământ: prospectând folosirea limbilor şi valorile acordate anumitor limbi de către studenţii ale comunităţilor minoritare istorice din Italia, Slovacia, România, Ungaria şi Serbia.

Astfel, din partea noastră Dégi Zsuzsanna ar dori să vă viziteze pentru a înregistra date lingvistice pentru cercetarea noastră.

Dacă dumneavostră permiteţi acest lucru, Zsuzsanna v-ar contacta telefonic pe dumneavoastră pentru a stabili o întâlnire preliminară, când vor putea fi stabilite detaliile.

Zsuzsanna este cercetătoare tânără, care studiază la Universitatea din Szeged, Programul de Doctorat de Lingvistică.

deplină.

Este o persoană conștiincioasă, viitor savant serios şi în care am încredere

Dacă aveţi eventuale întrebări, vă rog să mă contactaţi pe adresa de mail fenyvesi@lit.uszeged.hu, sau pe adresa de servici de mai sus.

Vă mulţumesc pentru timpul acordat şi pentru cooperare.

Cu stimă:

Dr. Anna Fenyvesi

Conferenţiar universitar şi coordinator de proiect

Universitatea din Szeged

Institutul Anglo-American 
Appendix 1b.

\section{Sample official letter to school principals}

Dear Sir/Madam,

Szeged, 22 October 2008

I am writing to you in order to ask you to allow a person, Ms. Zsuzsanna Dégi, a member of the research team under my coordination, to contact you and visit English teachers at your institution. With your and the teachers' approval we would like to observe some English classes and conduct interviews with the students.

The research team operates within the frameworks of the Bolzano University, Italy and the University of Szeged, Hungary. We are working on a consortium project, which incorporates universities from 9 different European countries, with the aim to study linguistic diversity in European countries.

The project is called LINEE (Languages in a Network of European Excellence). This, on the one hand, refers to the scientific research programmes from the ,excellence networks" of the European Union and, on the other hand, to the main purpose of the cooperation: coherent and interdisciplinary research of linguistic diversity in Europe.

Within this framework, our team studies the relationship between linguistic diversity and the educational system by investigating language use and the value associated to these languages by the historic minorities of Italy, Slovakia, Romania, Hungary and Serbia.

For this reason, Zsuzsanna Dégi would like to visit your institution in order to record data for our research.

If you agree to this, Zsuzsanna would contact you over the phone to establish a preliminary meeting, so that further details can be discussed in person.

Zsuzsanna is a young researcher; she is studying at the University of Szeged, at the English Applied Linguistics doctoral school.

She is a conscious, hard working person and a promising future scientist, whom I completely trust.

Should you have any further questions do not hesitate to contact me at the following email address: fenyvesi@ lit.u-szeged.hu, or the office address above.

Thank you very much for your time and cooperation.

Yours faithfully,

Dr. Anna Fenyvesi

Associate professor, project coordinator

University of Szeged

Institute of English and American Studies 


\section{Appendix 2a.}

\section{Convenție civilă bilaterală}

Prezenta convenţie s-a încheiat astăzi, ziua , luna anul 2012 în

localitatea Miercurea Cscolară

Covenţia de faţă s-a întocmit pentru a servi la efectuarea unei cercetări de natură academică în domeniul lingvisticii aplicate cu titlul: „Multicompetence in the EFL classroom: multiple case study".

Părţile semnatare ale prezentei convenţii sunt următoarele persoane fizice identificate mai jos:

Prima parte Zsuzsanna Dégi, cu domiciliul în localitatea Târgu Mureş, jud. Mureş, str. Mestecănişului nr. 14, având cardul de identitate seria MS, nr. 520216, eliberat de către SPCLEP Tg. Mureş, în calitate de cercetător.
A doua parte
cu domiciliul în localitatea
jud. str.

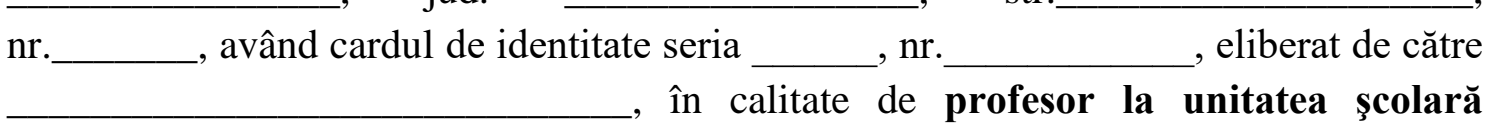 cercetată şi mai sus menţionată.

Zsuzsanna Dégi, în calitate de cercetător, prin prezenta convenţie sunt de acord ca datele provenind din cercetarea efectuată să fie tratate confidențial şi să nu le folosesc decât în ideea şi scopul pentru care au fost create. Datele - incluzând interviuri cu profesori şi elevi, şi înregistrările video - vor fi folosite pentru teza de doctorat şi lucrările ştiinţifice scrise de către Zsuzsanna Dégi, menţionând că imaginile video nu vor fi folosite în public, iar numele școlilor, profesorilor și elevilor nu vor fi menționate.

, în calitate de profesor/profesoară de engleză, prin prezenta convenţie sunt de acord ca Zsuzsanna Dégi să efectueze înregistrări video despre orele de engleză cu scopul de a-i servi la teza de doctorat. În calitate de profesor am dreptul să refuz sau să cer ştergerea înregistrărilor video dacă majoritatea elevilor dintr-o clasă nu sunt de acord cu utilizarea datelor.

DATA

SEMNĂTURILE PĂRŢILOR: 


\section{Appendix 2b.}

\section{Bilateral Confidentiality Agreement}

This Agreement is entered into on this day of by and between located at school , Miercurea Ciuc.

The Parties agree to sign the present agreement for the purpose of carrying out an academic research in linguistics entitled: „Multicompetence in the EFL classroom: multiple case study".

The present Agreement is signed by the following individuals:

The first party is, Zsuzsanna Dégi, residing in Târgu Mureș, Mureș county, Mestecănişului 14, ID Series MS, no. 520216, issued by SPCLEP Tg. Mureş, as researcher.

The second party residing in

county $\_$no._ St. issued by_ $\_$no.__ ID Series $\_$, as a teacher at the
aforementioned school visited.

Zsuzsanna Dégi, as a researcher, hereby agrees that all data obtained from the research will be kept confidential, and will not be used anywhere else but for the purpose and idea for which it was collected.

Data - including interviews with teachers and students and video recordings - will be used only for the purpose of the doctoral dissertation and scientific papers written by Zsuzsanna Dégi, mentioning that videos will not be shown on public display; and the names of students and schools will not be mentioned.

, as an English teacher hereby agree that Ms.

Zsuzsanna Dégi carries out video recordings of the English classes, with the purpose to collect data for her Doctoral dissertation. As a teacher I have the right to refuse or ask for the deletion of the video recording, if the majority of students do not agree with the use of the data.

DATE 1

SIGNATURES: 


\section{Appendix 3.}

\section{Questionnaire}

I need the following data for my linguistic research. There are no right or wrong answers. I will treat the data confidentially - the data will be used solely for the purposes of my research.

Thank you very much for helping me in my work.

0. Date

1. You are:

a. Female

b. Male

2. Your age: a) 20-29 $\begin{array}{lll}\text { b) } 30-39 & \text { c) } 40-49 & \text { d) } 50-59\end{array}$

3. Your nationality:

4. Your mother tongue:

5. For how long have you been teaching English?

6. What is the mother tongue of the students you teach:
a. Hungarian exclusively
b. Romanian exclusively
c. Mostly Hungarian
d. Mostly Romanian
e. Half Hungarian and half Romanian
f. Other:

7. What language(s) do you predominantly use during an English class:
a. English
b. English+Hungarian
c. English+ Romanian
d. English+Hungarian+Romanian
e. English+Hungarian+other FL
f. English+ Romanian+other FL
g. Other combination of languages:

8. When greeting the children (when entering/leaving the classroom), how often do you use these languages:

\begin{tabular}{|l|l|l|l|l|l|}
\hline & Always & Mostly & Sometimes & Rarely & Never \\
\hline EN & & & & & \\
\hline HU & & & & & \\
\hline RO & & & & & \\
\hline Other: & & & & & \\
\hline
\end{tabular}

9. When students greet you in the classroom, what are your expectations about how often they should use these languages:

\begin{tabular}{|l|l|l|l|l|l|}
\hline & Always & Mostly & Sometimes & Rarely & Never \\
\hline EN & & & & & \\
\hline HU & & & & & \\
\hline RO & & & & & \\
\hline Other: & & & & & \\
\hline
\end{tabular}


10. When discussing organizational matters in class, how often do you use these languages:

\begin{tabular}{|l|l|l|l|l|l|}
\hline & Always & Mostly & Sometimes & Rarely & Never \\
\hline EN & & & & & \\
\hline HU & & & & & \\
\hline RO & & & & & \\
\hline Other: & & & & & \\
\hline
\end{tabular}

11. When you give explanations in class (e.g. in grammar, spelling, writing etc.), how often do you use these languages:

\begin{tabular}{|l|l|l|l|l|l|}
\hline & Always & Mostly & Sometimes & Rarely & Never \\
\hline EN & & & & & \\
\hline HU & & & & & \\
\hline RO & & & & & \\
\hline Other: & & & & & \\
\hline
\end{tabular}

12. How frequently do you translate unknown words (rather than paraphrase them in English)?

a. I always translate

b. I mostly translate

c. I translate and paraphrase equally

d. I only translate a few times

e. I never translate

13. If you translate words, in what language do you translate them:
a. $\mathrm{HU}$
b. RO
c. Other:

14. During the lesson, do you make connections (lexical, grammatical similarities/dissimilarities) with languages other than the target language? If yes, how often do you use these languages:

\begin{tabular}{|l|l|l|l|}
\hline & Often & Sometimes & Never \\
\hline EN & & & \\
\hline HU & & & \\
\hline RO & & & \\
\hline Other: & & & \\
\hline
\end{tabular}

15. If a question is addressed to you in the student's mother tongue, in what language do you typically respond:
a. Student's MT
b. EN
c. Other:

16. If you ask a question in the target language but the student responds in his/her MT, what do you typically do:

a. Evaluate response in the target language 
b. Evaluate response in the MT of the student

c. Repeat student's answer in the target language

d. Ask the student to repeat the answer in the target language

e. Other:

17. During small group activities, what language(s) do you require from the students to use:

a. Only EN

b. EN+ student's MT

c. Other:

18. When telling off the students, how often do you use these languages:

\begin{tabular}{|l|l|l|l|l|l|}
\hline & Always & Mostly & Sometimes & Rarely & Never \\
\hline EN & & & & & \\
\hline HU & & & & & \\
\hline RO & & & & & \\
\hline Other: & & & & & \\
\hline
\end{tabular}

19. When you joke with students, how often do you use these languages:

\begin{tabular}{|l|l|l|l|l|l|}
\hline & Always & Mostly & Sometimes & Rarely & Never \\
\hline EN & & & & & \\
\hline HU & & & & & \\
\hline RO & & & & & \\
\hline Other: & & & & & \\
\hline
\end{tabular}

20. When talking about informal things, how often do you use these languages:

\begin{tabular}{|l|l|l|l|l|l|}
\hline & Always & Mostly & Sometimes & Rarely & Never \\
\hline EN & & & & & \\
\hline HU & & & & & \\
\hline RO & & & & & \\
\hline Other: & & & & & \\
\hline
\end{tabular}

21. How often do you use these languages when talking to the students outside the classroom, during break time:

\begin{tabular}{|l|l|l|l|l|l|}
\hline & Always & Mostly & Sometimes & Rarely & Never \\
\hline EN & & & & & \\
\hline HU & & & & & \\
\hline RO & & & & & \\
\hline Other: & & & & & \\
\hline
\end{tabular}

If you have any comments regarding this questionnaire or regarding your or your students' language use, you can write them here: 


\section{Appendix 4.}

\section{Interviews with students (guiding questions):}

Questions regarding their language background:

- How many languages do you know/speak? How well do you know them?

- What do you consider to be your 'first' language and why?

- When did you start learning your second/third/etc. languages?

- Have you studied these languages in school, and if so, from what age?

- Did you choose to study English/other languages or was it compulsory?

- Do you think it will be useful? Why? In what areas will it be useful? (For further study? For your career? For travel? For friendship?)

Questions regarding their language use during FL class:

- What languages do you hear during an English lesson?

- In what ways are they present? Who speaks them? Why?

- What languages does your teacher use during an English class? In what languages does she explain to you the grammar for example? Do you feel you need grammar to be explained to you in Hungarian/Romanian? Would you understand it in English?

- If many of you haven't done your homework and the teacher is angry with you what does she say? Does she say it in English or Hungarian?

- What kind of tasks do you like in the class? In what language are the instructions given? If you don't understand something about what you have to do, do you ask your teacher to repeat or your neighbour? What language does the teacher use when you ask for clarification of instructions or repetition of it? In what language do you ask your question? If you ask your neighbour, in what language does the conversation go on?

- Let's say you have to solve a problem in groups. What language(s) do you use during group work? Why do you use several languages? Are there also colleagues of yours that speak only in English? Do they say anything to you about what language to use? Why do you use only English? Does the teacher require the use of any specific language or you are free to use any language(s) you want to? Why does she require only English, what do you think? Do you agree with her? Why, why not? If she requires using only English, do you follow her instructions or are there occasions when you use other languages too? What are these instances?

- Does it happen to you that a word does not come to your mind? Do you ask it from the teacher or from your colleague? In what language?

- When you are talking to your neighbour during the lesson about personal things, or the homework of the next lesson in what language does the conversation go on?

- If you would need a pencil or pen, in what language would you ask for it, form your colleague? 
- What about the others students? Are they like you using several languages/using only English? What do they do, do they also speak in HU during the lesson? When are they using HU? What do you think about it?

- How would an EN lesson look like if you would be the teacher? Would you have any restrictions on the use of other languages? Why, why not?

\section{Multicompetence:}

- When do you use English? Only in school/other occasions? What are these occasions? Why?

- When writing an essay, how do you do it? In what language come your ideas in your mind?

- What do you do when you encounter an unknown word? (deduce/dictionary?)

- Is translation a big part of your language learning? For example, when you read in EN do you also try to translate it for yourself? Have you ever translated texts or have you interpreted for someone else? Tell me about it? What are your experiences regarding translations? Was it difficult? Into what language did you translate?

- Have you ever experienced meeting an unknown word, but you knew what it meant? What do you think, how do you know it?

- Did it ever happen to you that you mixed languages? Why do you think you did? How do you feel about it?

- Do any of your languages help you in learning EN?

- Does English help you in learning other languages? How? Why do you think it helps?

- Are there any resemblances between the languages that you know? What sort of similarities? What do you think, do similarities help or in contrary, do they make things worse? 


\section{Appendix 5.}

\section{Sample classroom observation transcription}

School: TVSec mixed vocational school in Târgu Mureș/Marosvásárhely

Transcription Key

CAPITAL LETTERS: words said with emphasis

$\%$.....\%: words spoken very quietly

(.) : short pause

(...): long pause

I: indicates the end of an utterance

$(())$ : doubt about accuracy of transcription

((???)): inaudible speech

$<>$ : additional information

S1, S2: students

$\mathrm{T}$ : teacher

1. <Noise in the class as the teacher comes in>

2. T: Da gata?/

3. S: Gata/

4. T: Ti-am zis ca/ Eniko/las ca le gasesti in pauza draga/ tot asa-i si in pauza/ nah(.)

5. S: Da, ce sa-i povestim

6. T: okay/ the notebooks/ if the uniforms are on notebooks/Bagi you're truly the best today/ he's the superstar of the class/ okay/ first of all do we have any absents?/

7. S: Yes ((Pal Elod $)) /$

8. T: He's the only one?

9. <students starting to enumerate the absents in the same time>

10. T: Could you please just one person because I don't understand the entire(.) Zii Eniko/

11. <student enumerates the absents>

12. T: Okay good(...)ai fost absenta ora trectuta?/ nah okay/ ramaneti pe loc/ so what was our last lesson?/

13. S: Present tense continuous/

14. $\mathrm{T}$ : Present tense continuous=

15. S:

$=\mathrm{Da}$

16. T: okay how do we form present tense continuous in the affirmative?/ give me a sentence/

17. <student walks in late>

18. S: 'Neata profesoara/

19. T: Vai nu pot sa cred/ Nu te-am vazut de o suta de ani/ Uniforma unde ti-i?

20. S: In ghiozdan/

21. T: In ghiozdan/ Dar n-am zis inca ca poti sa intri/

22. S: Am intrebat/ 
23. T: Tu m-ai intrebat dar nu poti/ Eu n-am spus nimica/

24. S: Nah bine.

25. <laughter>

26. T: Eu zic ca sa nu cauti nici ora asta/

27. S: ((???)) saptesnoua de absente/ cum se poate/

28. T: Poate eu le-am facut Sandor draga/

29. S: Cateodata si dumneata adica si dumneavoastra mi-ati trecut

30. T: Te cred eu dar hai sa vedem ai fost la ore si ti-am pus absenta/ Nah sezi si taci!/ Uniforma pe tine!/ Okay so can you give an example?/Incredible/ Cand s-o sunat in clasa?

31. S: I am writing a lesson/

32. T: I am writing a lesson/ what's the rule?/

33. S: writing

34. T: writing/da si?/

35. S: and ing/

36. T: ing/\%((???))\% In the negative/

37. S: I am not writing/

38. $\mathrm{T}$ : I am not writing/ and in the interrogative?/

39. S: $\mathrm{Am} \mathrm{I}=$

40. $\mathrm{T}: \quad=$ Am I writing?/ What kind of actions does present tense simple expresses?/ (.) What kind of action?/ (.) Zii Eniko! (.) Nu ti-ai ridicat mana?/

41. S: Nu nu/

42. T: Ah scuze atuncea/ So what kind of action?/ Definitely a present one but?/

43. S: An action in progress in the moment of the speech/

44. $\mathrm{T}$ : In the moment of speaking da?/I'm writing right now/ Bagi is speaking right now/ Sandor is talking to Szabi right now/ So Iza and Eniko is eating/ These are actions that take place right now/ okay?/ And they are (.) <laughter> okay so/ Sandor draga ce tiam spus cand ai intrat in clasa/ pliscu' inchis/ Toata ora/ Ne-am inteles?/ Tu nu tre' sa scoti absolut ABSOLUT nici o vorba/ Nici un sunet/ Nici un mormait/ NIMIC/ Ai priceput?/ (.) Da/ Pana n-ai venit o fost liniste/

45. S: dar nu pot sa fac asa/

46. T: Liniste!/ Poti sa-nchizi si te rog muzica/ ((???)) in afara de foame asa-i? Okay/ What's the difference between present simple and present continuous?/

47. S1: Cum?

48. S2: Present tense continuous is right now/

49. T: And present tense simple?/

50. S1: It's an action that we do =

51. S2:

=we do every day/

52. T: We do every day/ Okay so if I have the sentence: Noi mergem la mare in fiecare vara/ Ce timp folosim?/

53. S: present $=$

54. S: $\quad=$ Present tense simple/

55. T: Simple/ Cum o fi in engleza?/

56. S: Errr we go to the $=$

57. T: =seaside $=$

58. S: =seaside every year/

59. T: Every year/ Si daca va spun ca Eu merg la mare acum?/

60. S1: I am go (.)

61. S2: I'm going to the seaside. 
62. T: Asa/ I'm going to the seaside/ Acum timpurile astea vi le-am dat ca sa le puteti folosi corect in vorbire/ Sa nu va mai aud persoana a treia singular fara s/ Sa nu va mai aud ca He go He eat si asa mai departe/ Neaparat nu uitati de s/ Ne-am inteles?/ Si sa nu mai folositi in orice compunere He is going He is leaving every day/ Ca nu-i corect/ Neam inteles?/ Bun/ Today's lesson is going to be a writing lesson (.) < the teacher tells the title while she writes it on the blackboard> For and against writing (.)essay/ Do I have to translate this into Romanian?/

63. S: yes

64. T: Eseuri pro si contra/ (.)Eseuri pro si contra/ Considering the title could you guess some themes of essays?/(.) Nah nimic?/ Luandu-va dupa titlu puteti sa ghiciti cam ce fel de eseuri trebuie sa scrieti?/

65. S: Da

66. T: $\mathrm{Ce}$ ?

67. S: un argument

68. T: $\mathrm{Hm}$ ?

69. S: ca un argument

70. T: Da-mi un titlu/

71. S: Daca suntem de acord $\mathrm{cu}=$

72. $\mathrm{T}$ : $\quad=$ Cu ce?

73. S:cu tot ce este in propozitie sau(.)

74. T: Okay/ Let's see the structure. ((...))

75. <the teacher writes on the blackboard>

76. T: It is an essay where you have to bring arguments for and against/ how do you have to start?/na

77. S: I think/

78. T: No/ Never/ If it's for and against you never have to start with your opinion/ You have to start with/ <the teacher writes on the blackboard>State the theme/ You have to tell me first of all what you're talking about so I can understand/ And then you have to tell me some general (.) ideas of the theme/ For example if you have to speak for and against the internet/ How do you state the theme?

79. S: Internet/

80. T: Atat?/ Internet punct?/

81. S: Da

82. S: No ((???))

83. T: Clar/ Cum imi spuneti care-i tema?/ Daca subiectul la bac ar fi Speak about the advantages and disadvantages of the internet/ Cum incepeti?/ (.)

84. S1: Errrr/

85. S2: Let's speak about the internet/Internet is blablabla/

86. T: Asa deci In my essay I want to speak about the internet/ Si acum something general about internet/ ce spuneti ceva in general despre internet/

87. S1: in general

88. S2: Errr/

89. T: Nu/ Zii Eniko ca doar bine ai inceput/ Ca toata lumea foloseste internetul/ Ca folosim internetul ca alta data/ Nu?/ Nu astea-s idei generale?/ Idei generale/ Everybody uses the internet/ Internet is a means of communication/ We use the internet to search information and so on/ After that (.) <the teacher writes on the blackboard> the main body/ Ce scrieti in cuprins?/ (.) For the most basic essay/

90. S: Tot despre /

91. T: No no/ For the most basic internet you have to tell that/ In the first of all you have to bring arguments for plus = 
so good/ We say internet is the best because we need it at school we download movies we watch 69 sites and so on and=

94. S: $=$ and more $=$
95. T: =and JUSTIFICATION/ You have to give me examples from your own personal experiences or from what you heard from the others/ And <the teacher writes on the blackboard > arguments against plus justification/Internet is bad because we depend on=

96. S: $=$ Yeah $=$

97. T: $=$ And the justification is we never go out with friends because we stay all the day in front of the computer/ Or the internet ruins our sight because we have to wear glasses and so on/ Orice scrieti ca si argument neaparat justificat/ Daca nu justificati n-are nici o valoare si nu este notat/

98. S: de ce

99. T: si ce mai urmeaza/ (.) Conclusion/ Here Izabella you write your opinion/(.) Your opinion on the theme/ Aici aveti voie sa ziceti in my opinion the internet is/

100. S: \%((???))\%

101. T: N-ati avut voie pana acum/ ((???))Ai dreptate Nu va intreb acum daca aveti lucruri pe care nu le-ati inteles/O sa vad eu dupa exercitii/ Okay/ You will each get an example of a for and against writing/ (.) You will have to read it and you will have to tell me which is a errrr/ You'll have to make a structure of this essay/ You'll have to tell me what do you see/ which is the introduction the theme and the main idea which is the argument for and justification against plus example and the conclusion/ In your notebooks/

102. <the teacher hands out the essay topics>

103. T: unde ti-i caietul/

104. S: acasa

105. T: si cine vrei sa-ti scrie taica-tau draga?/< everybody starts speaking at the same time>de ce vorbiti atat in plus/ cu comportamentul asta ((???))na bine darga hai <argues with the boys in the back>

106. S: nu inteleg, sa-mi fiu propriul sef?

107. T: da/working for somebody else or owning your own business and working for you (.) So read the essay and in you notebooks/ <she draws a chart on the table> what's your topic, what's for and against and the conclusion/ What's your opinion/

108. S: Trebuie sa scriem in caiet?

109. T: ((???)) draga scriemi doar ideile/ da?/ Dati-i drumul/

110. <as they are left to work all start speaking>

111. T: Nah si citeste/

112. S: Am citit/

113. T: Tot?/ Nah si atunci care e tema eseului?/

114. <the teacher walks around and talks to the students, a conversation I couldn't understand>

115. T: na ai scris?

116. S: Irni is kell?

117. T: deschide-ti caietul si scrie repede <the teacher is walking around the class $>$

118. T: Sanyi te trimit in poarta/sa nu mai vorbiti

119. S: Mi a helyzet? Mi a helyzet? <a student asking the other what the problem is>

120. S: Ce inseamna state the theme general idea 
121. T: I have no idea, I've told you and I forgot it / I can't remember all these

122. S: Nici profa nu stie cum sa stii tu

123. T: da voi credeti ca eu le tin minte toate astea? Am terminat, na-i fost atent si la revedere/ Da/ Si ma supar nah(...)gura inchisa si fa odata/ BAGI

124. <teacher walks in the class and tries to keep/make discipline>

125. <Quiet for about $1 \mathrm{~min}>15: 30-16: 55$

126. <student raises his hand>

127. T: What?

128. S: Vreau sa stiu daca ((???))

T: Ideile imi trebuie/ Nu-mi trebuie o propozitie intreaga/ Da?/ Deci idea/ Da da asa/ <silence again>

129. S: ((???))

130. T: Da?

131. T: Deci scrii cu cuvintele tale dar extragi doar idea care te intereseaza da?/ si la argumentele nu trebuie sa-mi copiati tot paragraful ca doar stiu sa citesc si eu da?/ Deci voi doar sa-mi extrageti idea/ Atat/ Care sunt doua trei argumente care apar acolo/ Atat/

132. $((\ldots))$

133. <student raises his hand>

134. T: What?

135. S: Asa trebuie sa criem ca este vorba de

136. T: Vai/ Romaneste v-am explicat nu in chineza nu in engleza/ Idea/

137. S: ((???))

T: La introducere uitam uitam ca scrie acolo care-i tema / Pai care-i tema eseului pe care citesti/

138. S: ((???))

T: Pai da asta este idea/ Si atat trebuie sa-mi scrieti/ V-am zis ca nu-mi trebuie sa copiati ca doar nu v-am dat copiere/ (.) Un exercitiu asemanator am facut cand am facut descrierea unui text si v-am dat manualele sa cititi Paradise Tour/ Asa-i?/

$139 . \quad$ S: $\mathrm{Da} /$

140. T: Nah/

141. S: ((???)) double I

142. T: Da

143. S: ((???)) capisci/

144. T: Capisci/ Bravo/ Esti un geniu/

145. S: stiu

146. S: MB mountain bike

147. <The teacher walks around and checks the student's work>

148. T: Okay/Good/Mai ce v-am explicat si la bac/ Nu incercati sa folositi cuvinte pe care nu le cunoasteti/ Ca atunci n-ai pe cine sa intrebi ca doar n-o sa intrebi profesorul sa ti le explice/

149. S: Ba da/

150. T: Folosesti cuvinte pe care nu le sti/ca nu tre' sa impresionezi absolut pe nimeni/ Ca impresionezi numai negativ ca nu sti/ Foloseste cuvinte pe care le stii si incearca sa nu ma mai intrebi ca eu n-o sa fiu acolo si n-o sa fie nici Bagi sa-l intrebi /

151. S: Da pana-n clasa doispea=

T: $\quad$ =Pana in clasa a doispea/ Pana in clasa a doispea/ Nah foloseste cuvinte pe care le stii/ Ca degeaba te ajut eu acum acolo nu te ajuta nimeni/ 152. S: Nici eu 
153. T: Pot sa te ajut sa ajungi si pana la bac/ Poate nu-i sigur/ si mai este-n toamna si asa mai departe/ Okay let's check/ So what is the theme of the essay?/ What's the theme? Roland

154. S: Be your own boss

155. T: be your own boss <the teacher writes it on the board $>$ /Okay/Ibolya an argument for/ Give me an argument for/

156. S: Make your own decisions/

157. T: Make your own decisions<writes it on the board $>$

158. S: \%poti sa-ti iei singur decizii\% <translating to another student in the back>

159. T: Tunde/ hai na zice draga te rog

160. S: Make your program/

161. T: Make your program/

162. S: not work for somebody

163. T: not work for somebody else/ Okay other arguments/

164. S: Free, self employed/

165. T: Yeah self employed/ Something else?/ Okay

166. S: \%propriu salariat\%

167. T: Let's see arguments against /Zita/

168. S:Ce inseamna self-employed?

169. T: ca lucrezi pentru tine

170. S: You have to work long hours and sacrifice your personal life/

171. T: Work long hours/Sacrifice your/

172. S1: your life/

173. S2: your personal life/

174. T: your own personal life/

175. S: You have big chance of failure/

176. T: Chance of failure/ Okay/ Conclusion/ What's the opinion?/ Zii Zita

177. S: All things are considered to be a good experience although not one without difficulties/

178. T: Good experience/ Okay now that you have seen how a for and against essay looks like/

179. S: Yes/

180. T: I am not going to make you yet write your own essays it will be the next class/ But now in groups you will get a theme a topic and you have to bring the advanta errrrr the arguments for and against plus you have to give me justification and example/ So everyone will sit in groups okay? I'm not going to move you anyone

181. S: Just /

182. T: Two/ <The teacher hands out the topics meanwhile students get noisy>

183. S: ahelyett hogy szivatod en is ((???))

184. S: Ooo, ce usore

185. T:O sa va rog sa nu scrieti pe foile care vi le-am dat dar modelul pe care vi leam dat totul o aveti in caiete/ Da?/ Si toata grupa discutati incat sa nu lucreze numai unul din grupa ci toti/Va dati cu parerea/ Da?/Va ganditi tema va ganditi ce e pro si ce e contra si imi scrieti de ce/ Ai inteles?/ Deci Justification means de ce/ Ne-am inteles?/ Dati-i drumul!/ Zece minute aveti la dispozitie/

186. <the students start to work in group> 27:05

187. S: nem tudom kerdezd meg (27:29)

188. S: Dar putem sa scriem propozitii?/27:47

189. T: Da/ Dar neaparat sa-mi spui de ce/

190. <Students keep talking in groups, the teacher walks around checking on them> 
191. 27:50-29:06

192. <a student gets too loud>

193. T: Sunt convinsa Bagi ca parerile tale sunt nemaipomenite/ Esti un geniu/

194. 29:07-30:54

195. S: hogy mondjak, hogy kirandulni?

196. S: travel

197. 30:56-32:47

198. S: cum se spune doamna profesoara portar?

199. 32: $50-33: 22$

200. S: hogy mondjak biztositas?

201. 33:23-35:06

202. S: <asking from the teacher in Ro the same word he asked for in HU before> cum se spune la asigurare?

203. T: insurance

204. 35:10-35:19

205. T: Try to finish

206. <short discussion between teacher and student about his absences and how to motivate them, the class gets even noisier $>$

207. T: Voi patru toti vreti sa iesiti si nu stiti cum sa-mi explicate/na

208. S: Teacher?/

209. T:Yes?/

210. S: mult?

211. T: a lot

212. S: \%((???))\%

213. T: In caiet/ In caiet/

214. S: ((???))

215. T: Fiicai sau fiu inc-o data puteti sa-mi ziceti

216. S: Platim mult si vorbim putin

217. T: We pay a lot and errr we don't speak so much/(...)Cand se suna poti sa mergi/ Okay/ We'll check your works and then you're free/ Okay?/ So let's start/

Please first set up the theme/

218. S: the advantages and disadvantages=

219. S:

$=$ the theme

220. <the boys are till talking in the back>

221. T: Sa nu cumva sa va intreb dupa aia despre ce-am vorbit si habar sa n-aveti/ Va rog sa va ajutati colegii/

222. S: The advantages of mobile is that we can talk everywhere/

223. T: we can talk/ Asa/

224. S: Anywhere/ portable, possible to make photos/

225. T: Make photos/Take photos/Take este termenul pe care-l folosim/ Take photos/ Okay/ Disadvantages <The teacher writes on the blackboard>

226. S: \%((???))\%/

227. T: okay good / Barabasi

228. S: eu n-am nimic

229. T: cum n-ai nimic doar ai scris/Nah Andrea cine citeste?/contribuiai si tu si ei

230. S: you can depend on it

231. T: Domnul Sandor despre ce a citit Andrea?

232. S: ((???))

233. T: Nu nu, ai sarit vreo doua fraze/ Izabella despre ce ne citeste Andrea?/

234. S: despre tema care= 
235. T: = cine-mi poate zice despre ce citeste Andrea?

236. S: Eu nu

237. T: Apoi cum/ Apoi cum/ Suntem in gradinita aicea?/ Zii Andrea/

238. S: the advantages of being((???))/

239. T: Okay/ Very good/ Zalan Varga Kovacs

240. S: si noi cand

241. T: Las' ca si voi/ Cei mai buni pana la urma/

242. S: \%((???))\%/

243. T: And what's the justification?/

244. S: \%the traffic\%

245. T: The pollution/ okay and?/ The environment/

246. S: a lot of gas, many problems, earth gets warmer/

247. T: Let me give you a ((conclusion))/

248. S: ((???))/

249. T: Advantages and disadvantages of the uniform

250. S: equal

251. T: everybody's equal / Atat?/In cincispe minute/

252. S: bad material/

253. T: bad material /Zii Eniko care sunt avantajele contra si pro pe care le-a zis colega ta?/ (.)Oups

254. T: The advantages and disadvantages of / Disadvantage/ Disadvantage?/

255. S: ((???))

256. T: There is the risk to become depedent /Zita si cu Torok s-aud/

257. S: The advantages and disadvantages of owning a car/ Advantages it is good for yourself if you have to go somewhere and you don't have a bus, you don't depend to any else/

258. T: Depend on/ Depend on/ Asa/

259. S: If you have a car you can do many trips whenever you want/ Advantages against if you have a car/ with the car you have many problems you have to pay for insurance/

260. T: Insurance/

261. S: Insurance, if you have a car you have the possibility to make accidents/

262. T: good, another /the last the best/I hope you have many many arguments for and against/ ca sa va stergeti pacatele/ hai sa incepem cu advantages/ first of all what's the topic?/ What are you going to talk about?/

263. S: I am talking about ((???))/

264. T: Okay/ And what are the advantages?/

265. S: The advantage is that you can make more good things/

266. T: Give me some examples which are those good things/

267. S: internet for example, army, technology for example /

268. T: Good example hah?/

269. S: <laughter>

270. T: that's okay/ and some disadvantages

271. S: Disadvantages is/ <laughter> we don't find disadvantages/

272. T: No disadvantages?/

273. S: No/

274. T: And now/ (.) Next class on Friday=

275. S: =Friday Vasarnapra?

276. T:Friday we won't have class/Next Wednesday you will write your own essays/ And the topic / 
277. S: Si cine nu face ce-i?/

278. T: serios

279. <the teacher and the students talking in the same time in RO>

280. T: Domnul Bartha deschide te rog geamul in pauza/ thank you 